UNIVERSIDAD POLITÉCNICA DE VALENCIA

DEPARTAMENTO DE TECNOLOGÍA DE ALIMENTOS

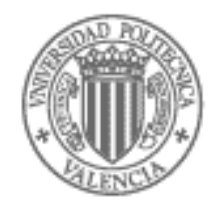

\title{
EFECTO DE LA COMPOSICIÓN DE RECUBRIMIENTOS COMESTIBLES A BASE DE HIDROXIPROPILMETILCELULOSA $Y$ CERA DE ABEJA EN LA CALIDAD DE CIRUELAS, NARANJAS Y MANDARINAS
}

TESIS DOCTORAL

Presentada por:

María Llanos Navarro Tarazaga

Directora:

Dra. María Bernardita Pérez Gago

Tutora:

Dra. Amparo Chiralt Boix

Valencia, 2007 
Da. MARÍA BERNARDITA PÉREZ GAGO, INVESTIGADORA DEL CENTRO DE TECNOLOGÍA POSTCOSECHA DEL INSTITUTO VALENCIANO DE INVESTIGACIONES AGRARIAS, FUNDACIÓN AGROALIMED,

CONSIDERA: Que la memoria titulada 'Efecto de la composición de recubrimientos comestibles a base de hidroxipropilmetilcelulosa y cera de abeja en la calidad de ciruelas, naranjas y mandarinas', presentada por $\mathrm{D}^{\mathrm{a}}$. María Llanos Navarro Tarazaga, y realizada bajo mi dirección en el Centro de Tecnología Postcosecha del Instituto Valenciano de Investigaciones Agrarias, reúne las condiciones adecuadas para su presentación como Tesis Doctoral, por lo que AUTORIZA a la interesada su presentación en ese doctorado. 
A las que creyeron, cseen y creesán que un mundo mejos es pasible, pos dedicas cada minuta a logsas un mundo mejos, pos la nobleza de sus cosazones y posque son la esperanga de la vida.

A mis seses quesidas, pas queserme tanto y, en especial, a mis padres, parque a ellas les delo todo en mi vida. 
Quiero agradecer a todas las personas e instituciones el apoyo ofrecido a lo largo de mi formación doctoral.

A la Dra. $M^{a}$ Bernardita Pérez, mi Directora de tesis, por enseñarme durante estos cuatro años, por su dedicación.

A la Dra. Amparo Chiralt, por colaborar como Tutora de tesis.

Al Ministerio de Ciencia y Tecnología, por la beca predoctoral concedida y a las empresas 'Brillocera' y 'Dow Chemical', por los materiales proporcionados.

A la Dra. Anne Plotto, al Dr. Robert Hagenmaier y al Dr. John Krochta, por compartir conmigo sus conocimientos, por sus consejos.

A Alicia, Cristina, Clara, Adriana y Silvia, mis compañeras, y a todos los miembros del Departamento de Postcosecha del I.V.I.A., por compartir conmigo el día a día, gracias por vuestro apoyo y por el ánimo que me habéis dado a lo largo de todo este tiempo.

A Pablo Lemos y Victor Real, gracias por ayudarme siempre. en esta tesis.

A @salumn@sen prácticas que colaboraron en las experiencias realizadas

Y, sobre todo, gracias a José, Olga, Natalia, Migue y a mis padres, por arroparme. 
Las características sensoriales, nutricionales y microbiológicas que determinan la calidad y vida útil de las frutas se ven alteradas durante la etapa postcosecha. La aplicación de recubrimientos en la superficie de las mismas permite reducir su pérdida de calidad, prolongando su periodo de vida útil. En los últimos años, el creciente interés de consumidores y productores por productos saludables, así como por preservar el medio ambiente, ha impulsado el desarrollo de recubrimientos formados a partir de componentes naturales comestibles y biodegradables. Sin embargo, a pesar del potencial estos recubrimientos prolongando la vida útil de las frutas en poscosecha, son pocas las aplicaciones industriales desarrolladas. La investigación para el desarrollo de estos recubrimientos cobra, por tanto, importancia y puede contribuir a su implantación en la industria postcosecha.

El objetivo de esta tesis fue estudiar el efecto de la composición de recubrimientos comestibles compuestos de hidroxipropilmetilcelulosa (HPMC), cera de abeja (CA), ácido graso (AG) y plastificante en la calidad postcosecha de ciruelas 'Angeleno', naranjas 'Valencia' y mandarinas 'Clemenules' y 'Ortanique', con el fin de desarrollar recubrimientos respetuosos con el medio ambiente e inocuos para la salud, que ralenticen el deterioro postcosecha de estos frutos, y no comprometan su calidad organoléptica.

La aplicación de los recubrimientos estudiados permitió reducir la pérdida de calidad postcosecha de las ciruelas 'Angeleno', reduciendo la deshidratación, el ablandamiento y la incidencia de desórdenes fisiológicos que afectan a la pulpa de esta variedad de ciruela. En mandarinas 'Clemenules' y 'Ortanique' los recubrimientos redujeron la deshidratación, la pérdida de firmeza y la incidencia de desórdenes fisiológicos, pero no mejoraron sustancialmente la calidad postcosecha de las naranjas 'Valencia'. Los factores de composición estudiados afectaron tanto a las propiedades barrera de los recubrimientos como a su aspecto. Sin embargo, las variaciones de composición no repercutieron en la calidad de las frutas de una manera unidireccional, puesto que, en algunos casos, las variaciones de composición que mejoraron unos parámetros de calidad empeoraron otros.

De los factores de composición estudiados, el que afectó la 
funcionalidad de los recubrimientos en mayor medida fue la proporción relativa de HPMC y CA. En ciruelas 'Angeleno', un aumento en el contenido de CA y una reducción del contenido de HPMC redujo la pérdida de peso y de turgencia, mejorando el aspecto externo de las mismas. Mientras que una reducción en el contenido de CA y un aumento del contenido de HPMC aumentó el brillo de la piel y redujo el ablandamiento y los daños fisiológicos de la pulpa. En mandarinas 'Clemenules', un aumento en el contenido de CA y una reducción del contenido de HPMC redujo la pérdida de peso y los niveles de etanol y acetaldehído, mejorando el sabor del fruto. Sin embargo, un exceso de CA y/o un defecto de HPMC del recubrimiento, empeoró el aspecto y brillo del mismo. Los resultados obtenidos, tanto en ciruelas como en mandarinas, se atribuyeron a las propiedades mecánicas y barrera de ambos componentes (HPMC y CA), siendo la HPMC el componente que mejoró la integridad física del recubrimiento, y el que incrementó la barrera a los gases, y la CA el componente que aportó la barrera a la humedad, y que redujo la integridad física del recubrimiento.

Los componentes minoritarios de la formulación, AG y plastificante, también afectaron las características de los recubrimientos. De los distintos tipos de AG estudiados, el ácido oleico fue el que proporcionó los mejores resultados, tanto en recubrimientos aplicados a ciruelas 'Angeleno', como en recubrimientos aplicados a mandarinas 'Ortanique'. El comportamiento de los recubrimientos que contenían ácido oleico en su formulación se atribuyó a un aumento de la elasticidad de los mismos, y, por tanto a una mayor capacidad de éstos para adaptarse a la superficie del fruto y reducir los procesos fisiológicos de respiración y transpiración.

La adición de glicerol como plastificante a las formulaciones mejoró la flexibilidad de los recubrimientos, mejorando sus propiedades funcionales y la calidad poscosecha de las ciruelas 'Angeleno' y naranjas 'Valencia' recubiertas.

El contenido en sólidos de los recubrimientos también afectó la calidad de las mandarinas 'Clemenules' recubiertas. Una disminución en el contenido en sólidos disminuyó la barrera a los gases $\mathrm{CO}_{2}$ y $\mathrm{O}_{2}$ del recubrimiento, los niveles de etanol y acetaldehído en zumo y los malos sabores. Además, al disminuir el contenido en sólidos de las 
formulaciones mejoró el aspecto externo y aumentó el brillo de las mandarinas recubiertas

La información obtenida en la presente tesis doctoral permite trazar, en líneas generales, el comportamiento de los recubrimientos comestibles a base de HPMC y CA en la calidad postcosecha de ciruelas 'Angeleno', mandarinas 'Clemenules' y 'Ortanique' y naranjas 'Valencia' a partir de cambios en su composición. Pero se requiere hacer más investigación para optimizar la composición de los mismos. En futuras investigaciones se puede, además, contemplar la capacidad de estos recubrimientos para actuar como agentes portadores de sustancias antimicrobianas y de carácter nutricional. 
Les característiques sensorials, nutricionals i microbiològiques que determinen la qualitat i la vida útil de les fruites es veuen alterades al llarg de l'etapa postcollita. L'aplicació de recobriments en la superfície de les fruites permet reduir la seua pèrdua de qualitat mitjançant la prolongació del periode de vida útil. En els darrers anys, l'interés creixent de consumidors i productors per productes saludables, així com per preservar el medi ambient, ha impulsat el desenvolupament de recobriments a base de components naturals comestibles i biodegradables. No obstant això, malgrat el potencial d'aquests recobriments per a prolongar la vida útil de les fruites en postcollita, són poques les aplicacions industrials desenvolupades. La investigació per al desenvolupament d'aquests recobriments guanya, per tant, importància i pot contribuir a la seua implantació en la indústria postcollita.

L'objectiu general d'aquesta tesi és estudiar l'efecte de la composició de recobriments comestibles basats en hidroxipropilmetil cel.lulosa (HPMC), cera d'abella (CA), àcid gras (AG) i plastificant en la qualitat postcollita de prunes, taronges i mandarines, amb la finalitat de desenvolupar recobrimets respectuosos amb el medi ambient e inofensius per a la salut, que alenteixen el deteriorament postcollita d'aquests fruits $i$ no comprometin la seua qualitat organolèptica.

L'aplicació dels recobriments estudiats permeté reduir la pèrdua de qualitat postcollita de les prunes 'Angeleno', reduint la deshidratació, l'ablaniment i la incidència de desordres fisiològics que afecten a la polpa d'aquesta varietat de pruna. En mandarines 'Clemenules' i 'Ortanique' els recobriments reduïren la deshidratació, la pèrdua de fermesa i la incidència de desordres fisiològics, però no milloraren sustancialment la qualitat postcollita de les taronges 'València'. Els factors de composició estudiats afectaren tant a les propietats barrera dels recobriments com al seu aspecte. No obstant això, les variacions de composició no repercutiren en la qualitat de les fruites d'una manera unidireccional, ja que, en alguns casos, les variacions de composició que milloraren uns paràmetres de qualitat empitjoraren uns altres.

Dels factors de composició estudiats, aquell que afectà majorment la funcionalitat del recobriments fou la proporció relativa d' HPMC i CA. En prunes 'Angeleno', un augment en el contingut de CA i una reducció 
del contingut d' HPMC reduí la pèrdua de pes i de turgencia, amb la millora de l'aspecte extern d'aquelles, mentre que una reducció en el contingut de CA i un augment del contingut d' HPMC augmentà la brillantor de la pell i reduí l'ablaniment i els danys fisiològics de la polpa. En mandarines 'Clemenules', un augment en el contingut de CA i una reducció del contingut d' HPMC reduí la pèrdua de pes i els nivells d'etanol i acetaldehído, amb millora en el sabor del fruit. Però un excés de CA i/o un defecte d' HPMC del recobriment, empitjorà l'aspecte i brillantor d'aquelles. Els resultats obtinguts, tant en prunes com en mandarines, s'atribuïren a les propietats mecàniques $i$ barrera de tots dos components (HPMC i CA), amb l' HPMC com el component que millorà la integritat física del recobriment i que augmentà la barrera als gasos, i la CA com el component que aportà la barrera a la humitat, i que reduí la integritat física del recobriment.

Els components minoritaris de la formulació, AG i plastificant, també afectaren les característiques dels recobriments. Dels diferents tipus d'AG estudiats, l'àcid oleic fou el que proporcionà els millors resultats, tant en recobriments aplicats en prunes 'Angeleno', com en recobriments aplicats en mandarines 'Ortanique'. El comportament dels recobriments que contenien àcid oleic en la seua formulació s'atribuí a un augment de la seua elasticitat i, per tant, a una major capacitat per a adaptar-se a la superfície del fruit i reduir el seu procés fisiològic de respiració i transpiració.

L'adició de glicerol com a plastificant a les formulacions millorà la flexibilitat dels recobriments, amb una millora de les seues propietats funcionals i de la qualitat postcollita de les prunes i taronges 'València' recobertes.

El contingut en sòlids dels recobriments també afectà la qualitat de les mandarines 'Clemenules' recobertes. Una disminució en el contingut en sòlids disminuí la barrera als gasos $\mathrm{CO}_{2}$ y $\mathrm{O}_{2}$ del recobriment, els nivells d'etanol i acetaldehído en suc i el mal sabor. A més a més, amb la disminució del contingut en sòlids de les formulacions millorà l'aspecte extern i augmentà la brillantor de les mandarines recobertes.

La informació obtinguda en aquesta tesi doctoral permet traçar, en línies generals, el comportament dels recobriments comestibles a base d' 
HPMC i CA en la qualitat postcollita de prunes 'Angeleno', mandarines 'Clemenules' i 'Ortanique' i taronges 'València', a partir de canvis en la seua composició, però es requereix tanmateix fer més investigació per a optimar aquesta. En investigacions futures es pot, a més a més, contemplar la capacitat d'aquests recobriments per a actuar com a agents portadors de sustàncies antimicrobianes i de caràcter nutricional. 
Fruit sensory, nutritional and microbiological quality are the main factors that determine fruit postharvest life. Coating application over fruit surface preserves fruit quality and helps extending fruit postharvet selflife. During the last years, consumers and producers preferences have changed focusing on healthier foods. This demanding has led to the development of postharvest technologies. Edible coatings formed by natural components have being taking protagonism. However, its use has not been totally explored and there are not many edible coatings available on the market. More research is needed to develop edible coating applications. The first step would imply research on the effect of edible coating composition on fruit quality.

The objective of this thesis was to study the effect of edible coating composition made with hydroxypropilmethyl cellulose (HPMC), beeswax (BW), fatty acid (FA) and plasticizer in the postharvest quality of plums, tangerines and oranges, in order to develop edible fruit coatings that preserve fruit quality.

The coatings improved postharvest quality of coated 'Angeleno' plums compared to control plums, reducing weight loss, softening and internal physiological disorders. The coatings also reduced weight loss, fruit softening and physiological disorders of 'Clemenules' and 'Ortanique' tangerines. However, the coatings did not significantly improve postharvest quality of coated 'Valencia' oranges compared to the control. Coating composition affected coating barrier properties and appearance. However, changes in coatings composition did not affect fruit postharvest quality in the same way (i.e some fruit quality parameters were improved, while others were worsened).

Among the factors studied, the ratio of HPMC and BW was the main factor affecting coating performance. In 'Angeleno' plums, an increase of BW content and a decrease in HPMC content reduced weight loss and shrinkage, improving plum external appearance; while a reduction in BW content and an increase in HPMC content increased shininess and reduced internal physiological disorders. In 'Clemenules' tangerines, an increase in BW content and a reduction in HPMC content reduced fruit weight loss and ethanol levels, improving fruit flavor. However, an excess of $\mathrm{BW}$ in the coating formulations and/or a defect of HPMC content 
worsened fruit external appearance and decreased shininess. These results, both in 'Angeleno' plums and 'Clemenules' tangerines, were explained by the mechanical and barrier properties of HPMC and BW. It was hypotized that HPMC was the main component providing the coating mechanical cohesion and coating gas barrier, while the BW was the main component providing the moisture barrier.

The type and content of FA and plasticizer also affected coating performance. Among the FA studied, oleic acid was the FA that provided the best coating performance in both fruits studied ('Angeleno' plums and 'Ortanique' tangerines). It was hipotized that an increase in coating flexibility by adding oleic acid to coating formulations improved coating ability to adapt to fruit surface, and the coating ability to reduce fruit respiration and transpiration.

Glicerol addition as plasticizer increased coating flexibility, which improved coating performance and postharvest quality of coated 'Angeleno' plums and 'Valencia' oranges.

Solid content (SC) of the coatings affected postharvest quality of coated 'Clemenules' tangerines. A decrease in SC decreased coating $\mathrm{CO}_{2}$ and $\mathrm{O}_{2}$ barrier, ethanol and acetaldehyde levels in juice and fruit off-flavor. In addition, a decrease in formulation SC improved appearance and shininess of coated tangerines.

The results of this thesis provided information of the effect of the different ingredients of HPMC-based coatings applied to 'Angeleno' plums, 'Clemenules and 'Ortanique' tangerines, and 'Valencia' oranges. However, more research is needed in order to optimize coating composition of this type of coatings. Future work may also be performed in order to study the ability of this coatings acting as carriers of microbiological and nutritional ingredients. 
I. INTRODUCCIÓN

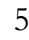

I.1. TECNOLOGÍAS POSTCOSECHA................................................................ 7

I.2. RECUBRIMIENTOS COMESTIBLES........................................................... 12

I.2.1. Definición y propiedades funcionales....................................................... 12

I.2.2. Componentes de los recubrimientos comestibles...................................... 12

I.2.3. Factores que afectan a la calidad de los frutos recubiertos con recubrimientos comestibles compuestos.

I.2.3.1. Factores que afectan a las propiedades funcionales de las películas comestibles compuestas............................................................... I.2.3.2. Otros factores que afectan a la calidad del fruto recubierto.... I.2.4. Investigación desarrollada y aplicación industrial de recubrimientos comestibles en frutas.

II. OBJETIVOS

III. MATERIALES Y MÉTODOS.

III.1. REACTIVOS UTILIZADOS EN LA PREPARACIÓN DE LOS RECUBRIMIENTOS COMESTIBLES Y DE LAS PELÍCULAS PREFORMADAS EN PLACA.

III.2. PREPARACIÓN DE LOS RECUBRIMIENTOS COMESTIBLES Y DE LAS PELÍCULAS PREFORMADAS EN PLACA.........................

III.3. APLICACIÓN DE LOS RECUBRIMIENTOS COMESTIBLES EN FRUTA

III.3.1. Efecto del contenido en cera de abeja del recubrimiento en la calidad postcosecha de ciruelas 'Angeleno'.....

III.3.2. Efecto del tipo y contenido de ácido graso del recubrimiento en la calidad postcosecha de ciruelas 'Angeleno'.

III.3.3. Efecto del tipo y contenido de plastificante y del contenido en cera de abeja del recubrimiento en la calidad postcosecha de ciruelas 'Angeleno'. III.3.4. Efecto del contenido en cera de abeja y del contenido en sólidos del recubrimiento en la calidad postcosecha de mandarinas 'Clemenules'....

III.3.5. Efecto del tipo y contenido de ácido graso del recubrimiento en la calidad postcosecha de mandarinas 'Ortanique'.

III.3.6. Efecto del tipo y contenido de plastificante del recubrimiento en la calidad postcosecha de naranjas 'Valencia'................................

III.4. ANÁLISIS.

III.4.1. Análisis de la emulsión y de la película preformada en placa.......... 52

III.4.1.1. Viscosidad de la emulsión........................... 53

III.4.1.2. Propiedades mecánicas de la película..................... 53

III.4.1.3. Permeabilidad al vapor de agua de la película............. 54

III.4.1.4. Espesor de la película............................. 55 
III.4.2. Análisis de calidad de los frutos................................ 55

III.4.2.1. Pérdida de peso................................... 55

III.4.2.2. Intensidad respiratoria............................ 55

III.4.2.3. Sólidos solubles totales, acidez, e índice de madurez..... 55

III.4.2.4. Contenido de $\mathrm{CO}_{2} \mathrm{y} \mathrm{O}_{2}$ interno.................... 56

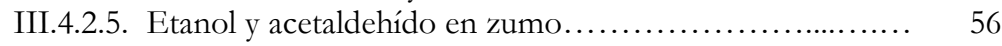

III.4.2.6. Firmeza..................................... 57

III.4.2.7. Desórdenes fisiológicos............................ 58

III.4.2.8. Color externo.................................. 58

III.4.2.9. Índice de desprendimiento del recubrimiento........... 59

III.4.2.10. Evaluación organoléptica.......................... 59

III.4.2.11. Aspecto externo y brillo del fruto................... 61

III.4.3. Análisis estadístico...................................... 62

IV. RESULTADOS Y DISCUSIÓN .

IV.1.EFECTO DEL CONTENIDO EN CERA DE ABEJA DE LA FORMULACIÓN EN LAS PROPIEDADES DE LAS PELÍCULAS Y EN LA CALIDAD POSTCOSECHA DE CIRUELAS 'ANGELENO' RECUBIERTAS.

IV.1.1. Análisis de las emulsiones y de las películas preformadas en placa.... IV.1.1.1. Aspecto de las emulsiones y de las películas.................

IV.1.1.2. Permeabilidad al vapor de agua de las películas............

IV.1.2. Análisis de calidad de las ciruelas ‘Angeleno’ recubiertas.............

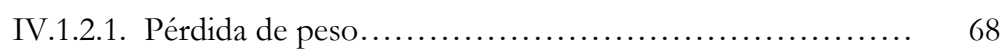

IV.1.2.2. Intensidad respiratoria............................ 70

IV.1.2.3. Sólidos solubles totales, acidez e índice de madurez...... 71

IV.1.2.4. Etanol y acetaldehído en zumo...................... 73

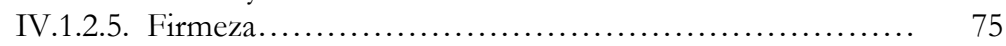

IV.1.2.6. Desórdenes fisiológicos............................ 76

IV.1.2.7. Color......................................... 78

IV.1.2.8. Evaluación organoléptica: 'flavor' y textura............... 79

IV.1.2.9. Aspecto externo y brillo del fruto..................... 79

IV.1.3. Síntesis de resultados ................................... 83

IV.2. EFECTO DEL TIPO Y CONTENIDO DE ÁCIDO GRASO DE LA FORMULACIÓN EN LAS PROPIEDADES DE LAS PELÍCULAS Y EN LA CALIDAD POSTCOSECHA DE CIRUELAS 'ANGELENO' RECUBIERTAS. .

IV.2.1. Análisis de las emulsiones y de las películas preformadas en placa.... IV.2.1.1. Aspecto de las emulsiones y de las películas................. IV.2.1.2. Propiedades mecánicas de las películas.................. IV.2.1.3. Permeabilidad al vapor de agua de las películas.............

IV.2.2. Análisis de calidad de las ciruelas ‘Angeleno' recubiertas............ 94

IV.2.2.1. Pérdida de peso.................................. 94

IV.2.2.2. Intensidad respiratoria $\ldots \ldots \ldots \ldots \ldots \ldots \ldots \ldots \ldots \ldots \ldots . \ldots 5$ 
IV.2.2.3. Sólidos solubles totales, acidez e índice de madurez..... 95

IV.2.2.4. Contenido de $\mathrm{CO}_{2} \mathrm{y} \mathrm{O}_{2}$ interno........................ 95

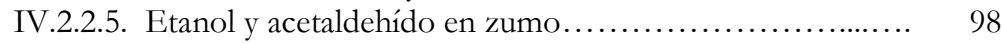

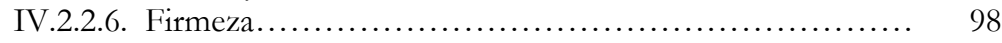

IV.2.2.7. Desórdenes fisiológicos.............................. 99

IV.2.2.8. Color.............................................. 101

IV.2.2.9. Evaluación organoléptica: 'flavor' y textura............. 103

IV.2.2.10. Aspecto externo y brillo del fruto.................... 105

IV.2.3. Síntesis de resultados..................................... 107

IV.3. EFECTO DEL TIPO Y CONTENIDO DE PLASTIFICANTE Y DEL CONTENIDO EN CERA DE ABEJA DE LA FORMULACIÓN EN LAS CARACTERÍSTICAS DE LAS PELÍCULAS Y EN LA CALIDAD POSTCOSECHA DE CIRUELAS ‘ANGELENO’ RECUBIERTAS.............. 108

IV.3.1. Análisis de las emulsiones y de las películas preformadas en placa.... 108

IV.3.1.1. Aspecto de las emulsiones y de las películas............. 108

IV.3.1.2. Propiedades mecánicas de las películas................. 110

IV.3.1.3. Permeabilidad al vapor de agua de las películas............ 113

IV.3.2. Análisis de calidad de las ciruelas 'Angeleno' recubiertas............ 115

IV.3.2.1. Pérdida de peso................................. 115

IV.3.2.2. Intensidad respiratoria............................ 119

IV.3.2.3. Etanol y acetaldehído en zumo......................... 119

IV.3.2.4. Firmeza......................................... 122

IV.3.2.5. Desórdenes fisiológicos........................... 124

IV.3.2.6. Evaluación organoléptica: 'flavor' y textura............. 126

IV.3.2.7. Aspecto externo y brillo del fruto................... 126

IV.3.3. Síntesis de resultados.................................... 128

IV.4. EFECTO DEL CONTENIDO EN CERA DE ABEJA Y DEL CONTENIDO EN SÓLIDOS DE LA FORMULACIÓN EN LAS CARACTERÍSTICAS DE LAS PELÍCULAS Y EN LA CALIDAD POSTCOSECHA DE MANDARINAS 'CLEMENULES’ RECUBIERTAS..... 129

IV.4.1. Análisis de las emulsiones y de las películas preformadas en placa.... 129 IV.4.1.1. Aspecto de las emulsiones y de las películas............. 129 IV.4.1.2. Permeabilidad al vapor de agua de las películas.......... 130

IV.4.2. Análisis de calidad de las mandarinas 'Clemenules' recubiertas...... 131

IV.4.2.1. Pérdida de peso................................ 131

IV.4.2.2. Sólidos solubles totales, acidez e índice de madurez..... 134

IV.4.2.3. Contenido de $\mathrm{CO}_{2} \mathrm{y} \mathrm{O}_{2}$ interno..................... 134

IV.4.2.4. Etanol y acetaldehído en zumo....................... 138

IV.4.2.5. Firmeza......................................... 140

IV.4.2.6. Desórdenes fisiológicos............................. 141

IV.4.2.7. Índice de desprendimiento del recubrimiento............ 142

IV.4.2.8. Evaluación organoléptica: 'flavor' y 'off-flavor'.......... 143

IV.4.2.9. Aspecto externo y brillo del fruto..................... 145

IV.4.3. Síntesis de resultados.................................... 148 
IV.5. EFECTO DEL TIPO Y CONTENIDO DE ÁCIDO GRASO DE LA FORMULACIÓN EN LAS CARACTERÍSTICAS DE LAS PELÍCULAS Y EN LA CALIDAD POSTCOSECHA DE MANDARINAS 'ORTANIQUE'

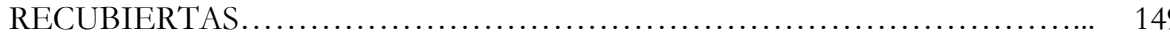

IV.5.1. Análisis de las emulsiones y de las películas preformadas en placa... 149

IV.5.1.1. Aspecto de las emulsiones y de las películas............. 149

IV.5.1.2. Propiedades mecánicas de las películas................. 149

IV.5.1.3. Permeabilidad al vapor de agua de las películas............ 149

IV.5.2. Análisis de calidad de las mandarinas 'Ortanique' recubiertas........ 150

IV.5.2.1. Pérdida de peso.................................................... 150

IV.5.2.2. Sólidos solubles totales, acidez e índice de madurez..... 152

IV.5.2.3. Contenido de $\mathrm{CO}_{2} \mathrm{y} \mathrm{O}_{2}$ interno....................... 152

IV.5.2.4. Etanol y acetaldehído en zumo....................... 156

IV.5.2.5. Firmeza......................................... 158

IV.5.2.6. Desórdenes fisiológicos.............................. 158

IV.5.2.7. Índice de color................................. 159

IV.5.2.8. Índice de desprendimiento del recubrimiento............ 159

IV.5.2.9. Evaluación organoléptica: 'flavor' y 'off-flavor'.......... 160

IV.5.2.10. Aspecto externo y brillo del fruto.................... 163

IV.5.3. Síntesis de resultados.................................... 163

IV.6. EFECTO DEL TIPO Y CONTENIDO DE PLASTIFICANTE DE LA FORMULACIÓN EN LAS CARACTERÍSTICAS DE LAS PELÍCULAS Y EN LA CALIDAD POSTCOSECHA DE NARANJAS 'VALENCIA' RECUBIERTAS........................................................ 164

IV.6.1. Análisis de las emulsiones y de las películas preformadas en placa... 164 IV.6.1.1. Aspecto de las emulsiones y de las películas............... 164 IV.6.1.2. Permeabilidad al vapor de agua de las películas............ 165

IV.6.2. Análisis de calidad de las naranjas 'Valencia' recubiertas............. 166

IV.6.2.1. Pérdida de peso..................................... 166

IV.6.2.2. Sólidos solubles totales, acidez e índice de madurez...... 168

IV.6.2.3. Contenido de $\mathrm{CO}_{2} \mathrm{y} \mathrm{O}_{2}$ interno...................... 168

IV.6.2.4. Etanol y acetaldehído en zumo........................ 171

IV.6.2.5. Firmeza......................................... 173

IV.6.2.6. Desórdenes fisiológicos............................. 173

IV.6.2.7. Índice de color................................ 173

IV.6.2.8. Índice de desprendimiento del recubrimiento............. 173

IV.6.2.9. Evaluación organoléptica: 'flavor' y 'off-flavor'.......... 174

IV.6.2.10. Aspecto externo y brillo del fruto.................... 175

IV.6.3. Síntesis de resultados..................................... 177

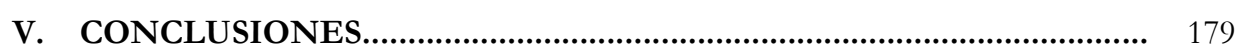

VI. BIBLIOGRAFÍA..................................................... 185 
Tabla I.1. Ejemplos de aditivos alimentarios utilizados en la formulación de recubrimientos comestibles.

Tabla III.1. Composición y viscosidad de los recubrimientos aplicados en la experiencia: efecto del contenido en CA del recubrimiento en la calidad postcosecha de ciruelas 'Angeleno'.

Tabla III.2. Características físico-químicas de los AG empleados en la formulación de los recubrimientos aplicados en la experiencia: efecto del tipo y contenido de AG del recubrimiento en la calidad postcosecha de ciruelas 'Angeleno'.

Tabla III.3. Composición de los recubrimientos aplicados en la experiencia: efecto del tipo y contenido de AG del recubrimiento en la calidad postcosecha de ciruelas 'Angeleno'.

Tabla III.4. Características físico-químicas de los plastificantes empleados en la formulación de los recubrimientos aplicados en la experiencia: efecto del tipo y contenido de plastificante y del contenido en CA del recubrimiento en la calidad postcosecha de ciruelas 'Angeleno'

Tabla III.5. Composición y viscosidad de los recubrimientos aplicados en la experiencia: efecto del tipo y contenido de plastificante y del contenido en CA del recubrimiento en la calidad postcosecha de ciruelas 'Angeleno'.

Tabla III.6. Composición de los recubrimientos aplicados en la experiencia: efecto del contenido en CA y del CS del recubrimiento en la calidad postcosecha de mandarinas 'Clemenules'.

Tabla III.7. Características físico-químicas de los plastificantes empleados en la formulación de los recubrimientos aplicados en la experiencia: efecto del tipo y contenido de plastificante del recubrimiento en la calidad postcosecha de naranjas 'Valencia'.

Tabla III.8. Composición de los recubrimientos aplicados en la experiencia: efecto del tipo y contenido de plastificante del recubrimiento en la calidad postcosecha de naranjas 'Valencia'.

Tabla IV.1. Efecto del contenido en CA de la formulación en la PVA de las películas.

Tabla IV.2. Pérdida de peso (\%) de ciruelas 'Angeleno' recubiertas y control: efecto del contenido en CA del recubrimiento....

Tabla IV.3. IR ( $\left.\mathrm{mL} \mathrm{CO}_{2} / \mathrm{kg} \mathrm{h}\right)$ de ciruelas 'Angeleno' recubiertas y control: efecto del contenido en CA del recubrimiento.................

Tabla IV.4. Sólidos solubles totales ('Brix) de ciruelas 'Angeleno' recubiertas y control: efecto del contenido en CA del recubrimiento. 
Tabla IV.5. Acidez (g ácido málico/100mL zumo)) de ciruelas 'Angeleno' recubiertas y control: efecto del contenido en CA del recubrimiento...

Tabla IV.6. IM de ciruelas 'Angeleno' recubiertas y control: efecto del contenido en CA del recubrimiento.

Tabla IV.7. Efecto del tipo y contenido de AG de la formulación en la PVA de las películas.

Tabla IV.8. Efecto del tipo y contenido de plastificante y del contenido en CA de la formulación en la PVA de las películas.

Tabla IV.9. Efecto del contenido en CA y del CS de la formulación en la PVA de las películas'.

Tabla IV.10. Efecto del tipo y contenido de plastificante de la formulación en la PVA de las películas.... 
Figura I.1. Factores que afectan a la calidad de los frutos recubiertos con recubrimientos comestibles compuestos..................... 17

Figura III.1. Ficha de cata para el análisis organoléptico de ciruelas............. 60

Figura III.2. Ficha de cata para el análisis organoléptico de cítricos.............. 61

Figura IV.1. Aspecto de las películas formuladas con (a) $0 \%$ de CA, (b) $20 \%$ de CA, (c) $40 \%$ de CA y (d) $60 \%$ de CA......................

Figura IV.2. Etanol y acetaldehído $(\mathrm{mg} / 100 \mathrm{~mL})$ en zumo de ciruelas 'Angeleno' recubiertas y control: efecto del contenido en CA del recubrimiento.....

Figura IV.3. Firmeza y daños por 'bleeding' de ciruelas 'Angeleno' recubiertas y control: efecto del contenido en CA del recubrimiento........................................

Figura IV.4. Tono de ciruelas 'Angeleno' recubiertas y control: efecto del contenido en CA del recubrimiento..........................

Figura IV.5. Aspecto externo y brillo de ciruelas 'Angeleno' recubiertas y control: efecto del contenido en CA del recubrimiento..............

Figura IV.6. Aspecto de las ciruelas ‘Angeleno' CSL (a) y recubiertas con la formulación $60 \% \mathrm{CA}$ (b) tras un almacenamiento de 6 semanas a $1^{\circ} \mathrm{C}+1$ semana a $20^{\circ} \mathrm{C}$.

Figura IV.7. Efecto del tipo y contenido de AG de la formulación en el aspecto de las emulsiones.................................

Figura IV.8. Efecto del tipo y contenido de AG de la formulación en el aspecto de las películas...................................

Figura IV.9. Efecto del tipo y contenido de AG de la formulación en las propiedades mecánicas de las películas.

Figura IV.10. $\quad \mathrm{CO}_{2}$ y $\mathrm{O}_{2}$ interno de ciruelas 'Angeleno' recubiertas y control: efecto del tipo y contenido de AG del recubrimiento...............

Figura IV.11. Firmeza de ciruelas 'Angeleno' recubiertas y control: efecto del tipo y contenido de AG del recubrimiento.....................

Figura IV.12. Daños por 'bleeding' de ciruelas 'Angeleno' recubiertas y control: efecto del tipo y contenido de $A G$ del recubrimiento....

Figura IV.13. Tono y luminosidad de ciruelas 'Angeleno' recubiertas y control: efecto del tipo y contenido de AG del recubrimiento..............

Figura IV.14. Flavor' y textura de ciruelas 'Angeleno' recubiertas y control: efecto del tipo y contenido de AG del recubrimiento..............

Figura IV.15. Aspecto externo y brillo de ciruelas 'Angeleno' recubiertas y control: efecto del tipo y contenido de AG del recubrimiento.... 
Figura IV.16. Efecto del tipo de plastificante en el aspecto de las películas: (a) $20 \%$ CA-300G y (b) $20 \%$ CA-300M.

Figura IV.17. Efecto del tipo y contenido de plastificante y del contenido en CA de la formulación en las propiedades mecánicas de las películas.

Figura IV.18. Pérdida de peso (\%) de ciruelas 'Angeleno' recubiertas y control: efecto del tipo y contenido de plastificante y del contenido en CA del recubrimiento.

Figura IV.19. Etanol y acetaldehído $(\mathrm{mg} / 100 \mathrm{~mL})$ en zumo de ciruelas 'Angeleno' recubiertas y control: efecto del tipo y contenido de plastificante y del contenido en CA del recubrimiento...

Figura IV.20. Firmeza de ciruelas 'Angeleno' recubiertas y control: efecto del tipo y contenido de plastificante y del contenido en CA del recubrimiento

Figura IV.21. 'Bleeding' de ciruelas 'Angeleno' recubiertas y control: efecto del tipo y contenido de plastificante y del contenido en CA del recubrimiento.....

Figura IV.22. Aspecto externo y brillo de ciruelas 'Angeleno' recubiertas y control: efecto del tipo y contenido de plastificante y del contenido en CA del recubrimiento.

Figura IV.23. Pérdida de peso (\%) de mandarinas 'Clemenules' recubiertas y control: efecto del contenido en CA y del CS del recubrimiento..

Figura IV.24. $\mathrm{CO}_{2}$ y $\mathrm{O}_{2}$ interno de mandarinas 'Clemenules' recubiertas y control: efecto del contenido en CA y del CS del recubrimiento..

Figura IV.25. Etanol y acetaldehído (mg/100mL) en zumo de mandarinas 'Clemenules' recubiertas y control: efecto del contenido en CA y del CS del recubrimiento.

Figura IV.26. Firmeza (\% deformación) de mandarinas 'Clemenules' recubiertas y control: efecto del contenido en CA y del CS del recubrimiento.

Figura IV.27. Índice de desprendimiento de los recubrimientos aplicados a mandarinas 'Clemenules': efecto del contenido en CA y del CS del recubrimiento.

Figura IV.28. 'Off-flavor' de mandarinas 'Clemenules' recubiertas y control: efecto del contenido en CA y del CS del recubrimiento......

Figura IV.29. Aspecto externo y brillo de mandarinas 'Clemenules' recubiertas y control: efecto del contenido en CA y del CS del recubrimiento.

Figura IV.30. Aspecto de mandarinas 'Clemenules' recubiertas y control tras un almacenamiento de 2 semanas a $5{ }^{\circ} \mathrm{C}+1$ semana a $20^{\circ} \mathrm{C} \ldots \ldots$. 
Figura IV.31. Pérdida de peso (\%) de mandarinas 'Ortanique' recubiertas y control: efecto del tipo y contenido de AG del recubrimiento....

Figura IV.32. $\mathrm{O}_{2}$ y $\mathrm{CO}_{2}$ interno de mandarinas 'Ortanique' recubiertas y control: efecto del tipo y contenido de AG del recubrimiento....

Figura IV.33. Etanol y acetaldehído $(\mathrm{mg} / 100 \mathrm{~mL})$ en zumo de mandarinas 'Ortanique' recubiertas y control: efecto del tipo y contenido de AG del recubrimiento.......................................

Figura IV.34. Firmeza (\% deformación) de mandarinas 'Ortanique' recubiertas y control: efecto del tipo y contenido de AG del recubrimiento...

Figura IV.35. Índice de desprendimiento de los recubrimientos aplicados a mandarinas 'Ortanique': efecto del tipo y contenido de AG del recubrimiento.........................................

Figura IV.36. 'Flavor' y 'Off-flavor' de mandarinas 'Ortanique' recubiertas y control: efecto del tipo y contenido de AG del recubrimiento....

Figura IV.37. Pérdida de peso (\%) de naranjas 'Valencia' recubiertas y control: efecto del tipo y contenido de plastificante del recubrimiento.....

Figura IV.38. $\quad \mathrm{CO}_{2}$ y $\mathrm{O}_{2}$ interno de naranjas 'Valencia' recubiertas y control: efecto del tipo y contenido de plastificante del recubrimiento.....

Figura IV.39. Etanol y acetaldehído $(\mathrm{mg} / 100 \mathrm{~mL})$ en zumo de naranjas 'Valencia' recubiertas y control: efecto del tipo y contenido de plastificante del recubrimiento..............................

Figura IV.40. 'Off-flavor' de naranjas 'Valencia' recubiertas y control: efecto del tipo y contenido de plastificante del recubrimiento........... 


\begin{tabular}{|c|c|}
\hline$\AA$ & amstrongs \\
\hline $\mathrm{AC}$ & atmósfera controlada \\
\hline $\mathrm{AE}$ & ácido esteárico \\
\hline AENOR & Asociación Española de Normalización y Certificación \\
\hline AG & ácido graso \\
\hline $\mathrm{AM}$ & atmósfera modificada \\
\hline ANOVA & análisis de la varianza \\
\hline $\mathrm{AO}$ & ácido oleico \\
\hline AP & ácido palmítico \\
\hline ASTM & American Society for Testing and Materials \\
\hline${ }^{\circ}$ Brix & grado brix \\
\hline b.s. & base seca \\
\hline${ }^{\circ} \mathrm{C}$ & grados centígrados \\
\hline CA & cera de abeja \\
\hline CI & calentamientos intermitentes \\
\hline CL & control lavado sin recubrir \\
\hline CSL & control sin lavar ni recubrir \\
\hline $\mathrm{cm}$ & centímetros \\
\hline $\mathrm{CO}_{2}$ & dióxido de carbono \\
\hline $\mathrm{cp}$ & centipoise \\
\hline CS & contenido en sólidos \\
\hline$\% \mathrm{E}$ & porcentaje de elongación máximo \\
\hline FID & detector de ionización de llama \\
\hline G & glicerol \\
\hline $\mathrm{h}$ & horas \\
\hline HPC & hidroxipropilcelulosa \\
\hline HPMC & hidroxipropilmetilcelulosa \\
\hline HR & humedad relativa \\
\hline 'HSP' & 'heat shock proteins' \\
\hline IC & índice de color \\
\hline ID & índice de deterioro \\
\hline $\mathrm{IM}$ & índice de madurez \\
\hline
\end{tabular}


IR intensidad respiratoria

I.V.I.A. Instituto Valenciano de Investigaciones Agrarias

$\mathrm{Kg} \quad$ kilogramos

'LSD' 'least significance difference'

M manitol

m metros

MC metilcelulosa

1-MCP 1-metilciclopropeno

mg miligramos

min minutos

$\mathrm{mL} \quad$ mililitros

$\mathrm{MPa}$ megapascales

N Newtons

$\mathrm{O}_{2} \quad$ oxígeno

P propilenglicol

Pág página

Pm peso molecular

pp páginas

PVA permeabilidad al vapor de agua

'SERB' 'stem end rind breakdown'

T tenacidad

TCD detector de termoconductividad

$\mathrm{Tg}$ temperatura de transición vítrea

TM tensión de tracción máxima

TR tensión de tracción a la rotura

UNE Una Norma Española

Y módulo de Young 
Las características sensoriales, nutricionales y microbiológicas que determinan la calidad y vida útil de las frutas se ven alteradas durante la etapa postcosecha. La aplicación de recubrimientos en la superficie de las frutas permite reducir su pérdida de calidad, prolongando su periodo de vida útil.

Desde su origen hasta nuestros días, según los objetivos perseguidos y la legislación vigente, las características de los recubrimientos, y en concreto su composición, han sido objeto de continuas modificaciones. Así, el agua, como solvente de las formulaciones de recubrimiento, ha reemplazado a los hidrocarburos de petróleo, y el uso de algunos componentes ha dejado de estar autorizado por la legislación de los distintos países. La composición de los recubrimientos, por tanto, está sujeta a continuos cambios basados en las necesidades de cada momento.

En los últimos años, el creciente interés de consumidores y productores por productos saludables, así como por preservar el medio ambiente, ha impulsado el desarrollo de recubrimientos formados a partir de sustancias naturales comestibles y biodegradables. Los recubrimientos comestibles presentan la ventaja de poder aplicarse a todo tipo de frutas, inclusive aquellas que se consumen con piel, como la fresa, la cereza y la frambuesa. Permiten reducir la generación de residuos plásticos de envasado y, a diferencia del resto de recubrimientos, se formulan a partir de ingredientes que, en su mayoría, proceden de fuentes renovables, evitando el uso de parafinas, aceites minerales, polietileno oxidado y plásticos procedentes del petróleo. Son una tecnología postcosecha que no requiere instalaciones sofisticadas, por lo que su aplicación también es viable en países en vías de desarrollo. Constituyen, por tanto, una alternativa saludable de mayor sostenibilidad medioambiental al envasado con materiales sintéticos, viable en las distintas regiones del mundo. Sin embargo, el potencial de los recubrimientos comestibles en postcosecha no está del todo explorado, siendo pocas las aplicaciones industriales desarrolladas.

El factor o factores limitantes para el desarrollo e implantación de esta tecnología postcosecha es el gran número de variables que condicionan su efectividad, las cuales se tienen que contemplar a la hora de 
'diseñar' un recubrimiento comestible. De esta manera, los recubrimientos se desarrollan para dar respuesta a las necesidades específicas de los frutos para los cuales se 'diseñan', lo que limita la versatilidad de los mismos y la implantación de esta tecnología en la industria postcosecha.

Muchos de los estudios realizados se han hecho con recubrimientos desarrollados por la industria, de los cuales se desconoce su composición. La información obtenida de los mismos es de gran utilidad para la industria que los formula, pero no repercute en un avance a nivel científico. Por lo tanto, es necesario investigar acerca del efecto de la composición de los recubrimientos en la calidad de los frutos recubiertos.

Algunos trabajos consultados en la bibliografía dan un paso adelante en este sentido. Sin embargo, los recubrimientos estudiados por los distintos equipos de investigación difieren entre sí en cuanto a tipo de emulsión e ingredientes de sus formulaciones, lo que limita las comparaciones entre ellos. Así, algunos recubrimientos son emulsiones realizadas por procedimientos físicos, mientras que otras son emulsiones realizadas por procedimientos químicos que requieren el uso de amoniaco en su formulación. Además, hay que considerar que el amoniaco presenta toxicidad por inhalación, y que su uso como coadyuvante en la formulación de recubrimientos puede suponer un problema de salud laboral en las industrias de elaboración de los mismos. Por tanto, el desarrollo de recubrimientos comestibles que eviten el uso de estas sustancias supone un avance para la industria postcosecha en general, y para la industria de elaboración de recubrimientos en particular. Así, la investigación para el desarrollo de estos recubrimientos cobra importancia, siendo la composición el objetivo de partida de la misma.

Las propiedades funcionales de los recubrimientos comestibles formando películas aisladas han sido objeto de una extensa investigación que ha permitido conocer los factores que rigen el comportamiento de las mismas. El presente trabajo aborda el desarrollo de recubrimientos comestibles desde una perspectiva genérica y versátil. Para ello, se han extrapolado los principales factores que rigen el comportamiento de las películas aisladas y se han estudiado en el recubrimiento de frutas. Se ha escogido un recubrimiento compuesto a base de hidroxipropilmetil celulosa (HPMC) y cera de abeja (CA) y se ha estudiado su comportamiento en dos tipos de frutos, cítricos y ciruelas, con sustanciales 
diferencias fisiológicas y de notable importancia económica en la Comunidad Valenciana.

La elección de recubrimientos compuestos de hidrocoloide y lípido se ha basado teniendo en consideración los principales factores del deterioro de las frutas. Puesto que las pérdidas de calidad de las frutas se asocian a procesos metabólicos de respiración y transpiración, los recubrimientos deben cumplir la doble función de barrera a los gases y al vapor de agua. La elección de HPMC como matriz del recubrimiento se basó en su permeabilidad selectiva a gases, que permite reducir la tasa respiratoria de las frutas retardando su deterioro, y en su capacidad para formar películas continuas de propiedades sensoriales neutras. Sin embargo, su alta permeabilidad al vapor de agua hace necesaria la incorporación de lípidos en las formulaciones, para lo cual se utilizó CA, seleccionada en base a trabajos previos. Además, las formulaciones incluyeron agentes plastificantes con el fin de mejorar las propiedades mecánicas de los recubrimientos, y ácidos grasos como agentes emulsificantes para mejorar la dispersión de la CA en la matriz de HPMC. 
I. INTRODUCCIÓN 


\section{I.1. TECNOLOGÍAS POSTCOSECHA}

Las frutas son 'tejidos vivos' que después de ser recolectadas experimentan continuos cambios que producen su deterioro. Durante el almacenamiento las frutas continúan respirando, consumiendo nutrientes y obteniendo la energía necesaria para su metabolismo. La velocidad de respiración determina, por tanto, la velocidad de deterioro del fruto. Además de respirar, las frutas transpiran, es decir, pierden agua, lo que produce una serie de alteraciones como la pérdida de turgencia del fruto y los cambios de color (Wills et al., 1981). Otros procesos metabólicos de naturaleza enzimática, como la síntesis de pigmentos y la degradación de las paredes celulares, también producen un deterioro en el fruto en la etapa postcosecha (Cheftel y Cheftel, 1976). A la actividad metabólica del fruto se suma el desarrollo de microorganismos patógenos, que reduce notablemente la calidad de las frutas. Las tecnologías postcosecha tienen por objeto ralentizar los procesos de deterioro del fruto, lo que permite prolongar su periodo de vida útil.

Idealmente, la máxima reducción de la actividad metabólica de las frutas y, por tanto, la máxima vida útil se logra a temperaturas ligeramente superiores al punto de congelación de las mismas. Las bajas temperaturas ofrecen la ventaja adicional de disminuir el ritmo de crecimiento microbiano y, si lo son suficientemente, impiden la germinación de las esporas fúngicas. Sin embargo, el frío puede ocasionar una lesión de los tejidos en frutos sensibles. Por tanto, para determinar la temperatura óptima de almacenamiento es imprescindible estudiar la respuesta del fruto a las bajas temperaturas.

La vida útil en refrigeración de los distintos frutos es muy variable y se correlaciona con su intensidad respiratoria (Day, 1993). Los beneficios de la refrigeración reduciendo el deterioro postcosecha del fruto han sido extensamente estudiados (Schiffmann-Nadel et al., 1971; Mitchell et al., 1972; Porrit, 1974; Paull, 1999; Schirra et al., 2004; Henriod, 2006). Para ciruelas las temperaturas de congelación de los tejidos varían de -2 a 1, dependiendo del contenido en sólidos solubles, y la temperatura óptima de almacenamiento es de $0^{\circ} \mathrm{C}$ (Ceretta et al., 2000; Crisosto y Kader, 2004). Para cítricos la temperatura óptima de almacenamiento varía de 5 a $8{ }^{\circ} \mathrm{C}$ dependiendo de la especie y cultivar. 
La refrigeración constituye la base de conservación de los frutos y si se combina con otras técnicas postcosecha se mejoran los resultados. Así la refrigeración se complementa con otras tecnologías como los tratamientos con calor, las atmósferas modificadas y controladas, los tratamientos químicos y las radiaciones ionizantes. Además, la utilización de envolturas plásticas y de recubrimientos (desarrollados en el Apartado I.2), al proporcionar al fruto una barrera de protección adicional, pueden mejorar la calidad de los frutos durante el almacenamiento en refrigeración.

En los tratamientos con calor se incluyen el curado y los calentamientos intermitentes (CI) que son técnicas para reducir los daños por frío. El curado es un tratamiento previo a la refrigeración y consiste en someter al fruto a altas temperaturas durante un corto periodo de tiempo para inducir la producción de proteínas de resistencia a las bajas temperaturas (heat shock proteins, HSP) (Laurie y Klein, 1991; Laurie et al., 1993; Whitaker, 1993). Los CI se basan en el carácter reversible de algunos daños por frío en la fase de latencia de la alteración. Consiste en someter al fruto a calentamientos intermitentes, en el curso de la conservación frigorífica convencional. La eficacia de los CI se atribuye a una serie de respuestas fisiológicas del fruto durante los mismos que incluyen: la restauración de las membranas celulares dañadas por el frío, la eliminación de metabolitos tóxicos acumulados a bajas temperaturas, y la síntesis de metabolitos indispensables para el correcto funcionamiento celular (Marcellin y Ulrich, 1983; Artés, 1995b). Se ha demostrado que los CI restablecen la respiración normal de cítricos, melocotones y tomates dañados por frío, y la emisión de etileno y el equilibrio de la actividad pectinesterasa y poligalacturonasa en melocotones que también presentaban daños por frío (Marcellín y Ulrich, 1983; Artés et al., 1996). En cultivares de cítricos sensibles al frío se ha observado una reducción de los daños mediante distintos tratamientos con calor (Cuquerella et al., 1988; Schirra y Mulas, 1995; Schirra y D’Hallewin, 1997).

Las atmósferas controladas (AC) o modificadas (AM) son técnicas en las que se altera la composición del aire que rodea al fruto con el fin de retrasar su deterioro (Kader, 1992; Kader et al., 1986, 1989). Generalmente se modifica la atmósfera con un incremento en la concentración de $\mathrm{CO}_{2}$ y una disminución de $\mathrm{O}_{2}$, aunque también se trabaja a altas concentraciones de $\mathrm{O}_{2}$ y ausencia de $\mathrm{CO}_{2}$ y se modifican los niveles 
de nitrógeno, etileno y monóxido de carbono. Cuando se fijan unos valores de estos gases y se controla exactamente su composición durante el tiempo de almacenamiento se habla de AC, mientras que cuando los niveles se fijan al inicio pero ya no se controlan a lo largo del almacenamiento se habla AM. En este último caso la atmósfera de almacenamiento evoluciona con el tiempo y se ve afectada por la actividad metabólica del fruto, que modifica los niveles de $\mathrm{O}_{2}, \mathrm{CO}_{2}$, etileno y vapor de agua $\mathrm{y}$, en el caso de frutos envasados o recubiertos, por la permeabilidad de los envases o coberturas que envuelven al fruto.

Algunas ventajas de las AC y AM son la reducción de la tasa respiratoria, la disminución de los efectos del etileno en la senescencia, la retención de firmeza y la reducción del desarrollo de hongos (Wills et al., 1998). En ciruelas, además, se ha observado una retención de los sólidos solubles (Claypool y Allen, 1951; Maxie et al., 1958; Couey, 1960, 1965; Smith, 1967; Sive y Resnizky, 1979; Ben y Gaweda, 1992). Las AC y AM tienen, además, propiedades fumígenas e insecticidas cuando se aplican a altos niveles de $\mathrm{CO}_{2}$ (superiores al $50 \%$ ) y muy bajos de $\mathrm{O}_{2}$ (inferiores al $1 \%$ ), siendo una alternativa a los tratamientos químicos o a la irradiación para combatir plagas en frutas (Mitchell y Kader, 1992). Asimismo, la combinación de AC y AM con la refrigeración permite aumentar las temperaturas de almacenamiento evitando los daños por frío, manteniendo el periodo de vida útil del fruto. Como desventajas cabe señalar el desarrollo de malos sabores y los desórdenes en la maduración por intolerancia a bajas concentraciones de $\mathrm{O}_{2}$ y/o altas concentraciones de $\mathrm{CO}_{2}$ (Kader, 1986).

Las frutas presentan diferente tolerancia al $\mathrm{O}_{2}$ y $\mathrm{CO}_{2}$ según la especie y cultivar, de acuerdo con su tasa respiratoria y permeabilidad de la piel (Baldwin, 1994). Bajas concentraciones de $\mathrm{O}_{2}$ y/o altas concentraciones de $\mathrm{CO}_{2}$ causan acumulación de etanol y acetaldehído, desarrollo de malos sabores y desórdenes en la maduración de manzanas (Fidler y North, 1971; Little y Peggie, 1987; Nichols y Patterson, 1987; Patterson y Nichols, 1988), decoloración superficial y pardeamientos de la pulpa en peras (Richardson, 1985), acumulación de etanol y acetaldehído y desarrollo de malos sabores en cítricos (Davis et al., 1973; Ke y Kader, 1990) y maduración anormal, pardeamiento de la pulpa y acumulación de etanol y acetaldehído en ciruelas (Kader, 1986; Smilanick y Fouse, 1989). Los cítricos presentan una baja tolerancia al $\mathrm{CO}_{2}$ lo que limita el uso de 
esta técnica postcosecha en estos frutos (Bruemmer, 1989; Agabbio, 1999; Artés, 2000). Los niveles de tolerancia mínimos al $\mathrm{O}_{2}$ aumentan al reducir el $\mathrm{CO}_{2}$ y viceversa. También los niveles de tolerancia al $\mathrm{CO}_{2}$ disminuyen si se reduce el $\mathrm{O}_{2}$ y a la inversa (Beaudry, 1999). Otros factores como el tiempo de exposición y la temperatura de almacenamiento modifican los niveles de tolerancia a ambos gases.

Entre los tratamientos químicos utilizados en postcosecha para prolongar la vida útil del fruto se incluyen los reguladores del crecimiento (benciladenina, ácido giberélico y ácido diclorofenoxiacético) (Wills et al., 1984); las poliaminas que tienen actividad antioxidante (Kramer et al., 1991; Ponappa et al., 1993); el calcio que retiene la firmeza del fruto (Mason et al., 1975; Abbot y Conway, 1989), reduce la incidencia de podredumbre (Conway et al., 1991) y previene distintos daños por frío (Wills et al., 1984); los metil-jasmonatos que también se utilizan para prevenir los daños por frío (Meir et al., 1996) y los fungicidas. Otro tratamiento químico es la aplicación gaseosa de 1-metilciclopropeno (1MCP) que inhibe la acción del etileno (Dong et al., 2002) retrasando la maduración de algunos frutos climatéricos (Jeong et al., 2002). En ciruelas la aplicación de 1-MCP disminuye la síntesis de etileno endógeno y la respiración, mantiendo la firmeza y retrasando la evolución del color (Dong et al., 2002; Salvador et al., 2003).

La aplicación de radiaciones ionizantes en postcosecha tiene por objeto la desinfestación de plagas por destrucción de larvas y huevos (Hallman, 1999), la inactivación de organismos patógenos (Gladon et al., 1997) y la reducción del metabolismo del fruto, disminuyendo la actividad respiratoria, la síntesis de etileno y la pérdida de agua (Dharkar et al., 1966; Maxie et al., 1966; Dharkar y Sreenivasan, 1971; Lu et al., 1991). Algunos trabajos muestran la aptitud de esta técnica para mejorar y alargar la conservación de ciertas frutas y hortalizas (O’Beirne, 1991; Yu et al., 1995; Gladon et al., 1997; El-Samahy et al., 2000; Martínez-Solano et al., 2001). Otros muestran un efecto negativo de las radiaciones ionizantes en algunos cultivares de fresas y arándonos que se manifiesta con una reducción de firmeza (Miller et al., 1995; Yu et al., 1996; Gladon et al., 1997). Los efectos de la radiación en las frutas depende de la especie y cultivar (Miller et al., 2000).

La aplicación de recubrimientos en la superficie de las frutas o 
'encerado' mejora las propiedades barrera de las ceras naturales (cera epicuticular) presentes en el fruto y/o reponen las mismas en caso de haber sido eliminadas por el lavado o manipulación postcosecha. El 'encerado' de frutas se remonta a la China del siglo XII que practicaba esta tecnología para reducir la deshidratación de cítricos (Hardenburg, 1967). El desarrollo de ceras 'modernas' comenzó alrededor de 1930 en Estados Unidos con la aplicación de ceras de parafina a naranjas. Estas ceras fueron sustituidas a finales de la siguiente década por las 'ceras solventes' o soluciones de resinas sintéticas (cumarona-indeno o colofonia) en hidrocarburos de petróleo (Hardenburg, 1967; Hall, 1981; Kaplan, 1986). Posteriormente se formularon las 'ceras al agua' o emulsiones acuosas de cera carnauba, candelilla y de polietileno que retardaban la deshidratación pero no aportaban tanto brillo como las 'ceras solventes'. Hacia 1960 se empezaron a utilizar 'ceras al agua' que incluían resinas, como la goma laca, que mejoraban sustancialmente el brillo de las 'ceras al agua' desarrolladas inicialmente (Petratrek et al., 1999).

Desde su origen hasta nuestros días, según los objetivos perseguidos y la legislación vigente, las características de los recubrimientos, y en concreto su composición, han sido objeto de continuas modificaciones. Así el agua, como solvente de las formulaciones de recubrimiento, ha reemplazado a los hidrocarburos de petróleo y el uso de algunos componentes ha dejado de estar autorizado por la legislación de los distintos países. En España la legislación vigente desautoriza el uso de componentes como la 'cera montana', la 'resina de colofonia' y la 'parafina' utilizados con anterioridad. La composición de los recubrimientos, por tanto, está sujeta a continuos cambios en base a las necesidades de cada momento y la tendencia actual es excluir los ingredientes que pudieran causar algún perjuicio. En este sentido, se observa un creciente interés por desarrollar recubrimientos alternatios a las ceras comerciales utilizadas por la industria. Las ceras comerciales son emulsiones iónicas cuya formulación requiere del uso de coadyuvantes, como el amoniaco, que pueden presentar toxicidad por inhalación y suponen un problema de salud laboral en las industrias de elaboración de las mismas.

En los últimos años el creciente interés de consumidores y productores por productos saludables, así como por preservar el medio ambiente, ha impulsado el desarrollo de recubrimientos formados a partir de sustancias naturales comestibles y biodegradables. Los recubrimientos 
comestibles presentan la ventaja de poder aplicarse a todo tipo de frutas, inclusive aquellas que se consumen con piel como la fresa, la cereza y la frambuesa. Permiten reducir la generación de residuos plásticos de envasado y, a diferencia de otros recubrimientos, se formulan a partir de ingredientes que, en su mayoría, proceden de fuentes renovables, evitando el uso de parafinas, aceites minerales, polietileno oxidado y plásticos procedentes del petróleo. Además, son una tecnología postcosecha que no requiere instalaciones sofisticadas, por lo que su aplicación también es viable en países en vías de desarrollo. Constituyen, por tanto, una alternativa saludable de mayor sostenibilidad medioambiental al envasado con materiales sintéticos y viable en las distintas regiones del mundo.

El Apartado I.2 trata de forma extensa las propiedades y aplicaciones de los recubrimientos comestibles en frutas.

\section{I.2. RECUBRIMIENTOS COMESTIBLES}

\section{I.2.1. Definición y propiedades funcionales}

Los recubrimientos comestibles se definen como productos comestibles que forman una fina capa sobre el alimento (Guilbert, 1986; Gennadios y Weller, 1990). Constituyen una barrera semipermeable a los gases y al vapor de agua que retrasa el deterioro del alimento (Krochta y de Mulder-Johnston, 1997), mejoran las propiedades mecánicas (Mellenthin et al., 1982), ayudan a mantener la integridad estructural de producto que envuelven, a retener compuestos volátiles (Nísperos-Carriedo y Shaw, 1990) y también pueden actuar de vehículo de aditivos alimentarios (antimicrobianos, microorganismos de control biológico, antioxidantes, aromatizantes, colorantes, etc.) (Kester y Fennema, 1986). Aplicados a frutas permiten controlar la respiración y senescencia de forma similar a las atmósferas modificadas (Banks et al., 1993; Cisneros-Zevallos y Krochta, 2002), ejerciendo una barrera a los gases que reduce el deterioro del fruto (Smith et al., 1987). Ejercen, asimismo, una barrera al vapor de agua que reduce la transpiración del fruto y el deterioro asociado a este proceso fisiológico (Baldwin, 1999).

\section{I.2.2. Componentes de los recubrimientos comestibles.}

Los principales componentes de los recubrimientos comestibles 
son polisacáridos, proteínas, lípidos y resinas. Las formulaciones pueden incluir, además, plastificantes y emulsificantes de distinta naturaleza química que mejoran las propiedades de los recubrimientos.

Los materiales utilizados en la formulación de recubrimientos comestibles deben estar autorizados por la legislación vigente. En la Unión Europea estos materiales se regulan por la directiva 95/2/CE de 20 de Febrero de 1995 relativa a aditivos alimentarios distintos de los edulcorantes. La última revisión legislativa es la Directiva 06/52/CE de 5 de Julio de 2006. La Tabla I.1 muestra algunos ejemplos de aditivos alimentarios utilizados en la formulación de recubrimientos comestibles.

Tabla I.1. Ejemplos de aditivos alimentarios utilizados en la formulación de recubrimientos comestibles

\begin{tabular}{llll}
\hline $\mathrm{N}^{\circ}$ E & Denominación & $\mathrm{N}^{\circ}$ E & Denominación \\
\hline E 901 & Cera de abejas & E 904 & Goma laca \\
E 902 & Cera candelilla & E 410 & Goma de garrofín \\
E 903 & Cera carnauba & E 412 & Goma guar \\
E 473 & Sucroésteres de ácidos grasos & E 415 & Goma xantana \\
E 474 & Sucroglicéridos & E 407 & Carragenatos \\
E 570 & Ácidos grasos & E 422 & Glicerina \\
E 461 & Metilcelulosa & E 421 & Manitol \\
E 463 & Hidroxipropilcelulosa & E 1520 & Propilenglicol \\
E 464 & Hidroxipropilmetilcelulosa & & \\
E 466 & Carboximetilcelulosa & & \\
\hline
\end{tabular}

Fuente: Directiva 95/2/CE.

Los polisacáridos y las proteínas son polímeros que forman redes moleculares cohesionadas por una alta interacción entre sus moléculas (puentes de hidrógeno, fuerzas de Van der Walls, London, Debye, de cristalización o de valencia primaria) (Sothornvit y Krochta, 2005). Su cohesión molecular les confiere buenas propiedades mecánicas, pudiendo ejercer de matriz estructural del recubrimiento (Guilbert, 1986), y buenas propiedades barrera a gases $\left(\mathrm{O}_{2}\right.$ y CO $\left.\mathrm{CO}_{2}\right)($ Kester y Fennema, 1986; Park et al., 1993; Nisperos-Carriedo, 1994). Sin embargo, la polaridad de estos polímeros hace que sean afines al agua y que ésta se integre fácilmente en su estructura estableciendo puentes de hidrógeno con las moléculas de polímero, reemplazando las uniones entre las moléculas del propio polímero. De esta manera, el polímero pierde cohesión y aumenta la 
permeabilidad tanto al agua como a los gases (McHugh y Krochta, 1994a).

A pesar de la alta permeabilidad al agua de los recubrimientos formados por polisacáridos (Kester y Fennema, 1986; Genadios y Weller, 1990), ciertos polisacáridos, como pectinas, alginatos y carragenatos, forman geles de alta humedad que actúan como agentes sacrificantes de agua evitando la deshidratación del producto que recubren (Allen et al., 1963; Kester y Fennema, 1986). Los derivados de celulosa, las fracciones del almidón y sus derivados, el quitosano, las gomas de garrofín, guar y santana, el pululano, levano y elsinano son algunos de los polisacaridos utilizados en la formulación de recubrimientos comestibles.

Las proteínas añaden valor nutricional a los alimentos que envuelven pero, por motivos culturales o de salud, pueden ser socialmente rechazadas (Baldwin et al., 1999). Así, las proteínas animales pueden ser rechazadas por personas vegetarianas o por personas a las que su religión se lo prohíba. Otras proteínas pueden causar intolerancias, como la intolerancia al gluten (enfermedad celíaca), a la lactosa de la leche y a las proteínas de la leche de vaca. Algunas proteínas utilizadas en la formulación de recubrimientos comestibles son la zeína de maíz, la proteína de soja, el gluten de trigo, la gelatina, la proteína de cacahuete, la queratina, el colágeno, la proteína del suero de leche y la caseína (Baldwin, 2002).

Los lípidos y las resinas, por su naturaleza hidrofóbica, ejercen una buena barrera al vapor de agua. Sin embargo, su falta de cohesividad e integridad estructural hace que presenten malas propiedades mecánicas formando recubrimientos quebradizos (Gontard et al., 1995). Las resinas aportan brillo al recubrimiento, son más permeables al vapor de agua que los lípidos y ejercen una importante barrera a la difusión de gases, por lo que pueden inducir la anaerobiosis del fruto recubierto (Hagenmaier y Shaw, 1991-1992). Los lípidos más utilizados en la formulación de recubrimientos comestibles son ceras naturales (cera de abeja, candelilla y carnauba), ácidos grasos, monoglicéridos acetilados y diversos aceites vegetales (de cacahuete, maíz y soja). Las resina más utilizada es la goma laca.

Debido a la distinta naturaleza de estos componentes es difícil obtener, a partir de un único material, un recubrimiento que posea al 
mismo tiempo buenas propiedades mecánicas y barrera. La combinación de distintos componentes permite aprovechar las ventajas de los mismos y obtener recubrimientos con buenas propiedades funcionales. Estos recubrimientos compuestos se formulan generalmente a partir de hidrocoloides (polisacáridos y proteínas), que constituyen la matriz estructural y la barrera a gases, y lípidos que aportan la resistencia al vapor de agua (Guilbert, 1986).

En los recubrimientos comestibles compuestos, el lípido puede estar emulsionado en la matriz de hidrocoloide formando lo que se denominan 'recubrimientos emulsionados', o separado de la matriz de hidrocoloide formando una doble capa, en cuyo caso hablamos de 'recubrimientos bicapa'. Estas 'películas bicapa' se pueden obtiener mediante dos pasos: (1) formación de la película de hidrocoloide y (2) formación de la película de lípido, o mediante un paso, por separación de fases tras la preparación una emulsión. Las propiedades de los 'recubrimientos emulsionados' se pueden mejorar añadiendo agentes emulsificantes a las formulaciones. Los emulsificantes favorecen la dispersión del lípido en la matriz hidrocoloide (Kester y Fennema, 1986; Baldwin et al., 1997) y mejoran la capacidad del recubrimiento para impregnar al alimento y formar una capa continua en la superficie del mismo. Además, las formulaciones pueden incluir agentes plastificantes que aportan flexibilidad al recubrimiento mejorando su integridad física.

La incorporación de plastificantes tiene como objetivo mejorar la flexibilidad de los recubrimientos, haciéndolos menos quebradizos. La rigidez de los recubrimientos se debe a las fuerzas de cohesión que estabilizan la matriz polimérica de polisacárido o proteína. Los plastificantes debilitan estas fuerzas de cohesión entre las cadenas de polímero, incrementando la movilidad de las mismas y mejorando la flexibilidad de la matriz polimérica (Banker, 1966). Sin embargo, la reducción de la cohesión del polímero se traduce en un incremento de la permeabilidad a los gases y al vapor de agua del recubrimiento (Banker, 1966; Mchugh y Krochta, 1994a). Algunos de los plastificantes utilizados en la formulación de recubrimientos son polioles, como glicerol, polietilenglicol, propilenglicol, sorbitol, sacarosa y glucosa, que tienen naturaleza hidrofílica y reducen significativamente la barrera al vapor de agua del recubrimiento. Para preservar la barrera al vapor de agua de los recubrimientos se pueden utilizar otros plastificantes de naturaleza 
hidrofóbica, como los ácidos grasos y sus derivados, y los aceites que, sin embargo, aumentan la permeabilidad al oxígeno del recubrimiento. Por tanto, en función de las características requeridas del recubrimiento se pueden utilizar un tipo u otro de plastificante, o una combinación de ambos (Sothornvit y Krochta, 2005).

Los emulsificantes, tensoactivos o surfactantes son sustancias anfifílicas con actividad superficial. Reducen la tensión interfacial sólidolíquido aumentando la capacidad del recubrimiento para impregnar al alimento en la etapa de aplicación del mismo. También reducen la tensión interfacial agua-lípido, favoreciendo la dispersión de los lípidos en agua y, por tanto, la formación de recubrimientos emulsionados. Por su carácter anfipático, estabilizan las emulsiones y reducen las fuerzas intermoleculares entre las cadenas de los polímeros, actuando, en cierto modo, como plastificantes de los mismos. Algunos de los emulsificantes usados en la formulación de recubrimientos comestibles son: ácidos grasos, monoacilgliceroles, lecitina y sus derivados, etilenglicol, monoestearato, glicerol monoestearato, ésteres de ácidos grasos y sorbitan o polioxeno (Tweens) y ésteres de sacarosa y ácidos grasos (Baldwin, 1999).

Las proteínas y polisacáridos, empleados como componentes principales en la formulación de recubrimientos emulsionados, también poseen una actividad estabilizante de las emulsiones, por lo que en algunos casos no es necesario la incorporación de otros agentes emulsificantes o tensoactivos. Tanto las proteínas como los polisacáridos se sitúan en la interfaz lípido-agua y establecen fuerzas de repulsión que evitan la coalescencia de las partículas de lípido, siendo estas de naturaleza electrostática en el caso de proteínas y estérica en el caso de polisacáridos (Callegarin et al., 1997). Asimismo, Sharma (1981) atribuye el efecto estabilizador de ambos polímeros al incremento que producen en la viscosidad de la fase continua (fase acuosa). Este incremento supone una disminución de la movilidad de las partículas de lípido y, por tanto, de la velocidad de coalescencia.

\section{I.2.3. Factores que afectan a la calidad de los frutos recubiertos con recubrimientos comestibles compuestos}

Las propiedades del recubrimiento, las características del fruto, la técnica de aplicación y secado del recubrimiento, y las condiciones de 
almacenamiento condicionan la calidad del fruto recubierto con recubrimientos comestibles compuestos. La Figura I.1 muestra los principales factores que intervienen en la calidad final de los frutos recubiertos con recubrimientos comestibles compuestos.

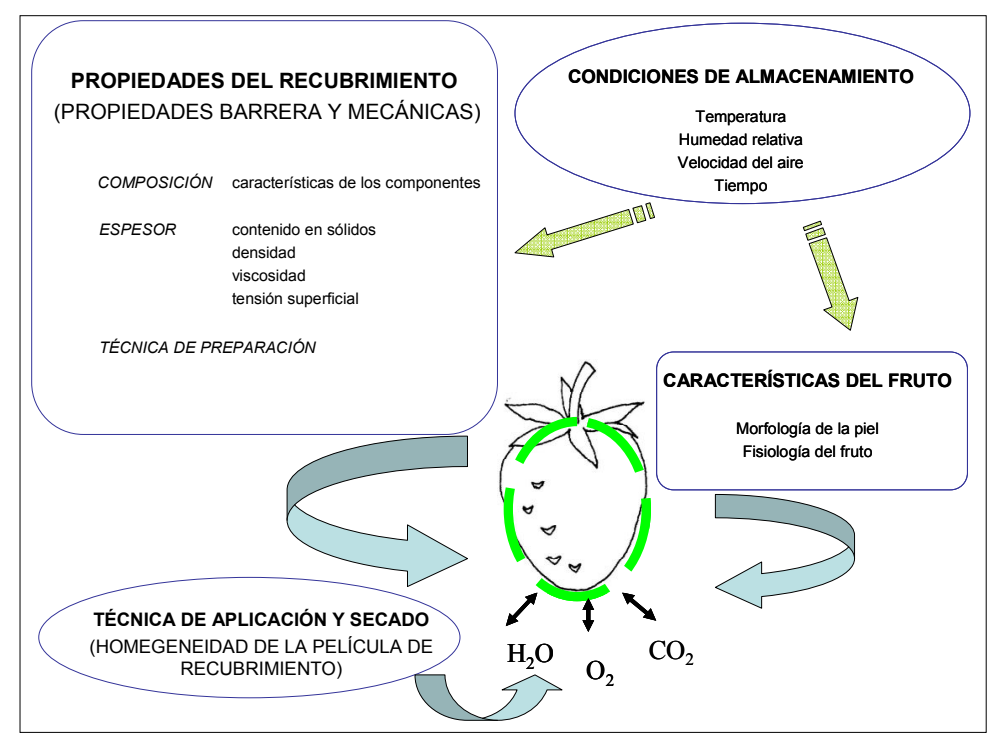

Figura I.1. Factores que afectan a la calidad de los frutos recubiertos con recubrimientos comestibles compuestos.

El potencial de los recubrimientos para proteger al fruto del deterioro depende de sus propiedades barrera y mecánicas. Las propiedades barrera, que se determinan en películas aisladas preformadas en placa, incluyen la permeabilidad al vapor de agua, a los gases, a compuestos volátiles y solutos. De éstas, la permeabilidad al vapor de agua y a los gases $\left(\mathrm{CO}_{2}\right.$ y $\left.\mathrm{O}_{2}\right)$ son las propiedades de mayor interés para el recubrimiento de frutas. Las propiedades mecánicas determinan la habilidad del recubrimiento para formar una capa continua con buena integridad física en torno al fruto. Las propiedades barrera y mecánicas de los recubrimientos dependen de factores intrínsecos del propio recubrimiento, como son la composición, el espesor y la técnica de preparación de los mismos, y de otros factores como las condiciones de secado y de almacenamiento.

Sin embargo, en la calidad final del fruto recubierto no sólo 
intervienen las propiedades barrera y mecánicas del recubrimiento. Otros factores, como la técnica de aplicación y la morfología de la piel del fruto, que condicionan la distribución del recubrimiento en la superficie del fruto, la fisiología del fruto y las condiciones de almacenamiento, determinan la calidad final del fruto recubierto.

El presente epígrafe se subdivide en dos apartados. El primero describe los factores que determinan el comportamiento de los recubrimientos comestibles compuestos formando películas aisladas (I.2.3.1.) y el segundo (I.2.3.2.) describe el resto de factores involucrados en el comportamiento del recubrimiento aplicado al fruto.

\section{I.2.3.1. Factores que afectan a las propiedades funcionales de las películas comestibles compuestas}

Las propiedades de las películas aisladas dependen de las características de sus ingredientes, del espesor de las mismas y de las condiciones de secado y almacenamiento.

\section{Efecto del lípido}

Muchos autores han observado que las características químicas de los lípidos determinan las propiedades barrera de las películas compuestas, en especial la permeabilidad al vapor de agua. La polaridad, longitud de la cadena hidrocarbonada, el estado físico, el grado de saturación y el polimorfismo son algunas características de los lípidos que afectan la permeabilidad al vapor de agua de las películas. Asimismo, la distribución del lípido en las películas formando 'películas bicapa' o 'películas emulsionadas', modifica las propiedades de las mismas. El contenido en lípido, el tamaño de la partícula, la estabilidad de la emulsión y las propiedades mecánicas de los lípidos son algunos de los factores que determinan la funcionalidad de las películas emulsionadas.

La resistencia al vapor de agua del lípido es inversamente proporcional a su polaridad. Los grupos polares atraen a las moléculas de agua reduciendo la efectividad de los lípidos como barrera al vapor de agua (Kestter y Fennema, 1989; Fennema et al., 1994; Gontard et al., 1994; McHugh y Krochta, 1994b; Quezada-Gallo et al., 2000; Yang y Paulson, 2000). Por el contrario, los grupos no polares confieren hidrofobicidad a 
la molécula y reducen la permeabilidad al vapor de agua de la película resultante. De esta manera se ha observado que al aumentar la longitud de la cadena hidrocarbonada de los lípidos se mejora la barrera al vapor de agua (Schultz et al., 1949; Kamper y Fennema, 1984a; Koelsch y Labuza, 1992; McHugh y Krochta, 1994a; Jongjareonrak et al., 2006).

Otro factor que afecta a las propiedades barrera de los lípidos es su estado físico. Los lípidos en estado sólido proporcionan mayor resistencia a la difusión del vapor de agua que en estado líquido (Kamper y Fennema, 1984a; Martín-Polo et al., 1992a). Esto se puede explicar en términos de solubilidad relativa del vapor de agua en la fase líquida o sólida y también se puede relacionar con la organización molecular de los lípidos. Los lípidos en estado sólido presentan una estructura cristalina muy compacta o de alta densidad que dificulta la difusión del agua haciéndolos más impermeables (Landmann et al., 1960; Watters y Brekkle, 1961; Kamper y Fennema, 1985). El estado físico depende asimismo de la temperatura y del grado de saturación del lípido. Las insaturaciones reducen la capacidad del lípido para formar estructuras ordenadas reduciendo por tanto su punto de fusión y su resistencia al vapor de agua (Pascatt, 1985). Los ácidos grasos de alto punto de fusión, los monoglicéridos, las grasas hidrogenadas y las ceras son buenas barreras al vapor de agua, mientras que los aceites poliinsaturados presentan peores propiedades barrera (Schultz et al., 1949; Kamper y Fennema, 1984b; Kester y Fennema, 1989a,d; Donhowe, 1993; Hagenmaier y Shaw, 1992; Koelsch y Labuza, 1992).

La forma de los cristales de lípido afecta su permeabilidad al vapor de agua y gases, y ésta varia con el tipo de lípido e incluso con las condiciones de cristalización, pudiendo darse distintas conformaciones en un mismo lípido (polimorfismo) (Morillon et al., 2002). Algunos autores han observado que los cristales ortorrómbicos presentes en cera de abeja y cera parafina proporcionan mejor barrera que los cristales hexagonales presentes en triestearina y monoglicéridos acetilados (Kester y Fennema, 1989 a,b; Martín-Polo et al., 1992 a,b) lo que se atribuye a una mejor compactación de los mismos, formando asociaciones densas sin apenas espacio para la difusión de las moléculas de vapor de agua y gases.

Además de la forma de los cristales del lípido, la orientación de los mismos respecto a la dirección del flujo de permeato juega un papel 
decisivo en las propiedades barrera del lípido. Así, las ceras, que se organizan perpendicularmente al flujo de vapor de agua ejercen mayor barrera al vapor de agua que los alcanos que se organizan de forma paralela al flujo de vapor de agua (Callegarin et al., 1997).

La distribución del lípido en la estructura final de la película formando 'peliculas bicapa' o 'peliculas emulsionadas' determina las propiedades barrera de las mismas. Martín-Polo et al. (1992b) modelizó el transporte al vapor de agua en ambos tipos de películas, proponiendo un modelo de resistencia en serie para las 'películas bicapa', donde la resistencia de la capa de hidrocoloide es muy baja comparada con la capa de lípido, y un modelo de resistencia en paralelo para 'películas emulsionadas', en el cual la transferencia de vapor de agua se da principalmente a través de la capa de hidrocoloide. Desde del punto de vista de la transferencia de masa, las 'peliculas bicapa' son más eficaces como barrera al vapor de agua que las 'películas emulsionadas'.

En 'películas emulsionadas' el contenido en lípido de las formulaciones, el tamaño de la partícula de lípido y su distribución en la matriz hidrofílica determina la permeabilidad al vapor de agua de las películas. A pesar de que existe una reducción de la permeabilidad al aumentar el contenido de lípido, algunos estudios muestran que hay un contenido crítico a partir del cual las propiedades barrera de la película no mejoran e incluso pueden empeorar. Sapru y Labuza (1994) observaron que para películas formuladas con ácido esteárico, metil celulosa y polietilenglicol, la mínima permeabilidad al vapor de agua se conseguía para un contenido en ácido esteárico de $14 \%$ en base seca (b.s.), aumentando por encima de este contenido en lípido. Koelsch y Labuza (1992) determinaron un contenido crítico de lípido del $30 \%$ (b.s.) en películas de metil celulosa y ácidos grasos. Shellhammer y Krochta (1997) observaron que un aumento del contenido en cera de abeja a partir del $50 \%$ (b.s.), no mejoraba la barrera al vapor de agua de películas a base de proteína de suero de leche. Avena-Bustillos y Krochta (1993) observaron un aumento de la permeabilidad al vapor de agua en películas de caseína a partir de un contenido en cera de abeja del $25 \%$ (b.s.) y lo atribuyeron a una mala dispersión del lípido en la matriz hidrocoloide a partir del umbral crítico.

En cuanto al tamaño y distribución de la partícula de lípido cabe 
decir que, en general, la barrera al vapor de agua se incrementa con una distribución homogénea del lípido en la matriz de hidrocoloide y una reducción del tamaño de la partícula de lípido (Koelsch y Labuza, 1992; McHugh y Krochta, 1994c; Debeafourt y Voilley, 1995). La presencia de un gran número de partículas de lípido uniformemente dispersas en el sistema dificulta la transferencia de vapor de agua dado que su difusión tiene lugar, principalmente, a través de la fase hidrofílica sorteando las partículas de lípido (Krochta, 1990). En el caso de películas compuestas a base de proteína de suero de leche, la reducción del tamaño de la partícula de lípido puede, además, fomentar la inmovilización de las proteínas entre las moléculas de lípido, mejorando la organización, interconexión y compactación de la estructura, lo que también se traduce en una mayor barrera al vapor de agua (Mchugh y Krochta, 1994c; Pérez-Gago y Krochta, 2001).

El tamaño de la partícula de lípido varía con la técnica de preparación de las emulsiones, la presencia de estabilizantes, y con el tipo y contenido de lípido de las formulaciones. La obtención de microemulsiones, con un tamaño de partícula de lípido que varia de 0.01 $\mu \mathrm{m}$ a $0.2 \mu \mathrm{m}$ se puede conseguir por distintos mecanismos fisicoquímicos: (1) por ionización de los lípidos y las resinas en medio básico (Hagenmaier y Shaw, 1992), lo que da lugar a microemulsiones iónicas y (2) por reducción de la tensión interfacial de las fases acuosa y de resinas o lípidos mediante la incorporación de surfactantes, lo que da lugar a microemulsiones no iónicas. Las microemulsiones presentan excelentes propiedades barrera, siendo translúcidas y termodinámicamente estables (Artz, 1990). Sin embargo, en el caso de las microemulsiones iónicas su formulación requiere el uso de coadyuvantes, como el amoníaco, cuya manipulación presenta cierto riego para la salud u otros coadyuvantes, como hidróxido sódico o potásico, que dejan residuos en la película resultante. Las microemulsiones no iónicas no presentan esta problemática, pero son difíciles de obtener, y, además, aplicadas como recubrimiento de frutas, presentan una baja barrera a la humedad. Mediante agitación física se obtienen macroemulsiones en las que las partículas de lípido tienen un tamaño variable de $0.2 \mu \mathrm{m}$ a $0.5 \mu \mathrm{m}$. Las macroemulsiones son fáciles de preparar, sin embargo, son termodinámicamente inestables, por lo que requieren la adición de emulsificantes en la formulación, y presentan un aspecto turbio (Baldwin, 1997), formando películas con menor brillo que las microemulsiones (Artz, 
1990).

El tipo y contenido en lípido de las formulaciones también afecta al tamaño de partícula del lípido de las películas. Sherwin et al. (1998) observaron que al aumentar la longitud de la cadena hidrocarbonada de los ácidos grasos de 14 a 22 aumentaba el tamaño de la partícula de lípido en películas formuladas con proteína de suero de leche y ácidos grasos. Han et al. (2006) observaron que al reducir el contenido en cera de abeja en películas a base de almidón, mejoraba la distribución del lípido y fomentaba la formación de partículas de lípido con forma esférica.

La interacción lípido-hidrocoloide y su efecto en las propiedades de las películas se describe en algunos trabajos. Koelsch y Labuza (1992) observaron que al mejorar la cohesión de las partículas de lípido en la matriz polimérica mejoraba notablemente la barrera al vapor de agua. La interacción entre ambos componentes afecta la estabilidad de las emulsiones y, por tanto, a las propiedades barrera de las películas emulsionadas (Apartado I.2.2) (Callegarin et al., 1997). La afinidad del polímero y del lípido depende de factores como la estructura y polaridad de ambos, su proporción relativa y las condiciones del medio $(\mathrm{pH}$, viscosidad y temperatura) (Callegarin et al., 1997). Martín Polo et al. (1992b) observaron que la afinidad entre la fase continua y la dispersa aumentaba con la diferencia de polaridad entre las fases mejorando la homogeneidad de la película emulsionada y la barrera al vapor de agua. Así por ejemplo, Wong et al., (1992) observaron que la compatibilidad estructural del quitosano y el ácido laurico proporcionaba películas con buenas propiedades barrera, mientras que otros ácidos grasos resultaban incompatibles con este polímero y empeoraban las propiedades de la película resultante.

No solo la naturaleza química del lípido tiene un efecto en la permeabilidad al vapor de agua. Shellhamer y Krochta (1997) observaron que las propiedades viscoelásticas de los lípidos afectan a la permeabilidad de las películas emulsionadas. Algunos lípidos, como la cera candelilla y carnauba, que aislados muestran una barrera efectiva al vapor de agua, pierden efectividad cuando se incorporan a 'peliculas emulsionadas'. Sin embargo, otros lípidos, como la cera de abeja y la fracción grasa de la leche, que aislados son menos efectivos reduciendo la permeabilidad al vapor de agua, producen películas emulsionadas con mejor barrera a la 
humedad. Los lípidos viscoelásticos como la cera de abeja o la fracción grasa de la leche, se pueden deformar durante la etapa de secado de la película, en la cual se da una retracción de la misma, produciendo películas homogéneas libres de microfracturas que ofrecen mayor resistencia a la difusión de agua.

En 'películas emulsionadas' las moléculas de lípido dispersas en la matriz de hidrocoloide interrumpen la continuidad de la misma modificando las propiedades mecánicas de la película. En general, las discontinuidades que produce el lípido en la matriz de hidrocoloide son puntos de fractura que reducen la resistencia de la película a la tracción (Shellhammer y Krochta, 1997; Pérez-Gago y Krocha, 2001; Petersson y Stading, 2005). Sin embargo, el efecto de los lípidos en el resto de propiedades mecánicas de las películas (elongación y tenacidad) varía con el tipo de lípido y proporción, y con el tipo de hidrocoloide con el que se combine. Algunos lípidos, como la cera de abeja, de carácter viscoelástico, forman películas de mayor flexibilidad y extensibilidad que otros lípidos, como la cera carnauba, que presentan mayor rigidez (Talens y Krochta, 2005). Otros lípidos, como los ácidos grasos y sus derivados y los aceites, aumentan la flexibilidad de las películas y pueden ser incorporados a las formulaciones como agentes plastificantes hidrofóbicos. Las propiedades mecánicas de los lípidos dependen de características como la longitud de su cadena. Así por ejemplo, Jongjareonrak et al. (2006) observaron que un aumento en la longitud de la cadena de los lípidos aumentaba la resistencia mecánica a la tracción de películas de gelatina de pescado y ácidos grasos o sucroésteres. También hay trabajos en la bibliografía que muestran que el efecto del lípido en las propiedades mecánicas de las películas varía con el tipo de hidrocoloide con que se combine. De esta manera, Talens y Krochta (2005) observaron que la cera de abeja facilitaba la deformación de películas de proteína de suero de leche, mientras que Han et al. (2006) observaron un efecto contrario en películas de almidón. En cuanto al contenido en lípido, cabe señalar que un aumento del mismo empeora las propiedades mecánicas de las películas (Shellhammer y Krochta, 1997; Pérez-Gago y Krochta, 2001; Bravin et al., 2004; Petersson y Stading, 2005) y que su exceso da lugar a películas frágiles. Gontard et al. (1994) observaron un aumento de la fragilidad en películas a base de gluten y lípido a partir de un $40 \%$ (b.s.) de lípido. 


\section{Efecto del hidrocoloide}

Los hidrocoloides (polisacáridos y proteínas) presentan una buena barrera a los gases (Kester y Fennema, 1986) y forman la matriz estructural de las películas compuestas (Guilbert, 1986). Son, por tanto, los componentes principales de la barrera al $\mathrm{CO}_{2}$ y $\mathrm{O}_{2}$ y de las propiedades mecánicas de las películas compuestas.

Las propiedades de las películas de hidrocoloide dependen del grado de interacción de sus moléculas. Así, un alto grado de interacción de las moléculas de hidrocoloide reduce la movilidad de las mismas y el volumen libre para la difusión de materia, lo que confiere rigidez a la película resultante y reduce su permeabilidad. La forma y peso molecular del hidrocoloide, la presencia de grupos polares en su molécula, la presencia de agentes de entrecruzamiento, la temperatura y, especialmente, los plastificantes afectan al grado de interacción de las moléculas de hidrocoloide y, por tanto, a las propiedades de la película.

Los hidrocoloides de molécula linear pueden formar estructuras ordenadas y compactas en las que las moléculas están muy próximas entre sí y dejan poco volumen libre para la difusión de gases y vapor de agua. Por el contrario, la presencia de anillos en la molécula de hidrocoloide reduce su grado de interacción intermolecular y su capacidad para formar estructuras ordenadas (Ashley, 1985). La presencia de grupos polares permite la asociación de cadenas mediante puentes de hidrógeno pero aumenta la afinidad por el agua, lo que hace a los hidrocoloides malas barreras al vapor de agua. Las proteínas por su carácter iónico y linealidad molecular presentan mayor interacción molecular que los polisacáridos, lo que, en general, les confiere una mayor barrera al oxígeno (Miller y Krochta, 1997).

Algunos trabajos muestran el efecto del peso molecular del hidrocoloide en las propiedades de las películas. En general, al reducir el peso molecular del hidrocoloide disminuye la interacción entre sus moléculas y el polímero pierde densidad aumentando el volumen libre, lo que se traduce en un aumento de la flexibilidad de la película resultante (Sothornvit y Krochta, 2005). Aunque, la permeabilidad de las películas también se ve afectada por el peso molecular del hidrocoloide, no se puede hablar de un efecto generalizado del mismo, puesto que la bibliografía 
disponible muestra resultados contradictorios. Así por ejemplo, Ayranci et al. (1997) observaron un aumento en la barrera al vapor de agua de películas de hidroxipropilmetilcelulosa (HPMC) y metilcelulosa (MC) al aumentar el peso molecular de los mismos. Mientras que Park et al. (1993) observaron una reducción en la barrera al vapor de agua y al $\mathrm{O}_{2}$ al aumentar el peso molecular de MC e hidroxipropilcelulosa (HPC).

La incorporación de compuestos que ayuden a formar puentes de unión entre las moléculas de polímero, reduce la movilidad de las mismas e incrementa la cohesión del polímero. Estos compuestos o agentes de entrecruzamiento, se añaden a las formulaciones para reducir la permeabilidad y solubilidad de las películas e incrementar su resistencia mecánica a la tracción (Kumins, 1965; Mahmoud y Savello, 1992, 1993; Avena-Bustillos y Krochta, 1993; Orliac et al., 2002).

La temperatura determina el estado físico del polímero lo cual afecta a la densidad molecular del mismo y, por tanto, a sus propiedades mecánicas y difusionales (Martínez-Navarrete et al., 1998). Los hidrocoloides forman sólidos amorfos que, dependiendo de la temperatura, presentan un estado vítreo o gomoso. En estado vítreo las moléculas muestran un grado de movilidad similar al de los sólidos cristalinos, mientras que en estado gomoso la movilidad molecular aumenta drásticamente y el hidrocoloide adquiere fluidez, aumentando la permeabilidad y flexibilidad. La temperatura a la cual se da el cambio de fase de vítreo a gomoso se conoce como 'temperatura de transición vítrea' (Tg) (Roos y Karel, 1991; Buera y Karel, 1993).

\section{Efecto del plastificante}

Los plastificantes, entre los que se incluye el agua, son los principales componentes que afectan a las propiedades barrera y mecánicas de los hidrocoloides. Los plastificantes interfieren en las uniones entre las cadenas de polímero reduciendo así su cohesión (Banker, 1966). Estos aumentan la movilidad entre las cadenas de polímero y, por tanto la flexibilidad y elasticidad del mismo, y aumentan el volumen libre, aumentando la permeabilidad y disminuyendo la temperatura de transición vítrea (Banker, 1966; McHugh y Krochta, 1994d). Las moléculas de plastificante no enlazadas al polímero ejercen asimismo una función lubricante entre cadenas que mejora la flexibilidad del polímero (Doolittle, 
1965; Sears y Darby, 1982).

La habilidad del plastificante para romper los enlaces entre las cadenas de polímero y para atraer agua al sistema plastificante-hidrocoloide depende de la naturaleza química, tamaño, forma, polaridad, longitud de cadena, estado físico y numero de grupos funcionales del plastificante capaces de interaccionar con el polímero (Ninnemann, 1968; Lieberman y Gilbert 1973; Donhowe y Fennema 1993a; Cuq et al., 1997; Gueguen et al., 1998; Sothornvit y Krochta 2001). En general, los mejores plastificantes, en términos de mejorar las propiedades mecánicas son aquellos de pequeño volumen y con muchos grupos polares distanciados entre sí en su molécula. Los plastificantes de molécula lineal difunden con mayor facilidad en la matriz polimérica que los que presentan anillos en su molécula (Sothornvit et al., 2002). Los plastificantes de similar estructura pueden diferir en cuanto a peso molecular, siendo los de menor peso los que presentan mejor difusividad en la matriz polimérica (Inmergut y Mark, 1965), pero a su vez son los que presentan menor permanencia en la matriz de hidrocoloide separándose de esta fácilmente.

La afinidad del plastificante por el agua determina su capacidad para atraer agua al sistema, la cual, a su vez, contribuye a la plastificación del mismo y afecta la permeabilidad de las películas. Así, la mayor higroscopicidad del plastificante potencia la capacidad del plastificante para mejorar las propiedades mecánicas de las películas, pero reduce la barrera al vapor de agua y a los gases $\left(\mathrm{CO}_{2}\right.$ y $\left.\mathrm{O}_{2}\right)$ (Sothornvit y Krochta, 2005). El estado físico de los plastificantes también modifica su efectividad. Sothornvit et al. (2002) observaron que el glicerol, polietilenglicol y propilenglicol, gracias a su estado líquido, plastifican mejor las películas proteicas de $\beta$-Lactoglobulina que otros plastificantes, como a sacarosa, que a temperatura ambiente se encuentran en estado sólido.

La naturaleza hidrofílica o hidrofóbica del plastificante determina su efecto en las propiedades barrera de la película. Así, los plastificantes hidrofílicos aumentan de manera más acusada la permeabilidad al vapor de agua de la película que la permeabilidad a los gases; mientras que con los plastificantes hidrofóbicos sucede lo contrario (Sothornvit y Krochta, 2005). La mayor compatibilidad de los plastificantes hidrofílicos con la matriz de hidrocoloide mejora su eficacia como plastificante frente a los hidrofóbicos. Por este motivo la tendencia es combinar los dos tipos para 
logar las ventajas de ambos y minimizar las desventajas.

El contenido y tipo de plastificante de la formulación afecta tanto a las propiedades barrera como a las propiedades mecánicas de la película. En general, el aumento del contenido en plastificante aumenta el efecto del mismo en las propiedades mecánicas y barrera al vapor de agua y al $\mathrm{O}_{2}$, aumentando la flexibilidad y elongación y la permeabilidad de la película. Sin embargo, en determinadas condiciones ciertos plastificantes pueden producir efectos contrarios a los deseados. Se habla de antiplastificación para referirse al aumento de la fragilidad y de la barrera al vapor de agua de la película por adición de un plastificante. La antiplastificación se atribuye a diversos mecanismos como la reducción del volumen libre entre cadenas de polímero, la interación polímero-plastificante y la presencia de moléculas de plastificante anejas a los grupos polares del polímero (Guo, 1993; Seow et al., 1999). Un bajo contenido de plastificante puede inducir asimismo la cristalización del polímero al reducir la energía de transición de fase promoviendo la formación de estructuras ordenadas en la región amorfa del polímero (Wilson, 1995).

\section{Efecto del espesor}

Las propiedades barrera de las películas varían con el espesor de las mismas, ya que el espesor determina la distancia que el permeato (vapor de agua y gases) debe recorrer para difundir de un lado a otro de la película (Ben-Yehoshua, 1967; Meheriuk y Lau, 1988; Hagenmaier y Shaw, 1992; Hagenmaier y Baker, 1994; Park et al, 1994).

El espesor de las películas formadas en la superficie de los frutos o recubrimientos, varia con el contenido en sólidos de las formulaciones, la densidad, viscosidad, tensión superficial y velocidad de secado (CisnerosZevallos y Krochta, 2003).

Efecto de la temperatura y humedad relativa durante el secado y el almacenamiento

La temperatura de secado de las emulsiones afecta tanto a la cohesión de la matriz de hidrocoloide, como a la morfología del lípido y a su distribución en la película resultante (Debeaufort y Voilley, 1995; Phan et al., 2002). El aumento de la temperatura produce la fusión del lípido y 
reduce la viscosidad de la fase continua de hidrocoloide, facilitando la coalescencia de las partículas de lípido y permitiendo la separación de fases (Bravin et al., 2004). Si la separación de fases es importante se llega incluso a obtener una 'película bicapa'. Así pues, la desestabilización de las emulsiones por calentamiento controlado durante la etapa de secado ha permitido obtener 'películas bicapa' con buenas propiedades mecánicas (McHugh, 2000).

Sin embargo, un exceso de temperatura durante el secado puede acelerar la evaporación del solvente inmovilizando las moléculas de polímero antes de su coalescencia, lo que impide la formación de una red cohesionada (Banker, 1966). Donhowe y Fennema (1993b) observaron un aumento en la cristalinidad de películas de metilcelulosa al aumentar la temperatura de secado de $50{ }^{\circ} \mathrm{C}$ a $100{ }^{\circ} \mathrm{C}$. Aunque no determinaron el efecto de esta cristalinización en las propiedades mecánicas de la película, si que apuntaron un posible aumento de la resistencia a la tracción y una pérdida de flexibilidad.

Las propiedades barrera de las películas y la difusividad del permeato (vapor de agua y gases) se ven afectadas por la temperatura. Conforme a la ley de Arrenius, tanto la permeabilidad de los materiales como la difusividad de los gases aumentan exponencialmente con la temperatura (Pascat, 1985). Además, hay que considerar que la temperatura condiciona el estado físico de los lípidos y los hidrocoloides, modificando sus propiedades mecánicas y barrera y condiciona también la hidratación de las películas, lo que también afecta las propiedades de las mismas. Por tanto, el efecto de la temperatura en las propiedades mecánicas y barrera de la película dependerá de los cambios que produzca en los componentes que lo integran.

Las distintas conformaciones estructurales del lípido dependen de la temperatura, pudiendo variar de estructuras cristalinas ordenadas y compactas, a estructuras de menor organización y mayor fluidez. En general, a temperaturas superiores a los puntos de fusión de los lípidos estos se funden y aumenta la permeabilidad al vapor de agua puesto que, los lípidos en estado líquido son más permeables al vapor de agua que en estado sólido (Landmann et al., 1960; Kamper y Fennema, 1984a). Sin embargo, el aumento de la temperatura de almacenamiento no siempre incrementa la permeabilidad al vapor de agua. Delporte (1995) observó en 
películas bicapa que cuando tiene lugar un cambio de fase del lípido, un aumento de la temperatura aumenta la permeabilidad de la película. Sin embargo, cuando no hay un cambio de fase la permeabilidad disminuye con la temperatura. Hutchinson y Krochta (2002) observaron que el calentamiento de películas emulsionadas de proteína de suero de leche y cera de abeja producía una separación de fases que mejoraba significativamente la barrera al vapor de agua de la película. Fox (1958) observó que un aumento en la temperatura de $23{ }^{\circ}$ a $35^{\circ} \mathrm{C}$ y del periodo de almacenamiento inducía la recristalización y reestructuración de las ceras mejorando el empaquetamiento de las mismas y la orientación y, por tanto, la barrera al vapor de agua. Kester y Fennema (1989c) obtuvieron resultados similares en películas de papel con una lámina de estearil alcohol. Kamper y Fennema (1985) observaron que en películas bicapa de HPMC y ácidos palmítico y esteárico un descenso en la temperatura de 5 a $-19^{\circ} \mathrm{C}$ aumentaba la permeabilidad al vapor de agua probablemente por la rigidez y microfractura de la película a bajas temperaturas. También observaron el mismo efecto al reducir la temperatura de 25 a $5{ }^{\circ} \mathrm{C}$. Asimismo, el incremento de la permeabilidad al vapor de agua al reducir la temperatura de almacenamiento se ha observado en distintos películas comestibles a base de lípidos (Landman et al., 1960; Biquet y Labuza, 1988). Además, la temperatura modifica la capacidad de las películas para absorber agua lo que afecta las propiedades mecánicas y barrera de las mismas. Así por ejemplo, Noguchi (1981) observó que en películas de polisacárido un descenso de la temperatura de $20{ }^{\circ} \mathrm{C}$ a $0{ }^{\circ} \mathrm{C}$ duplicaba la hidratación de las mismas.

La humedad relativa durante el almacenamiento afecta las propiedades de las películas hidrofílicas (McHugh et al., 1993; McHugh y Krochta, 1994d). El agua actúa plastificando los polímeros. Por tanto, las altas humedades relativas durante el almacenamiento incrementan la flexibilidad y permeabilidad de la película. La hidratación de los hidrocoloides incrementa la permeabilidad de estos tanto al agua, como a los gases $\left(\mathrm{CO}_{2} \mathrm{y} \mathrm{O}_{2}\right)$, viéndose más afectada la permeabilidad al $\mathrm{CO}_{2}$ que la permeabilidad al $\mathrm{O}_{2}$. Esto es debido a que la solubilidad en agua del $\mathrm{CO}_{2}$ es mayor que la del $\mathrm{O}_{2}$ lo que hace que las películas de hidrocoloide hidratadas muestren mayor permeabilidad al $\mathrm{CO}_{2}$ que al $\mathrm{O}_{2}$. Cuando estas películas se aplican a frutas que se almacenan en ambientes de humedad relativa alta, limitan más la entrada de $\mathrm{O}_{2}$ al fruto que la salida de $\mathrm{CO}_{2}$ lo que permite restringir la respiración del fruto evitando la anaerobiosis y el 
desarrollo de malos sabores (Baldwin, 1994).

\section{I.2.3.2. Otros factores que afectan la calidad del fruto recubierto}

La homogeneidad del recubrimiento en la superficie del fruto, el secado, las características del fruto (morfología de la piel y fisiología) y las condiciones de almacenamiento afectan la calidad final del fruto recubierto.

Para ejercer una barrera efectiva, los recubrimientos deben formar una capa continua en la superficie del fruto penetrando en los poros del mismo. La tensión superficial y la viscosidad de las emulsiones que forman el recubrimiento determinan la capacidad de estos impregnando al fruto en la etapa de aplicación y, por tanto, determinan su capacidad para taponar poros y formar una capa continua en la superficie del fruto (Hagenmaier y Baker, 1993a; Hershko y Nussinovitch, 1998).

Una distribución homogénea del recubrimiento se consigue mediante una aplicación y secado adecuados. Existen distintas técnicas de aplicación de recubrimientos (por inmersión, por aspersión de espuma y por atomización) que proporcionan distintos resultados. La inmersión es una técnica de bajo coste que permite obtener una distribución homogénea del recubrimiento si se realiza adecuadamente. Sin embargo, puede originar problemas de contaminación microbiana o dilución de las emulsiones si la fruta no está previamente seca. La aspersión de espuma y la atomización requieren equipos de aplicación que permiten agilizar el proceso de aplicación. La aspersión de espuma presenta la ventaja de facilitar el secado porque permite el uso de formulaciones de alto contenido en sólidos, pero puede dar lugar a una mala distribución del recubrimiento. La atomización de las soluciones de recubrimiento da buenos resultados y es la técnica más empleada (Austin y Burns, 1994)

Los recubrimientos se comportan de distinta manera en función del tipo de fruto y cultivar al que se apliquen (Banks, 1983, 1984, 1985; Smith y Stow, 1984; Bai et al., 2003a), debido a las características fisiológicas y morfológicas de los mismos. La piel del fruto ejerce una barrera natural a los gases y al vapor de agua, y condiciona la distribución de los recubrimientos en la superficie del mismo (Claypool y King, 1941). Las características morfológicas de la piel varían para cada especie y cultivar. La presencia de tricomas, como en el caso de melocotones, el tipo y 
espesor de la cutícula y el número de estomas y lenticelas son algunos factores que diferencian unos frutos de otros (Claypool y King, 1941). La fisiología del fruto, que determina los procesos senescentes del mismo, también varía con la especie y cultivar. Algunos frutos como los cítricos tienden a desarrollar malos sabores asociados a procesos anaeróbicos, lo que los hace especialmente vulnerables a los recubrimientos con baja permeabilidad a los gases (Baldwin, 1994). Sin embargo, otros frutos como las peras, sensibles a la pérdida de firmeza de la pulpa y menos susceptibles al desarrollo de malos sabores que los cítricos, mejoran su calidad postcosecha mediante la modificación de la atmósfera (Kader, 1986; Smith et al., 1987), respondiendo bien a los recubrimientos de baja permeabilidad a los gases (Meheriuk y Lau, 1988), siempre que se mantengan los niveles de tolerancia al $\mathrm{O}_{2}$ y $\mathrm{CO}_{2}$ (Richardson, 1985). Algunos frutos como los albaricoques que por carecer de cera epicuticular son sensibles a la deshidratación (Snowdon, 1990) pueden mejorar notablemente su calidad postcosecha con el uso de recubrimientos hidrofóbicos. Otros, como las fresas, que presentan una actividad metabólica alta y son susceptibles a podredumbres, mejoran su calidad postcosecha con recubrimientos de adecuada barrera a los gases que incluyan sustancias antifúngicas en su formulación (Han et al., 2004; Tanada-Palmu y Grosso, 2005; Muñoz-Hernández et al., 2006; Vargas et al., 2006)

Por último las condiciones de almacenamiento (temperatura, humedad relativa y tiempo) determinan la calidad final del fruto recubierto ya que afectan tanto a las propiedades funcionales del recubrimiento (apd. I.5.3.1.), como a la fisiología del fruto.

\section{I.2.4. Investigación desarrollada y aplicación industrial de recubrimientos comestibles en frutas}

El presente epígrafe describe las investigaciones llevadas a cabo hasta el momento en materia de recubrimientos comestibles para frutas, así como las aplicaciones industriales desarrolladas.

El trabajo más extenso se ha realizado en recubrimientos para cítricos. Se han formulado recubrimientos efectivos reduciendo la pérdida de peso que, en algunos casos, mejoran el aspecto externo proporcionado brillo. Sin embargo, el factor crítico que ha determinado la calidad final de 
los cítricos recubiertos ha sido el desarrollo de malos sabores asociados a una excesiva barrera a los gases del recubrimiento. Algunos trabajos muestran que se puede obtener un equilibrio entre la calidad organoléptica y la pérdida de peso restringiendo el periodo de almacenamiento del fruto. Se han desarrollado algunas formulaciones con goma laca que proporcionan alto brillo pero que presentan una excesiva barrera a los gases produciendo malos sabores en mandarinas (Cohen et al., 1990; Baldwin et al., 1995; Hagenmaier y Shaw, 2002) e incluso manchas en la piel asociadas a la baja permeabilidad a gases de estos recubrimientos (Petracek et al., 1998, 1997). Hagenmaier y Baker (1997) formularon recubrimientos a base de ácidos grasos y mezclas de cera de abeja, candelilla y carnauba que redujeron la pérdida de peso y aportaron brillo al fruto. También se han aplicado recubrimientos compuestos a base de hidroxipropil metilcelulosa y lípido (Pérez-Gago et al., 2002) y a base de goma de garrofín (Rojas, 2002) que reducen la pérdida de peso de mandarinas cv. 'Fortune'. Monterde et al., (2002, 2003) y Martínez-Jávega y Cuquerella (2000) formularon recubrimientos a base de goma laca y distintas ceras (de abeja, caranuba o candelilla) que resultaron efectivos reduciendo la pérdida de peso y de firmeza de naranjas 'Valencia', 'Navelina' y 'Lanelate' y mandarinas 'Fortune' y 'Clemenules'. También se han aplicado recubrimientos de quitosano que reducen la pérdida de peso y de firmeza de mandarinas 'Fortune' (Monterde et al., 2003), y recubrimientos con derivados de dextrina y ésteres de glicerina que reducen la pérdida de peso y de firmeza de mandarinas 'Clemenules' y 'Fortune' (Ben-Abda y Martínez-Jávega, 1999; Ben-Abda et al., 1999). Otros recubrimientos compuestos a base de carboximetilcelulosa, aceite de soja y oleato sódico han resultado efectivos manteniendo los niveles de sólidos solubles, la acidez, y la vitamina C en mandarinas (Togrul y Arslan, 2003a). En limones se han aplicado aceites vegetales que reducen la incidencia de lesiones por frío (McDonald, 1986) y recubrimientos de celulosa que reducen el 'degreening' (Chen y Grant, 1995). Para pomelos se han desarrollado recubrimientos de aceites vegetales que reducen la incidencia de daños por frío (Aljuburi y Huff, 1984). Se han realizado algunos trabajos para mejorar las características de permeabilidad a los gases de algunos recubrimientos comerciales. Uno de estos trabajos es el de Porat et al. (2005), en el que se consigue reducir la barrera a los gases y el desarrollo de malos sabores de mandarinas cv. 'Mor' modificando el contenido en sólidos y el contenido en goma laca del recubrimiento comercial 'Tagß'. 
Para manzanas se han formulado recubrimientos con distinto grado de permeabilidad a los gases. Smith y Stow (1984) diseñaron un recubrimiento hecho a base de sucroésteres que retardaba la senescencia y prevenía el escaldado superficial cuando se incluían antioxidantes en la formulación (Bauchot et al, 1995). Alleyne y Hagenmaier (2000) han formulado recubrimientos de cera candelilla y goma laca que aportan brillo y reducen la transpiración. Como alternativa a los recubrimientos de goma laca, Bai et al. (2002, 2003b) formularon recubrimientos de proteína de maíz con un brillo similar a los de goma laca.

Para ciruela se han desarrollado recubrimientos compuestos de hidroxipropil metilcelulosa y lípido que mejoraran la calidad postcosecha del cv. 'Otoño Gigante' (Pérez-Gago et al., 2003a).

En albaricoques se han aplicado recubrimientos a base de metilcelulosa, polietilenglicol, ácido esteárico y ácidos ascórbico o cítrico que reducen la pérdida de peso y la pérdida de vitamina C (Ayranci y Tunc, 2004). Rojas (2002) observó una reducción en la pérdida de peso y de firmeza en albaricoques cv. 'Canino' a los que aplicó recubrimientos a base de goma de garrofín, cera de abeja y glicerol.

Otros recubrimientos comestibles compuestos a base de carboximetilcelulosa y lípidos han resultado efectivos prolongando la vida útil de peras y melocotones. En concreto para melocotones los recubrimientos se formularon con carboximetilcelulosa, cera de abeja, trietanol amina y ácido oleico. Para peras se formularon con carboximetilcelulosa, aceite de soja y oleato sódico (Togrul y Arslan, 2003b).

Se han desarrollado recubrimientos a base de celulosa y emulsificantes y recubrimientos a base de cera carnauba y sales de ácidos grasos que prolongan la vida útil de los mangos, reduciendo la tasa respiratoria y la senescencia de los mismos (Baldwin et al., 1999).

Han et al. (2004) observaron una reducción de la pérdida de peso y de la incidencia de podredumbre, así como una conservación del color, $\mathrm{pH}$ y acidez en fresas y frambuesas a las que se aplicó recubrimientos a base de quitosano. Otros trabajos muestran el efecto beneficioso de los recubrimientos de quitosano en estos frutos (Ghaouth et al., 1991; García 
et al., 1998; Zhang y Quantick, 1998, Hernández-Muñoz et al., 2006) y melocotones ( $\mathrm{Li}$ y Yu, 2001). Vargas et al. (2006) observaron una reducción de la deshidratación y de la pérdida de firmeza en fresas recubiertas con quitosano y ácido oleico. Sin embargo, observaron una pérdida de aroma y sabor en estos frutos. Tanada-Palmu y Grosso (2004) observaron una mejora en la retención de la firmeza, en el aspecto externo y en el sabor de fresas cv. 'Oso Grande' a las que se aplicó recubrimientos a base de gluten y glicerol.

Se han aplicado recubrimientos comestibles a base de goma de garrofín, carnauba y oleína en cerezas de los cv. 'Burlat' y 'Ambrunesa' que reducen la deshidratación y la pérdida de firmeza y que mantienen el color de las cerezas 'Ambrunesa'. Estos recubrimientos permiten prolongar el almacenamiento sin un aumento de los niveles de etanol o acetaldehído suficiente como para desarrollar malos sabores (Rojas et al., 2003).

Para uva de mesa se ha patentado un recubrimiento a base de gel de aloe vera. El efecto de este recubrimiento se estudió en uva cv. 'Crimson Sedles' y mostró una gran habilidad para mantener la calidad postcosecha del fruto. El recubriendo redujo la pérdida de peso, el cambio de color, la pérdida de firmeza, el pardeamiento del raquis y la incidencia de podredumbres (Valverde et al., 2005).

Algunos recubrimientos comestibles han dado el salto del diseño a la aplicación industrial en frutas. Se trata de recubrimientos compuestos de polisacáridos y lípidos. En concreto un grupo importante de estos

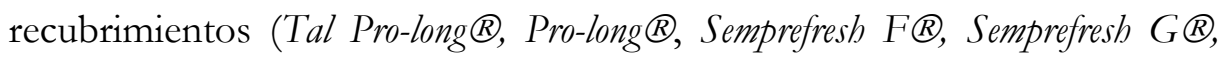

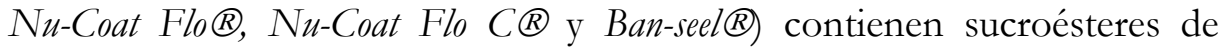
ácidos grasos y carboximetilcelulosa, con o sin agentes antiespumantes. Estos recubrimientos se aplican a un gran número de frutas entre las que se encuentran cítricos, ciruela, mango, banana, plátano, piña, melón, pera, manzana y cereza. Otros, que se comercializan como BrilloshineC $\mathbb{B}$ y

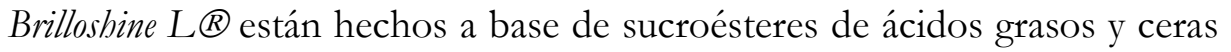
$y$, al igual que los anteriores, tienen un amplio espectro de aplicación.

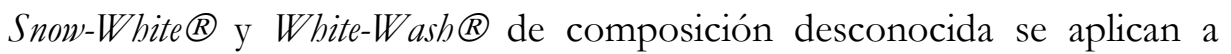
patatas troceadas y enteras respectivamente.

A pesar del potencial de los recubrimientos comestibles mejorando la calidad postcosecha de las frutas, son pocas las aplicaciones industriales 
desarrolladas. El factor o factores limitantes del desarrollo e implantación de esta tecnología postcosecha, es el gran número de variables que condicionan su efectividad, las cuales se tienen que contemplar a la hora de 'diseñar' un recubrimiento comestible. De esta manera, los recubrimientos se desarrollan para dar respuesta a las necesidades específicas de los frutos para los cuales se 'diseñan', lo que limita la versatilidad de los mismos y la implantación de esta tecnología en la industria postcosecha.

Muchos de los estudios realizados se han hecho con recubrimientos desarrollados por la industria, de los cuales se desconoce su composición. La información obtenida de los mismos es de gran utilidad para la industria que los formula, pero no repercute en un avance a nivel científico. Es, por tanto, necesario hacer investigación acerca del efecto de la composición de los recubrimientos en la calidad de los frutos recubiertos.

Algunos trabajos expuestos en el presente epígrafe dan un paso adelante en éste sentido. Sin embargo, cabe decir que los recubrimientos estudiados por los distintos equipos de investigación difieren entre sí en cuanto a tipo de emulsión e ingredientes de sus formulaciones, lo que limita las comparaciones entre ellos. Así, algunos recubrimientos son macroemulsiones compuestas de hidrocoloides y lípidos mientras, que otras son microemulsiones iónicas que incluyen amoníaco en su formulación.

En los últimos años el creciente interés de consumidores y productores por productos saludables así como por preservar el medio ambiente ha impulsado el desarrollo de recubrimientos formados a partir de sustancias biodegradables e inocuas. En este sentido, las microemulsiones iónicas presentan el inconveniente de incorporar ciertos coadyuvantes, como el amoníaco, que pueden presentar toxicidad por inhalación y suponen un problema de salud laboral en las industrias de elaboración de las mismas. Por tanto, el desarrollo de recubrimientos comestibles que eviten el uso de estas sustancias supone un avance para la industria postcosecha en general y para la industria de elaboración de recubrimientos en particular. La investigación para el desarrollo de estos recubrimientos cobra importancia, siendo la composición, el objetivo de partida de la misma. 
II. OBJETIVOS 
El objetivo general de esta tesis es estudiar el efecto de la composición de recubrimientos comestibles compuestos de hidroxipropilmetil celulosa (HPMC), cera de abeja (CA), ácido graso (AG) y plastificante en la calidad postcosecha de ciruelas, naranjas y mandarinas, con el fin de desarrollar recubrimientos respetuosos con el medio ambiente e inocuos para la salud, que ralentizen el deterioro postcosecha de estos frutos y no comprometan su calidad organoléptica.

Los objetivos específicos son los siguientes:

- Determinar el efecto de la composición de películas compuestas a base de HPMC y CA en la permeabilidad al vapor del agua y en las propiedades mecánicas de las mismas y correlacionar estos resultados con el comportamiento de los recubrimientos aplicados al fruto

- Estudiar el efecto del contenido en CA de recubrimientos compuestos a base de HPMC y CA en la calidad postcosecha de ciruelas cv. 'Angeleno' y mandarinas cv. 'Clemenules'

- Estudiar el efecto del tipo y contenido de AG de recubrimientos compuestos a base de HPMC y CA en la calidad postcosecha de ciruelas cv. 'Angeleno' y mandarinas cv. 'Ortanique'

- Estudiar el efecto del tipo y contenido de plastificante de recubrimientos compuestos a base de HPMC y CA en la calidad postcosecha de ciruelas cv. 'Angeleno' y naranjas cv. 'Valencia'

- Estudiar el efecto del contenido en sólidos de recubrimientos compuestos a base de HPMC y CA en la calidad postcosecha de mandarinas cv. Clemenules. 
III. MATERIALES Y MÉTODOS 


\section{III.1. REACTIVOS UTILIZADOS EN LA PREPARACIÓN DE LOS RECUBRIMIENTOS COMESTIBLES Y DE LAS PELÍCULAS PREFORMADAS EN PLACA}

Para las formulaciones se empleó como matriz hidrocoloide hidroxipropilmetilcelulosa (HPMC) de distinto peso molecular (Pm), identificada según el fabricante como E-15 y K-99, y suministrada por Dow Chemical Co. (Midland, MI, EE.UU.), como componente hidrofóbico cera de abeja (CA) de grado 1, suministrada por Brillocera, S.A (Valencia), como agentes plastificantes glicerol $(\mathrm{G})$, sacarosa (S), propilenglicol $(\mathrm{P})$ y manitol $(\mathrm{M})$, y como emulsificante ácido graso (AG) (ácido esteárico (AE), ácido palmítico (AP) y ácido oleico (AO)), todos de Panreac ${ }^{\circledR}$ Química, S.A. (Barcelona, España).

\section{III.2. PREPARACIÓN DE LOS RECUBRIMIENTOS COMESTIBLES Y DE LAS PELÍCULAS PREFORMADAS EN PLACA}

Para la preparación de los recubrimientos y de las películas se elaboró inicialmente una solución acuosa de HPMC. La concentración de ésta solución varió en función del tipo de HPMC empleado, siendo del 5\% (p/p) en el caso de la HPMC tipo E-15, y del 2,5\% (p/p) en el caso de la HPMC tipo K-99. Para ambos tipos de HPMC se siguió el mismo procedimiento de preparación, que incluyó dos etapas: (1) dispersión de la HPMC en agua caliente a temperaturas entre $80-90{ }^{\circ} \mathrm{C}$, y (2) hidratación del producto a temperatura inferior a $30{ }^{\circ} \mathrm{C}$ con continua agitación. A continuación, a la solución de HPMC se añadió el resto de ingredientes de la formulación que incluyeron la CA, el plastificante, el AG y agua en las cantidades correspondientes a cada formulación, como se indica al final del presente apartado. La mezcla con todos los ingredientes se calentó a $90 \pm$ $2{ }^{\circ} \mathrm{C}$ para lograr la fusión de la CA y se homogeneizó con un UltraTurrax (Mod. T25 basic; IKA-Werke GmbH \& Co. KG, Staufen, Alemania) durante $1 \mathrm{~min}$ a 13,000 rpm más $3 \mathrm{~min}$ a 22,000 rpm. Tras la homogenización, la emulsión se enfrió por debajo de $30{ }^{\circ} \mathrm{C}$ para hidratar la HPMC.

Las emulsiones se almacenaron a $5{ }^{\circ} \mathrm{C}$ durante un periodo de tiempo no superior a $48 \mathrm{~h}$ para su posterior aplicación en la fruta. 
Para la preparación de las películas preformadas se prepararon 3 emulsiones o réplicas de cada formulación, siguiendo los pasos descritos anteriormente. Las emulsiones se desgasificaron y vertieron en placas de polietileno de alta densidad de $15 \mathrm{~cm}$ de diámetro. La cantidad de emulsión vertida en cada placa fue constante $(30 \mathrm{~g})$ con el fin de obtener películas de espesor similar para las distintas formulaciones. Las placas conteniendo la emulsión se colocaron en una superficie horizontal nivelada durante aproximadamente 4 días a $55 \pm 5 \% \mathrm{HR}$ y $20 \pm 2{ }^{\circ} \mathrm{C}$ para su secado. Tras el secado, las películas formadas se separaron de su correspondiente placa.

La composición de las emulsiones de los recubrimientos y de las películas se modificó en función del objetivo de cada experiencia. Las formulaciones de los recubrimientos se describen en el Apartado III.3. Las formulaciones de las películas variaron respecto a las formulaciones de los recubrimientos en el contenido en sólidos, que se mantuvo constante al $10 \%$ en el caso de las películas.

\section{III.3. APLICACIÓN DE LOS RECUBRIMIENTOS COMESTIBLES EN FRUTA}

III.3.1. Efecto del contenido en cera de abeja del recubrimiento en la calidad postcosecha de ciruelas 'Angeleno'

Las formulaciones incluyeron HPMC E-15, CA, G y AE. Se formularon 4 recubrimientos con distinto contenido en CA $(0 \%, 20 \%$, $40 \%$ y $60 \%$ en b.s.), cuyos ratios HPMC:G y CA:AE se mantuvieron constantes en todas las formulaciones siendo 1:0,5 y 1:0,2. El CS de las formulaciones fue del 4\%. La viscosidad de los recubrimientos varió de 7 a $30 \mathrm{cp}$ de acuerdo con el contenido en HMPC de los mismos. La Tabla III.1 muestra la composición y viscosidad de los recubrimientos estudiados en esta experiencia. 
Tabla III.1. Composición y viscosidad de los recubrimientos aplicados en la experiencia: efecto del contenido en $C A$ del recubrimiento en la calidad postcosecha de ciruelas 'Angeleno'

\begin{tabular}{cccccc}
\hline Recubrimiento & $\begin{array}{c}\mathrm{HPMC}^{\mathrm{z}} \\
(\% \mathrm{bs})\end{array}$ & $\begin{array}{c}\mathrm{CA} \\
(\% \mathrm{bs})\end{array}$ & $\begin{array}{c}\mathrm{G} \\
(\% \mathrm{bs})\end{array}$ & $\begin{array}{c}\mathrm{AE} \\
(\% \mathrm{bs})\end{array}$ & $\begin{array}{c}\text { Viscosidad } \\
(\mathrm{cp})\end{array}$ \\
\hline $0 \% \mathrm{CA}$ & 66,7 & ---- & 33,3 & ---- & $29,8 \pm 0,9$ \\
$20 \% \mathrm{CA}$ & 50,7 & 20,0 & 25,3 & 4,0 & $17,2 \pm 0,3$ \\
$40 \% \mathrm{CA}$ & 34,7 & 40,0 & 17,3 & 8,0 & $14,2 \pm 1,3$ \\
$60 \% \mathrm{CA}$ & 18,7 & 60,0 & 9,3 & 12,0 & $7,0 \pm 0,9$ \\
\hline
\end{tabular}

${ }^{2}$ HPMC tipo E-15.

El CS se mantuvo constante en todas las formulaciones al 4\%.

Las ciruelas 'Angeleno' cosechadas en Villena (Alicante) el 26/09/03 se transportaron sin refrigerar al Instituto Valenciano de Investigaciones Agrarias (I.V.I.A.). Tras 3 días de almacenamiento a $1{ }^{\circ} \mathrm{C}$ y $85 \pm 5 \% \mathrm{HR}$ se seleccionaron por tamaño y ausencia de lesiones y se dividieron en 6 lotes homogéneos: 4 para la aplicación de los recubrimientos, 1 para el control lavado sin recubrir (CL) y 1 para el control sin lavado ni recubrimiento (CSL). Los recubrimientos se aplicaron por inmersión del fruto durante 1,5 min y su exceso se eliminó por escurrido. Los frutos recubiertos y los control se pasaron por un túnel de secado a $45-50{ }^{\circ} \mathrm{C}$ durante 3 min y se almacenaron 2 , 4 y 6 semanas a 1 ${ }^{\circ} \mathrm{C}$ y $85 \pm 5 \%$ HR, seguido de 1,2 y 3 semanas a $20{ }^{\circ} \mathrm{C}$ y $90 \pm 5 \%$ HR para su posterior análisis.

\section{III.3.2. Efecto del tipo y contenido de ácido graso del recubrimiento en la calidad postcosecha de ciruelas 'Angeleno'}

Las formulaciones incluyeron HPMC E-15, CA, G y AG. Se formularon 6 recubrimientos con distinto tipo de AG (AE, AP y AO), y distinta proporción CA:AG (1:0,5 y 1:0,2). La Tabla III.2 muestra las características fisico-químicas más relevantes de los AG estudiados. El contenido en CA, ratio HPMC:G y CS se mantuvo constante en todas las formulaciones siendo $40 \%$ (b.s.), 1:0,5 y 4\%, respectivamente. Los recubrimientos presentaron una viscosidad en torno a $10 \mathrm{cp}$. La Tabla III.3 muestra la composición de los recubrimientos estudiados en esta experiencia. 
Tabla III.2. Características físico-químicas de los AG empleados en la formulación de los recubrimientos aplicados en la experiencia: efecto del tipo y contenido de $A G$ del recubrimiento en la calidad postcosecha de ciruelas 'Angeleno'

\begin{tabular}{|c|c|c|c|c|}
\hline $\mathrm{AG}$ & $\mathrm{Pm}$ & $\begin{array}{l}\text { Punto } \\
\text { de } \\
\text { Fusión } \\
\left({ }^{\circ} \mathrm{C}\right)\end{array}$ & $\begin{array}{l}\text { Fórmula } \\
\text { Química }\end{array}$ & Estructura Molecular \\
\hline $\mathrm{AE}$ & 284 & 69,6 & $\mathrm{C}_{18} \mathrm{H}_{36} \mathrm{O}_{2}$ & \\
\hline AP & 256 & 82,9 & $\mathrm{C}_{16} \mathrm{H}_{32} \mathrm{O}_{2}$ & \\
\hline $\mathrm{AO}$ & 282 & 15,3 & $\mathrm{C}_{18} \mathrm{H}_{34} \mathrm{O}_{2}$ & \\
\hline
\end{tabular}

Fuente: es.wikipedia.org

Tabla III.3. Composición de los recubrimientos aplicados en la experiencia: efecto del tipo y contenido de $A G$ del recubrimiento en la calidad postcosecha de ciruelas 'Angeleno'

\begin{tabular}{ccccc}
\hline Recubrimiento & $\begin{array}{c}\mathrm{HPMC}^{z} \\
(\% \mathrm{bs})\end{array}$ & $\begin{array}{c}\mathrm{CA} \\
(\% \mathrm{bs})\end{array}$ & $\begin{array}{c}\mathrm{G} \\
(\% \mathrm{bs})\end{array}$ & $\begin{array}{c}\mathrm{AG} \\
(\% \mathrm{bs})\end{array}$ \\
\hline CA:AG $(1: 0,5)$ & 26,7 & 40,0 & 13,3 & 20,0 \\
CA:AG $(1: 0,2)$ & 34,7 & 40,0 & 17,3 & 8,0 \\
\hline
\end{tabular}

z HPMC tipo E-15.

En todas las formulaciones se mantuvo constante el CS al 4\% y la viscosidad en torno a $10 \mathrm{cp}$.

Las ciruelas 'Angeleno' cosechadas en Villena (Alicante) el 22/09/04 se transportaron sin refrigerar al I.V.I.A. donde se seleccionaron por tamaño y ausencia de lesiones y se dividieron en 8 lotes homogéneos: 6 para la aplicación de recubrimientos, 1 para el CL y 1 para el CSL. Los recubrimientos se aplicaron por inmersión del fruto durante 1,5 min y su exceso se eliminó por escurrido. Los frutos recubiertos y los control se pasaron por un túnel de secado a $45-50{ }^{\circ} \mathrm{C}$ durante 3 min y se almacenaron 2, 4, 6 y 8 semanas a $1{ }^{\circ} \mathrm{C}$ y $85 \pm 5 \%$ HR, más 1 semana a $5{ }^{\circ} \mathrm{C}$ y $90 \pm 5 \%$ 
$\mathrm{HR}$, y 5 días a $20{ }^{\circ} \mathrm{C}$ y $90 \pm 5 \% \mathrm{HR}$ para su posterior análisis. El almacenamiento de las ciruelas a $5{ }^{\circ} \mathrm{C}$ durante 1 semana se realizó para inducir daños por frío en las mismas. Esto permitió estudiar el efecto del tiempo de almacenamiento y de los distintos tratamientos en el desarrollo de lesiones por frío.

III.3.3. Efecto del tipo y contenido de plastificante y del contenido en cera de abeja del recubrimiento en la calidad postcosecha de ciruelas 'Angeleno'

Las formulaciones incluyeron HPMC E-15, CA, AE y plastificante. Se formularon 8 recubrimientos con distinto contenido en CA $(20 \%$ y $40 \%$ b.s.), distinto tipo de plastificante ( $\mathrm{G}$ y $\mathrm{M}$ ), y distinta proporción HPMC:plastificante $(1: 100$ y 1:300 $\mathrm{mol} / \mathrm{mol})$. Las características físicoquímicas más relevantes de estos plastificantes se muestran en la Tabla III.4. El ratio CA:AE y el CS se mantuvieron constantes en todas las formulaciones siendo 1:0,2 y 4\%, respectivamente. La elección de la base de comparación de los distintos plastificantes $(\mathrm{mol} / \mathrm{mol})$, fue de acuerdo con el trabajo de Cuq et al. (1997). Estos autores observaron que para una misma proporción de hidrocoloide:plastificante en base masa/masa, los plastificantes de menor Pm proporcionaban mayor plastificación que los plastificantes de mayor $\mathrm{Pm}$, lo que atribuyeron al mayor número de moléculas de plastificante por mol en el caso de plastificantes de bajo Pm. Estos resultados sugieren que el efecto del plastificante se debe examinar en base molar (mol/mol) (Sothornvit y Krochta, 2001). La Tabla III.5 muestra la composición y viscosidad de los recubrimientos estudiados en esta experiencia. 
Tabla III.4. Características físico-químicas de los plastificantes empleados en la formulación de los recubrimientos aplicados en la experiencia: efecto del tipo y contenido de plastificante y del contenido en $C A$ del recubrimiento en la calidad postcosecha de ciruelas 'Angeleno'

\begin{tabular}{cccc}
\hline & Punto & & \\
Plastificante & Pm & Fórmula & Fusión \\
& & Química & \\
& & & \\
\hline
\end{tabular}

glicerol $\quad 92 \quad 18 \quad \mathrm{C}_{3} \mathrm{H}_{8} \mathrm{O}_{3}$

manitol $182 \quad 167 \quad \mathrm{C}_{6} \mathrm{H}_{14} \mathrm{O}_{6}$<smiles>[R]C(CO)[C@@H](O)[C@@H](O)[C@@H](I)CO</smiles>

Fuente: es.wikipedia.org

Tabla III.5. Composición y viscosidad de los recubrimientos aplicados en la experiencia: efecto del tipo y contenido de plastificante y del contenido en $C A$ del recubrimiento en la calidad postcosecha de ciruelas 'Angeleno'

\begin{tabular}{ccccccc}
\hline Recubrimiento & $\begin{array}{c}\mathrm{HPMC} \\
(\% \mathrm{bs})\end{array}$ & $\begin{array}{c}\mathrm{CA} \\
(\% \mathrm{bs})\end{array}$ & $\begin{array}{c}\mathrm{G} \\
(\% \mathrm{bs})\end{array}$ & $\begin{array}{c}\mathrm{M} \\
(\% \mathrm{bs})\end{array}$ & $\begin{array}{c}\mathrm{AE} \\
(\% \mathrm{bs})\end{array}$ & $\begin{array}{c}\text { Viscosidad } \\
(\mathrm{cp})\end{array}$ \\
\hline $20 \% \mathrm{CA}-100 \mathrm{G}$ & 65,9 & 20,0 & 10,1 & --- & 4,0 & $30,5 \pm 1,3$ \\
$40 \% \mathrm{CA}-100 \mathrm{G}$ & 45,1 & 40,0 & 6,9 & --- & 8,0 & $14,8 \pm 1,8$ \\
$20 \% \mathrm{CA}-300 \mathrm{G}$ & 52,0 & 20,0 & 24,0 & --- & 4,0 & $20,7 \pm 0,3$ \\
$40 \% \mathrm{CA}-300 \mathrm{G}$ & 35,6 & 40,0 & 16,4 & --- & 8,0 & $10,2 \pm 1,5$ \\
$20 \% \mathrm{CA}-100 \mathrm{M}$ & 58,3 & 20,0 & --- & 17,7 & 4,0 & $23,8 \pm 1,0$ \\
$40 \% \mathrm{CA}-100 \mathrm{M}$ & 39,9 & 40,0 & --- & 12,1 & 8,0 & $11,5 \pm 1,3$ \\
$20 \% \mathrm{CA}-300 \mathrm{M}$ & 39,8 & 20,0 & --- & 36,2 & 4,0 & $10,5 \pm 2,5$ \\
$40 \% \mathrm{CA}-300 \mathrm{M}$ & 27,2 & 40,0 & --- & 24,8 & 8,0 & $8,2 \pm 1,2$ \\
\hline
\end{tabular}

z HPMC tipo E-15.

En todas las formulaciones se mantuvo constante el CS al 4\%. 
Las ciruelas 'Angeleno' cosechadas en Villena (Alicante) el $22 / 09 / 05$ se transportaron sin refrigerar al I.V.I.A. Tras 4 días de almacenamiento a $1{ }^{\circ} \mathrm{C}$ y $85 \pm 5 \%$ HR se seleccionaron por tamaño y ausencia de lesiones y se dividieron en 10 lotes homogéneos: 8 para la aplicación de recubrimientos, 1 para el CL y 1 para el CSL. Los recubrimientos se aplicaron por inmersión del fruto durante 1,5 min y su exceso se eliminó por escurrido. Los frutos recubiertos y los control se pasaron por un túnel de secado a $50-55{ }^{\circ} \mathrm{C}$ durante 2,2 min y se almacenaron $2,4,6$ y 8 semanas a $1{ }^{\circ} \mathrm{C}$ y $85 \pm 5 \% \mathrm{HR}$, mas 1 semana a $5{ }^{\circ} \mathrm{C}$ y $85 \pm 5 \% \mathrm{HR}$, y 1 ó 2 semanas a $20{ }^{\circ} \mathrm{C}$ y $90 \pm 5 \%$ HR para su posterior análisis. El almacenamiento de las ciruelas a $5{ }^{\circ} \mathrm{C}$ durante 1 semana se realizó para inducir daños por frío en las mismas. Esto permitió estudiar el efecto del tiempo de almacenamiento y de los distintos tratamientos en el desarrollo de lesiones por frío.

\section{III.3.4. Efecto del contenido en cera de abeja y del contenido en sólidos del recubrimiento en la calidad postcosecha de mandarinas 'Clemenules'}

Las formulaciones incluyeron HPMC, CA, G y AE. Se formularon 6 recubrimientos con distinto contenido en CA $(40 \%, 60 \%$ y $80 \%$ b.s.) y distinto CS (4\% y 8\%). Las proporciones HPMC:G y CA:AE se mantuvieron constantes en todas formulaciones siendo 1:0,5 y 1:0,2, respectivamente. Se utilizó HPMC de distinto Pm para conseguir formulaciones de similar viscosidad $(10 \mathrm{cp})$, salvo en la formulación $40 \%$ CA- $8 \%$ CS cuya viscosidad fue de $50 \mathrm{cp}$. La Tabla III.6 muestra la composición de los recubrimientos estudiados en esta experiencia.

Tabla III.6. Composición de los recubrimientos aplicados en la experiencia: efecto del contenido en CA y del CS del recubrimiento en la calidad postcosecha de mandarinas 'Clemenules'

\begin{tabular}{lccccc}
\hline Recubrimiento & $\begin{array}{c}\text { HPMC } \\
(\% \mathrm{bs})\end{array}$ & $\begin{array}{c}\mathrm{CA} \\
(\% \mathrm{bs})\end{array}$ & $\begin{array}{c}\mathrm{G} \\
(\% \mathrm{bs})\end{array}$ & $\begin{array}{c}\mathrm{AE} \\
(\% \mathrm{bs})\end{array}$ & $\begin{array}{c}\text { Tipo HPMC } \\
(\mathrm{Pm})\end{array}$ \\
\hline $40 \% \mathrm{CA}-{ }^{{ }} \% \mathrm{CS}$ & 34,7 & 40,0 & 17,3 & 8,0 & $\mathrm{E}-15(60.000)$ \\
$60 \% \mathrm{CA}-{ }^{{ }} \% \mathrm{CS}$ & 18,7 & 60,0 & 9,3 & 12,0 & $\mathrm{E}-15(60.000)$ \\
$80 \% \mathrm{CA}-{ }^{{ }^{0}} \% \mathrm{CS}$ & 2,7 & 80,0 & 1,3 & 16,0 & $\mathrm{~K}-99(100.000)$ \\
\hline
\end{tabular}

${ }^{z}$ Los recubrimientos se formularon al $4 \%$ y al 8\% de CS, siendo 4 u 8 respectivamente

Las mandarinas 'Clemenules' cosechadas en Valencia el 25/11/05 
se transportaron al I.V.I.A. donde se seleccionaron por tamaño y ausencia de lesiones. Tras aplicar un baño de imazalil a $1000 \mathrm{ppm}$ y un secado a $20 \pm 2{ }^{\circ} \mathrm{C}$ durante $24 \mathrm{~h}$, los frutos se dividieron en 7 lotes homogéneos: 6 para la aplicación de recubrimientos y 1 para el control sin recubrir (control). Los recubrimientos se aplicaron por inmersión del fruto durante 1 min y su exceso se eliminó por escurrido. Los frutos recubiertos y los control se pasaron por un túnel de secado a $45-50{ }^{\circ} \mathrm{C}$ durante 2,8 min y se almacenaron 2,3 y 4 semanas a $5{ }^{\circ} \mathrm{C}$ y $80 \pm 5 \% \mathrm{HR}$, mas 1 semana a $20^{\circ} \mathrm{C}$ y $85 \pm 5 \%$ HR para su posterior análisis.

\section{III.3.5. Efecto del tipo y contenido de ácido graso del recubrimiento en la calidad postcosecha de mandarinas 'Ortanique'}

En esta experiencia se formularon los mismos recubrimientos que en la experiencia: efecto del tipo y contenido de $A G$ del recubrimiento en la calidad postcosecha de ciruelas 'Angeleno' (apartado III.3.2)

Las mandarinas 'Clemenules' cosechadas en Sagunto (Valencia) el 03/03/04 se transportaron sin refrigerar al I.V.I.A. donde se seleccionaron por tamaño y ausencia de lesiones. Tras aplicar un baño de imazalil a 1000 ppm y un secado a $20 \pm 2{ }^{\circ} \mathrm{C}$ durante $24 \mathrm{~h}$, los frutos se dividieron en 7 lotes homogéneos: 6 para la aplicación de recubrimientos y 1 para el control sin recubrir (control). Los recubrimientos se aplicaron por inmersión del fruto durante $1 \mathrm{~min}$ y su exceso se eliminó por escurrido. Los frutos recubiertos y los control se pasaron por un túnel de secado a $45-50{ }^{\circ} \mathrm{C}$ durante 2,5 min y se almacenaron 1 y 2 semanas a $20{ }^{\circ} \mathrm{C}$, simulando las condiciones de comercialización directa del fruto sin conservación en refrigeración, y 3 y 6 semanas a $5{ }^{\circ} \mathrm{C}$ y $80 \pm 5 \% \mathrm{HR}$, mas 1 semana a $20{ }^{\circ} \mathrm{C}$ y $85 \pm 5 \% \mathrm{HR}$, simulando condiciones de frigoconservación seguido de un periodo de comercialización, para su posterior análisis.

\section{III.3.6. Efecto del tipo y contenido de plastificante del recubrimiento en la calidad postcosecha de naranjas 'Valencia'}

Las formulaciones incluyeron HPMC E-15, CA, AE y plastificante. Se formularon 6 recubrimientos con distinto tipo de plastificante $(G, S$ y P), y distinta proporción HPMC:plastificante (1:100 y 1:300 $\mathrm{mol} / \mathrm{mol})$. Las características físico-químicas más relevantes de estos plastificantes se 
muestran en la Tabla III.7. El contenido en CA, el ratio CA:AE y el CS se mantuvieron constantes en todas las formulaciones siendo $40 \%$ b.s., 1:0,5 y 4\%, respectivamente. Todos los recubrimientos presentaron una viscosidad en torno a $10 \mathrm{cp}$. La Tabla III.8 muestra la composición de los recubrimientos estudiados en esta experiencia.

Tabla III.7. Características físico-químicas de los plastificantes empleados en la formulación de los recubrimientos aplicados en la experiencia: efecto del tipo y contenido de plastificante del recubrimiento en la calidad postcosecha de naranjas 'Valencia'.

$\begin{array}{lcccc}\text { Plastificante } & \mathrm{Pm} & \begin{array}{c}\text { Punto } \\ \text { de } \\ \text { Fusión } \\ \left({ }^{\circ} \mathrm{C}\right)\end{array} & \begin{array}{c}\text { Fórmula } \\ \text { Química }\end{array} \\ \text { glicerol } & 92 & 18 & \mathrm{C}_{3} \mathrm{H}_{8} \mathrm{O}_{3} & \text { Estructura Molecular } \\ \text { sacarosa } & 342 & 186 & \mathrm{C}_{12} \mathrm{H}_{22} \mathrm{O}_{11} & \\ \text { propilenglicol } & 76 & -59 & \mathrm{C}_{3} \mathrm{H}_{8} \mathrm{O}_{2} & \end{array}$

Fuente: es.wikipedia.org 
Tabla III.8. Composición de los recubrimientos aplicados en la experiencia: efecto del tipo y contenido de plastificante del recubrimiento en la calidad postcosecha de naranjas 'V alencia'.

\begin{tabular}{ccccccc}
\hline Recubrimiento & $\begin{array}{c}\mathrm{HPMC}^{\mathrm{z}} \\
(\% \mathrm{bs})\end{array}$ & $\begin{array}{c}\mathrm{CA} \\
(\% \mathrm{bs})\end{array}$ & $\begin{array}{c}\mathrm{G} \\
(\% \mathrm{bs})\end{array}$ & $\begin{array}{c}\mathrm{S} \\
(\% \mathrm{bs})\end{array}$ & $\begin{array}{c}\mathrm{P} \\
(\% \mathrm{bs})\end{array}$ & $\begin{array}{c}\mathrm{AE} \\
(\% \mathrm{bs})\end{array}$ \\
\hline $100 \mathrm{G}$ & 34,7 & 40,0 & 5,3 & --- & --- & 20,0 \\
$100 \mathrm{~S}$ & 25,5 & 40,0 & --- & 14,5 & --- & 20,0 \\
$100 \mathrm{P}$ & 35,3 & 40,0 & --- & --- & 4,5 & 20,0 \\
$300 \mathrm{G}$ & 24,7 & 40,0 & 12,6 & --- & --- & 20,0 \\
$300 \mathrm{~S}$ & 14,8 & 40,0 & --- & 25,2 & --- & 20,0 \\
$300 \mathrm{P}$ & 29,0 & 40,0 & --- & --- & 11,0 & 20,0 \\
\hline
\end{tabular}

${ }^{2}$ HPMC tipo E-15.

En todas las formulaciones se mantuvo constante el CS al $4 \%$ y la viscosidad en torno a $10 \mathrm{cp}$.

Las naranjas 'Valencia' cosechadas en Oliva (Valencia) el 12/04/05 se transportaron sin refrigerar al I.V.I.A. donde se seleccionaron por tamaño y ausencia de lesiones. Tras aplicar un baño de imazalil a 1000 ppm y un secado a $20 \pm 2{ }^{\circ} \mathrm{C}$ durante $24 \mathrm{~h}$, los frutos se dividieron en 7 lotes homogéneos: 6 para la aplicación de recubrimientos y 1 para el control sin recubrir (control). Los recubrimientos se aplicaron por inmersión del fruto durante 1 min y su exceso se eliminó por escurrido. Los frutos recubiertos y los control se pasaron por un túnel de secado a $45-50{ }^{\circ} \mathrm{C}$ durante $2 \mathrm{~min}$ y se almacenaron 1 semana a $20{ }^{\circ} \mathrm{C}$ y $80 \pm 5 \% \mathrm{HR}$ y $2,4,6$ y 8 semanas a $5{ }^{\circ} \mathrm{C}$ y $80 \pm 5 \% \mathrm{HR}$, mas 1 semana a $20^{\circ} \mathrm{C}$ y $85 \pm 5 \%$ HR para su posterior análisis.

\section{III.4. ANÁLISIS}

\section{III.4.1. Análisis de la emulsión y de la película preformada en placa}

Una vez preparadas las emulsiones correspondientes a los recubrimientos y películas, se hizo un análisis visual de las mismas para detectar posibles problemas de inestabilidad y se midió la viscosidad de las mismas. En el caso de películas preformadas en placa se hizo un análisis visual para detectar posibles defectos de integridad física y coalescencia de lípido y se midieron las propiedades mecánicas, la permeabilidad al vapor de agua (PVA) y el espesor del las mismas. 


\section{III.4.1.1. Viscosidad de la emulsión}

Las emulsiones se atemperaron a $20^{\circ} \mathrm{C}$ y se midió su viscosidad con un viscosímetro Brookfield (mod. LVF; Brookfield Engineering Laboratorios, Inc Middleboro, Massachussets, EE.UU), realizándose tres medidas en cada réplica formulada.

Según Mitchell (1979) y Villalobos (2003) las soluciones diluidas de hidrocoloide a bajo gradiente de velocidad de deformación muestran un comportamiento reológico Newtoniano, pudiéndose determinar una viscosidad característica de la solución. Dado que el método de aplicación de las emulsiones de recubrimiento al fruto supuso gradientes de velocidad de deformación bajos (comparables a las del estudio de Villalobos (2003)) y las concentraciones de las mismas fueron bajas (comparables a las de las emulsiones de Villalobos (2003)), se asumió un comportamiento Newtoniano de las emulsiones, determinándose una viscosidad característica para cada formulación.

\section{III.4.1.2. Propiedades mecánicas de la película}

Se seleccionaron 3 películas correspondientes a cada emulsión que no presentaran burbujas, fracturas o agregados de CA y se acondicionaron durante 24 h a $23 \pm 2{ }^{\circ} \mathrm{C}$ y $50 \pm 1 \%$ HR en una cabina herméticamente cerrada y provista de una solución saturada de nitrato de magnesio hexahidrato, para evitar la fractura y pérdida de integridad física de las mismas durante su manipulación. A continuación se cortaron en forma de rectángulos de dimensiones $50 \mathrm{~mm} \times 8 \mathrm{~mm}$, obteniéndose 12 muestras de cada película. Las propiedades mecánicas de éstas muestras se determinaron mediante un ensayo de tracción hasta la rotura, realizado con un Instron Universal Machine (Mod. 3343; Instron Corp., Canton, MA, U.S.A) según el método ASTM D882-97. Para logar mayor sensibilidad en la medida se modificó la magnitud de la fuerza de tracción aplicada y la velocidad de separación de las mordazas respecto al método ASTMD88297, empleándose una fuerza de $0,3 \mathrm{KN}$ y una velocidad de separación de $5 \mathrm{~mm} / \mathrm{min}$. El análisis se hizo en condiciones controladas de temperatura y HR $\left(23 \pm 2{ }^{\circ} \mathrm{C}\right.$ and $50 \pm 1 \%$ HR), medidas con un Digital Max-Min hygrometer-thermometer (Mod. 30.5000; Shanghai Hua Chen Medical Instruments Co., China). 
Las propiedades mecánicas determinadas fueron la tensión de tracción máxima (TM) soportada por la muestra durante el ensayo, medida en MPa y calculada como el cociente entre la fuerza de tracción máxima soportada por la muestra y la sección o espesor inicial de la misma; la tensión a la rotura (TR) medida en MPa y calculada como el cociente entre la fuerza de tracción soportada por la muestra en el momento de la rotura y la sección o espesor inicial de la misma; el Modulo de Young (Y), expresado en $\mathrm{MPa}$, que representa la fuerza de tensión necesaria para deformar la muestra una determinada cantidad, y que fue calculado como la pendiente de la curva tensión-deformación en la región de comportamiento elástico de la muestra; el porcentaje de elongación máximo $(\% \mathrm{E})$, que representa el incremento longitudinal relativo a la longitud inicial de la muestra tras soportar una fuerza de tracción, siendo una medida de la extensibilidad de la película; y la tenacidad (T), expresada en $\mathrm{MPa}$, y que es el área comprendida bajo la curva de tensión-elongación y que representa la capacidad de la película para absorber energía de tracción-deformación sin romperse. Para los correspondientes cálculos y previamente al ensayo de tracción, se determinó el espesor de las muestras según el método descrito en el apd. III.4.1.4.

\section{III.4.1.3. Permeabilidad al vapor de agua de la película}

Para determinar la PVA de las películas se utilizó el método gravimétrico ASTM E96, con las modificaciones hechas por McHugh et al. (1993) para películas hidrofílicas. Se seleccionaron 3 películas de cada réplica de recubrimiento sin defectos (ausencia de burbujas, fracturas y agregados de CA). De cada película se cortaron dos muestras y se colocaron en celdas de polimetacrilato conteniendo $6 \mathrm{~mL}$ de agua destilada. Ambas muestras se colocaron con distinta orientación: bien con la superficie en contacto con el aire durante el secado encarada al ambiente de menor humedad relativa (orientación 'up') o viceversa (orientación 'down). Las celdas se colocaron en una cabina estanca provista de un ventilador en condiciones constantes de temperatura y $\mathrm{HR}\left(25 \pm 2{ }^{\circ} \mathrm{C}\right.$ y 40 $\pm 5 \% \mathrm{RH}$ respectivamente) para lo cual se utilizó una solución saturada de carbonato potásico anhidro. Alcanzado el régimen estacionario del sistema, se pesaron las celdas de forma periódica. A partir de los datos de peso, tiempo y espesor de la película (medido según el procedimiento descrito en el apd. III.4.1.4) y con las ecuaciones descritas por McHugh et al. (1993) se calculó la PVA expresándose en $\mathrm{g} \mathrm{mm} / \mathrm{KPa} \mathrm{h} \mathrm{m²}$. 


\section{III.4.1.4. Espesor de la película}

El espesor de la película se midió con un micrómetro digital Mitutoyo (Mod. Quickmike Series 293-IP-54; Mitutoyo Corp., Kanawava, Japón), haciéndose 9 medidas en posiciones aleatorias a lo largo de la misma. El espesor de cada película se calculó como la media aritmética de las 9 medidas tomadas.

\section{III.4.2. Análisis de calidad de los frutos}

\section{III.4.2.1. Pérdida de peso}

Para determinar la pérdida de peso se utilizaron lotes de 30 frutos por tratamiento. El resultado se expresó como porcentaje de pérdida de peso respecto al peso inicial.

\section{III.4.2.2. Intensidad respiratoria}

La intensidad respiratoria se determinó en 10 frutos por tratamiento. Para ello se colocaron los frutos en recipientes cerrados de $450 \mathrm{~mL}$ de capacidad (un fruto por cada recipiente) y se almacenaron a 20 ${ }^{\circ} \mathrm{C}$. Al cabo de 2 horas se tomó $1 \mathrm{~mL}$ del aire del interior del recipiente y se analizó por cromatografía gaseosa. Para ello se utilizó un cromatógrafo de gases (Modelo Trace; Thermo Fisher Scientific, Inc., Waltham, MA, EE.UU.) equipado con detector de termoconductividad (TCD) y columnas Poropak QS 80/100 (1,2 m x 0,32 cm) y Tamiz Molecular, $5 \AA$ 45/60 (1,2

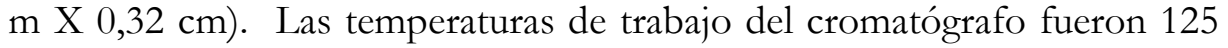
${ }^{\circ} \mathrm{C}, 35^{\circ} \mathrm{C}$ y $180{ }^{\circ} \mathrm{C}$ para inyector, horno y detector respectivamente y el caudal de gas portador fue $22 \mathrm{~mL} / \mathrm{min}$. El resultado se expresó en $\mathrm{mL}$ de $\mathrm{CO}_{2}$ o $\mathrm{O}_{2}$ por $\mathrm{Kg}$ de fruto y hora producidos o consumidos, respectivamente.

\section{III.4.2.3. Sólidos solubles totales, acidez, e índice de madurez}

Para las determinaciones de sólidos solubles y acidez, se separaron 3 lotes de 10 frutos por tratamiento de los que se obtuvieron 3 zumos. Los sólidos solubles se midieron con un refractómetro digital Atago (Modelo PR1; Atago Co. Ltd, Japón) y se expresaron en ${ }^{\circ}$ Brix. Para determinar la acidez se valoraron alícuotas de $5 \mathrm{~mL}$ de zumo con una solución de $\mathrm{NaOH}$ 
0.1N hasta $\mathrm{pH} 8,2$ utilizando para ello un pH-metro Consort (Modelo C830, Consort, Turnhout, Bélgica). El resultado se expresó como g ácido málico/100mL zumo en el caso de ciruelas, o como g ácido cítrico/100mL zumo en el caso de cítricos. El índice de madurez (IM) se calculó como el cociente entre los sólidos solubles y la acidez.

\section{III.4.2.4. Contenido de $\mathrm{CO}_{2}$ y $\mathrm{O}_{2}$ interno}

El contenido de $\mathrm{CO}_{2}$ y $\mathrm{O}_{2}$ interno se determinó por cromatografía gaseosa, analizándose 10 frutos por tratamiento. La extracción del aire interno del fruto varió en función del tipo de fruto (ciruela o cítrico). En el caso de ciruelas, que no cuentan con una cavidad interna de la cual se pueda extraer aire, la muestra se obtuvo según el método de extracción a vacío descrito por Saltveit (1982). Para ello se colocó el fruto en un recipiente cerrado lleno de agua previamente desgasificada. Tras colocar un embudo invertido sobre el fruto se aplicó vacío para extraer el aire interno de la ciruela. El aire extraído formó un espacio de cabeza en el cuello del embudo del cual se tomo la muestra con una jeringuilla Hamilton 1001. En el caso de cítricos, que cuentan con una cavidad interna de la cual se puede extraer el aire fácilmente, el fruto se sumergió en agua y se extrajo el aire de esta cavidad con una jeringuilla Hamilton 1001.

Se inyectó $1 \mathrm{~mL}$ de aire interno del fruto en un cromatógrafo de gases (Modelo Trace; Thermo Fisher Scientific, Inc., Waltham, MA, EE.UU.) equipado con TCD y columnas Poropak QS 80/100 (1,2 m x

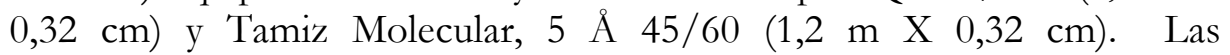
temperaturas de trabajo del cromatógrafo fueron $125{ }^{\circ} \mathrm{C}, 35^{\circ} \mathrm{C}$ y $180{ }^{\circ} \mathrm{C}$ para inyector, horno y detector respectivamente y el caudal de gas portador fue $22 \mathrm{~mL} / \mathrm{min}$. El resultado se expresó en porcentaje de $\mathrm{CO}_{2} \mathrm{y}_{2}$ interno.

\section{III.4.2.5. Etanol y acetaldehído en zumo}

Las concentraciones de etanol y acetaldehído en zumo se determinaron por cromatografía de espacio de cabeza según el método descrito por Ke y Kader (1990). Se separaron 3 lotes de 10 frutos por tratamiento de los que se obtuvieron 3 zumos. Se transfirieron alícuotas de $5 \mathrm{~mL}$ de zumo en viales de $10 \mathrm{~mL}$ de capacidad. Los viales conteniendo 
el zumo se sellaron con tapón de TFE/silicona y se almacenaron a $-18{ }^{\circ} \mathrm{C}$ para su posterior análisis. Previo al análisis, se descongelaron a $20^{\circ} \mathrm{C}$.

El análisis de cada zumo se realizó por triplicado con un cromatógrafo de gases (Mod. Trace; Thermo Fisher Scientific, Inc., Waltham, MA, EE.UU.) equipado con muestreador automático (Modelo HS 2000), detector de ionización de llama (FID) y columna Poropak QS $80 / 100(1,2 \mathrm{~m} \times 0.32 \mathrm{~cm})$. Los viales conteniendo el zumo se incubaron durante 10 minutos a $60^{\circ} \mathrm{C}$ en el caso de ciruelas y a $30^{\circ} \mathrm{C}$ en el caso de cítricos. Tras la incubación se inyectó $1 \mathrm{~mL}$ de aire del espacio de cabeza del vial. Las temperaturas de trabajo del cromatógrafo fueron $175^{\circ} \mathrm{C}, 150$ ${ }^{\circ} \mathrm{C}$ y $200{ }^{\circ} \mathrm{C}$ para inyector, horno y detector respectivamente y el caudal de gas portador fue $28 \mathrm{~mL} / \mathrm{min}$. El etanol y el acetaldehído de las muestras se identificó por comparación de tiempos de retención con soluciones patrón. Los resultados se expresaron como mg de etanol o acetaldehído en $100 \mathrm{~mL}$ de zumo.

\section{III.4.2.6. Firmeza}

\section{Firmeza de la pulpa de ciruelas}

La firmeza se determinó como la fuerza máxima, en Newtons $(\mathrm{N})$, para penetrar la pulpa de la ciruela. Se determinó en lotes de 20 frutos por tratamiento haciéndose dos medidas por fruto en sendas caras de la zona ecuatorial desprovistas de piel. Para el análisis se utilizó un Instron Universal Testing Machine (Modelo 3343; Instron Corp., Canton, MA, EE.UU.), un punzón de $8 \mathrm{~mm}$ de diámetro y una velocidad de punción de $10 \mathrm{~mm} / \mathrm{min}$.

\section{Firmeza de cítricos}

La firmeza se determinó mediante un ensayo de compresión en el que se aplicó una fuerza de $1 \mathrm{Kg}$ sobre la zona ecuatorial del fruto. La medida se realizó en 20 frutos por tratamiento con un texturómetro Instron Universal Machine (Modelo 3343; Instron Corp., Canton, MA, EE.UU.) utilizando una placa de $35 \mathrm{~mm}$ de diámetro y una velocidad de compresión de $5 \mathrm{~mm} / \mathrm{min}$. El resultado se expresó como porcentaje de deformación relativo al diámetro inicial del fruto. 


\section{III.4.2.7. Desórdenes fisiológicos}

\section{Desórdenes fisiológicos de ciruelas}

Se evaluaron los desórdenes fisiológicos que afectan a la pulpa de las ciruelas (pigmentación roja o 'bleeding', harinosidad, acorchado, pardeamiento y vitrescencia) según la escala descrita por Crisosto et al. (1999). Para su determinación los frutos se seccionaron por la zona ecuatorial y se hizo una evaluación visual del mesocarpo y del área circundante al hueso. Se analizaron 30 frutos por tratamiento. La pigmentación roja, harinosidad y acorchado se evaluó con una escala de 1 a $3(1=$ ausencia; $2=$ moderada; $3=$ severa $)$. El pardeamiento y vitrescencia se evaluó con una escala de 1 a 6 (1=ausencia, $2=$ muy ligera, $3=$ ligera, $4=$ moderada, $5=$ severa, $6=$ extrema). Se consideraron daños moderados cuando el área afectada fue inferior al 50\% y daños extremos cuando superó el 75\%. Para cada desorden o alteración se calculó la media ponderada de las puntuaciones asignadas a los frutos y se expresó el resultado como daño correspondiente a cada alteración.

\section{Desórdenes fisiológicos de cítricos}

Se evaluaron los daños fisiológicos que afectan al aspecto externo de los cítricos como necrosis peripeduncular o 'stem end rind breakdown' ('SERB') y 'pitting'. Para ello se hizo un examen visual de 50 frutos por tratamiento evaluándose la intensidad de las alteraciones o desórdenes fisiológicos con una escala gradual de 0 a 3 . Las alteraciones se calificaron como ligeras $(=1)$ cuando el área afectada fue inferior al 10\%, medias $(=2)$ cuando el área afectada abarcó entre un 10 y un $20 \%$ del fruto, y severas (=3) cuando sobrepasaron el $20 \%$ del fruto. Para frutos sanos se asignó una puntuación de 0 . Cuando un fruto presentó distintas alteraciones se consideró la de mayor intensidad o puntuación, obviándose el resto de alteraciones. Se calculó la media ponderada de las puntuaciones obtenidas expresándose el resultado como índice de deterioro (ID).

\section{III.4.2.8. Color externo}

El color se midió en el espacio de color CieLab* en el caso de ciruelas y se expresó con los parámetros tono, croma y luminosidad. En cítricos el color se midió en el espacio de color Hunter y se expresó con el 
índice de color $(\mathrm{IC}=1000 \mathrm{a} / \mathrm{Lb})$ (Jiménez-Cuesta et al., 1981). Para su medida se utilizó un colorímetro Minolta (Modelo CR-300; Ramsey, N.Y. EE.UU) utilizando el iluminante $\mathrm{C}$ y el observador $2^{\circ}$. Se analizaron 30 frutos por tratamiento haciéndose dos medidas por fruto en sendas caras de la zona ecuatorial.

\section{III.4.2.9. Índice de desprendimiento del recubrimiento}

El índice de desprendimiento del recubrimiento o resistencia a la abrasión, se evaluó en cítricos recubiertos según el método propuesto por Hagenmaier y Baker (1995). El método consistió en cuantificar la cantidad de recubrimiento desprendida del fruto y depositada sobre un paño negro tras frotar el fruto con este paño. La escala utilizada fue la siguiente:

0.- no se desprende recubrimiento

1.- se desprende una pequeña cantidad

2.- se desprende recubrimiento pero se considera aceptable

3.- se desprende gran cantidad de recubrimiento

4.- se desprende prácticamente todo el recubrimiento

\section{III.4.2.10. Evaluación organoléptica}

\section{Evaluación organoléptica de ciruelas: 'flavor' y textura}

La evaluación organoléptica de los frutos la realizó un panel semientrenado de 10 jueces en una sala de análisis sensorial libre de olores y ruidos y equipada con cabinas individuales, que cumple todos los requisitos exigidos por la norma UNE 87004 (AENOR, 1997). Para la preparación de las muestras se tomaron de cada tratamiento 6 frutos al azar que se pelaron y dividieron en secciones longitudinales. Se escogieron 2 secciones procedentes de 2 frutos distintos y se colocaron en recipientes desechables identificados con un código de tres dígitos al azar, sirviéndose a los jueces para el análisis. Los jueces se enjuagaron la boca con agua mineral antes y después de cada muestra.

Para la evaluación del 'flavor' se utilizó una escala de 1 a 9, donde 1 representa un sabor de pésima calidad y 9 un sabor excelente. La textura fue evaluada con una escala gradual de 1 a 7 , donde 7 indica una textura muy firme, 4 textura intermedia y 1 textura muy blanda. La figura III.1 
reproduce la ficha de cata presentada a los jueces para el análisis organoléptico.

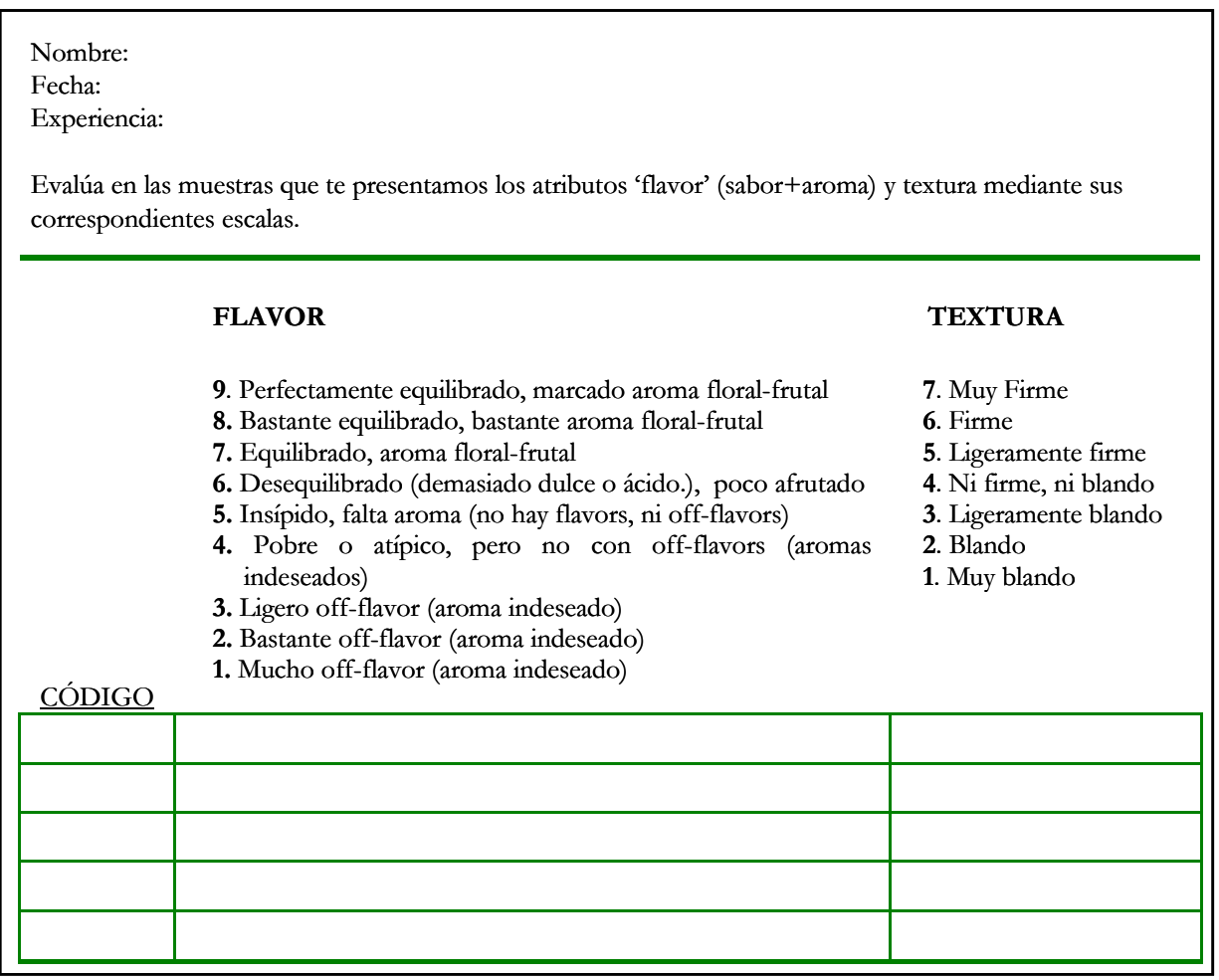

Figura III.1. Ficha de cata para el análisis organoléptico de ciruelas.

\section{Evaluación organoléptica de cítricos: 'flavor'y 'off-flavor'}

La evaluación organoléptica de los frutos la realizó un panel semientrenado de 10 jueces en una sala de análisis sensorial libre de olores y ruidos y equipada con cabinas individuales, que cumple todos los requisitos exigidos por la norma UNE 87004 (AENOR, 1997). Para la preparación de las muestras se tomaron de cada tratamiento 6 frutos al azar que se pelaron y dividieron en gajos. Se escogieron 2 gajos procedentes de 2 frutos distintos y se colocaron en recipientes desechables identificados con un código de tres dígitos al azar sirviéndose a los jueces para el análisis. Los jueces se enjuagaron la boca con agua mineral antes y después de cada muestra. 
Para la evaluación del 'flavor' se utilizó una escala gradual de 1 a 9, donde se agruparon los valores en tres grados de calidad (1-3: calidad mala; 4-6: calidad aceptable; 7-9: calidad excelente). La evaluación del 'offflavor' (malos sabores) se realizó mediante una escala de 0 a 5 , donde 0 es ausencia de malos sabores y 5 presencia acusada. La Figura III.2 reproduce la ficha de cata presentada a los jueces para el análisis organoléptico.

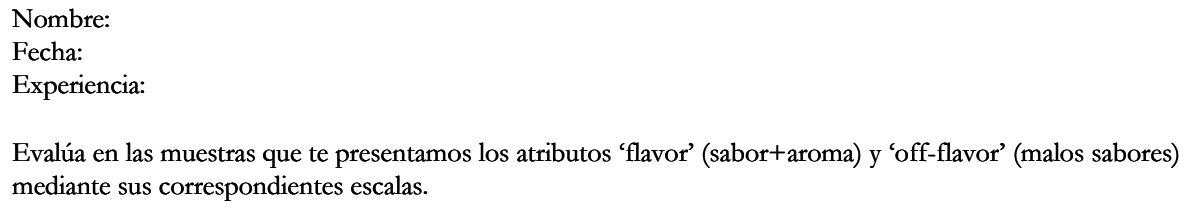

\section{FLAVOR}

\begin{tabular}{|c|c|}
\hline & Calidad excelente \\
\hline$\frac{6}{5}$ & $\begin{array}{l}\text { Calidad aceptable } \\
\text { (satisfactorio) }\end{array}$ \\
\hline $\begin{array}{l}\frac{3}{2} \\
1 \\
\end{array}$ & $\begin{array}{c}\text { Mala calidad } \\
\text { (no satisfactorio) }\end{array}$ \\
\hline
\end{tabular}

\section{OFF-FLAVOR}

5. Presencia acusada

4. Muy perceptibles

3. Bastante perceptibles

2. Medianamente perceptibles

1. Ligeramente perceptibles

0. Ausencia

\begin{tabular}{|l|l|l|}
\hline & & \\
\hline & & \\
\hline & & \\
\hline & & \\
\hline & & \\
\hline
\end{tabular}

Figura III.2. Ficha de cata para el análisis organoléptico de cítricos.

\section{III.4.2.11. Aspecto externo y brillo del fruto}

Para detectar el efecto de los recubrimientos en el aspecto externo del fruto, se hizo una evaluación visual de los frutos recubiertos y de los frutos control. La evaluación la realizó un panel semientrenado de 10 jueces en una sala de análisis sensorial provista de cabinas individuales con iluminación intensa y homogénea en toda la cabina, que cumple todos los requisitos exigidos por la norma UNE 87004 (AENOR, 1997). Se 
evaluaron 5 frutos por tratamiento utilizándose una escala de 1 a 3 , donde 1 indicó mal aspecto, 2 aceptable y 3 bueno.

También se estudió el efecto de los recubrimientos en el brillo de los frutos. Se evaluaron muestras de 6 frutos por tratamiento y la evaluación consistió en ordenar de mayor a menor brillo los distintos tratamientos. La evaluación la realizó un panel semientrenado de 10 jueces en una sala de análisis sensorial provista de cabinas individuales con iluminación intensa y homogénea en toda la cabina.

\section{III.4.3. Análisis estadístico}

El tratamiento estadístico de los resultados se realizó mediante análisis de varianza (ANOVA). Las diferencias mínimas entre las medias se establecieron con intervalos LSD con un nivel de confianza del 95\%. Los análisis se realizaron con el paquete estadístico STATGRAPHICS Plus 4.1 (Manugistics, Inc., Rockville, Maryland, EE.UU.).

Para determinar las diferencias de brillo entre tratamientos se utilizó el test de Friedman, que es el que corresponde a ensayos de clasificación por ordenación. Para determinar diferencias significativas entre medias se utilizó el test de Dunnett con un nivel de confianza del 95\% (UNE 87023 1995). 
IV. RESULTADOS y DISCUSIÓN 


\title{
IV.1. EFECTO DEL CONTENIDO EN CERA DE ABEJA DE LA FORMULACIÓN EN LAS PROPIEDADES DE LAS PELÍCULAS $Y$ EN LA CALIDAD POSTCOSECHA DE CIRUELAS 'ANGELENO' RECUBIERTAS
}

\author{
IV.1.1. Análisis de las emulsiones y de las películas preformadas en \\ placa
}

\section{IV.1.1.1. Aspecto de las emulsiones y de las películas}

La turbidez y estabilidad de las emulsiones así como el brillo, opacidad y separación de fases de las películas tienen un efecto en la calidad del fruto recubierto. Algunos autores han observado una correlación entre la turbidez de las emulsiones y propiedades como la estabilidad, la capacidad de impregnar una superficie de las mismas y el brillo del recubrimiento resultante. Así se ha observado que un aumento de la turbidez de las emulsiones se corresponde con una mayor separación de fases y una peor capacidad de impregnar de las emulsiones, así como con un menor brillo del recubrimiento resultante (Hagenmaier, 1997). También se ha observado una relación entre la estabilidad de las emulsiones y la PVA de las películas (McHugh, 2000). Por tanto, estas características de las emulsiones y películas pueden proporcionar una información interesante a la hora de interpretar el efecto de los correspondientes recubrimientos aplicados a frutas.

El contenido en CA de las formulaciones tuvo un efecto en el aspecto de las emulsiones y de las películas (Figura IV.1). La ausencia de lípido (CA y AE) en la formulación dio lugar a películas transparentes, de color ligeramente amarillo. La adición de lípido redujo la transparencia de las emulsiones y las películas, y aportó un color blanquecino a ambas. Otros autores han observado el efecto de los lípidos reduciendo la transparencia de películas de hidrocoloide de distinto tipo (Gontard et al, 1994; Quezada-Gallo et al, 2000; Yang and Paulson, 2000; Pérez-Gago y Krochta, 2001; Bertran et al., 2005). Además, la turbidez de las emulsiones y opacidad de las películas aumentó al aumentar el contenido de CA de las formulaciones.

La formulación 0\% CA dio películas brillantes, mientras que el 
resto de formulaciones dio películas de aspecto mate en la cara expuesta al aire durante el secado y de aspecto brillante en la cara en contacto con la placa durante el secado. El incremento en el contenido de lípido acentuó las diferencias de aspecto entre ambas caras. Esta diferencia de aspecto entre ambas caras de las películas conteniendo lípido, sugiere una separación de fases en las mismas con un enriquecimiento de lípido en la cara expuesta al aire durante el secado. Esta posible separación de fases de las películas se correlaciona con la separación de fases observada en las emulsiones de algunas formulaciones. En concreto, las emulsiones con $40 \%$ CA y $60 \%$ CA, tras $24 \mathrm{~h}$ de su elaboración, presentaron una capa blanca enriquecida en lípido sobre la emulsión clarificada, que tras la agitación volviá a dar una emulsión homogénea.

Algunos trabajos presentes en la bibliografía muestran que la turbidez y estabilidad de las emulsiones y películas depende del tamaño de partícula de lípido en suspensión y del contenido en lípido. En general, un aumento del tamaño de partícula y del contenido de lípido aumenta la turbidez (Hernández y Baker, 1991, Pérez-Gago y Krochta, 2001) y promueve la separación de fases de la emulsión (Prince, 1977) y de la película resultante (Pérez-Gago y Krochta, 2001). El tamaño de partícula también afecta al brillo de las películas observándose menor brillo al aumentar el tamaño de partícula (Bennett, 1975).

La homogeneidad de las películas varió con el contenido en CA de la formulación. Mientras que las películas con 20\% CA presentaron un aspecto continuo, las películas con $40 \%$ CA y $60 \%$ CA presentaron pequeños agregados de CA que aumentaron al aumentar el contenido en CA. Estos resultados indican una saturación del sistema a partir de un $40 \%$ de lípido que pudo ser debida a un defecto del tipo y contenido de emulsificante o a un exceso de lípido (CA) en el sistema. En las formulaciones ensayadas, el emulsificante empleado fue $\mathrm{AE} y$ la proporción CA:AE se mantuvo constante al 1:0,2. Los resultados indican la necesidad de estudiar estas variables de la formulación (tipo y contenido de $A G$ ) en futuras experiencias (Apartado IV.2.1.1). Otros autores han observado el efecto del contenido en lípido en la isotropía de las películas. Así por ejemplo, Han et al. (2006) observaron que al reducir el contenido en CA en películas a base de almidón, mejoraba la distribución del lípido.

La integridad física de las películas también varió con el contenido 
en CA, disminuyendo a medida que aumentaba en contenido en CA. Mientras que las películas exentas de lípido presentaban buena integridad física, la películas con $60 \%$ CA fueron frágiles y quebradizas. La pérdida de integridad física con la adición de lípido y/o incremento de su contenido se puede atribuir a las discontinuidades que el lípido produce en la matriz de HPMC, constituyendo puntos de fractura que reducen la resistencia de la película a la tracción mecánica (Shellhammer y Krochta, 1997; Pérez-Gago y Krocha, 2001; Petersson y Stading 2005).

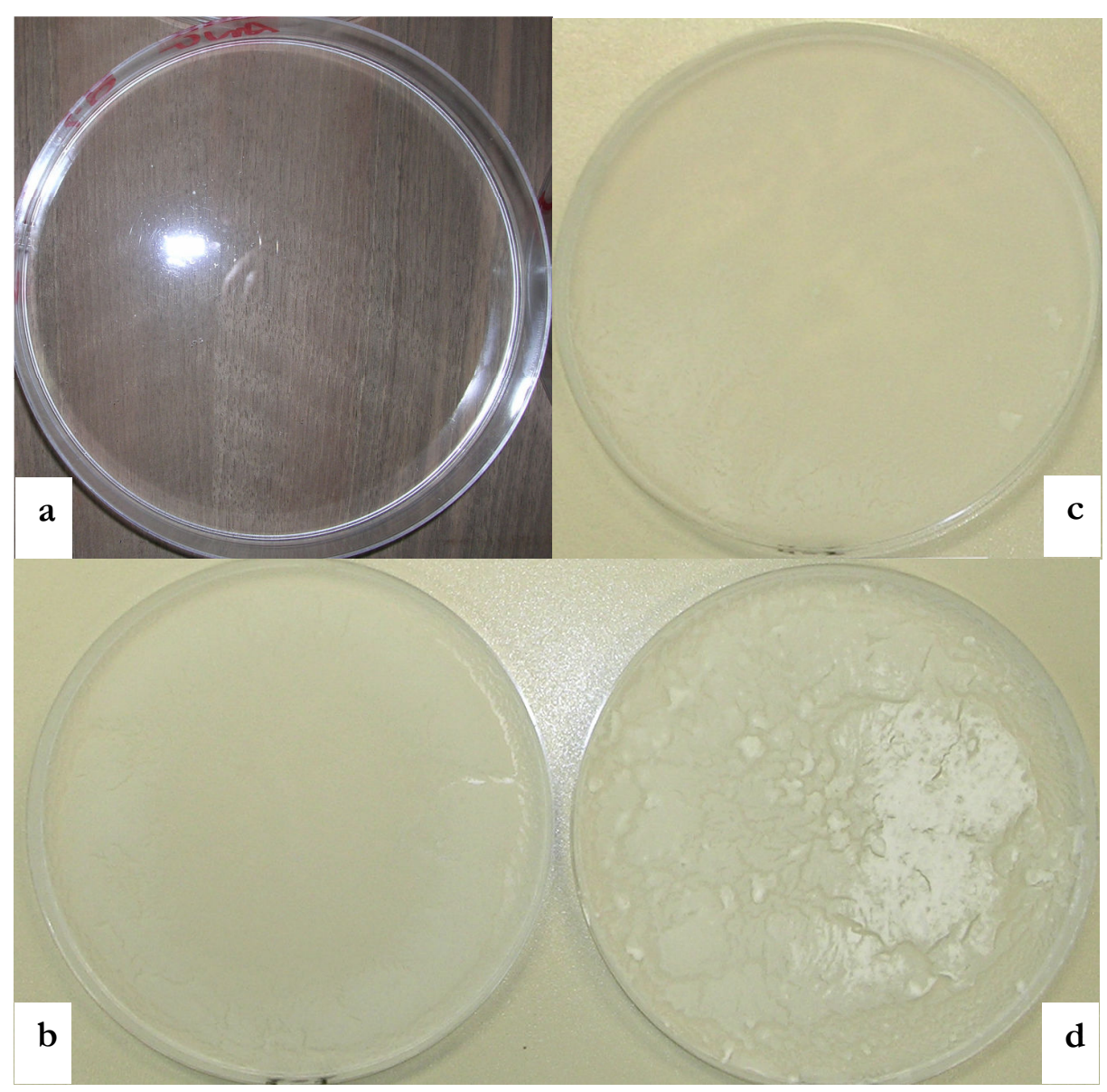

Figura IV.1. Aspecto de las películas formuladas con (a) $0 \%$ de CA, (b) $20 \%$ de CA, (c) $40 \%$ de CA y (d) $60 \%$ de CA. 


\section{IV.1.1.2. Permeabilidad al vapor de agua de las películas}

Según la bibliografía, un aumento en el contenido de lípido de las películas emulsionadas mejora la barrera al vapor de agua de las mismas, siempre que éste se distribuya de forma homogénea en la matriz de hidrocoloide (Koelsch y Labuza, 1992; Avena-Bustillos y Krochta, 1993; McHugh y Krochta, 1994c; Debeafourt y Voilley, 1995). En las películas formadas, un aumento del contenido en CA de $0 \%$ a $60 \%$ aumentó la barrera al vapor de agua de las películas (Tabla IV.1). Las películas con 0\%CA mostraron la mayor PVA, lo que confirma que los polisacáridos, por su carácter hidrofílico, forman películas de alta PVA (Kester y Fennama, 1986; Genadios y Weller, 1990). La orientación de las películas durante el análisis no afectó significativamente su PVA, lo que pudo ser debido a que el cremado de lípido fue lo suficiente importante (Apartado IV.1.1) como para formar 'películas bicapa' o la presencia de microfracuras en las películas.

Tabla IV.1. Efecto del contenido en CA de la formulación en la PVA de las películas

\begin{tabular}{ccc}
\hline Formulación & \multicolumn{2}{c}{ PVA $\left(\mathrm{g} \mathrm{mm} / \mathrm{KPa} \mathrm{h} \mathrm{m}^{2}\right)$} \\
\cline { 2 - 3 } & $u^{\mathrm{z}}$ & down \\
\hline $0 \% \mathrm{CA}$ & $7,44 \mathrm{c}$ & $7,10 \mathrm{~d}$ \\
$20 \% \mathrm{CA}$ & $5,52 \mathrm{~b}$ & $5,29 \mathrm{c}$ \\
$40 \% \mathrm{CA}$ & $4,55 \mathrm{~b}$ & $4,32 \mathrm{~b}$ \\
$60 \% \mathrm{CA}$ & $3,32 \mathrm{a}$ & $2,94 \mathrm{a}$ \\
\hline
\end{tabular}

Z Orientación de la película durante la determinación de la PVA en función de la posición de secado en placa.

Por columnas, valores de PVA seguidos de la misma letra no difieren significativamente $(\mathrm{p}<0,05)$. No se observaron diferencias significativas al variar la orientación de la película en ninguna de las formulaciones estudiadas $(\mathrm{p}<0,05)$.

\section{IV.1.2. Análisis de calidad de las ciruelas 'Angeleno' recubiertas}

\section{IV.1.2.1. Pérdida de peso}

La pérdida de agua por transpiración del fruto es la principal causa de pérdida de peso del mismo durante el almacenamiento. En ciruelas esta deshidratación se ve reducida por las presencia de una cobertura cérea externa o cera epicuticular (Mrozek y Burhardt, 1973; Storey y Price, 1999) 
que aumenta la resistencia de la cutícula a la difusión de agua (Price et al., 2000). La aplicación de recubrimientos hidrofóbicos en la superficie de las frutas aporta una barrera adicional a la deshidratación (Baldwin, 1997).

La Tabla IV.2 muestra la pérdida de peso de ciruelas 'Angeleno' recubiertas y control, expresada en porcentaje de peso relativo al peso inicial del fruto. En ella se observa que los recubrimientos con 40 y $60 \%$ de CA fueron efectivos reduciendo la pérdida de peso a partir de 4 semanas de almacenamiento a $1{ }^{\circ} \mathrm{C}$.

En general, el recubrimiento con $0 \% \mathrm{CA}$ no redujo la pérdida de peso de las ciruelas. Sin embargo, la incorporación de CA a las formulaciones, redujo la pérdida de peso, lo que indica que para ejercer una barrera al agua, los recubrimientos deben contener componentes hidrofóbicos. Otros trabajos como el de Johnston y Banks (1998) ponen de manifiesto que los recubrimientos hidrofílicos no ejercen una barrera al vapor de agua efectiva. Así, estos autores observaron que la aplicación de recubrimientos de carboximetilcelulosa al 2\% no reducía la pérdida de peso en aguacates.

Un incremento en el contenido de CA de las formulaciones de $20 \%$ a $40 \%$, redujo la pérdida de peso de las ciruelas. Sin embargo, no se observó mayor efectividad del recubrimiento al incrementar el contenido de CA por encima del 40\%. Pérez-Gago et al. (2003a) observaron que un aumento del contenido en lípido en recubrimientos a base de HPMC reducía la pérdida de peso de ciruelas 'Otoño gigante' recubiertas.

En películas aisladas un incremento del contenido en CA de 40 a $60 \%$ si que redujo la PVA (Tabla IV.1), lo que pone de manifiesto las diferencias de comportamiento entre las películas aisladas y el recubrimiento cuando se encuentra aplicado al fruto. Estas diferencias se pueden atribuir a factores que afectan exclusivamente el comportamiento de las películas formando recubrimientos en la superficie de las frutas. Así por ejemplo, la distribución del recubrimiento en la superficie del fruto y, especialmente, la capacidad de éste para formar una capa continua y/o de penetrar en los poros del fruto (Hagenmaier y Baker, 1993a) afecta la funcionalidad de los mismos. Otros factores como la morfología de la piel del fruto (presencia de tricomas, grosor y tipo de cutícula, número de estomas y lenticelas) (Claypool y King, 1941) y las propiedades 
físicoquímicas del recubrimiento, que afectan la capacidad del recubrimiento sellando poros (tensión superficial y viscosidad) (Hagenmaier y Baker, 1993a), afectan notablemente los procesos de transferencia de materia del fruto recubierto. En la presente experiencia un aumento del contenido en CA hasta el $60 \%$, con la consiguiente reducción del contenido de HPMC (Tabla III.1), aumentó la hidrofobicidad del recubrimiento con respecto al recubrimiento con $40 \%$ de CA. Sin embargo, pudo empeorar la habilidad de éste para formar una capa continua en la superficie del mismo, y, por tanto, no mejorar la barrera al vapor de agua con respecto al recubrimiento con $40 \%$ de CA. En películas aisladas, su flexibilidad o adaptabilidad no afecta la PVA, siempre y cuando éstas no presenten fracturas.

No se observaron diferencias de pérdida de peso entre las ciruelas CL y las CSL, lo que indica que la inmersión en agua no eliminó de forma sustancial las ceras naturales de las ciruelas. Estos resultados se contraponen a los observados por Pérez-Gago et al. (2003a) que observaron mayor pérdida de peso en ciruelas 'Otoño gigante' cuando éstas se lavaron previamente en agua, lo que pone de manifiesto el efecto del cultivar en el comportamiento postcosecha del fruto.

Tabla IV.2. Pérdida de peso (\%) de ciruelas 'Angeleno' recubiertas y control: efecto del contenido en CA del recubrimiento.

\begin{tabular}{cccccccccc}
\hline & \multicolumn{3}{c}{$\begin{array}{c}2 \text { semanas a } 1{ }^{\circ} \mathrm{C}+ \\
\text { Tratamiento }\end{array}$} & \multicolumn{3}{c}{ semanas a $20^{\circ} \mathrm{C}$} & \multicolumn{2}{c}{$\begin{array}{c}\text { semanas a } 1{ }^{\circ} \mathrm{C}+ \\
\text { semanas a } 20^{\circ} \mathrm{C}\end{array}$} & \multicolumn{2}{c}{$\begin{array}{c}\text { semanas a } 1{ }^{\circ} \mathrm{C}+ \\
\text { semanas a } 20^{\circ} \mathrm{C}\end{array}$} \\
\cline { 2 - 10 } & 1 & 2 & 3 & 1 & 2 & 3 & 1 & 2 & 3 \\
\hline $0 \% \mathrm{CA}$ & $2,46 \mathrm{bc}$ & $3,92 \mathrm{~b}$ & $4,61 \mathrm{c}$ & $5,34 \mathrm{~b}$ & $5,71 \mathrm{~cd}$ & $7,51 \mathrm{c}$ & $6,30 \mathrm{ab}$ & $7,07 \mathrm{bc}$ & $8,86 \mathrm{~b}$ \\
$20 \% \mathrm{CA}$ & $2,50 \mathrm{c}$ & $3,27 \mathrm{ab}$ & $4,11 \mathrm{ab}$ & $5,22 \mathrm{~b}$ & $4,70 \mathrm{~b}$ & $5,82 \mathrm{ab}$ & $5,46 \mathrm{a}$ & $6,87 \mathrm{bc}$ & $7,09 \mathrm{a}$ \\
$40 \% \mathrm{CA}$ & $2,28 \mathrm{a}$ & $2,79 \mathrm{a}$ & $3,98 \mathrm{ab}$ & $4,33 \mathrm{a}$ & $3,97 \mathrm{a}$ & $5,20 \mathrm{a}$ & $5,43 \mathrm{a}$ & $5,58 \mathrm{a}$ & $6,20 \mathrm{a}$ \\
$60 \% \mathrm{CA}$ & $2,16 \mathrm{a}$ & $3,33 \mathrm{a}$ & $3,63 \mathrm{a}$ & $3,96 \mathrm{a}$ & $5,02 \mathrm{bc}$ & $5,33 \mathrm{a}$ & $5,46 \mathrm{a}$ & $6,24 \mathrm{ab}$ & $7,29 \mathrm{a}$ \\
$\mathrm{CL}$ & $2,09 \mathrm{a}$ & $3,13 \mathrm{ab}$ & $4,36 \mathrm{ab}$ & $5,31 \mathrm{~b}$ & $4,83 \mathrm{~b}$ & $6,81 \mathrm{bc}$ & $6,06 \mathrm{~b}$ & $6,84 \mathrm{bc}$ & $8,63 \mathrm{~b}$ \\
$\mathrm{CSL}$ & $2,22 \mathrm{ab}$ & $3,05 \mathrm{a}$ & $4,06 \mathrm{bc}$ & $4,60 \mathrm{ab}$ & $6,16 \mathrm{~d}$ & $6,63 \mathrm{bc}$ & $6,71 \mathrm{~b}$ & $7,86 \mathrm{c}$ & $9,04 \mathrm{~b}$ \\
\hline
\end{tabular}

$\mathrm{CL}=$ control lavado sin recubrir. $\mathrm{CSL}=$ control sin lavar ni recubrir. $\mathrm{CA}=$ cera de abeja. Por columnas, valores de PVA seguidos de la misma letra no difieren significativamente $(\mathrm{p}<0,05)$.

\section{IV.1.2.2. Intensidad respiratoria}

La IR de las ciruelas varió con el tiempo de almacenamiento pero no con el tratamiento aplicado. Al prolongar el almacenamiento a $1{ }^{\circ} \mathrm{C}$ se 
observó un aumento de la IR y a partir de 4 semanas a $1{ }^{\circ} \mathrm{C}$ se observó un aumento de la IR al prolongar el almacenamiento a $20^{\circ} \mathrm{C}$ (Tabla IV.3). En general, los frutos recubiertos mostraron una IR similar a la de los frutos control, lo que se contrapone a los resultados obtenidos por otros autores. Así por ejemplo, Kays (1991); Banks et al. (1993) y Cisneros-Zevallos y Krochta, (2002) observaron los recubrimientos crean una barrera semipermeable a los gases $\left(\mathrm{CO}_{2}\right.$ y $\left.\mathrm{O}_{2}\right)$ y reducen la IR de las mismas. Sin embargo, otros autores tampoco han observado un efecto de los recubrimientos en la IR de frutas recubiertas, lo que han atribuido a un posible estrés causado en el fruto por la manipulación del mismo durante la aplicación de los recubrimientos (Rojas, 2002).

Tabla IV.3. IR ( $\mathrm{mL} \mathrm{CO} \mathrm{CO}_{2} / \mathrm{kg} \mathrm{h}$ ) de ciruelas 'Angeleno' recubiertas y control: efecto del contenido en CA del recubrimiento.

\begin{tabular}{|c|c|c|c|c|c|c|c|c|c|}
\hline \multirow[t]{2}{*}{ Tratamiento } & \multicolumn{3}{|c|}{$\begin{array}{c}2 \text { semanas a } 1^{\circ} \mathrm{C}+ \\
\text { semanas a } 20^{\circ} \mathrm{C} \\
\end{array}$} & \multicolumn{3}{|c|}{$\begin{array}{c}4 \text { semanas a } 1^{\circ} \mathrm{C}+ \\
\text { semanas a } 20^{\circ} \mathrm{C}\end{array}$} & \multicolumn{3}{|c|}{$\begin{array}{c}6 \text { semanas a } 1^{\circ} \mathrm{C}+ \\
\text { semanas a } 20^{\circ} \mathrm{C}\end{array}$} \\
\hline & 1 & 2 & 3 & 1 & 2 & 3 & 1 & 2 & 3 \\
\hline $0 \% \mathrm{CA}$ & $10,8 b$ & $11,9 \mathrm{ab}$ & $11,82 \mathrm{c}$ & $11,6 \mathrm{~ns}$ & $10,3 a$ & $11,4 \mathrm{a}$ & $14,9 \mathrm{a}$ & $18,0 \mathrm{~d}$ & $21,4 \mathrm{c}$ \\
\hline $20 \% \mathrm{CA}$ & $10,1 \mathrm{~b}$ & $12,3 \mathrm{ab}$ & $10,6 \mathrm{ab}$ & $12,1 \mathrm{~ns}$ & $12,9 \mathrm{~b}$ & $19,1 \mathrm{c}$ & $17,9 \mathrm{~b}$ & $16,4 \mathrm{~cd}$ & $14,0 \mathrm{a}$ \\
\hline $40 \% \mathrm{CA}$ & $10,7 b$ & $11,2 \mathrm{~b}$ & $10,9 \mathrm{bc}$ & $12,2 \mathrm{~ns}$ & $12,9 b$ & $14,2 b$ & $14,0 \mathrm{a}$ & $12,6 \mathrm{a}$ & $17,0 \mathrm{ab}$ \\
\hline $60 \% \mathrm{CA}$ & $11,0 \mathrm{~b}$ & $12,7 b$ & $12,2 \mathrm{c}$ & $11,6 \mathrm{~ns}$ & $11,6 b$ & $14,1 b$ & $15,4 \mathrm{ab}$ & $16,3 \mathrm{~cd}$ & $18,9 \mathrm{bc}$ \\
\hline CL & $8,9 a$ & $11,0 \mathrm{a}$ & $9,1 \mathrm{a}$ & $12,2 \mathrm{~ns}$ & $12,5 b$ & $14,5 b$ & $12,4 \mathrm{a}$ & $13,3 \mathrm{ab}$ & $21,0 \mathrm{c}$ \\
\hline CSL & $11,2 \mathrm{~b}$ & $12,4 \mathrm{ab}$ & $9,6 \mathrm{ab}$ & $11,2 \mathrm{~ns}$ & $12,3 b$ & $15,3 b$ & $13,5 a$ & $15,2 \mathrm{bc}$ & $20,4 \mathrm{c}$ \\
\hline
\end{tabular}

$\mathrm{CL}=$ control lavado sin recubrir. $\mathrm{CSL}=$ control sin lavar ni recubrir. $\mathrm{CA}=$ cera de abeja. Por columnas, valores de PVA seguidos de la misma letra no difieren significativamente $(\mathrm{p}<0,05)$.

\section{IV.1.2.3. Sólidos solubles totales, acidez e índice de madurez}

Los sólidos solubles totales no variaron al prolongar el almacenamiento (Tabla IV.4), pero la acidez disminuyó al prolongar el almacenamiento tanto a $1{ }^{\circ} \mathrm{C}$ como a $20^{\circ} \mathrm{C}$ (Tabla IV.5), lo que se tradujo en un aumento del IM (Tabla IV.6). El consumo de azúcares y ácidos orgánicos durante la respiración del fruto, la conversión de ácidos orgánicos en azúcares, la pérdida de agua por deshidratación así como la hidrólisis de polisacáridos con la liberación de azúcares solubles propia del metabolismo del fruto (Barreiro et al., 2001), dan como resultado un balance negativo de ácidos orgánicos y una estabilización del contenido en azúcares que se traduce en una estabilización de los sólidos solubles totales. El aumento de la IR observado al prolongar el almacenamiento 
(Tabla IV.3) explica la reducción de la acidez al prolongar el almacenamiento. En general, no hubo diferencias entre tratamientos que pudieran indicar una tendencia de su efecto en los sólidos solubles, acidez e IM, lo que también se corresponde con los resultados de IR observados.

Tabla IV.4. Sólidos solubles totales ('Brix) de ciruelas 'Angeleno' recubiertas y control: efecto del contenido en CA del recubrimiento.

\begin{tabular}{cccccccccc}
\hline & \multicolumn{3}{c}{2 semanas a $1{ }^{\circ} \mathrm{C}+$} & \multicolumn{3}{c}{4 semanas a $1{ }^{\circ} \mathrm{C}+$} & \multicolumn{2}{c}{6 semanas a $1^{\circ} \mathrm{C}+$} \\
Tratamiento & \multicolumn{3}{c}{ semanas a $20^{\circ} \mathrm{C}$} & \multicolumn{2}{c}{ semanas a $20^{\circ} \mathrm{C}$} & \multicolumn{2}{c}{ semanas a $20^{\circ} \mathrm{C}$} \\
\cline { 2 - 10 } & 1 & 2 & 3 & 1 & 2 & 3 & 1 & 2 & 3 \\
\hline $0 \% \mathrm{CA}$ & $14,7 \mathrm{bc}$ & $14,6 \mathrm{~ns}$ & $14,1 \mathrm{ab}$ & $14,9 \mathrm{~ns}$ & $14,2 \mathrm{~ns}$ & $15,0 \mathrm{~ns}$ & $15,4 \mathrm{~b}$ & $13,6 \mathrm{a}$ & $15,2 \mathrm{~ns}$ \\
$20 \% \mathrm{CA}$ & $14,2 \mathrm{a}$ & $14,3 \mathrm{~ns}$ & $14,2 \mathrm{bc}$ & $15,1 \mathrm{~ns}$ & $14,8 \mathrm{~ns}$ & $14,3 \mathrm{~ns}$ & $13,6 \mathrm{a}$ & $13,9 \mathrm{ab}$ & $14,5 \mathrm{~ns}$ \\
$40 \% \mathrm{CA}$ & $14,1 \mathrm{a}$ & $13,8 \mathrm{~ns}$ & $13,3 \mathrm{a}$ & $14,9 \mathrm{~ns}$ & $14,4 \mathrm{~ns}$ & $14,2 \mathrm{~ns}$ & $13,4 \mathrm{a}$ & $14,4 \mathrm{bc}$ & $14,6 \mathrm{~ns}$ \\
$60 \% \mathrm{CA}$ & $14,5 \mathrm{ab}$ & $14,4 \mathrm{~ns}$ & $13,6 \mathrm{ab}$ & $14,6 \mathrm{~ns}$ & $15,2 \mathrm{~ns}$ & $13,7 \mathrm{~ns}$ & $15,0 \mathrm{~b}$ & $14,7 \mathrm{c}$ & $14,5 \mathrm{~ns}$ \\
$\mathrm{CL}$ & $14,4 \mathrm{ab}$ & $14,5 \mathrm{~ns}$ & $14,5 \mathrm{c}$ & $15,0 \mathrm{~ns}$ & $15,0 \mathrm{~ns}$ & $14,2 \mathrm{~ns}$ & $14,5 \mathrm{ab}$ & $13,9 \mathrm{ab}$ & $13,8 \mathrm{~ns}$ \\
$\mathrm{CSL}$ & $15,0 \mathrm{c}$ & $14,0 \mathrm{~ns}$ & $14,3 \mathrm{c}$ & $14,7 \mathrm{~ns}$ & $15,2 \mathrm{~ns}$ & $14,4 \mathrm{~ns}$ & $15,6 \mathrm{~b}$ & $15,4 \mathrm{~d}$ & $14,8 \mathrm{~ns}$ \\
\hline
\end{tabular}

$\mathrm{CL}=$ control lavado sin recubrir. $\mathrm{CSL}=$ control sin lavar ni recubrir. $\mathrm{CA}=$ cera de abeja. Por columnas, valores de PVA seguidos de la misma letra no difieren significativamente $(\mathrm{p}<0,05)$.

Tabla IV.5. Acidez (g ácido málico/100mL zumo) de ciruelas 'Angeleno' recubiertas y control: efecto del contenido en CA del recubrimiento.

\begin{tabular}{|c|c|c|c|c|c|c|c|c|c|}
\hline \multirow[t]{2}{*}{ Tratamiento } & \multicolumn{3}{|c|}{$\begin{array}{c}2 \text { semanas a } 1^{\circ} \mathrm{C}+ \\
\text { semanas a } 20^{\circ} \mathrm{C}\end{array}$} & \multicolumn{3}{|c|}{$\begin{array}{c}4 \text { semanas a } 1^{\circ} \mathrm{C}+ \\
\text { semanas a } 20^{\circ} \mathrm{C}\end{array}$} & \multicolumn{3}{|c|}{$\begin{array}{c}6 \text { semanas a } 1^{\circ} \mathrm{C}+ \\
\text { semanas a } 20^{\circ} \mathrm{C}\end{array}$} \\
\hline & 1 & 2 & 3 & 1 & 2 & 3 & 1 & 2 & 3 \\
\hline $0 \% \mathrm{CA}$ & $8,80 \mathrm{~ns}$ & $8,46 \mathrm{~ns}$ & $8,24 \mathrm{~ns}$ & $7,51 \mathrm{a}$ & $7,28 \mathrm{a}$ & $7,10 \mathrm{~ns}$ & $7,28 \mathrm{ab}$ & $6,93 \mathrm{~ns}$ & $6,81 b$ \\
\hline $20 \% \mathrm{CA}$ & $8,98 \mathrm{~ns}$ & $8,60 \mathrm{~ns}$ & $8,02 \mathrm{~ns}$ & $7,23 \mathrm{a}$ & $7,83 \mathrm{bc}$ & $7,35 \mathrm{~ns}$ & $6,81 \mathrm{ab}$ & $7,01 \mathrm{~ns}$ & $7,36 \mathrm{c}$ \\
\hline $40 \% \mathrm{CA}$ & $9,12 \mathrm{~ns}$ & $8,12 \mathrm{~ns}$ & $7,62 \mathrm{~ns}$ & $7,39 \mathrm{a}$ & 7,61ab & $7,01 \mathrm{~ns}$ & $6,77 \mathrm{a}$ & $6,84 \mathrm{~ns}$ & $7,09 \mathrm{bc}$ \\
\hline $60 \% \mathrm{CA}$ & $8,77 \mathrm{~ns}$ & $8,63 \mathrm{~ns}$ & $8,12 \mathrm{~ns}$ & $7,32 \mathrm{a}$ & $7,97 \mathrm{~cd}$ & $6,64 \mathrm{~ns}$ & $7,00 \mathrm{a}$ & $7,03 \mathrm{~ns}$ & $7,41 \mathrm{c}$ \\
\hline $\mathrm{CL}$ & $9,07 \mathrm{~ns}$ & $8,82 \mathrm{~ns}$ & $8,35 \mathrm{~ns}$ & $8,46 b$ & $8,28 \mathrm{~cd}$ & $6,84 \mathrm{~ns}$ & $7,62 \mathrm{~b}$ & $7,51 \mathrm{~ns}$ & $6,40 \mathrm{a}$ \\
\hline CSL & $9,10 \mathrm{~ns}$ & $8,85 \mathrm{~ns}$ & $8,28 \mathrm{~ns}$ & $8,30 \mathrm{~b}$ & $8,47 d$ & $7,38 \mathrm{~ns}$ & $8,21 \mathrm{c}$ & $6,87 \mathrm{~ns}$ & $7,00 \mathrm{~b}$ \\
\hline
\end{tabular}

$\mathrm{CL}=$ control lavado $\sin$ recubrir. $\mathrm{CSL}=$ control sin lavar ni recubrir. $\mathrm{CA}=$ cera de abeja. Por columnas, valores de PVA seguidos de la misma letra no difieren significativamente $(\mathrm{p}<0,05)$. 
Tabla IV.6. IM de ciruelas 'Angeleno' recubiertas y control: efecto del contenido en CA del recubrimiento.

\begin{tabular}{|c|c|c|c|c|c|c|c|c|c|}
\hline \multirow[t]{2}{*}{ Tratamiento } & \multicolumn{3}{|c|}{$\begin{array}{c}2 \text { semanas a } 1^{\circ} \mathrm{C}+ \\
\text { semanas a } 20^{\circ} \mathrm{C} \\
\end{array}$} & \multicolumn{3}{|c|}{$\begin{array}{c}4 \text { semanas a } 1^{\circ} \mathrm{C}+ \\
\text { semanas a } 20^{\circ} \mathrm{C}\end{array}$} & \multicolumn{3}{|c|}{$\begin{array}{c}6 \text { semanas a } 1^{\circ} \mathrm{C}+ \\
\text { semanas a } 20^{\circ} \mathrm{C}\end{array}$} \\
\hline & 1 & 2 & 3 & 1 & 2 & 3 & 1 & 2 & 3 \\
\hline $0 \% \mathrm{CA}$ & $16,7 \mathrm{c}$ & $17,2 \mathrm{c}$ & $17,0 \mathrm{~ns}$ & $19,9 \mathrm{~b}$ & $19,5 \mathrm{~ns}$ & $21,1 \mathrm{~ns}$ & $21,2 \mathrm{~ns}$ & $19,6 \mathrm{ab}$ & $22,3 c$ \\
\hline $20 \% \mathrm{CA}$ & $15,8 \mathrm{ab}$ & $16,7 \mathrm{bc}$ & $17,7 \mathrm{~ns}$ & $20,8 b$ & $18,9 \mathrm{~ns}$ & $19,4 n$ & $20,0 \mathrm{~ns}$ & $19,9 \mathrm{bc}$ & $19,8 \mathrm{ab}$ \\
\hline $40 \% \mathrm{CA}$ & $15,5 \mathrm{a}$ & $17,0 \mathrm{bc}$ & $17,4 \mathrm{~ns}$ & $20,2 b$ & $18,9 \mathrm{~ns}$ & $20,3 \mathrm{~ns}$ & $19,8 \mathrm{~ns}$ & $21,0 \mathrm{c}$ & $20,6 b c$ \\
\hline $60 \% \mathrm{CA}$ & $16,5 b c$ & $16,7 b c$ & $17,3 \mathrm{~ns}$ & $20,0 \mathrm{~b}$ & $19,1 \mathrm{~ns}$ & $20,7 \mathrm{~ns}$ & $21,5 \mathrm{~ns}$ & $21,0 \mathrm{c}$ & $19,5 \mathrm{a}$ \\
\hline CL & $15,8 \mathrm{ab}$ & $16,4 \mathrm{~b}$ & $17,3 \mathrm{~ns}$ & $17,6 \mathrm{a}$ & $18,1 \mathrm{~ns}$ & $20,8 \mathrm{~ns}$ & $19,1 \mathrm{~ns}$ & $18,5 \mathrm{a}$ & $21,6 c$ \\
\hline CSL & $16,5 b c$ & $15,7 \mathrm{a}$ & $16,7 \mathrm{~ns}$ & $17,7 \mathrm{a}$ & $18,0 \mathrm{~ns}$ & $19,7 \mathrm{~ns}$ & $19,0 \mathrm{~ns}$ & $22,4 d$ & $21,2 b c$ \\
\hline
\end{tabular}

$\mathrm{CL}=$ control lavado sin recubrir. $\mathrm{CSL}=$ control sin lavar ni recubrir. $\mathrm{CA}=$ cera de abeja.

Por columnas, valores de PVA seguidos de la misma letra no difieren significativamente $(\mathrm{p}<0,05)$.

\section{IV.1.2.4. Etanol y acetaldehído en zumo}

La Figura IV.2 muestra el contenido en etanol y acetaldehído en zumo de las ciruelas control y de las ciruelas recubiertas. Se observó un incremento de los niveles de etanol y acetaldehído al prolongar el almacenamiento a $20^{\circ} \mathrm{C}$, pero no se observó un incremento significativo de ambos compuestos al prolongar el tiempo de almacenamiento a $1{ }^{\circ} \mathrm{C}$. $\mathrm{El}$ recubrimiento con $0 \% \mathrm{CA}$ dio lugar a valores mayores de etanol que el resto de recubrimientos, aumentando de manera significativa tras 4 semanas de almacenamiento a $1{ }^{\circ} \mathrm{C}$, seguido de almacenamiento a $20^{\circ} \mathrm{C}$.

Algunos autores han observado una acumulación de etanol y acetaldehído en cítricos almacenados en atmósferas modificadas de bajo contenido en $\mathrm{O}_{2}$ y alto contenido en $\mathrm{CO}_{2}$ (Davis et al., 1973; Ke y Kader, 1990). Por tanto, al aplicar recubrimientos que ejercen una barrera a ambos gases se puede producir una modificación en la atmósfera interna del fruto con un incremento en el contenido en $\mathrm{CO}_{2}$ y un empobrecimiento en $\mathrm{O}_{2}$ (Banks et al., 1993 y Cisneros-Zevallos y Krochta, 2002), con el consiguiente incremento de los niveles de etanol y acetaldehído en el zumo. En la presente experiencia los recubrimientos con $0 \%$ CA, que presentaron mayor contenido de HPMC que el resto de recubrimientos (Tabla III.1), pudieron ejercer una mayor barrera a los gases $\mathrm{CO}_{2} \mathrm{y} \mathrm{O}_{2}$, dado que los hidrocoloides como la HPMC presentan una baja permeabilidad a ambos gases (Kester y Fennema, 1986; Park et al., 1993; Nísperos-Carriedo, 1994). Esto explicaría los mayores niveles de 
etanol en los frutos recubiertos con las formulaciones de 0\%CA.

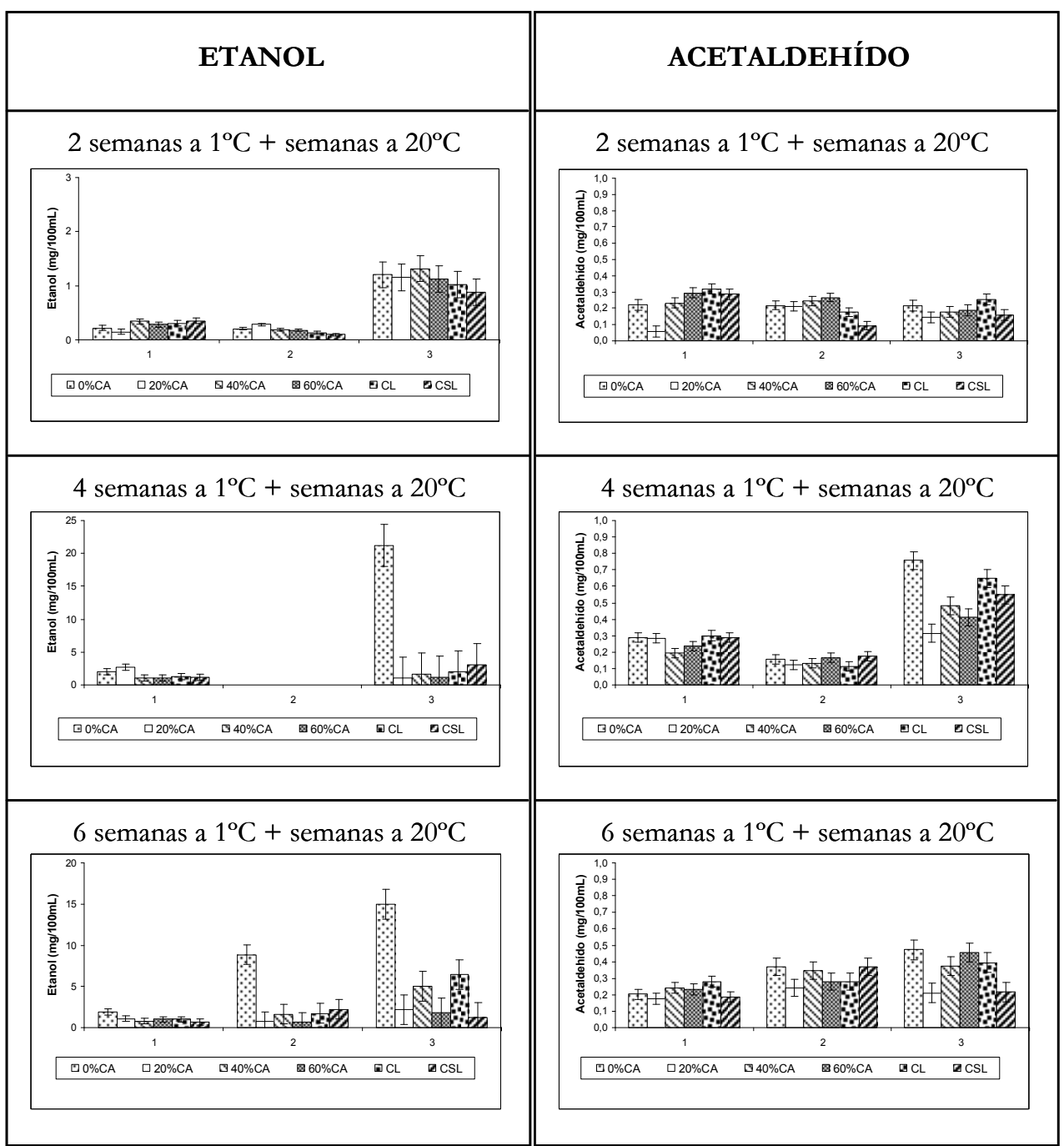

Las barras de error muestran valores de LSD (5\%).

Datos de etanol correspondientes al periodo de almacenamiento de 4 semanas a $1{ }^{\circ} \mathrm{C}+2$ semanas a $20^{\circ} \mathrm{C}$ no disponibles.

Figura IV.2. Etanol y acetaldehído $(\mathrm{mg} / 100 \mathrm{~mL}$ ) en zumo de ciruelas 'Angeleno' recubiertas y control: efecto del contenido en CA del recubrimiento. 


\section{IV.1.2.5. Firmeza}

En general, al prolongar el almacenamiento a $1{ }^{\circ} \mathrm{C}$ se mantuvo la firmeza de las ciruelas, pero al prolongar el almacenamiento a $20{ }^{\circ} \mathrm{C}$ se observó una reducción importante de la firmeza de las mismas. Los recubrimientos mantuvieron la firmeza del fruto cuando se almacenaron 4 y 6 semanas a $1{ }^{\circ} \mathrm{C}$ más 2 y 3 semanas a $20{ }^{\circ} \mathrm{C}$. Los recubrimientos $0 \% \mathrm{CA}$ y $20 \%$ CA fueron más efectivos manteniendo la firmeza de las ciruelas que los de mayor contenido en CA (Figura IV.3).

En estudios realizados en cítricos se ha observado una correlación entre la firmeza global del fruto (medida en el fruto entero) y la pérdida de peso de los mismos, siendo la deshidratación responsable de la pérdida de turgencia del fruto y, por tanto, de la pérdida de firmeza global (BenYehoshua, 1985; Cuquerella et al., 1988; Pozzan et al., 1993). En el presente trabajo, los tratamientos de mayor firmeza no correspondieron con los de menor pérdida de peso. Por tanto, el efecto de los recubrimientos manteniendo la firmeza de las ciruelas no se puede atribuir a una menor deshidratación de éstas sino a otros factores involucrados en la pérdida de firmeza de la pulpa.

El ablandamiento o pérdida de firmeza de la pulpa de las frutas se debe a la degradación de las pectinas y hemicelulosas de las paredes celulares y en ella intervienen procesos de hidrólisis enzimática y procesos no enzimáticos como cambios en el $\mathrm{pH}$ o fuerza iónica del medio que envuelve la pared celular (Fishman et al., 1989; Schweikert et al., 2000). Una refrigeración adecuada y el uso de atmósferas modificadas o controladas ralentiza los procesos de senescencia del fruto en general (Artés, 2006) y el ablandamiento de la pulpa en particular (Couey, 1960, 1965; Smith, 1967; Ke et al., 1991; Ben y Gaweda, 1992).

Según Banks et al. (1993) y Cisneros-Zevallos y Krochta (2002) los recubrimientos comestibles permiten controlar la respiración y senescencia de las frutas de forma similar a las atmósferas modificadas. Por tanto, el efecto de los recubrimientos manteniendo la firmeza se puede atribuir a que éstos modificaron la atmósfera interna de las ciruelas respecto a la de los frutos control. La mayor efectividad de los recubrimientos $0 \% \mathrm{CA}$ y $20 \%$ CA pudo ser debida a un incremento de la barrera a los gases $\mathrm{CO}_{2} \mathrm{y}$ $\mathrm{O}_{2}$ de estos recubrimientos, que se tradujo en mayores niveles de etanol y 
acetaldehído (Figura IV.2). Pérez-Gago et al. (2003a) obtuvieron resultados similares en ciruelas 'Otoño gigante' a las que se aplicó recubrimientos a base de HPMC y lípido, y Baldwin et al. (1999) en mangos recubiertos con derivados de celulosa.

\section{IV.1.2.6. Desórdenes fisiológicos}

Una refrigeración adecuada permite prolongar el periodo de vida útil de las ciruelas (Mitchell y Crisosto, 1995), pero el uso de temperaturas excesivamente bajas causa desórdenes fisiológicos. La sensibilidad de las ciruelas al frío varía con el cultivar (Crisosto et al., 1999). Así por ejemplo, en ciruelas cv. 'Angeleno' los daños por frío se producen en torno a los $5^{\circ} \mathrm{C}$ y la temperatura óptima de almacenamiento está en torno a $1^{\circ} \mathrm{C}$ (Ceretta et al. 2000; Crisosto y Kader, 2004). Además de los daños causados por frío, existen otros daños fisiológicos que reducen la calidad de las ciruelas como la pigmentación roja de la pulpa o 'bleeding'. El 'bleeding' se manifiesta en cultivares de ciruela, entre ellos el cv. 'Angeleno', que presentan células anejas al hueso que contienen antocianinas o pigmentos rojos que se pueden difundir a lo largo de la pulpa modificando la coloración de la misma y reduciendo la calidad del fruto. Esta pigmentación roja de la pulpa o 'bleeding' se atribuye a los procesos de maduración y senescencia del fruto y se puede prevenir con el uso de atmósferas controladas (Laurie et al., 1992; Retamales et al., 1992, Crisosto et al., 1999).

Los daños fisiológicos observados en nuestra experiencia fueron principalmente daños por 'bleeding'. Daños como el pardeamiento y la deshidratación de la pulpa, que se atribuyen a las bajas temperaturas, fueron puramente testimoniales, lo que pudo ser debido al uso de temperaturas óptimas de refrigeración $\left(1^{\circ} \mathrm{C}\right)$.

La Figura IV.3. muestra que los daños por 'bleeding' aumentaron al prolongar el almacenamiento a $20{ }^{\circ} \mathrm{C}$ y que los recubrimientos fueron, en general, efectivos reduciéndolos a partir de 4 semanas de almacenamiento refrigerado. Se observó una relación entre la firmeza de la pulpa y la incidencia de 'bleeding', que pudo ser debida a que la pérdida de integridad física de las paredes celulares, que produce el ablandamiento de la pulpa, facilitara asimismo la difusión de las antocianinas. Los efectos beneficiosos de los recubrimientos reduciendo los daños fisiológicos han 
sido observados por otros autores (Basiouny y Baldwin, 1997; Pérez-Gago et al., 2003a). No se observó un efecto del contenido en CA del recubrimiento en la incidencia de éste desorden.

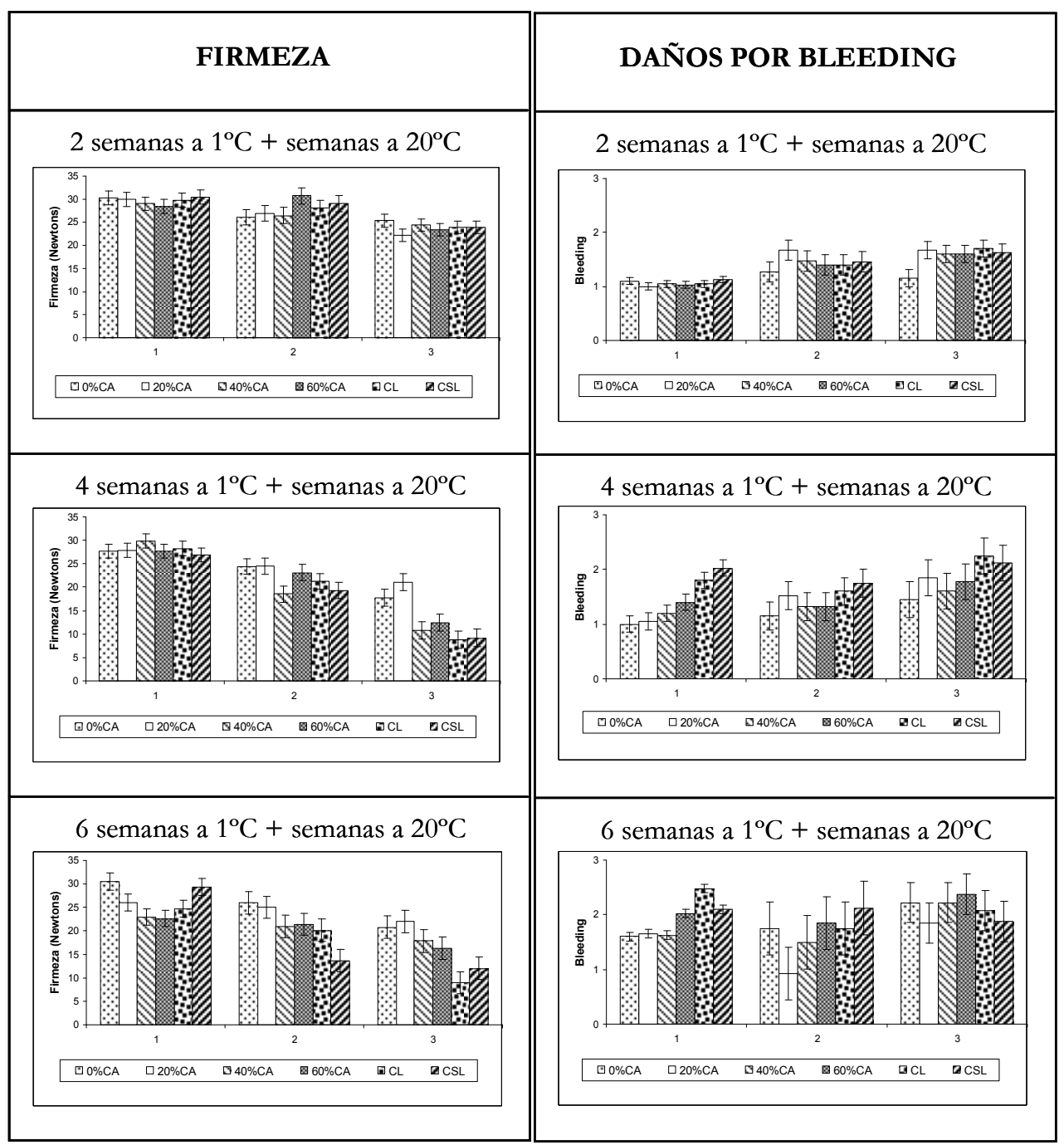

Las barras de error muestran valores de LSD (5\%).

Figura IV.3. Firmeza y daños por 'bleeding' de ciruelas 'Angeleno' recubiertas y control: efecto del contenido en CA del recubrimiento. 


\section{IV.1.2.7. Color}

La disminución de los valores de luminosidad de las frutas es un indicador del oscurecimiento que sufren durante su almacenamiento. Una disminución del croma indica un cambio a colores menor vivos o intensos, asociados a los procesos de senescencia de las frutas. Asimismo, una disminución del tono puede indicar una evolución de color, que en frutos rojo-violáceos varia, desde colores rojos a violetas (Holcroft y Kader, 1999).

En la presente experiencia la luminosidad de las ciruelas varió con el tiempo de almacenamiento pero no con la aplicación de recubrimientos, ni con el contenido en $\mathrm{CA}$ de los mismos. Al prolongar el almacenamiento a partir de 4 semanas de frigoconservación se observó una reducción de luminosidad lo que se tradujo en un oscurecimiento del color (no se muestran datos). El croma osciló a lo largo del almacenamiento y el efecto de los recubrimientos varió para los distintos periodos de almacenamiento ensayados, lo que dificulta extraer conclusiones al respecto (no se muestran datos). En general, el tono del fruto diminuyó al prolongar el almacenamiento, lo que se tradujo en un cambio de coloración de rojo a violáceo. Además, la aplicación de recubrimientos ralentizó esta evolución o viraje de color respecto a las ciruelas control. En general, no se observó un efecto del contenido en CA del recubrimiento en el tono de las ciruelas (Figura IV.4).

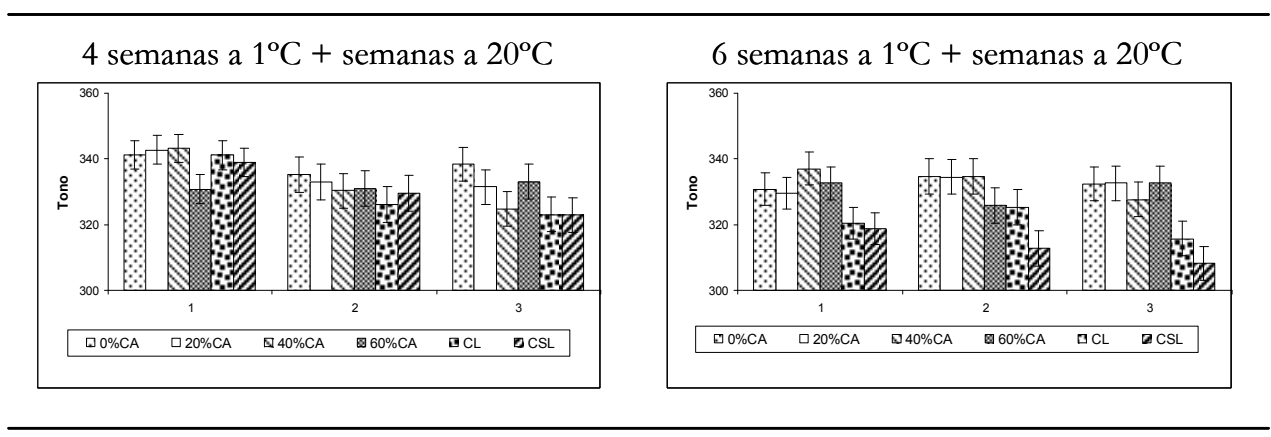

Las barras de error muestran valores de LSD (5\%).

Figura IV.4. Tono de ciruelas 'Angeleno' recubiertas y control: efecto del contenido en CA del recubrimiento. 


\section{IV.1.2.8. Evaluación organoléptica: 'flavor' y textura}

Cuando los recubrimientos ejercen una excesiva barrera a los gases $\mathrm{CO}_{2}$ y $\mathrm{O}_{2}$, aumentan los niveles de etanol y acetaldehído del fruto y disminuye la calidad organoléptica de los mismos (Cohen et al., 1990; Baldwin et al., 1995; Hagenmaier y Shaw, 2002). Para detectar un posible efecto de los recubrimientos estudiados y del tiempo de almacenamiento en el 'flavor' de las ciruelas, se realizó el análisis sensorial de los frutos. También se analizó la textura de las ciruelas para confirmar las diferencias de firmeza de la pulpa observadas mediante el análisis instrumental. De esta manera, se observó una disminución del 'flavor' al prolongar el tiempo de almacenamiento, lo que se corresponde con una pérdida de calidad organoléptica. Sin embargo, no se observaron diferencias de 'flavor' entre tratamientos (no se muestran datos). Este resultado indica que los recubrimientos aplicados no empeoraron la calidad del fruto respecto al control, lo que guarda relación con los bajos niveles de etanol y acetaldehído detectados en zumo (Figura IV.2).

La textura de la pulpa de las ciruelas es un factor importante en la calidad de las mismas y limita su periodo de almacenamiento. En la experiencia realizada, los jueces detectaron una pérdida de textura al prolongar el almacenamiento a $20{ }^{\circ} \mathrm{C}$ (no se muestran datos). La textura de las ciruelas fue aceptable hasta 6 semanas a $1{ }^{\circ} \mathrm{C}$ más 1 semana a $20^{\circ} \mathrm{C}$, siendo inaceptable a partir de éste periodo de almacenamiento. Los jueces no detectaron mayor firmeza en los frutos recubiertos respecto a los frutos control, ni siquiera en los recubiertos con las formulaciones de $0 \% \mathrm{CA}$ y 20\% CA, los cuales mostraron mayor firmeza instrumental (Figura IV.3).

\section{IV.1.2.9. Aspecto externo y brillo del fruto}

Para detectar el efecto de los recubrimientos en el aspecto externo del fruto, así como del tiempo de almacenamiento, los jueces evaluaron el aspecto externo tanto de los frutos recubiertos como de los frutos control. Así, observaron que el efecto de los recubrimientos variaba para los distintos periodos de almacenamiento ensayados (Figura IV.5). Para un almacenamiento a $1{ }^{\circ} \mathrm{C}$ de 2 semanas, los frutos recubiertos con la formulación de $0 \%$ CA y los CL mostraron un aspecto brillante y homogéneo siendo los mejor valorados (mayores puntuaciones). Los tratamientos $40 \% \mathrm{CA}, 60 \%$ CA y CSL presentaron un aspecto blanquecino 
y fueron los peor valorados. El aspecto blanquecino del fruto, que redujo la puntuación de la apariencia, pudo ser debido a la propia pruína del fruto y/o a la CA de los recubrimientos que, como se ha observado en el Apartado IV.1.1.1 aumentaba la turbidez de las emulsiones y reducía la transparencia de las películas. Sin embargo, el hecho de no existir diferencias significativas de aspecto entre los tratamientos 40\%CA, 60\% CA y CSL, indica que estos recubrimientos no afectaron negativamente a éste parámetro de calidad del fruto.

El lavado de las ciruelas pudo producir una eliminación parcial de las ceras naturales y/o un cambio en su distribución. Esto explicaría el efecto del lavado reduciendo el manchado de los frutos sin afectar la pérdida de peso respecto a las ciruelas sin lavar (CSL). Algunos trabajos consultados en la bibliografía muestran cómo el lavado de los frutos produce un cambio en las propiedades barrera de la piel de los frutos que afecta a la transferencia de gases $\mathrm{CO}_{2}$ y $\mathrm{O}_{2}$, sin afectar la transferencia del vapor de agua (Hagenmaier y Baker, 1993b).

Al prolongar el almacenamiento en refrigeración los frutos perdieron turgencia, marchitándose y arrugándose como consecuencia de su deshidratación (Wills et al, 1998). La pérdida de turgencia, varió con el tratamiento aplicado, siendo los tratamientos con 40\% CA y $60 \% \mathrm{CA}$ los que mejor preservaron la turgencia de las ciruelas y los que menor pérdida de peso registraron (Figura IV.6). La puntuación del aspecto externo del fruto varió con la turgencia de los mismos, siendo los tratamientos con $40 \%$ CA y $60 \%$ CA los mejor valorados (Figura IV.5).

El efecto de los recubrimientos en el brillo de las ciruelas varió con la presencia de manchas blancas de pruína y/o CA, siendo los tratamientos 0\% CA, 20\%CA y CL los más brillantes (mayores puntuaciones). Este resultado se correlaciona con el aspecto de las películas (Apartado IV.1.1.1) que varió desde un aspecto brillante en las películas con $0 \% \mathrm{CA}$ a un aspecto mate en las películas con CA. Las diferencias de brillo entre los tratamientos con 40\%CA, $60 \%$ CA y CSL no fueron significativas, lo que indica que la aplicación de estos recubrimientos no modifica el brillo respecto a los frutos CSL. 


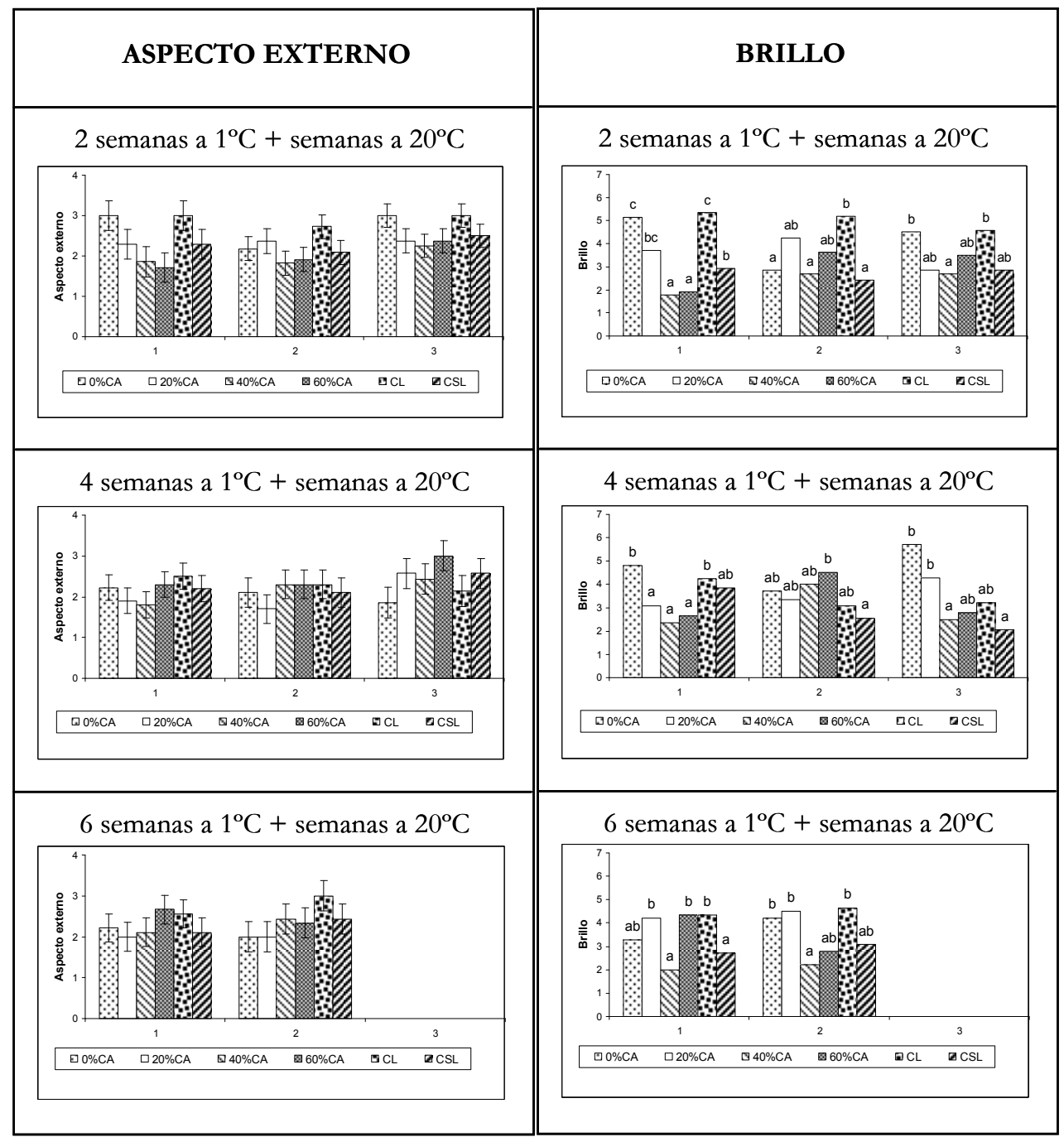

Las barras de error muestran valores de LSD (5\%).

En cada periodo de almacenamiento, valores seguidos de la misma letra no difieren significativamente $(\mathrm{p}<5 \%)$.

Datos de aspecto y brillo correspondientes al periodo de almacenamiento de 6 semanas a $1{ }^{\circ} \mathrm{C}+3$ semanas a $20^{\circ} \mathrm{C}$ no disponibles.

Figura IV.5. Aspecto externo y brillo de ciruelas 'Angeleno' recubiertas y control: efecto del contenido en CA del recubrimiento. 

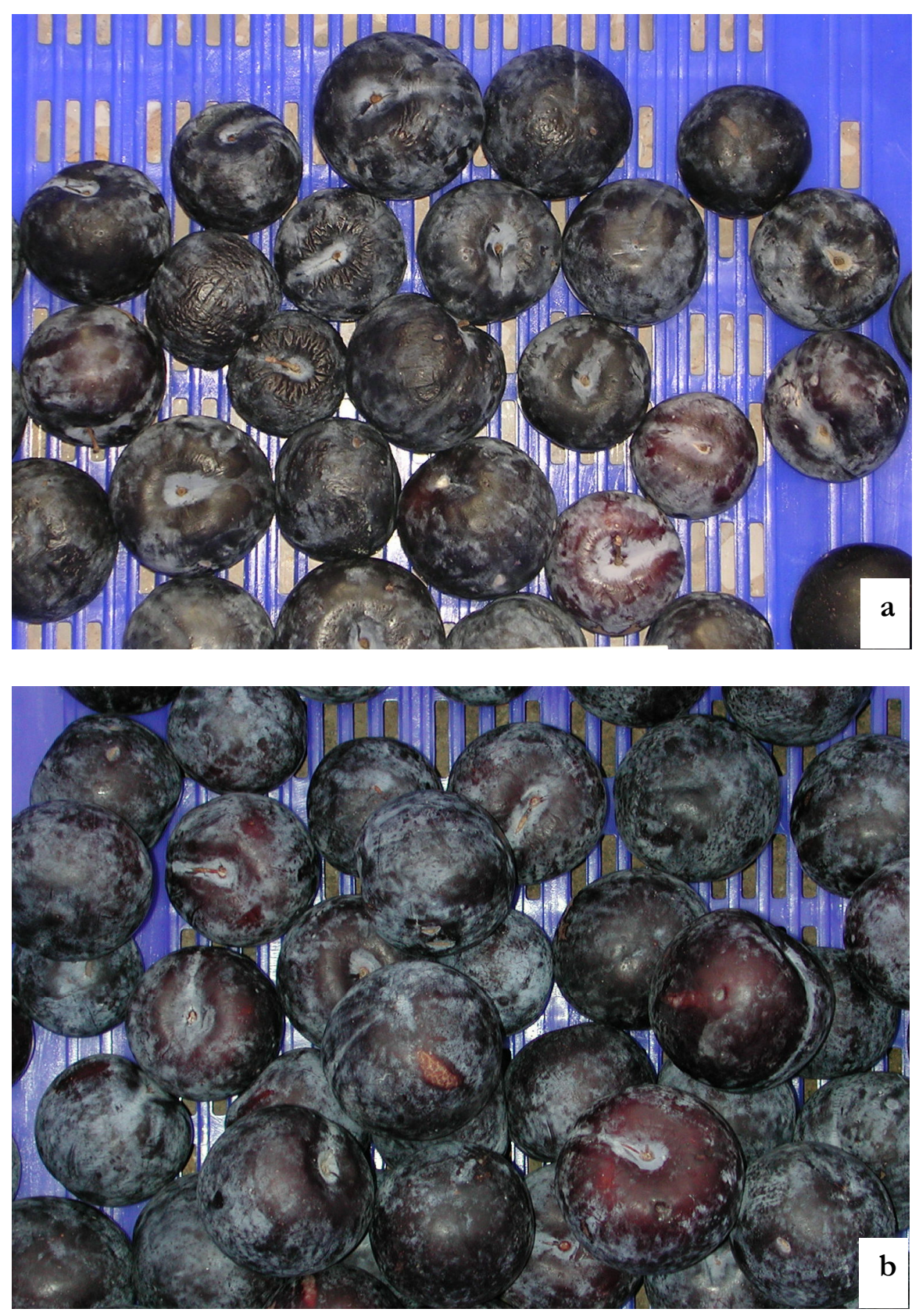

Figura IV.6. Aspecto de las ciruelas 'Angeleno' CSL (a) y recubiertas con la formulación $60 \% \mathrm{CA}$ (b) tras un almacenamiento de 6 semanas a $1^{\circ} \mathrm{C}+$ 1 semana a $20^{\circ} \mathrm{C}$. 


\section{IV.1.3. Síntesis de resultados}

El objetivo de la presente experiencia fue estudiar el efecto del contenido de CA de recubrimientos compuestos a base de HPMC y CA en la calidad postcosecha de ciruelas cv. 'Angeleno'. Para ello se estudió el efecto de este factor en las propiedades de películas aisladas y se evaluaron distintos parámetros de calidad de las ciruelas recubiertas, comparándolas con frutas control. A continuación se hace un resumen de los resultados más relevantes.

El efecto de los recubrimientos en la pérdida de peso de las ciruelas dependió de la proporción relativa de CA:HPMC del recubrimiento. Los recubrimientos con $40 \%$ de CA presentaron un equilibrio entre hidrofobicidad e integridad estructural que permitió obtener la máxima reducción de pérdida de peso. Una reducción en el contenido de CA del recubrimiento (respecto al recubrimiento con 40\% de CA) disminuyó la hidrofobicidad del mismo y su capacidad para reducir la pérdida de peso de las ciruelas, y un aumento en el contenido de CA (respecto al recubrimiento con $40 \%$ de CA) empeoró su integridad estructural, proporcionando una reducción del peso comparable a los recubrimientos con $40 \%$ de CA. Sin embargo, en películas aisladas la PVA se vio reducida al aumentar el contenido en CA al 60\%.

La aplicación de recubrimientos formulados sin CA supuso un incremento en el contenido de etanol de las ciruelas respecto a las recubiertas con recubrimientos que incorporaron CA en su formulación. Esto sugiere una mayor barrera a los gases $\left(\mathrm{CO}_{2}\right.$ y $\left.\mathrm{O}_{2}\right)$ de los recubrimientos formulados exclusivamente con HPMC.

Los recubrimientos ensayados redujeron el ablandamiento de la pulpa de las ciruelas, y la composición de los mismos afectó a su comportamiento. Se observó una correlación entre la proporción relativa de CA:HPMC del recubrimiento y la firmeza de la pulpa, de manera que un aumento en el contenido de HPMC, con la consiguiente reducción del contenido de CA, aumentó la firmeza de la pulpa de las ciruelas. Estos resultados se pueden relacionar con un aumento de la barrera a los gases $\left(\mathrm{CO}_{2}\right.$ y $\left.\mathrm{O}_{2}\right)$ del recubrimiento al aumentar el contenido de HPMC y a la modificación de la atmósfera interna del fruto que reduce el ablandamiento 
de la pulpa.

La aplicación de recubrimientos redujo los daños por 'bleeding' y se observó una relación entre la firmeza de la pulpa y los daños por 'bleeding'. Esta relación pudo ser debida a que la pérdida de integridad física de las paredes celulares de la pulpa de las ciruelas, que produce el ablandamiento de la misma, facilitara asimismo la difusividad de los pigmentos responsables del 'bleeding'.

Los recubrimientos que incorporaron CA en su formulación dieron un aspecto ligeramente blanquecino al fruto, similar al que proporciona la propia pruína de las ciruelas. Este aspecto blanquecino se hizo más evidente al aumentar el contenido en CA del recubrimiento. Sin embargo, la valoración del aspecto externo de las ciruelas hecha por el panel de análisis sensorial varió a lo largo del almacenamiento y el efecto del contenido en CA del recubrimiento en el aspecto de las ciruelas recubiertas dependió del grado de deshidratación del fruto. Para cortos periodos de almacenamiento, en los que la deshidratación de las ciruelas no produce una pérdida importante de turgencia, los recubrimientos con menor contenido en CA mejoraron el aspecto de las ciruelas, puesto que estas ciruelas mostraron un aspecto menos blanquecino. Sin embargo, para un almacenamiento prolongado el aumento en el contenido de CA del recubrimiento evitó la pérdida de turgencia y el arrugamiento de la piel de las ciruelas, mejorando el aspecto externo de las mismas.

El brillo de la piel varió con el contenido de CA del recubrimiento de manera que al aumentar el contenido en CA se observó una reducción de brillo.

Como conclusión acerca de la funcionalidad de los recubrimientos aplicados cabe decir que las mejoras observadas en los distintos atributos de calidad de las ciruelas 'Angeleno' recubiertas con recubrimientos a base de HPMC y CA no son unidireccionales, puesto que las variables de composición de los recubrimientos estudiadas (contenido de CA) mejoran unos parámetros de calidad empeorando otros. En concreto un aumento en el contenido de CA y una reducción del contenido de HPMC reduce la pérdida de peso y de turgencia, mejorando el aspecto externo de las ciruelas. Sin embargo, aumenta el ablandamiento y los daños fisiológicos de la pulpa. Estos resultados indican que a la hora de seleccionar el 
contenido de CA óptimo hay que establecer un compromiso entre los distintos atributos de calidad involucrados $\mathrm{y} / \mathrm{u}$ optimizar los recubrimientos a base de HPMC y CA para su aplicación a ciruelas 'Angeleno'.

\section{IV.2. EFECTO DEL TIPO Y CONTENIDO DE ÁCIDO GRASO DE LA FORMULACIÓN EN LAS PROPIEDADES DE LAS PELÍCULAS Y EN LA CALIDAD POSTCOSECHA DE CIRUELAS ‘ANGELENO’ RECUBIERTAS}

\section{IV.2.1. Análisis de las emulsiones y de las películas preformadas en} placa

Generalmente los AG, por su carácter hidrofóbico, son incorporados a la formulaciones de las películas compuestas para mejorar su resistencia al vapor de agua (Sothornvit y Krochta, 2005). Pero, además, su carácter anfipático los dota de capacidad emulsificante, mejorando la dispersión de otros lípidos en la fase acuosa de las películas (Baldwin, 1999). A las propiedades de los AG descritas, se suma su capacidad para modificar las propiedades mecánicas de las películas, ejerciendo un efecto plastificante en las mismas (Sothornvit y Krochta, 2005). Por tanto, una modificación en el contenido y tipo de AG de las formulaciones afectará tanto a la estabilidad de las emulsiones, como a las propiedades barrera y mecánicas de las películas.

\section{IV.2.1.1. Aspecto de las emulsiones y de las películas}

En la presente experiencia el tipo y contenido de AG de las formulaciones afectó al aspecto de las emulsiones (Figura IV.7) y películas resultantes (Figura IV.8). La estabilidad de las emulsiones varió con el tipo de AG. A las $24 \mathrm{~h}$ de su elaboración, las formulaciones conteniendo AO mostraron una separación de fases similar a la descrita en el Apartado IV.1.1.1, presentando una capa blanca enriquecida en lípido sobre la emulsión clarificada, lo que indica que el AO no aportó estabilidad a las emulsiones. La formulación CA:AP 1:0,5 también mostró una separación de fases a las $24 \mathrm{~h}$ de su elaboración, mientras que la formulación CA:AP 1:0,2 formó emulsiones estables. El hecho de que al reducir el contenido 
en AP mejorara la estabilidad de la emulsión indica que este AG no ejerce una buena estabilización de las mismas. Por tanto, la mejora observada podría deberse a la acción de otros componentes de la formulación, concretamente al HPMC. El incremento del contenido en HPMC de las formulaciones CA:AP 1:0,2 (Tabla III.3) pudo mejorar la estabilidad de las mismas dado que, como han descrito algunos autores, los hidrocoloides como el HPMC aportan estabilidad a las emulsiones ejerciendo fuerzas de repulsión estérica entre las partículas de lípido (Callegarin et al., 1997). El análisis instrumental del tamaño de partícula de lípido de las emulsiones mostró que las formulaciones con $\mathrm{AO}$ y la formulación CA:AP 1:0,5 tenían mayor tamaño de partícula que el resto (no se muestran datos). Según Prince (1977) un incremento en el tamaño de la partícula de lípido de las emulsiones, reduce la estabilidad de las mismas, lo que podría explicar la menor estabilidad de las formulaciones con AO y la formulación CA:AP 1:0,5.

Todas las películas presentaron distinto aspecto en la cara expuesta al aire y a la placa, respectivamente, durante el secado de las mismas, lo que sugiere una separación de fases o estratificación de las películas, tal y como se describe en el Apartado IV.1.1.1. Además, en el caso de las películas con AO la migración del mismo se hizo evidente puesto que formó una capa de aceite en la superficie de las mismas.

El aspecto de la sección longitudinal de las películas varió con el contenido y tipo de AG. La homogeneidad de las películas mejoró al reducir el contenido en $\mathrm{AG}$, lo que pudo ser debido a un mayor contenido de HPMC en las formulaciones CA:AG 1:0,2. En cuanto al tipo de AG, las películas conteniendo $\mathrm{AE}$ mostraron un aspecto más homogéneo que las formuladas con los otros $A G$, lo que indica una mejor distribución de la CA en la matriz de HPMC. Las películas con AO y las películas AP 1:0,5 mostraron un aspecto heterogéneo, donde la fase opaca de lípido quedaba interrumpida por otra transparente de hidrocoloide. Al reducir el contenido en AP de la formulación las películas mostraron un aspecto homogéneo, lo que pudo ser debido al poder estabilizador de la HPMC, como se ha descrito previamente.

Las diferencias fisicoquímicas entre los AG estudiados, en cuanto a la longitud de cadena, grado de saturación y estado físico (Tabla III.2) pudieron afectar la capacidad emulsificante y estabilizante de los mismos. 
Algunos autores han descrito que las insaturaciones o dobles enlaces en las cadenas hidrocarbonadas de los AG modifican la estructura de los mismos y su capacidad para formar agregados. Las insaturaciones reducen la capacidad de rotación de los átomos de carbono de las cadenas hidrocarbonadas y producen un plegamiento de las mismas, lo que interfiere en la capacidad de éstos para organizarse y formar agregados estables. Sin embargo, los AG saturados presentan cadenas hidrocarbonadas lineales y con capacidad de rotación a nivel de sus enlaces simples, lo que facilita su organización y la formación de agregados estables (Gunstone y Padley, 1997; Garro, 1998). Por tanto, la insaturación de la molécula de AO pudo reducir su capacidad para organizarse y formar micelas estables en torno a las moléculas de CA, disminuyendo su capacidad emulsificante.

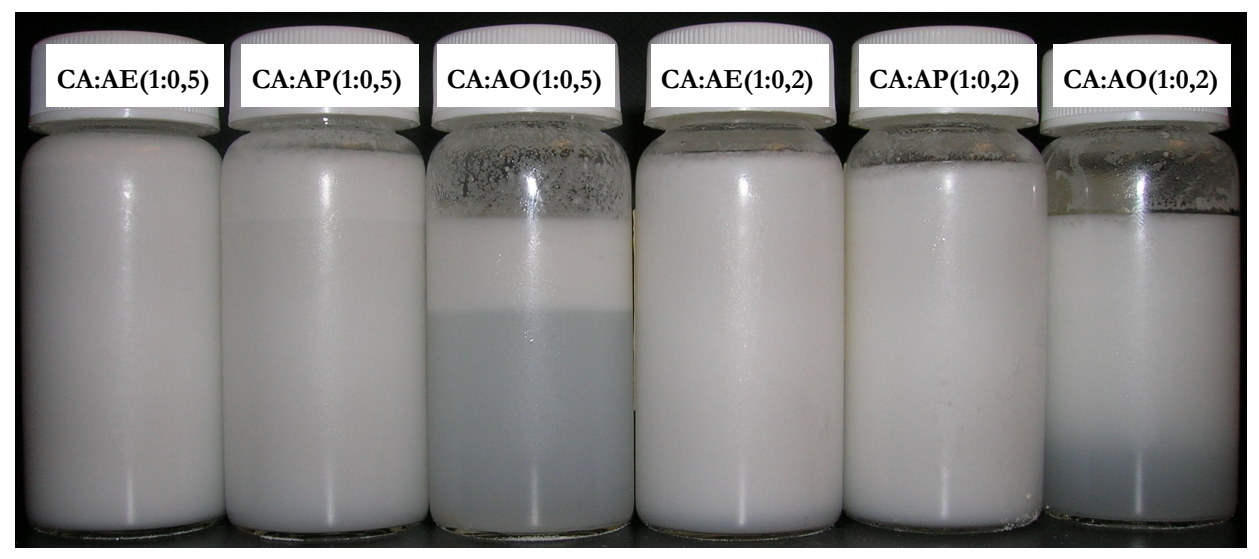

Figura IV.7. Efecto del tipo y contenido de AG de la formulación en el aspecto de las emulsiones. 


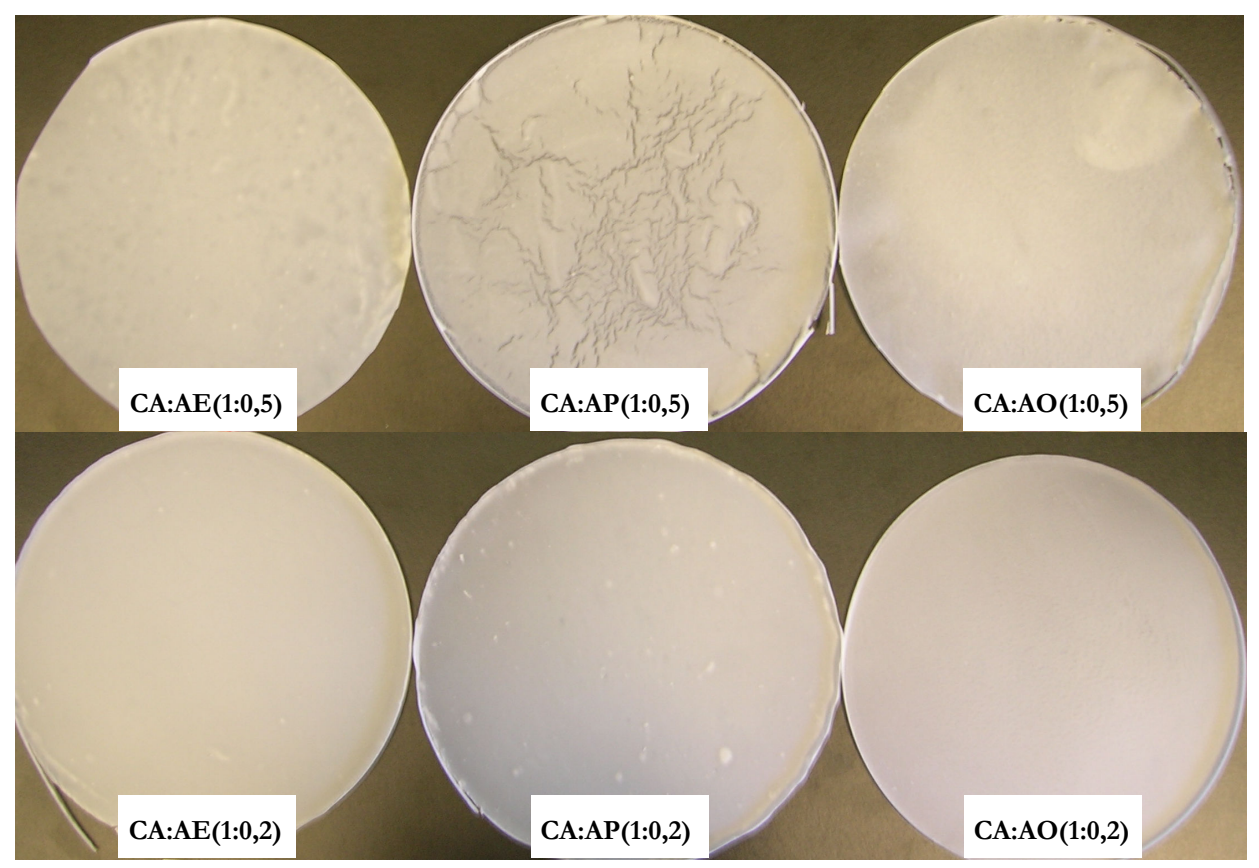

Figura IV.8. Efecto del tipo y contenido de AG de la formulación en el aspecto de las películas.

\section{IV.2.1.2. Propiedades mecánicas de las películas}

Las propiedades mecánicas determinan la funcionalidad de las películas y de los recubrimientos, puesto que afectan a su integridad física, resistencia a la manipulación y durabilidad en general. Además, en el caso de recubrimientos aplicados a frutas, las propiedades mecánicas afectan también a la capacidad de éstos para formar una capa continua sobre la superficie de las mismas, y a su habilidad para adaptarse a los cambios de volumen, tanto del fruto, como consecuencia de la deshidratación que experimentan, como del propio recubrimiento, debido a los cambios de temperatura a los que está expuesto (secado, refrigeración y acondicionamiento a $20^{\circ} \mathrm{C}$ ). Así por ejemplo, Karel et al. (1959), Labuza y Contreras-Medellin (1981), Kamper y Fennema (1985), Biquet (1987) y Debeaaufort et al. (1994) observaron que la dilatación y contracción de las películas debida a cambios de temperatura, producía fracturas y discontinuidades en las mismas, y Zabik y Dawson (1963) observaron la importancia de la flexibilidad de los recubrimientos aplicados a productos 
congelados en las propiedades barrera de los mismos.

Entre los distintos parámetros mecánicos analizados el Módulo de Young $(\mathrm{Y})$ representa la resistencia de las películas a la deformación, y es un indicador de la flexibilidad o rigidez de la mismas que proporciona una información relevante para predecir el comportamiento de los correspondientes recubrimientos. Valores altos de $\mathrm{Y}$ indican poca flexibilidad o ductilidad del recubrimiento, lo que puede dificultar la capacidad de adaptación de los mismos a los cambios de volumen del fruto a lo largo de su almacenamiento. La tenacidad ( $\mathrm{T}$ ) también aporta una información relevante dado que representa la energía de traccióndeformación que pueden absorber las películas sin llegar a fracturarse, lo que puede resultar interesante para predecir la resistencia de los recubrimientos a la manipulación mecánica. En el presente apartado se hará un análisis de estos parámetros mecánicos y de otros como la tensión máxima (TM), tensión a la rotura (TR) y porcentaje de elongación máximo $(\% \mathrm{E})$ para tener una visión más completa de las características de las películas y hacer una mejor aproximación de las propiedades mecánicas de los correspondientes recubrimientos.

La Figura IV. 5 muestra las propiedades mecánicas de las películas al variar el tipo y contenido de AG de su formulación. En ella se observa que ambas variables afectaron el comportamiento mecánico de las películas. Las películas con AE mostraron mayores valores de Y, T, TM y TR que las películas con AP, y estas, a su vez, mayores que las películas con AO. El efecto del tipo de AG en el \%E de las películas varió con las proporción CA:AG de las mismas. Para una proporción CA:AG de 1:0,5 las películas con AE y AP mostraron un \%E similar, y menor a la de las películas con AO. Para una proporción CA:AG de 1:0,2 se observó un efecto contrario. Las películas con $\mathrm{AE}$ fueron, por tanto, fuertes y poco dúctiles, las películas con $\mathrm{AO}$ fueron, en cambio, fácilmente deformables y extensibles y las películas con AP mostraron propiedades mecánicas intermedias. De éstos resultados se puede predecir un mejor comportamiento de los recubrimientos con $\mathrm{AO}$ respecto a los recubrimientos con $\mathrm{AP}$ y $\mathrm{AE}$, respectivamente, presentando mayor adaptabilidad a los cambios de volumen del fruto durante el almacenamiento. Los recubrimientos con AE pueden, sin embargo, resultar más rígidos y menos adaptables al fruto. 
Una reducción en el contenido en AE aumentó la T y el \% $\mathrm{E}$ y no fue significativo para el resto de atributos, lo que sugiere que este AG no ejerce un efecto plastificante en las películas. Una reducción en el contenido de AP aumentó todos los parámetros salvo la TR, que no varió significativamente. Una reducción en el contenido de AO aumentó el Y, la TM y la TR, redujo el \% y no modificó la T, lo que indica, claramente, el efecto plastificante del $\mathrm{AO}$ en las películas.

En 'películas emulsionadas' las moléculas de lípido dispersas en la matriz de hidrocoloide interrumpen la continuidad de la misma, modificando las propiedades mecánicas de la película. En general, las discontinuidades que produce el lípido en la matriz de hidrocoloide son puntos de fractura que reducen la resistencia de la película a la tracción (Shellhammer y Krochta, 1997; Pérez-Gago y Krocha, 2001; Petersson y Stading 2005). Sin embargo, el efecto de los lípidos en el resto de propiedades mecánicas de las películas (\% $\%$ y T) varía con el tipo de lípido y proporción. Algunos lípidos, como la CA, que presentan carácter viscoelástico, forman películas de mayor flexibilidad y extensibilidad que otros lípidos, como la cera carnauba, que presentan mayor rigidez o resistencia a la deformación (Talens y Krochta, 2005). Los AG sus derivados y los aceites, aumentan la flexibilidad de las películas y, en algunos casos, son incorporados a las formulaciones como agentes plastificantes. Las propiedades mecánicas de los AG dependen, asimismo, de características como la longitud de su cadena. Así por ejemplo, Jongjareonrak et al. (2006) observaron que un aumento en la longitud de la cadena de los AG aumentaba el $\mathrm{Y}$ en películas de gelatina de pescado y AG o sucroésteres. En la presente experiencia la mayor longitud de la cadena hidrocarbonada del AE respecto al AP (Tabla III.2) podría explicar los mayores valores de $\mathrm{Y}$ de las películas de AE.

Además, otros autores han observado que las moléculas de plastificante no enlazadas a los hidrocoloides actúan como agentes lubricantes de las cadenas de hidrocoloide, mejorando la flexibilidad de los mimos (Doolittle, 1965; Sears y Darby, 1982) y algunos autores han observado que los aceites aportan un efecto lubricante a las películas de polisacáridos que mejora su elasticidad (Quezada-Gallo et al., 2000). Por tanto, las diferencias en el estado físico de los AG estudiados, de acuerdo con sus distintos puntos de fusión (Tabla III.2), pudo contribuir a las diferencias de elasticidad de las películas, mejorando en el caso de las que 
contenían $\mathrm{AO}$, que se encuentra en estado líquido a la temperatura de ensayo.
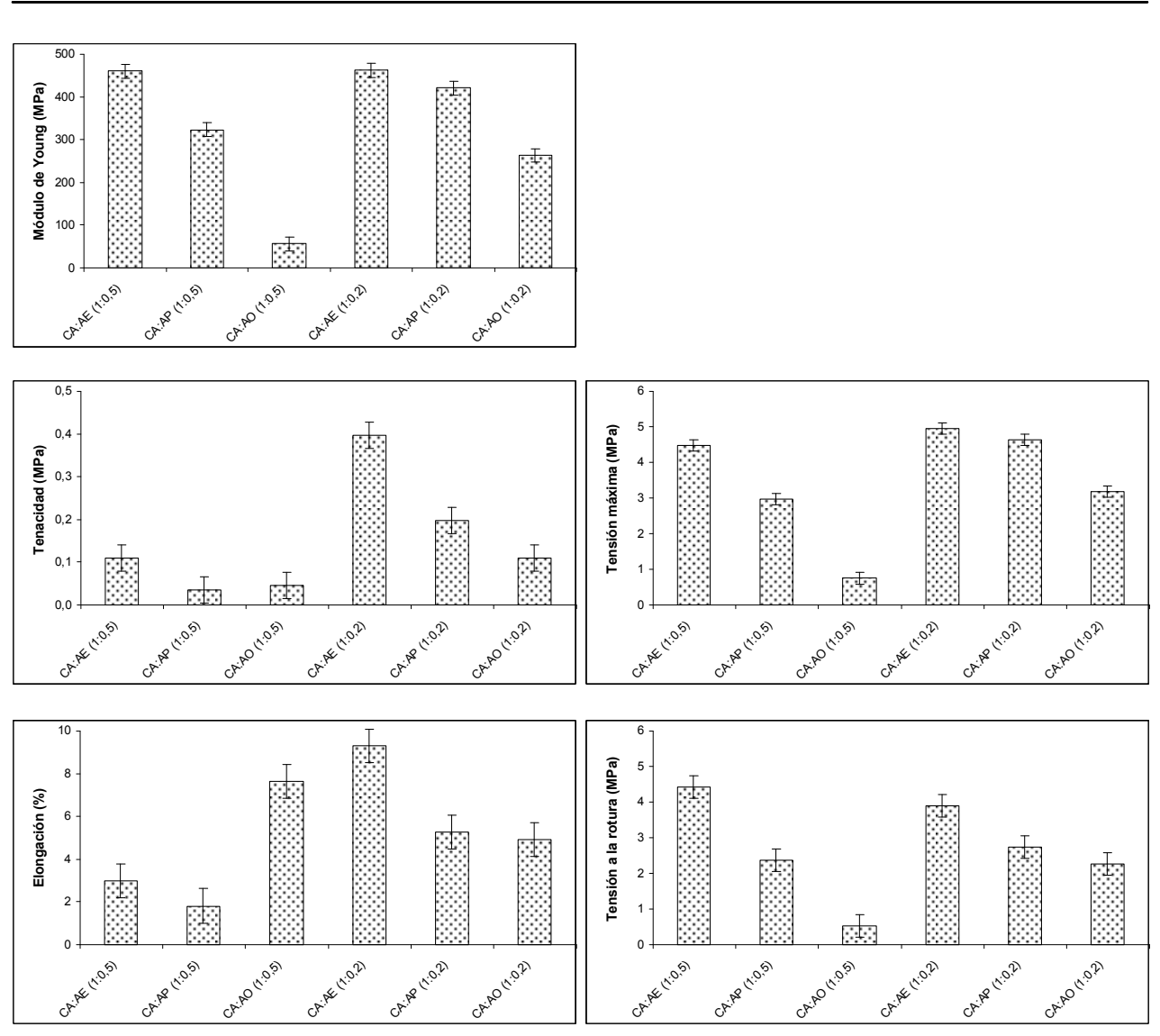

Las barras de error muestran valores de LSD (5\%).

Figura IV.9. Efecto del tipo y contenido de AG de la formulación en las propiedades mecánicas de las películas.

\section{IV.2.1.3. Permeabilidad al vapor de agua de las películas}

El tipo de AG tuvo un efecto en la PVA de las películas siendo máxima en las que contenían AE y mínima en que contenían AO. Sin embargo, la proporción de CA:AG no afectó la PVA de las películas, lo que indica que un aumento del $8 \%$ (b.s.) al 20\% (b.s.) en el contenido de 
AG no mejora las propiedades barrera de las películas estudiadas (Tabla IV.7).

A pesar de la mayor inestabilidad de las emulsiones con AO, la PVA de las películas con AO no varió con la orientación de las mismas y si varió en las películas con $\mathrm{AE}$ y $\mathrm{AP}$ cuyas emulsiones presentaron mayor estabilidad (Tabla IV.7). Los resultados indican que la estabilidad de las emulsiones no es el único factor que afecta la PVA de las películas resultantes ya que existen otros factores, como la continuidad de la fase lipídica formada, que afectan la PVA de la película resultante.

La polaridad, longitud de la cadena hidrocarbonada, el estado físico, el grado de saturación y el polimorfismo son algunas características de los lípidos que afectan la permeabilidad al vapor de agua de las películas. Asimismo, la distribución del lípido en las películas y las propiedades mecánicas de los lípidos afectan la PVA de las películas emulsionadas.

Estudios previos en películas a base de hidrocoloide y AG indican que una reducción de la longitud de la cadena hidrocarbonada y del grado de saturación del AG aumenta la PVA de las películas (Schultz et al., 1949; Kamper y Fennema, 1984a; Koelsch y Labuza, 1992; McHugh y Krochta, 1994a; Jongjareonrak et al., 2006). Sin embargo, en la presente experiencia el AO, que es insaturado, resultó más efectivo reduciendo la PVA de las películas que el resto de $A G$, que son saturados. Además, el AE que presenta mayor longitud de cadena que el AP dio películas de mayor PVA que éste.

Las diferencias entre los resultados observados en el presente trabajo y los obtenidos por otros autores se pueden atribuir, principalmente, al hecho de que en la presente experiencia, las formulaciones incluyeron CA como componente hidrofóbico mayoritario y el AG se incorporó en pequeñas cantidades con el objetivo de actuar como agente emulsificante de la formulación, mientras que en las formulaciones de otros autores el único componente hidrofóbico en la matriz de hidrocoloide fue el AG. De este modo, en la presente experiencia el AG, además de aportar cierta hidrofobicidad a las películas, ejerció una función más o menos emulsificante y estabilizante de las partículas de CA en la matriz de hidrocoloide, afectando la distribución de 
las mismas y las propiedades de PVA de las películas.

Según se ha descrito en el Apartado IV.2.1.1, el AO dio lugar a emulsiones de CA poco estables. Por tanto, la menor PVA de las películas con $\mathrm{AO}$ no se puede atribuir a una mejor distribución de la CA en la matriz de HPMC, lo que pone de manifiesto la existencia de otros factores involucrados en las PVA de las mismas. Shellhammer y Krochta (1997) observaron que los lípidos viscoelásticos como la cera de abeja, se pueden deformar durante la etapa de secado de la película, en la cual se da una retracción de la misma, produciendo películas homogéneas libres de microfracturas y mejorando resistencia a la difusión de agua. En la presente experiencia el $\mathrm{AO}$ mejoró la flexibilidad de las películas durante el secado, evitando la formación de microfracturas y mejorando las propiedades barrera de las películas (Figura IV.9). Además, la formación de una capa de aceite superficial en las películas con AO, pudo sellar las discontinuidades de las películas y ejercer una barrera a la difusión de agua en las zonas de la película desprovistas de CA, mejorando así las propiedades barrera al vapor de agua de las mismas.

Tabla IV.7. Efecto del tipo y contenido de AG de la formulación en la PVA de las películas

\begin{tabular}{ccc}
\hline Formulación & \multicolumn{2}{c}{ PVA $\left(\mathrm{g} \mathrm{mm} / \mathrm{KPa} \mathrm{h} \mathrm{m}^{2}\right)$} \\
\cline { 2 - 3 } & \multicolumn{1}{c}{$\mathrm{p}^{\mathrm{z}}$} & $\mathrm{down}{ }^{\mathrm{z}}$ \\
\hline CA:AE $(1: 0,5)$ & $6,90 \mathrm{bc} \mathrm{B}$ & $5,57 \mathrm{c} \mathrm{A}$ \\
CA:AP $(1: 0,5)$ & $5,97 \mathrm{~b} \mathrm{~B}$ & $5,02 \mathrm{~b} \mathrm{~A}$ \\
CA:AO $(1: 0,5)$ & $1,85 \mathrm{a} \mathrm{ns}$ & $1,24 \mathrm{a} \mathrm{ns}$ \\
CA:AE $(1: 0,2)$ & $7,43 \mathrm{c} \mathrm{B}$ & $4,82 \mathrm{~b} \mathrm{~A}$ \\
CA:AP $(1: 0,2)$ & $6,40 \mathrm{bc} \mathrm{B}$ & $4,53 \mathrm{~b} \mathrm{~A}$ \\
CA:AO $(1: 0,2)$ & $2,17 \mathrm{a} \mathrm{ns}$ & $1,43 \mathrm{a} \mathrm{ns}$ \\
\hline
\end{tabular}

Z Orientación de la película durante la determinación de la PVA en función de la posición de secado en placa.

Por columnas, valores de PVA seguidos de la misma letra minúscula no difieren significativamente $(\mathrm{p}<0,05)$.

Por filas, valores de PVA seguidos de la misma letra mayúscula no difieren significativamente $(\mathrm{p}<0,05)$. 


\section{IV.2.2. Análisis de calidad de las ciruelas 'Angeleno' recubiertas}

\section{IV.2.2.1. Pérdida de peso}

En general, no se observaron diferencias de pérdida de peso entre los tratamientos (no se muestran datos). La aplicación de recubrimientos hidrofóbicos en la superficie de los frutos aporta una barrera adicional a la deshidratación, que se suma a la barrera que ejerce la propia piel de las frutas y a las ceras naturales presentes en la misma (Baldwin, 1997). Sin embargo, los recubrimientos estudiados no redujeron la pérdida de peso. Este resultado se contrapone al obtenido en experiencias anteriores (Tabla IV.2) dónde se observó que recubrimientos de similar composición a los estudiados en esta experiencia $(40 \% \mathrm{CA})$ fueron efectivos reduciendo la pérdida de peso de las ciruelas recubiertas. La afinidad química de las emulsiones de recubrimiento y las ceras naturales de las ciruelas pudo favorecer, en este caso, la disolución y eliminación parcial de las mismas durante la etapa de aplicación de los recubrimientos. En este supuesto, los recubrimientos habrían reemplazado las ceras naturales ejerciendo una barrera a la difusión de agua similar a la de éstas. Además, la alta HR $(90 \%)$ durante el almacenamiento de las ciruelas pudo aumentar la PVA de los recubrimientos ya que éstos contienen componentes hidrofílicos (HPMC y G) en su formulación (McHugh et al., 1993; McHugh y Krochta, 1994d).

Otros autores han obtenido resultados similares a los observados en ésta experiencia. Así por ejemplo, Baldwin et al. (1997) observaron que la aplicación de recubrimientos comestibles a base de HPC y aceite de soja o cera carnauba no reducía la pérdida de peso de cerezas recubiertas. Bai et al. (2002) observaron que recubrimientos a base de cera carnauba y polisacárido no reducían la pérdida de peso de manzanas 'Red delicious' y Erbil et al. (1986) observaron un incremento de pérdida de peso en melocotones a los que se aplicó recubrimientos a base de CMC y aceite de coco.

El tipo de AG de la formulación afectó la PVA de las películas aisladas (Tabla IV.7). Sin embargo, no afectó la barrera al vapor de agua de los recubrimientos. En la calidad postcosecha de los frutos recubiertos, además de las propiedades de la película de recubrimiento intervienen otros factores como las características del fruto y las condiciones de 
almacenamiento. La HR de ambos ensayos (PVA de la película y pérdida de peso de las ciruelas recubiertas) varió, siendo mayor en el caso de los recubrimientos. Esto pudo incrementar la PVA de los recubrimientos disipando el efecto de los AG en la PVA de los mismos.

\section{IV.2.2.2. Intensidad respiratoria}

No se observó una disminución de la IR en los frutos recubiertos ni tampoco un efecto del tipo y contenido de AG en la IR de las ciruelas para los distintos periodos de almacenamiento ensayados (no se muestran datos).

En general, la aplicación de recubrimientos a frutas crea una barrera semipermeable a los gases $\mathrm{CO}_{2}$ y $\mathrm{O}_{2}$ que reduce la IR de las mismas (Banks et al., 1993; Cisneros-Zevallos y Krochta, 2002). Sin embargo, esto no siempre se observa en frutos recubiertos dado que la aplicación de los mismos conlleva una manipulación del fruto que puede generar un estrés y aumento en la IR (Rojas, 2002).

\section{IV.2.2.3. Sólidos solubles totales, acidez e índice de madurez}

Al prolongar el almacenamiento se observó una reducción de la acidez y un aumento del IM, manteniéndose el contenido en sólidos solubles (no se muestran datos). En general, no hubo diferencias de estos parámetros entre tratamientos lo que se corresponde con los resultados de IR observados.

\section{IV.2.2.4. Contenido de $\mathrm{CO}_{2}$ y $\mathrm{O}_{2}$ interno}

Durante la respiración, el fruto consume el $\mathrm{O}_{2}$ presente en el interior del mismo y genera $\mathrm{CO}_{2}$, lo que empobrece en $\mathrm{O}_{2}$ la atmósfera interna del fruto y la enriquece en $\mathrm{CO}_{2}$. De ésta manera, se establece un gradiente de concentración de ambos gases entre la atmósfera interna del fruto y la atmósfera que rodea al mismo, que genera un flujo de ambos gases a través de la piel del fruto, entrando $\mathrm{O}_{2}$ al interior del mismo y saliendo $\mathrm{CO}_{2}$. Los recubrimientos aplicados en la superficie de los frutos, aportan una barrera adicional a los gases $\mathrm{CO}_{2}$ y $\mathrm{O}_{2}$ que afecta el transporte de éstos, modificándolo en mayor o menor medida en función de las características de los mismos (composición, grosor, habilidad sellando las 
rutas de paso de los gases, etc.).

La Figura IV.10 muestra el contenido de $\mathrm{CO}_{2}$ y $\mathrm{O}_{2}$ interno de las ciruelas 'Angeleno' recubiertas y control. Las ciruelas recubiertas mostraron mayor contenido de $\mathrm{CO}_{2}$ interno y menor contenido de $\mathrm{O}_{2}$ que los frutos control lo que indica que los recubrimientos ejercieron una barrera a los gases $\mathrm{CO}_{2} \mathrm{y} \mathrm{O}_{2}$. Aunque existieron diferencias en los niveles de $\mathrm{CO}_{2} \mathrm{y} \mathrm{O}_{2}$ en los frutos recubiertos con las distintas formulaciones no se observó una tendencia en función del tipo y contenido de AG para los distintos periodos de almacenamiento ensayados. Por tanto, a partir de los resultados obtenidos es difícil definir el efecto del tipo y contenido de AG de las formulaciones en la atmósfera interna del fruto. En general, el recubrimiento de CA:AP $(1: 0,5)$ fue el que mayor nivel de $\mathrm{CO}_{2}$ interno proporcionó. 

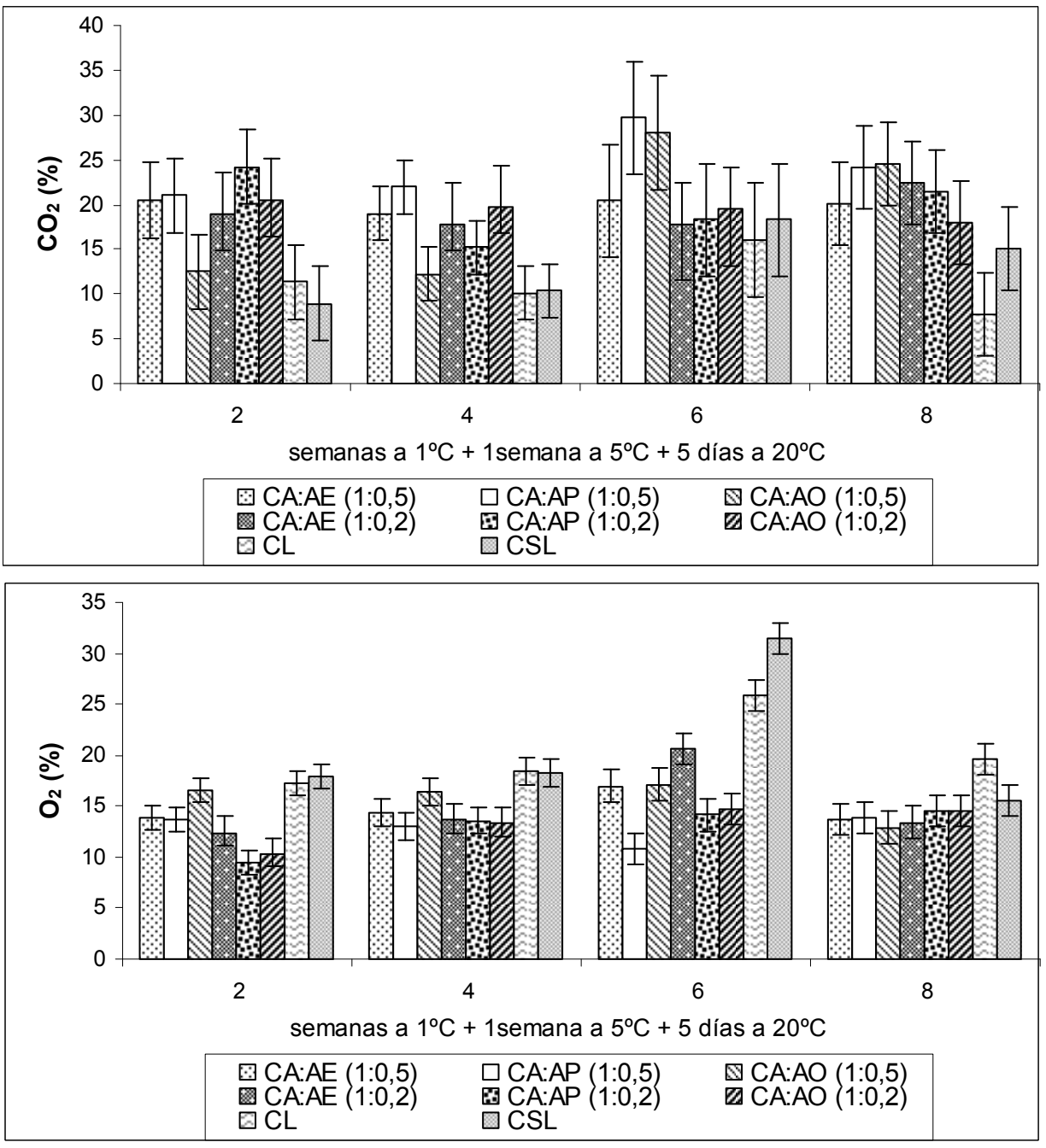

Las barras de error muestran valores de LSD (5\%).

Figura IV.10. $\mathrm{CO}_{2}$ y $\mathrm{O}_{2}$ interno de ciruelas 'Angeleno' recubiertas y control: efecto del tipo y contenido de AG del recubrimiento. 


\section{IV.2.2.5. Etanol y acetaldehído en zumo}

A pesar de que los recubrimientos produjeron una modificación en la atmósfera interna del fruto, no hubo un incremento significativo de los niveles de etanol y acetaldehído en los frutos recubiertos respecto a los frutos control. El tipo y contenido de AG del recubrimiento no afectó los niveles de estos componentes en el zumo de las ciruelas (no se muestran datos).

\section{IV.2.2.6. Firmeza}

En general, los recubrimientos fueron efectivos reduciendo la pérdida de firmeza de las ciruelas. Sin embargo, no se observó un efecto del tipo y contenido de AG en la firmeza. En general, los recubrimientos CA:AO (1:0,5) y CA:AE (1:0,2) fueron los más efectivos, reteniendo la firmeza hasta un $11 \%$ con respecto a los frutos control al cabo de 8 semanas de frigoconservación (Figura IV.11).

La retención de firmeza observada en las ciruelas 'Angeleno' recubiertas se puede atribuir a la modificación de la atmósfera interna inducida por los recubrimientos (Figura IV.10). Los recubrimientos comestibles permiten controlar la respiración y senescencia de forma similar a las atmósferas modificadas creando una modificación de la atmósfera interna del fruto que ralentiza los procesos de senescencia en general (Artés, 2006) y el ablandamiento de la pulpa en particular (Couey, 1960, 1965; Smith, 1967; Ke et al., 1991; Ben y Gaweda, 1992). 


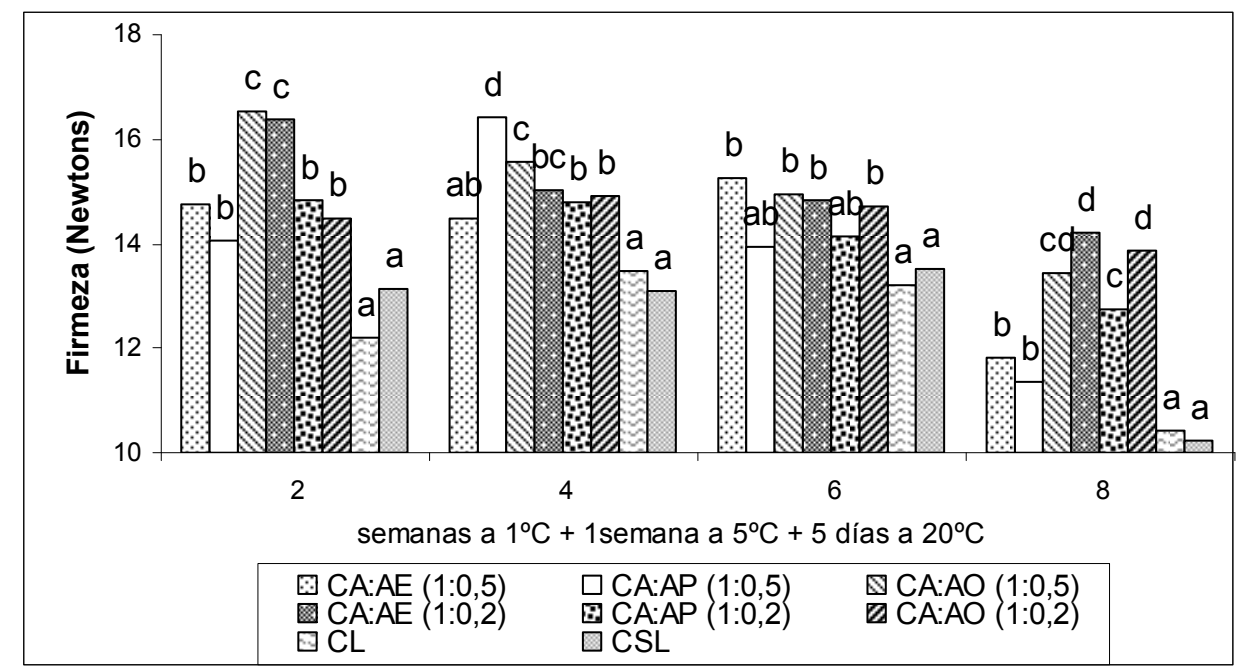

En cada periodo de almacenamiento, valores seguidos de la misma letra no difieren significativamente $(\mathrm{p}<5 \%)$.

Figura IV.11. Firmeza de ciruelas 'Angeleno' recubiertas y control: efecto del tipo y contenido de AG del recubrimiento.

\section{IV.2.2.7. Desórdenes fisiológicos}

Las ciruelas presentaron desórdenes de la pulpa que se manifestaron como pigmentación roja o 'bleeding', pardeamiento y vitrescencia, y que en general aumentaron al prolongar el almacenamiento. En la mayoría de los casos estos desórdenes aparecieron de forma simultánea, lo cual dificultó su cuantificación, especialmente el pardeamiento que se vió enmascarado por la pigmentación roja o 'bleeding'. No se observó una pérdida importante de jugosidad por harinosidad o acorchado de la pulpa (no se muestran datos).

Los daños más importantes fueron por 'bleeding', que en algunos tratamientos fueron moderados (Figura IV.12). Los recubrimientos redujeron esta lesión a partir de 4 semanas de frigoconservación. El tipo y contenido de AG del recubrimiento no tuvo un efecto en la incidencia de esta lesión.

La lesión por 'bleeding' consiste en una deslocalización de los pigmentos por pérdida de la integridad celular. Se atribuye a la senescencia 
del fruto correlacionándose inversamente con el contenido de ácidos orgánicos del tejido (Lurie y Crisosto, 2005) y previniéndose con las atmósferas controladas (Laurie et al., 1992; Retamales et al., 1992). Por tanto, el efecto de los recubrimientos reduciendo la incidencia de esta lesión pudo ser debido a la modificación de la atmósfera interna inducida por los recubrimientos y a la retención de firmeza.

La incidencia de desórdenes asociados a bajas temperaturas de almacenamiento (pardeamiento y vitrescencia de la pulpa) fue mínima y no se observó un efecto de los recubrimientos reduciendo los mismos (no se muestran datos). En ciruelas 'Angleno' las lesiones por frío tienen lugar a temperaturas en torno a los $5{ }^{\circ} \mathrm{C}$ y se manifiestan tras un periodo de acondicionamiento del fruto a temperaturas en torno a los $20{ }^{\circ} \mathrm{C}$ (Ceretta et al., 2000; Crisosto y Kader, 2004). En esta experiencia las ciruelas se sometieron a un periodo de almacenamiento a temperatura 'letal' $\left(5{ }^{\circ} \mathrm{C}\right)$ durante 1 semana, con el objetivo de inducir los daños por frío. Tras este periodo de inducción de los daños, las ciruelas se almacenaron a $20{ }^{\circ} \mathrm{C}$ durante 5 días, con el objetivo de que los daños producidos se manifestaran. Sin embargo, no se observaron daños, lo que pudo ser debido a que tanto el periodo de inducción a $5{ }^{\circ} \mathrm{C}$ como el periodo a $20^{\circ} \mathrm{C}$ fuera insuficiente para la producción y/o manifestación de daños. PérezGago et al. (2003a) observaron un bajo índice de daños por frío en ciruelas 'Otoño Gigante' almacenadas 3 días a temperaturas no óptimas de conservación $\left(5{ }^{\circ} \mathrm{C}\right)$ seguido de 1 día a $20^{\circ} \mathrm{C}$, sin observar diferencias significativas entre ciruelas recubiertas y control. Sin embargo, al prolongar el almacenamiento a $20^{\circ} \mathrm{C}$ hasta 25 días, los daños por frío se hicieron más acusados observándose una reducción significativa de los mismos en los frutos recubiertos respecto a los control sin recubrir. 


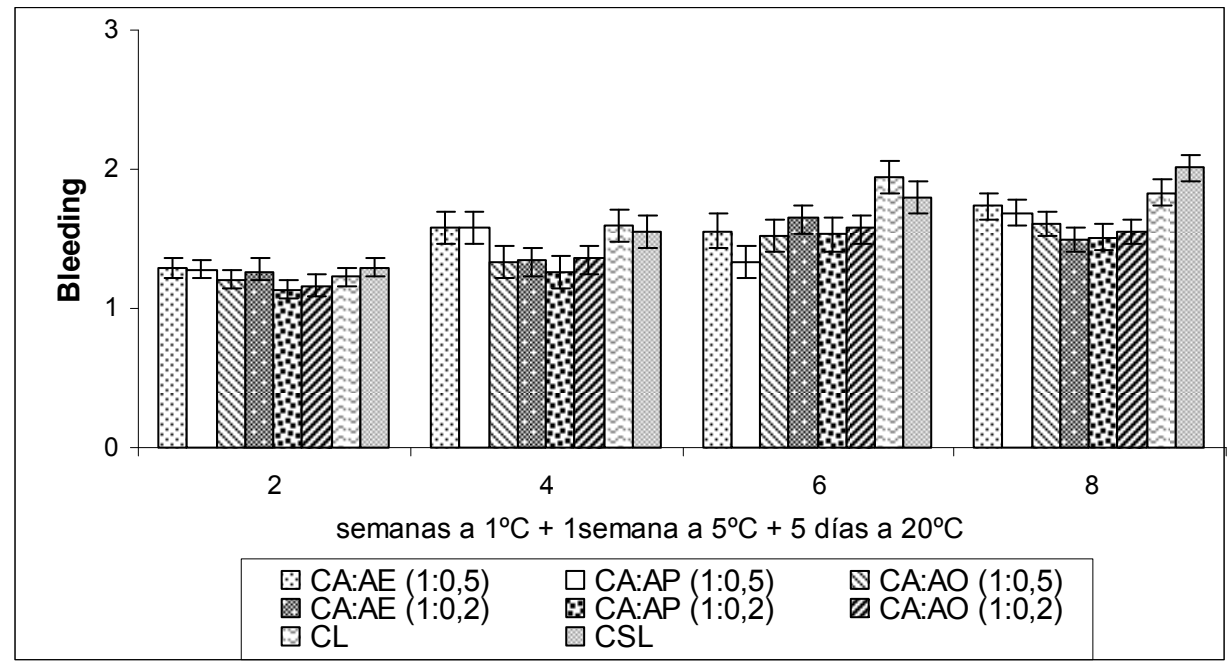

Las barras de error muestran valores de LSD (5\%).

Figura IV.12. Daños por 'bleeding' de ciruelas 'Angeleno' recubiertas y control: efecto del tipo y contenido de AG del recubrimiento.

\section{IV.2.2.8. Color}

El color de las ciruelas evolucionó al prolongar el almacenamiento desde tonos rojos a violetas disminuyendo el ángulo de tono (Figura IV.13). No se observó una evolución de la luminosidad (Figura IV.13) ni del croma (no se muestran datos) con el tiempo. La aplicación de recubrimientos preservó la luminosidad de las ciruelas a partir de 6 semanas de frigocoservación, evitando el oscurecimiento de las mismas pero no modificó el resto de atributos de color. El tipo de AG del recubrimiento afectó la luminosidad de los frutos, siendo el AO el que proporcionó menores valores de este, pero no afectó el resto de atributos de color. El contenido de AG del recubrimiento no modificó el color de las ciruelas. 


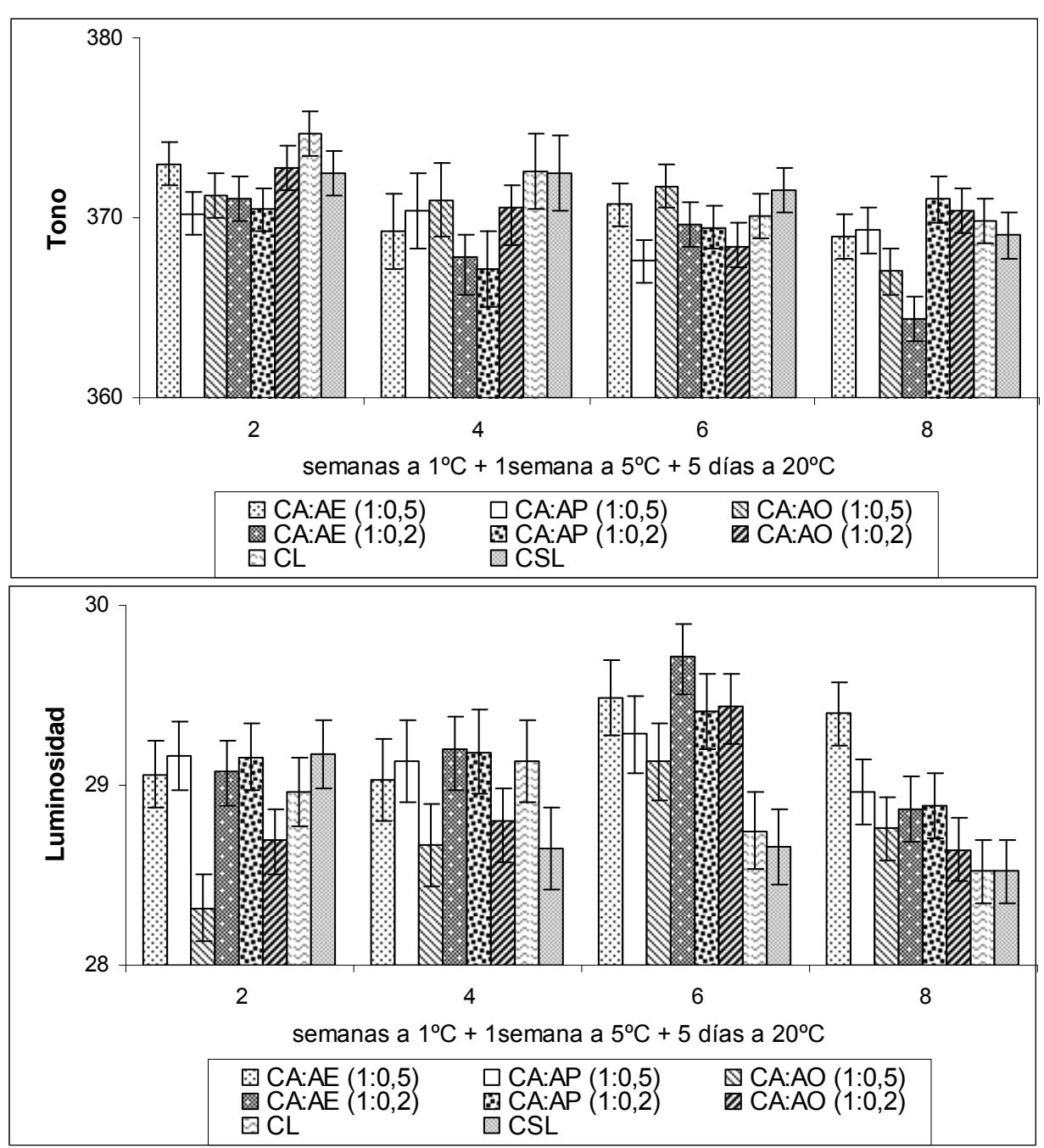

Las barras de error muestran valores de LSD (5\%).

Figura IV.13. Tono y luminosidad de ciruelas 'Angeleno' recubiertas y control: efecto del tipo y contenido de AG del recubrimiento. 


\section{IV.2.2.9. Evaluación organoléptica: 'flavor’ y textura}

$\mathrm{Ni}$ el 'flavor', ni la textura de las ciruelas cambiaron sustancialmente a lo largo del almacenamiento. En general, no se observaron diferencias en el 'flavor' y la textura entre tratamientos (Figura IV.14) Los niveles de etanol y acetaldehído fueron similares entre tratamientos lo que puede explicar la similitud de 'flavor' entre tratamientos. Sin embargo, la retención de firmeza instrumental observada en los frutos recubiertos (Figura IV.11) no fue detectada en el análisis organoléptico. 

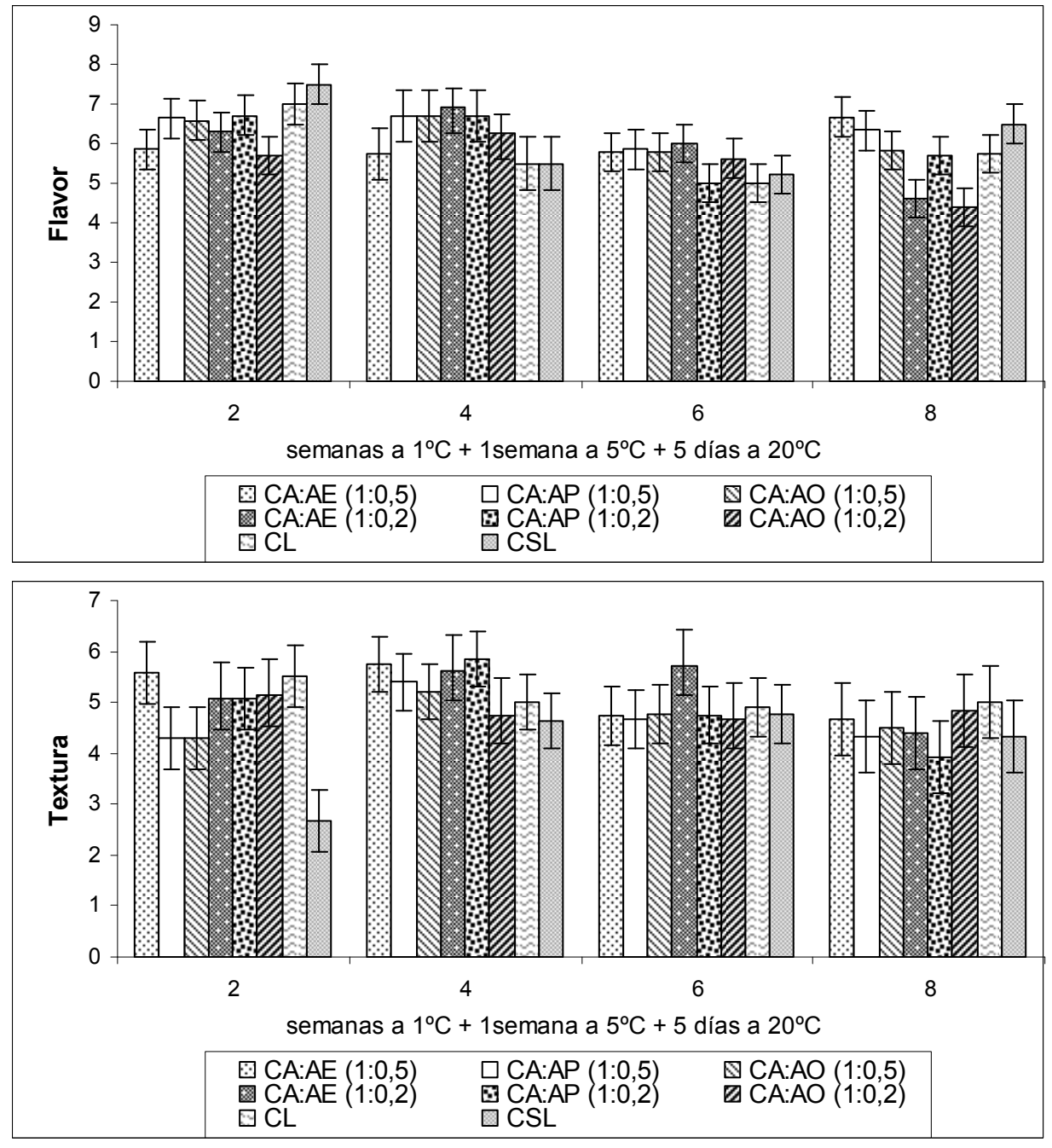

Las barras de error muestran valores de LSD (5\%).

Figura IV.14. 'Flavor' y textura de ciruelas 'Angeleno' recubiertas y control: efecto del tipo y contenido de AG del recubrimiento. 


\section{IV.2.2.10. Aspecto externo y brillo del fruto}

Los frutos presentaron un aspecto turgente y sin arrugas incluso tras un almacenamiento prolongado. Se observó el manchado característico de la piel de las ciruelas que proporciona un aspecto blanquecino y mate de las mismas. Sin embargo, este manchado fue menos evidente en los frutos CL y en aquellos a los que se aplicó recubrimientos con $\mathrm{AO}$. Las diferencias de aspecto descritas se tradujeron en una mayor puntuación de aspecto y brillo de los tratamientos CL, CA:AO $(1: 0,5)$ y CA:AO $(1: 0,2)$ respecto al resto de tratamientos. El resto de tratamientos, aunque obtuvieron menores puntuaciones de aspecto, fueron valorados con una calidad aceptable. Los resultados indican que los recubrimientos con $\mathrm{AO}$ mejoraron el aspecto de las ciruelas respecto a las ciruelas CSL, mientras que el resto de recubrimientos no modificaron el aspecto de las ciruelas respecto a las CSL. Los frutos CSL obtuvieron puntuaciones de brillo similares a los tratamientos CL, CA:AO $(1: 0,5)$ y CA:AO (1:0,2) (Figura IV.15).

El lavado de los frutos pudo eliminar parcialmente la pruína de las ciruelas reduciendo el manchado de las mismas. En cuanto a los resultados obtenidos en ciruelas recubiertas, éstos se pueden relacionar con las características de las emulsiones y de las películas. Como se describe en el apartado IV.2.1.1, las emulsiones de recubrimiento tuvieron un aspecto turbio y de color blanco y proporcionaron películas blancas y opacas, lo que podría explicar el ligero manchado de las ciruelas recubiertas. Todas las películas salvo las de $\mathrm{AO}$ mostraron un aspecto mate en la cara en contacto con el aire durante el secado. Las películas con AO presentaron una capa superficial de aceite, lo que explicaría el aumento del brillo en ciruelas a las que se aplicó los recubrimientos con AO. 

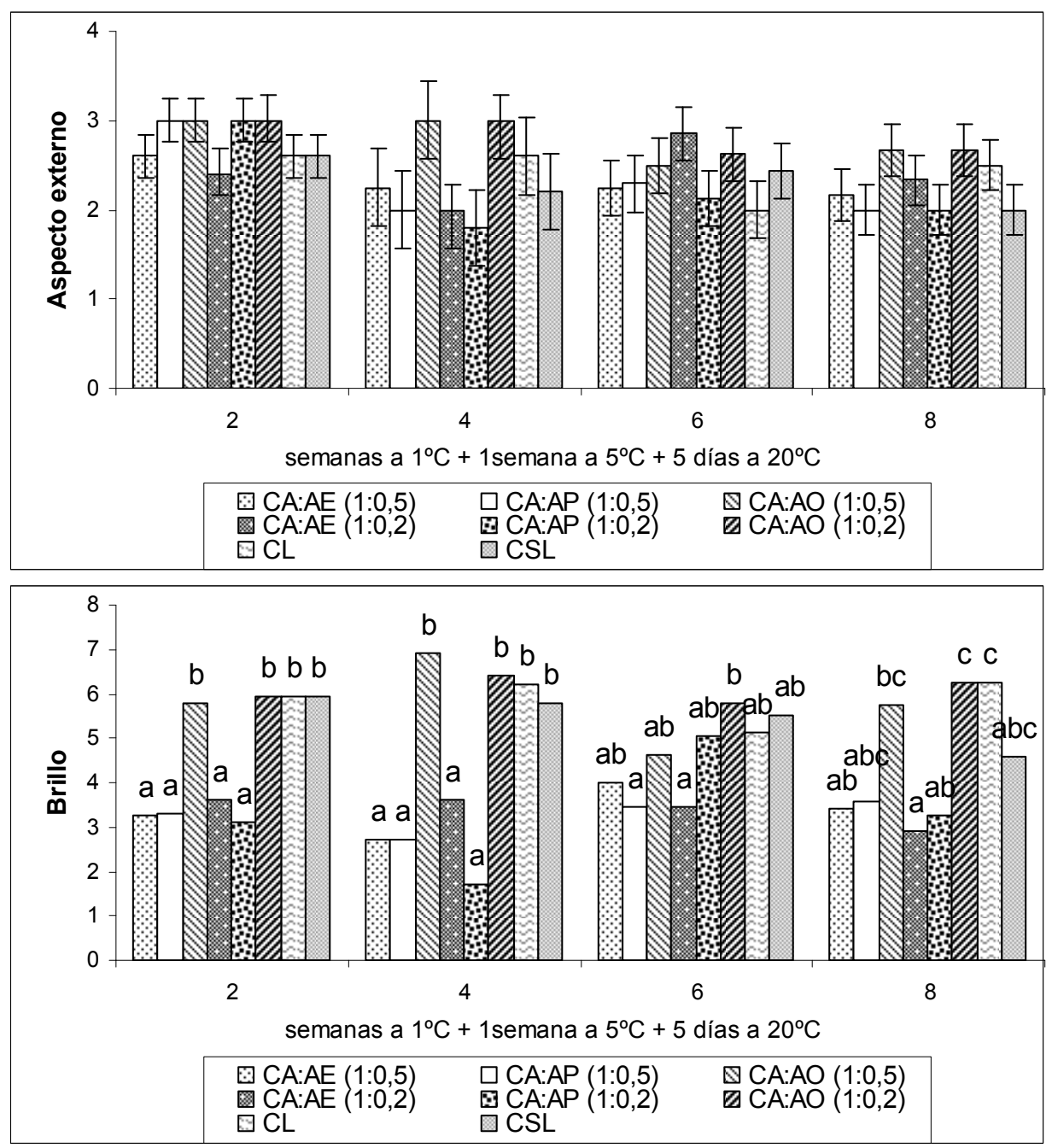

Las barras de error muestran valores de LSD (5\%).

En cada periodo de almacenamiento, valores seguidos de la misma letra no difieren significativamente $(\mathrm{p}<5 \%)$.

Figura IV.15. Aspecto externo y brillo de ciruelas 'Angeleno' recubiertas y control: efecto del tipo y contenido de AG del recubrimiento. 


\section{IV.2.3. Síntesis de resultados}

El objetivo de la presente experiencia fue estudiar el efecto del tipo y contenido de AG de recubrimientos compuestos a base de HPMC y CA en la calidad postcosecha de ciruelas cv. 'Angeleno'. Para ello se estudió el efecto de estos factores en las propiedades de películas aisladas y se evaluaron distintos parámetros de calidad de las ciruelas recubiertas, comparándolas con frutas control. A continuación se hace un resumen de los resultados más relevantes.

El tipo y contenido de $A G$ afectó las propiedades mecánicas y la barrera al vapor de agua de las películas aisladas. De los AG estudiados (AE, AP y AO), el AO proporcionó películas con mayor flexibilidad y mayor barrrera al vapor de agua. El estado líquido del AO pudo ejercer un efecto lubricante, mejorando la flexibilidad de las películas, y pudo facilitar el sellado de discontinuidades de las películas por las que iene lugar la difusión de vapor de agua.

Los recubrimientos no fueron efectivos reduciendo la pérdida de peso de las ciruelas pero produjeron una modificación de la atmósfera interna de las mismas que mejoró su firmeza y redujo la incidencia de 'bleeding'. Los recubrimientos no afectaron al 'flavor' de las ciruelas, pero si al aspecto externo y al brillo de las mismas. De los AG estudiados, el $\mathrm{AO}$ fue el que proporcionó mejor aspecto y mayor brillo. Las proporciones de AG estudiadas no afectaron la calidad de las ciruelas recubiertas. El resto de atributos de calidad de las ciruelas estudiados (pérdida de peso, contenido de etanol y acetaldehído en zumo, 'bleeding', 'flavor' y textura) no se vieron afectados por el tipo y contenido de AG del recubrimiento. 


\section{IV.3. EFECTO DEL TIPO Y CONTENIDO DE PLASTIFICANTE Y DEL CONTENIDO EN CERA DE ABEJA DE LA FORMULACIÓN EN LAS CARACTERÍSTICAS DE LAS PELÍCULAS Y EN LA CALIDAD POSTCOSECHA DE CIRUELAS ‘ANGELENO’ RECUBIERTAS}

IV.3.1. Análisis de las emulsiones y de las películas preformadas en placa

\section{IV.3.1.1. Aspecto de las emulsiones y de las películas}

Todas las formulaciones proporcionaron emulsiones opacas de color blanco, aspecto homogéneo, y estables a las 24 h de su elaboración. Las películas resultantes mostraron un aspecto mate en la cara expuesta al aire durante el secado y un aspecto brillante en la cara expuesta a la placa durante el secado, lo que indicó una estratificación de las mismas o separación de fases. Además, el aspecto de la cara expuesta al aire durante el secado varió con el tipo y contenido de plastificante (Figura IV.16). Las películas que contenían $\mathrm{G}$ mostraron un aspecto homogéneo cuando se formularon al $20 \%$ de CA y presentaron pequeños agregados de CA cuando se formularon al 40\% de CA. Las películas que contenían M mostraron una cristalización del mismo que pudo ser debida a una incompatibilidad del M con la matriz de HPMC. Zhang y Han (2006) observaron que para evitar la separación y cristalización de los plastificantes, estos deben tener cierto grado de interacción con la matriz de hidrocoloide, estableciendo puentes de hidrógeno u otro tipo de enlaces. En nuestra experiencia es probable que la interacción entre el M y el HPMC no fuera suficientemente importante como para evitar la separación y cristalización del M. Además, algunos autores han observado que las condiciones de almacenamiento de las películas pueden promover la migración y cristalización de los plastificantes sólidos (Sothornvit y Krochta, 2000). En la presente experiencia las condiciones de almacenamiento empleadas $\left(23 \pm 2{ }^{\circ} \mathrm{C}\right.$ y $\left.50 \pm 1 \% \mathrm{HR}\right)$ pudieron promover al cristalización del $\mathrm{M}$. 

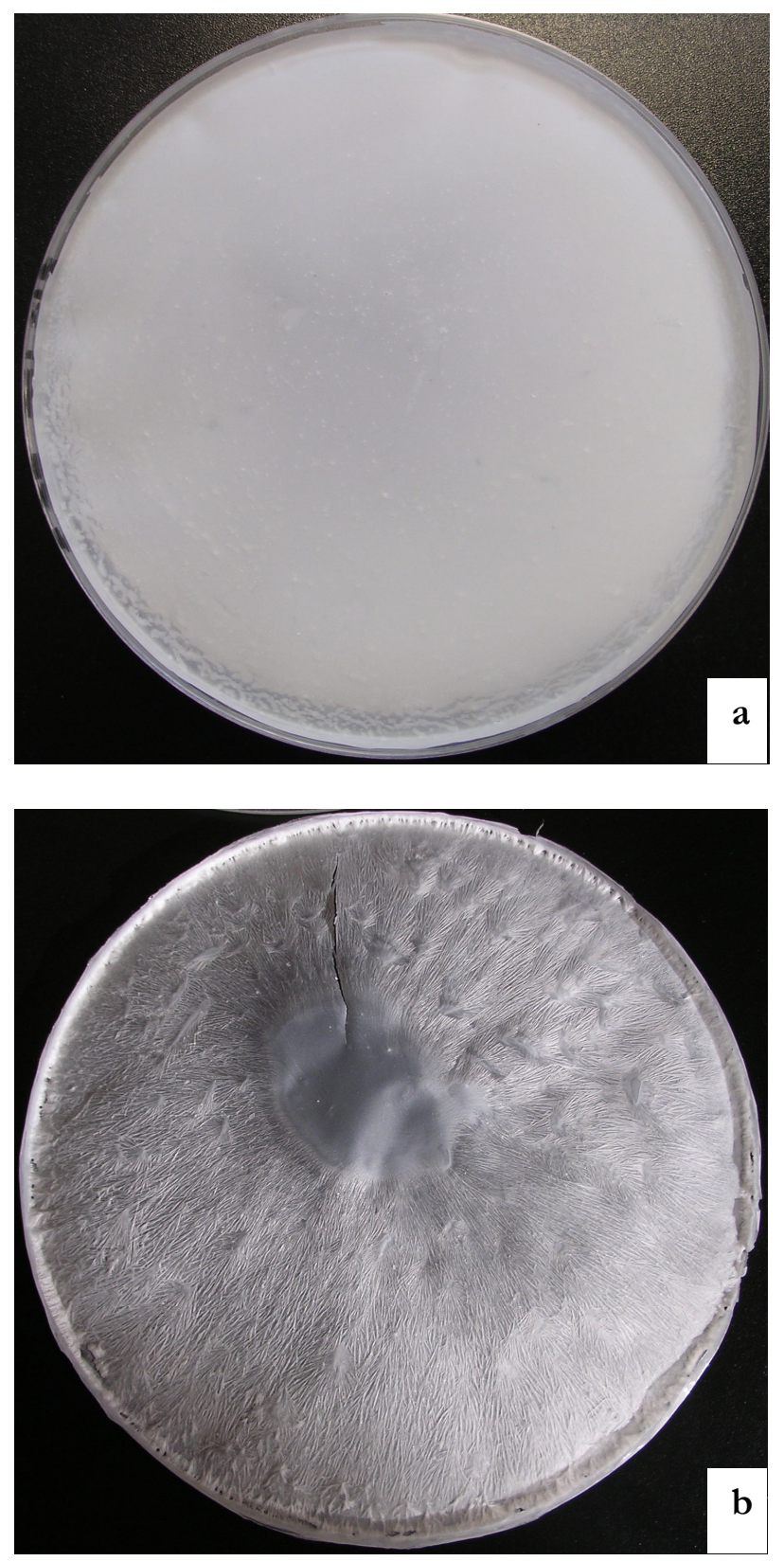

Figura IV.16. Efecto del tipo de plastificante en el aspecto de las películas: (a) $20 \%$ CA-300G y (b) $20 \%$ CA-300M. 


\section{IV.3.1.2. Propiedades mecánicas de las películas}

La Figura IV.17 muestra las propiedades mecánicas de las películas objeto de estudio en la presente experiencia. En ella se observa que el tipo de plastificante tuvo un efecto en las propiedades mecánicas de las mismas. Las películas de $\mathrm{M}$ presentaron mayor $\mathrm{Y}$, menor $\% \mathrm{E}$ y $\mathrm{T}$, independientemente de la proporción HPMC:plastificante utilizada, y mayor TM y TR en películas con proporción HPMC:plastificante 1:100 que las películas de G. Las películas de M fueron, por tanto, fuertes, presentando una alta resistencia a la tracción mecánica, pero poco deformables y muy quebradizas. Las películas de $G$, en cambio, fueron menos fuertes pero más dúctiles, extensibles y tenaces. Estos resultados indican que el $G$ puede formar recubrimientos más flexibles y menos fracturables que el M, lo que puede mejorar la continuidad de los mismos en la superficie de los frutos.

La habilidad de los plastificantes para romper los enlaces entre las cadenas de polímero y para atraer agua al sistema plastificante-hidrocoloide depende de la naturaleza química, tamaño, forma, polaridad, longitud de cadena, estado físico y numero de grupos funcionales del plastificante capaces de interaccionar con el polímero. Estas características pudieron ser, por tanto, las responsables del distinto comportamiento del G y M (Tabla III.4).

La estructura molecular de los plastificantes utilizados en nuestra experiencia es similar. Por tanto, las diferencias observadas entre ambos no se pueden atribuir a este factor. Sin embargo, el Pm, la afinidad por el agua y el estado físico de los mismos difiere para ambos plastificantes, lo que pudo tener un efecto en las propiedades mecánicas de las películas. Así, el menor Pm del G pudo mejorar la difusividad de éste en la matriz de HPMC (Sothornvit y Krochta, 2005), aumentando su interacción con las moléculas de HPMC y la flexibilidad de las películas. La mayor afinidad por el agua del $G$ respecto al M (Leung, 1986) pudo atraer mayor cantidad de agua a las películas formuladas con $G$, aumentando la flexibilidad de las películas, dado el efecto plastificante de ésta (Sothornvit y Krochta, 2005). En cuanto al estado físico del plastificante, cabe apuntar que algunos trabajos indican que la efectividad los mismos es mayor cuando éstos se encuentran en estado líquido que cuando se encuentran en estado sólido 
(Sothornvit et al., 2002), lo que puede estar relacionado con el efecto lubricante de los plastificantes líquidos. Doolittle (1965) y Sears y Dary (1982) observaron que las moléculas de plastificante no enlazadas al hidrocoloide actúan como agentes lubricantes entre las cadenas de hidrocoloide, mejorando la flexibilidad de los mimos. Por tanto, el estado líquido del $G$ en las condiciones de ensayo del presente estudio frente al estado sólido del $\mathrm{M}$ pudo mejorar la capacidad plastificante del mismo, incrementando la flexibilidad de las películas.

El contenido en plastificante también afectó las propiedades de las películas. El Y, TM y TR disminuyeron al aumentar el contenido de ambos plastificantes. Sin embargo, el \%E aumentó al incrementar el contenido de $G$ y disminuyó al incrementar el contenido de M. La T disminuyó al aumentar el contenido de ambos plastificantes en películas con un $20 \%$ de CA, y no varió en las películas con $40 \%$ de CA. Por tanto, un incremento en el contenido en $\mathrm{G}$ mejoró la flexibilidad de las películas, mientras que un aumento del contenido en $\mathrm{M}$ incrementó la fragilidad de las mimas.

$\mathrm{El}$ incremento en la fragilidad de las películas al adicionar $\mathrm{M}$ en sus formulaciones sugiere que éste tuvo un efecto antiplastificante en las mismas (Sothornvit y Krochta, 2005). La antiplastificación se atribuye a diversos mecanismos como la reducción del volumen libre entre cadenas de polímero, la interación polímero-plastificante y la presencia de moléculas de plastificante rígidas anejas a los grupos polares del polímero (Guo, 1993; Seow et al., 1999). En la presente experiencia, el efecto antiplastificante del $\mathrm{M}$ pudo estar relacionado con la cristalización del mismo (Apartado IV.3.1.1).

Los valores de las propiedades mecánicas disminuyeron al aumentar el contenido en CA de las películas. Lo que indica que un aumento del contenido en CA da lugar a películas y recubrimientos más dúctiles pero, a su vez, menos resistentes, extensibles y tenaces.

En 'películas emulsionadas' las moléculas de lípido dispersas en la matriz de hidrocoloide interrumpen la continuidad de las mismas, modificando las propiedades mecánicas de la película. En general, las discontinuidades que produce el lípido en la matriz de hidrocoloide son puntos de fractura que reducen la resistencia de las películas a la tracción 
mecánica (Gontard et al., 1994; Shellhamer y Krochta, 1997; Pérez-Gago y Krocha, 2001; Petersson y Stading 2005) debido a que los lípidos presentan una baja cohesividad estructural y son fácilmente fracturables (Gontard et al., 1995). Otros trabajos previos a éste muestran la reducción de las propiedades mecánicas de la películas al incrementar el contenido en lípido de las mimas (Gontard et al., 1994; Shellhammer y Krochta, 1997; Quezada-Gallo et al, 2000; Pérez-Gago y Krochta, 2001; Bravin et al., 2004; Petersson y Stading, 2005; Talens y Krochta, 2005). Además, la incorporación de lípidos no sólo crea discontinuidades en las películas sino que aumenta la hidrofobicidad de las mismas, lo que reduce su capacidad de adsorción de agua y la plastificación que ésta produce. Quezada-Gallo et al. (2000) observaron menor contenido de agua y menores valores de las propiedades mecánicas en películas emulsionadas de hidrocoloide y lípido que en películas formuladas exclusivamente con ese mismo hidrocoloide. 

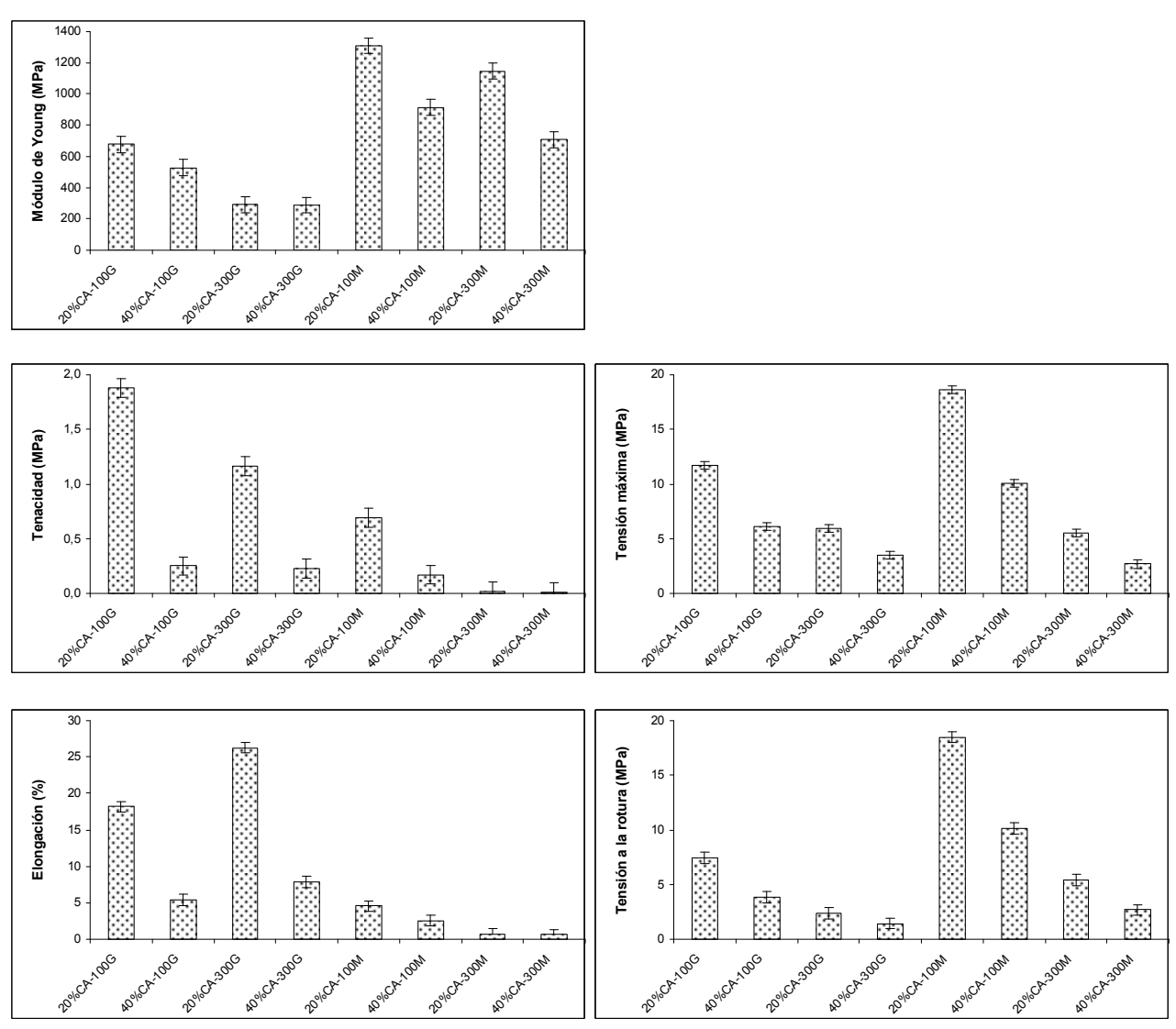

Las barras de error muestran valores de LSD (5\%).

Figura IV.17. Efecto del tipo y contenido de plastificante y del contenido en CA de la formulación en las propiedades mecánicas de las películas.

\section{IV.3.1.3. Permeabilidad al vapor de agua de las películas}

Los plastificantes interfieren en las uniones entre las cadenas de los hidrocoloides reduciendo su cohesión y aumentando la permeabilidad de las películas resultantes (Banker, 1966; McHugh y Krochta, 1994d). Algunos estudios muestran un efecto del tipo y contenido de plastificante en las propiedades barrera de las películas (Ninnemann, 1968; Lieberman y Gilbert 1973; Donhowe y Fennema 1993a, Cuq et al., 1997; Gueguen et 
al., 1998; Sothornvit y Krochta 2001).

En esta experiencia el tipo de plastificante de las formulaciones tuvo un efecto en la PVA de las películas de modo que las películas formuladas con $G$ mostraron mayor PVA que las formuladas con $M$ (Tabla IV.8). Este resultado confirma la mayor habilidad del G para reducir la cohesión de la matriz de HPMC, lo que se atribuye a diferencias en el Pm, afinidad por el agua y estado físico de ambos plastificantes, tal y como se expone en el Apartado IV.3.1.2.

El aumento del contenido de $\mathrm{G}$ de las formulaciones aumentó la PVA de las películas. Sin embargo, el contenido en M no modificó la PVA de las películas, lo que indica que el $\mathrm{M}$ no tuvo un efecto plastificante en las proporciones estudiadas en esta experiencia.

La orientación de las películas durante el análisis no afectó la PVA, lo que pudo ser debido a que el cremado del lípido fuera lo suficientemente importante como para formar 'peliculas bicapa', o a la presencia de microfracturas en las mismas.

En cuanto al contenido en CA de las formulaciones cabe señalar que éste sólo afectó la PVA de las películas en el caso de las formulaciones HPMC:G 1:300, en las cuales un aumento en el contenido de CA redujo la PVA. Sin embargo, el contenido en CA no afectó la PVA del resto de las formulaciones. Como se ha apuntado con anterioridad, un incremento en el contenido en lípido de las películas emulsionadas mejora la barrera al vapor de agua de las mismas. Sin embargo, algunos trabajos ponen de manifiesto que existe un contenido de lípido crítico a partir del cual la PVA puede no verse modificada, o incluso aumentar (Koelsch y Labuza, 1992; Sapru y Labuza, 1994; Shellhammer y Krochta, 1997), lo que algunos autores han atribuido a una saturación en lípido del sistema o a una mala distribución del lípido en la matriz de hidrocoloide, respectivamente (Avena-Bustillos y Krochta, 1993). En la presente experiencia, el aumento en el contenido en CA pudo dificultar su distribución en la matriz de HPMC produciendo la coalescencia de las partículas de CA durante el secado de la película. La presencia de agregados de CA en las películas a partir de un contenido de CA del 20\% (Apartado IV.3.1.1), podría ser la causa de los resultados observados. 
Tabla IV.8. Efecto del tipo y contenido de plastificante y del contenido en CA de la formulación en la PVA de las películas

\begin{tabular}{lcc}
\hline Formulación & \multicolumn{2}{c}{ PVA $\left(\mathrm{g} \mathrm{mm} / \mathrm{KPa} \mathrm{h} \mathrm{m}^{2}\right)$} \\
\cline { 2 - 3 } & $4,20 \mathrm{~b}$ & down \\
\hline $20 \%$ CA-100G & $3,65 \mathrm{~b}$ & $4,09 \mathrm{~cd}$ \\
$40 \%$ CA-100G & $7,62 \mathrm{~d}$ & $3,32 \mathrm{bc}$ \\
$20 \%$ CA-300G & $5,53 \mathrm{c}$ & $6,58 \mathrm{e}$ \\
$40 \%$ CA-300G & $2,27 \mathrm{a}$ & $5,25 \mathrm{de}$ \\
$20 \%$ CA-100M & $1,83 \mathrm{a}$ & $1,91 \mathrm{ab}$ \\
$40 \%$ CA-100M & $2,31 \mathrm{a}$ & $1,60 \mathrm{a}$ \\
$20 \%$ CA-300M & $1,74 \mathrm{a}$ & $2,25 \mathrm{ab}$ \\
$40 \%$ CA-300M & $1,63 \mathrm{a}$ \\
\hline
\end{tabular}

Z Orientación de la película durante la determinación de la PVA en función de la posición de secado en placa.

Por columnas, valores de PVA seguidos de la misma letra no difieren significativamente $(\mathrm{p}<0,05)$.

No se observaron diferencias significativas al variar la orientación de la película en ninguna de las formulaciones estudiadas $(\mathrm{p}<0,05)$.

\section{IV.3.2. Análisis de calidad de las ciruelas 'Angeleno' recubiertas}

\section{IV.3.2.1. Pérdida de peso}

La Figura IV.18 muestra la pérdida de peso de las ciruela 'Angeleno' recubiertas y control. No se observaron diferencias de pérdida de peso entre ciruelas CL y ciruelas CSL. Por tanto, la inmersión en agua no eliminó de forma sustancial las ceras naturales de las ciruelas, lo que pudo ser debido a una falta de afinidad química entre éstas y el agua de lavado.

$\mathrm{Al}$ prolongar el almacenamiento aumentó la pérdida de peso de las ciruelas y las diferencias entre ciruelas recubiertas y control se hicieron más evidentes. Hasta 6 semanas a $1{ }^{\circ} \mathrm{C}$ no se observaron diferencias entre tratamientos. Después de 6 semanas a $1^{\circ} \mathrm{C}$ la mayoría de los frutos recubiertos mostraron una pérdida de peso mayor que los frutos control y después de 8 semanas a $1^{\circ} \mathrm{C}$ todos los frutos recubiertos mostraron mayor pérdida de peso que los frutos control. Los resultados indican que la aplicación de los recubrimientos no mejoró la barrera al vapor de agua de las ciruelas e incluso la empeoró. Este resultado pudo ser debido a que los recubrimientos reemplazaran las ceras naturales que revisten la piel de las 
ciruelas, aportando una barrera al vapor de agua de menor efectividad. La afinidad química de las ceras naturales y las soluciones de recubrimientos habría facilitado la disolución de éstas durante la fase de aplicación de los recubrimientos. Además, las condiciones de HR (90\%) durante el almacenamiento de las ciruelas pudieron aumentar la PVA de los recubrimientos ya que éstos contienen componentes hidrofílicos en su formulación. En anteriores experiencias se observó una falta de efectividad de los recubrimientos reduciendo la pérdida de peso de los frutos cuando éstos presentaban un contenido en CA inferior al 40\%. Sin embargo, se observó que para un 40\% de CA, los recubrimientos reducían la pérdida de peso de las ciruelas (Tabla IV.2).

La pérdida de peso del fruto recubierto no varió con el tipo de plastificante de la formulación pero si con el contenido del mismo. En general, un aumento en el contenido de plastificante redujo la pérdida de peso de las ciruelas recubiertas. Estos resultados se contraponen a los resultados obtenidos de PVA en las películas, donde un incremento en el contenido de $G$ aumentaba la PVA y un incremento de $M$ no afectaba la PVA, lo que confirma que el comportamiento de las películas aisladas no siempre se correlaciona con el comportamiento del recubrimiento aplicado al fruto.

Las diferencias de comportamiento entre los recubrimientos y las películas aisladas pueden ser debidas a la existencia de factores que afectan exclusivamente al comportamiento de los recubrimientos en el fruto. Así por ejemplo, la distribución del recubrimiento en la superficie del fruto y, especialmente, la capacidad de éste para formar una capa continua y/o de penetrar en los poros del fruto (Hagenmaier y Baker, 1993a) afecta la funcionalidad de los mismos. Otros factores como la morfología de la piel del fruto (presencia de tricomas, grosor y tipo de cutícula, número de estomas y lenticelas) (Claypool y King, 1941) y las propiedades físicoquímicas del recubrimiento, que afectan la capacidad del recubrimiento sellando poros (tensión superficial y viscosidad) (Hagenmaier y Baker, 1993a), afectan notablemente los procesos de transferencia de materia del fruto recubierto.

En el caso de los recubrimientos formulados con $G$, la mejora de las propiedades barrera al vapor de agua al incrementar el contenido de éste, pudo ser debida a un incremento en la flexibilidad de los 
recubrimientos (Figura IV.17), lo que pudo mejorar la integridad del mismo y favorecer la formación de una capa continua en la superficie del fruto. El análisis microestructural de recubrimientos a base de almidón ha puesto de manifiesto que la adición de $G$ mejora la integridad del recubrimiento durante el almacenamiento, evitando la formación de microfracturas (García et al., 1999; Zaritzky et al., 2000). Sin embargo, la mejora de las propiedades barrera de los recubrimientos formulados con $\mathrm{M}$ al incrementar el contenido de éste, no se puede explicar con una mejora de las propiedades mecánicas, ya que un incremento en el contenido de M aumentó la fragilidad de las películas (Figura IV.17). 


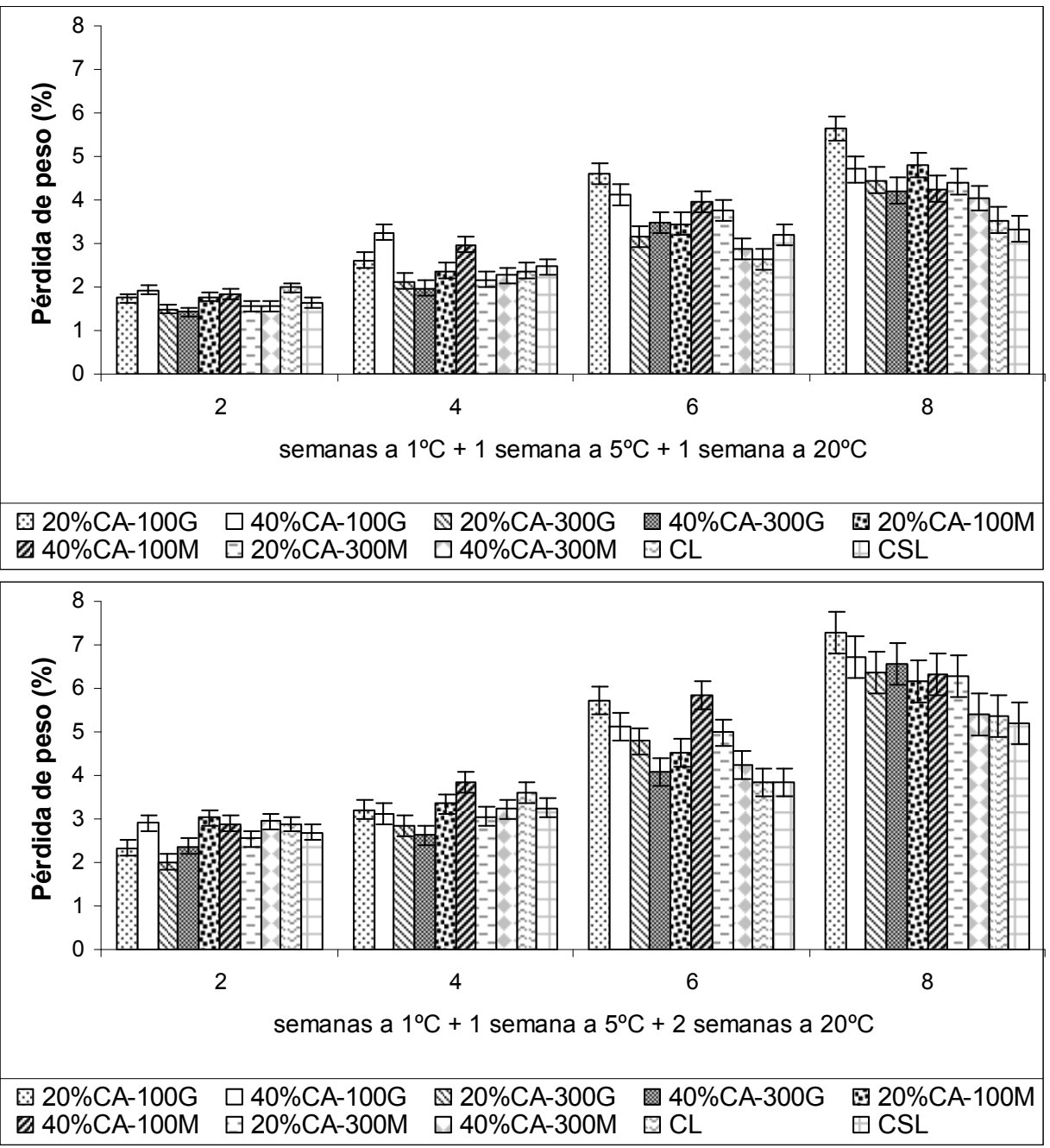

Las barras de error muestran valores de LSD (5\%).

Figura IV.18. Pérdida de peso (\%) de ciruelas 'Angeleno' recubiertas y control: efecto del tipo y contenido de plastificante y del contenido en CA del recubrimiento. 


\section{IV.3.2.2. Intensidad respiratoria}

No se observó un efecto de la aplicación de los recubrimientos en la IR de las ciruelas. Además, el comportamiento de los recubrimientos varió en los distintos periodos de almacenamiento ensayados sin mostrar una tendencia. No se pueden establecer, por tanto, conclusiones acerca del efecto del contenido en plastificante y del contenido en CA en la IR de los frutos recubiertos. Tampoco se observa una tendencia de la IR a lo largo del tiempo de almacenamiento (no se muestran datos).

\section{IV.3.2.3. Etanol y acetaldehído en zumo}

La Figura IV.19 muestra el contenido en etanol y acetaldehído de las ciruelas recubiertas y control. Las ciruelas recubiertas mostraron un contenido en etanol y acetaldehído mayor al de las ciruelas control, lo que indica que los recubrimientos ejercieron una barrera adicional a los gases $\mathrm{CO}_{2}$ y $\mathrm{O}_{2}$ que modificó la atmósfera interna del fruto (Hagenmaier y Baker, 1993a; Baldwin et al., 1995).

El contenido de etanol y acetaldehído del fruto varió con la composición del recubrimiento. Una reducción en el contenido de CA (asociada a un incremento en el contenido de HPMC, ver Tabla III.5), produjo un incremento en los niveles de etanol y acetaldehído de las ciruelas, lo que indica un aumento en la barrera a los gases del recubrimiento. Este resultado guarda relación con la baja permeabilidad a los gases de hidrocoloides como el HPMC (Kester y Fennema, 1986; Park et al., 1993; Nisperos-Carriedo, 1994). Además, Han et al. (2006) observaron un incremento en la permeabilidad al $\mathrm{O}_{2}$ en películas a base de polisacárido a partir de un contenido crítico de CA. Estos autores asumieron que en las películas estudiadas, la transmisión de $\mathrm{O}_{2}$ tenía lugar a través de canales hidrofóbicos de $\mathrm{CA}$, dado que las moléculas de $\mathrm{O}_{2}$ son solubles en lípido y que un incremento en el contenido de CA aumentaba el contacto entre moléculas de CA y la formación de canales de difusión del $\mathrm{O}_{2}$. En nuestro trabajo, la reducción del contenido en CA pudo reducir el número de canales de transporte de $\mathrm{O}_{2}$ y la permeabilidad de los recubrimientos a este gas, aumentando el contenido de etanol y acetaldehído del fruto. El aumento del contenido de etanol y acetaldehído del fruto recubierto al reducir el contenido en CA y aumentar el contenido 
en HPMC de las formulaciones, fué observado con anterioridad en ciruelas 'Otoño gigante' (Pérez-Gago et al., 2003a) y en mandarinas 'Fortune' (Pérez-Gago et al., 2002).

Las ciruelas a las que se aplicaron los recubrimientos formulados con $\mathrm{G}$ mostraron mayores niveles de etanol y acetaldehído que las ciruelas a las que se aplicaron los recubrimientos formulados con M. Estos resultados indican una mayor habilidad de los recubrimientos de $G$ modificando la atmósfera interna de las ciruelas lo que pudo ser debido a la mayor flexibilidad de éstos (Figura IV.17). La mayor flexibilidad de los recubrimientos de $G$ pudo mejorar la integridad física del recubrimiento y la adaptación del mismo a los cambios de volumen que experimenta el fruto durante el almacenamiento, mejorando sus propiedades barrera al $\mathrm{CO}_{2}$ y al $\mathrm{O}_{2}$.

El contenido de plastificante de los recubrimientos al 20\% de CA afectó los niveles de etanol y acetaldehído de las ciruelas, pero el contenido en plastificante no afectó los niveles de etanol y acetaldehído en recubrimientos al 40\% de CA. El efecto del contenido en plastificante sólo en el caso de los recubrimientos al 20\% de CA indica que existe una cantidad de HPMC a partir de la cual la interacción plastificante-HPMC, y por tanto la cohesión de la matriz de HPMC, es el factor dominante de las propiedades barrera a los gases $\mathrm{CO}_{2}$ y $\mathrm{O}_{2}$ del recubrimiento. Por debajo de éste contenido crítico de HPMC, los efectos de la cohesión de la matriz de hidrocoloide y del contenido en plastificante estarían enmascarados por el efecto de la CA (descrito anteriormente).

Una reducción del contenido en plastificante de los recubrimientos al 20\% de CA incrementó los niveles de etanol y acetaldehído de las ciruelas, lo que puede estar relacionado con un incremento de la cohesión de la matriz de HPMC. Las propiedades mecánicas de las películas pusieron de manifiesto un efecto plastificante del $G$ y un efecto antiplastificante del $\mathrm{M}$, el cual proporcionó películas frágiles y quebradizas (Figura IV.17). La plastificación de las películas, además de producir un incremento de la flexibilidad de las mismas, aumenta la permeabilidad al vapor de agua y a los gases $\mathrm{CO}_{2}$ y $\mathrm{O}_{2}$ (Banker, 1966; McHugh y Krochta, 1994a). Por tanto, una reducción del contenido en $G$ mejoró las propiedades barrera al $\mathrm{CO}_{2}$ y al $\mathrm{O}_{2}$ de los recubrimientos. Asimismo, una reducción en el contenido de $\mathrm{M}$ mejoró la integridad de los recubrimientos 
y las propiedades barrera al $\mathrm{CO}_{2}$ y al $\mathrm{O}_{2}$ de los mismos.

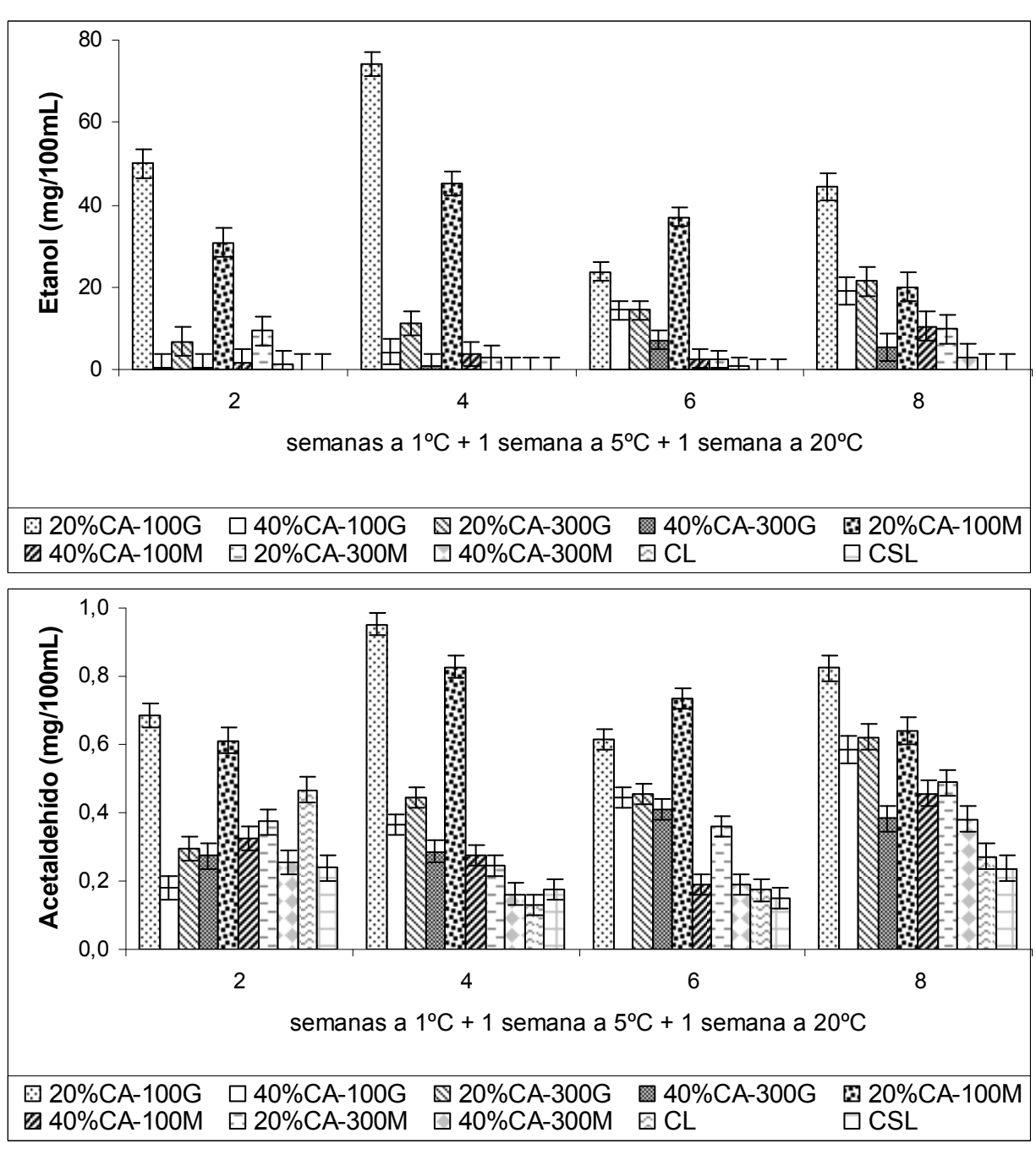

Las barras de error muestran valores de LSD (5\%).

Figura IV.19. Etanol y acetaldehído $(\mathrm{mg} / 100 \mathrm{~mL})$ en zumo de ciruelas 'Angeleno' recubiertas y control: efecto del tipo y contenido de plastificante y del contenido en CA del recubrimiento. 


\section{IV.3.2.4. Firmeza}

La Figura IV.20 muestra la firmeza de la pulpa de las ciruelas 'Angeleno' recubiertas y control. La firmeza de la pulpa disminuyó al prolongar el tiempo de almacenamiento a $1{ }^{\circ} \mathrm{C}$, pero se observó una reducción mucho más importante al prolongar el tiempo de almacenameinto a $20{ }^{\circ} \mathrm{C}$, alcanzándose unas reducciones de pérdida de firmeza en torno a un $25 \%$ respecto a los frutos control.

Los recubrimientos redujeron la pérdida de firmeza de la pulpa y este efecto dependió de la composición de los mismos. La mejora de firmeza observada en los frutos recubiertos pudo estar relacionada con la habilidad de los recubrimientos modificando la atmósfera interna del fruto que, como se ha descrito en distintos trabajos, reduce la degradación de las pectinas y el consiguiente ablandamiento de la pulpa (Couey, 1960, 1965; Smith, 1967; Ke et al., 1991; Ben y Gaweda, 1992). La bibliografía consultada muestra los efectos beneficiosos de las atmósferas modificadas (Ke et al., 1991) y de la aplicación de recubrimientos (Pérez-Gago et al., 2003a) en la firmeza de las ciruelas. Asimismo, las experiencias descritas en los apartados previos, confirman el efecto beneficioso de los recubrimientos reteniendo la firmeza de las ciruelas.

Los recubrimientos con bajo contenido en CA (y alto contenido en HPMC) fueron más efectivos reteniendo la firmeza que los de mayor contenido en CA ( $\mathrm{y}$ menor contenido en HPMC). Este resultado pudo ser debido a una mejora de la barrera a los gases al reducir el contenido en CA del recubrimiento ( $y$ aumentar el contenido en HPMC), aumentando la modificación de la atmósfera interna de las ciruelas. Baldwin et al. (1999) obtuvieron resultados similares a éstos en mangos recubiertos con formulaciones de distinta permeabilidad y Pérez-Gago et al (2003a) obtuvieron resultados similares a los descritos en ciruelas recubiertas con formulaciones de distinta proporción de HPMC y CA.

La firmeza de las ciruelas no estuvo afectada por el tipo de plastificante del recubrimiento, pero si por el contenido del mismo. En general, los recubrimientos con un bajo contenido en plastificante fueron más efectivos reteniendo la firmeza de las ciruelas. La mejora de la firmeza al reducir el contenido en plastificante de la formulación pudo estar relacionada con la mejora de la cohesión de la matriz de HPMC y de la 
barrera a los gases como se describe en el Apartado IV.3.2.3.
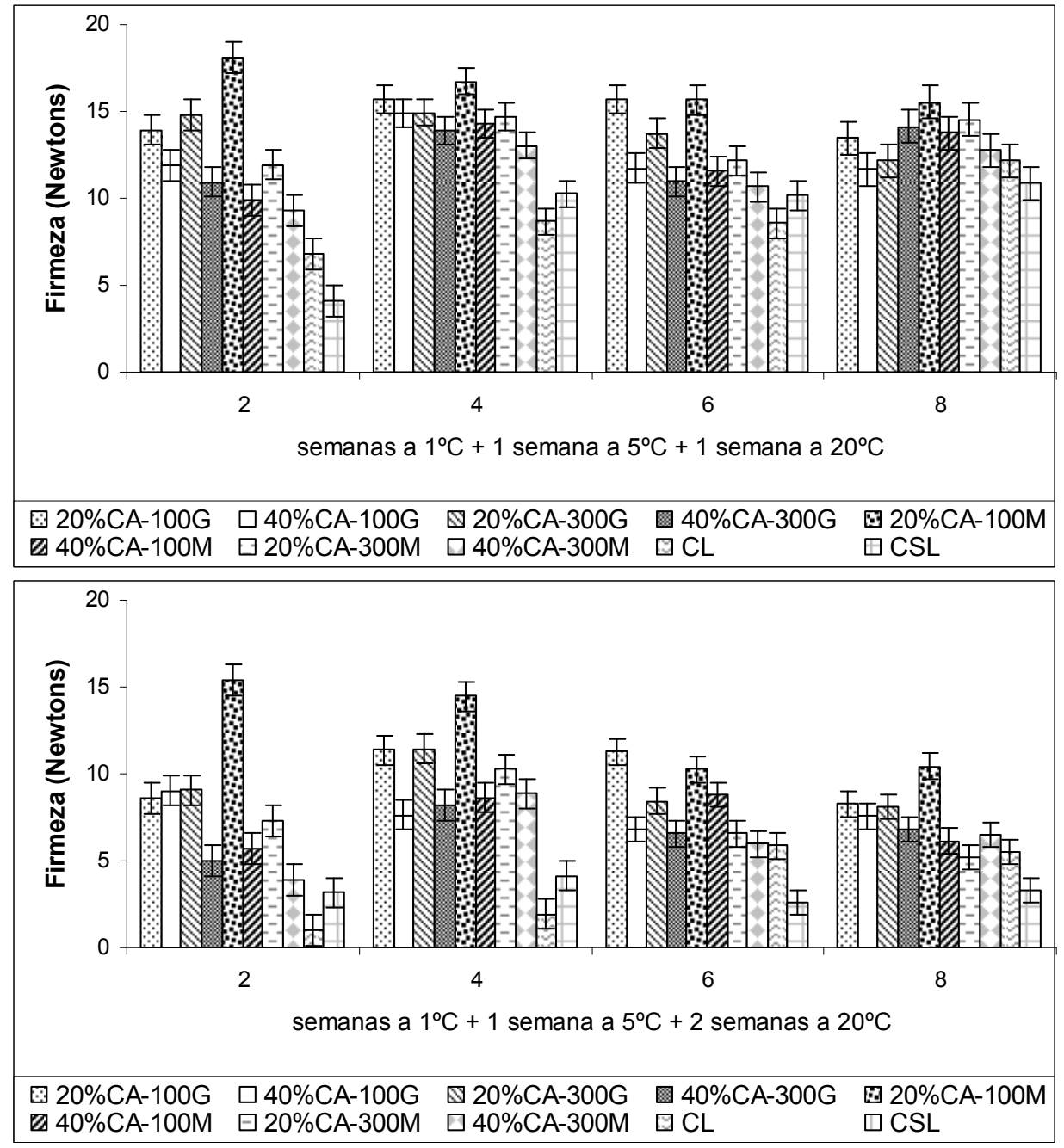

Las barras de error muestran valores de LSD (5\%).

Figura IV.20. Firmeza de ciruelas 'Angeleno' recubiertas y control: efecto del tipo y contenido de plastificante y del contenido en CA del recubrimiento. 


\section{IV.3.2.5. Desórdenes fisiológicos}

En la presente experiencia el principal desorden fisiológico observado fue el daño por 'bleeding', y pudo enmascarar otros daños. La Figura IV.21 muestra el 'bleeding' de ciruelas 'Angeleno' recubiertas y control. En ella se observa que al aumentar el tiempo de almacenamiento a $20{ }^{\circ} \mathrm{C}$ aumentó, notablemente, el daño por 'bleeding' llegando a ser severo (3) en los frutos control. Los recubrimientos redujeron significativamente los daños por 'bleding' e incluso tras 2 semanas de almacenamiento a $20{ }^{\circ} \mathrm{C}$ los frutos recubiertos presentaron un 'bleeding' nulo (1) o moderado (2), dependiendo de la composición del recubrimiento. El contenido en CA del recubrimiento afectó la incidencia de bleeeding en la pulpa de las ciruelas. Sin embargo, el tipo y contenido de plastificante no afectaron la incidencia de éste desorden. Al disminuir el contenido en CA y aumentar el contenido en HPMC disminuyó el 'bleeding' del fruto.

La menor incidencia de 'bleeding' en los casos señalados, pudo ser debida a una modificación de la atmósfera interna de las ciruelas (Apartado IV.3.2.3) y se correlaciona con la retención de firmeza de la pulpa de las ciruelas (Figura IV.20). 


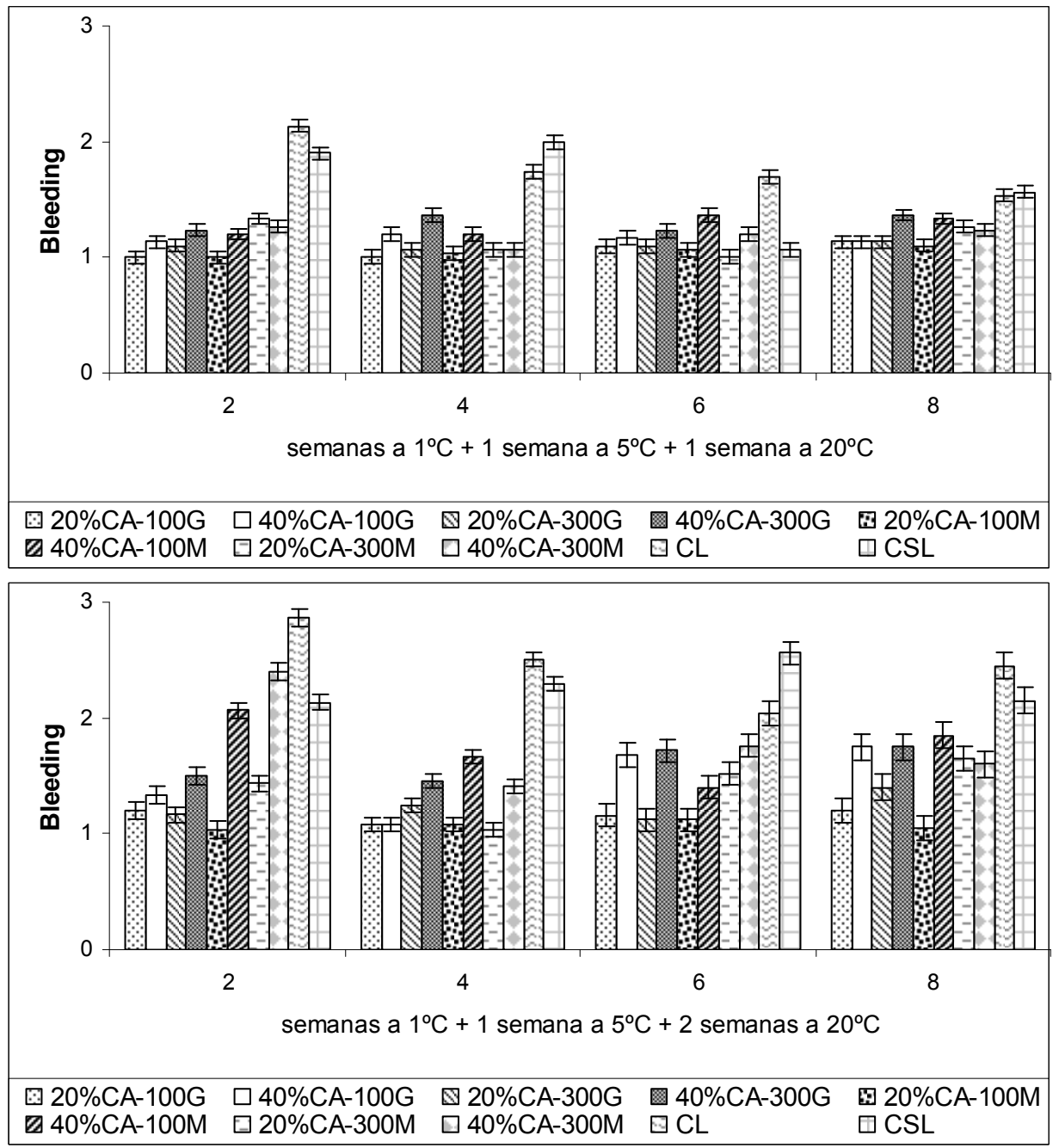

Las barras de error muestran valores de LSD (5\%).

Figura IV.21. 'Bleeding' de ciruelas 'Angeleno' recubiertas y control: efecto del tipo y contenido de plastificante y del contenido en CA del recubrimiento. 


\section{IV.3.2.6. Evaluación organoléptica: 'flavor’ y textura}

La puntación de 'flavor' no varió con el tiempo de almacenamiento ni con el tratamiento aplicado, siendo aceptable en todos los tratamientos (no se muestran datos). El efecto de los recubrimientos en la textura de las ciruelas varió con el tiempo de almacenamiento a $1{ }^{\circ} \mathrm{C}$. Hasta 2 semanas a $1{ }^{\circ} \mathrm{C}$ las ciruelas recubiertas mostraron mayor textura que las control. $\mathrm{Al}$ prolongar el almacenamiento en refrigeración, la textura de las ciruelas disminuyó y no se detectaron diferencias entre tratamientos (no se muestran datos)

\section{IV.3.2.7. Aspecto externo y brillo del fruto}

La Figura IV.22 muestra el aspecto externo y brillo de las ciruelas recubiertas y control. La puntuación del aspecto externo de las ciruelas disminuyó al prolongar el almacenamiento, lo que indica una pérdida de calidad del mismo. En general, los tratamientos 20\%CA-300M y 40\%CA$300 \mathrm{M}$ fueron los que peor aspecto mostraron, lo que pudo ser debido a una cristalización del $\mathrm{M}$ y a la formación de recubrimientos quebradizos, tal y como se observó en las películas formuladas con M (Apartado IV.3.1.2). El tratamiento CL fue el que mejor aspecto mostró lo que pudo ser debido a la eliminación parcial de la pruína de la piel de las ciruelas.

No se observó un efecto del tiempo de almacenamiento en el brillo de las ciruelas pero si un efecto del tratamiento aplicado. Los tratamientos 20\%CA-100G, 20\%CA-300G y control, fueron los que mayor brillo presentaron. Un aumento en el contenido de CA disminuyó el brillo y el M proporcionó menor brillo a los frutos que el G. En anteriores experiencias realizadas con ciruelas 'Angeleno' también se observó una reducción del brillo al aumentar el contenido en CA, atribuyéndose a la turbidez que proporciona la CA (Apartado IV.1.1.1). Algunos autores han observado que un aumento de la turbidez de las emulsiones se corresponde con un menor brillo del recubrimiento resultante (Hagenmaier y Baker, 1997). 

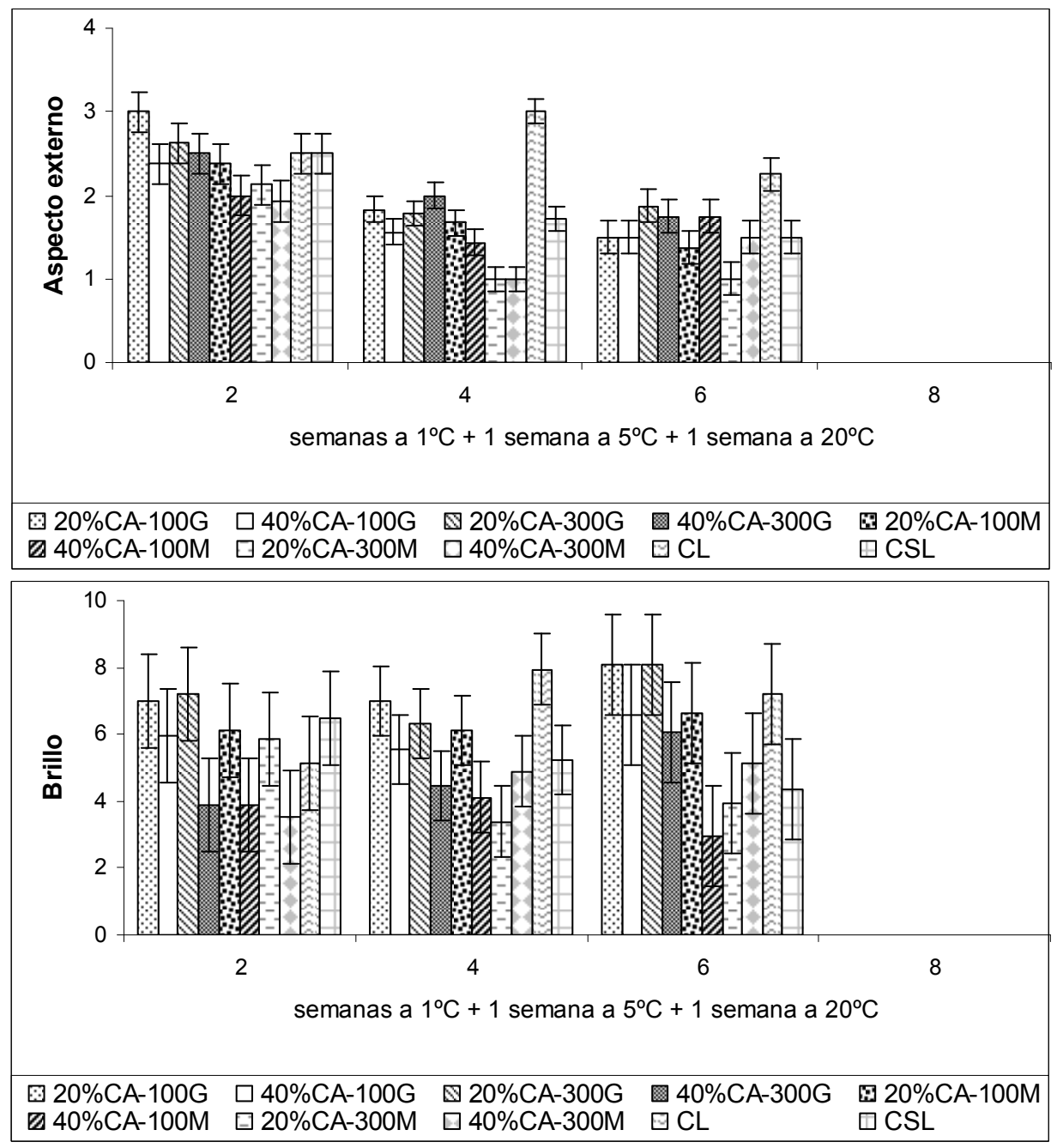

Las barras de error muestran valores de LSD (5\%).

Datos de aspecto y brilllo correspondientes al periodo de almacenamiento de 8 semanas a $1{ }^{\circ} \mathrm{C}+1$ semana a $5^{\circ} \mathrm{C}+1$ semana a $20^{\circ} \mathrm{C}$ no disponibles.

Figura IV.22. Aspecto externo y brillo de ciruelas 'Angeleno' recubiertas y control: efecto del tipo y contenido de plastificante y del contenido en CA del recubrimiento. 


\section{IV.3.3. Síntesis de resultados}

El objetivo de la presente experiencia fue estudiar el efecto del tipo y contenido de plastificante y del contenido de CA de recubrimientos compuestos a base de HPMC y CA en la calidad postcosecha de ciruelas cv. 'Angeleno'. Para ello se estudió el efecto de estos factores en las propiedades de películas aisladas y se evaluaron distintos parámetros de calidad de las ciruelas recubiertas, comparándolas con frutas control. A continuación se hace un resumen de los resultados más relevantes.

El tipo y contenido de plastificante así como el contenido de CA afectaron las propiedades mecánicas y la barrera al vapor de agua de las películas aisladas. De los plastificantes estudiados (G y M), el G presentó mayor habilidad para reducir la cohesión de la matriz de HPMC y aumentar la flexibilidad y la PVA de las películas, mejorando la integridad física de las mismas. El peso molecular, afinidad por el agua y el estado físico de los plastificantes estudiados pudieron determinar las propiedades de los mismos, de manera que el menor peso molecular, mayor afinidad por el agua y el estado líquido del $G$ mejorara su habilidad plastificante. Al aumentar el contenido en $G$, aumentó la flexibilidad y la PVA de las películas y al aumentar el contenido en $\mathrm{M}$, aumentó la rigidez y fragilidad de las películas y no varió la PVA. El contenido en CA afectó a las propiedades mecánicas de las películas pero no a su PVA. Un aumento en el contenido de CA del 20 al 40\% aumentó la flexibilidad de las películas, pero redujo su tenacidad. El aumento en el contenido en CA estuvo asociado a una peor dispersión de la CA en las películas y no mejoró la barrera al vapor de agua de las mimas.

Se observó un incremento de los niveles de etanol y acetaldehído, una mayor firmeza de la pulpa y una menor incidencia de 'bleeding' en los frutos recubiertos, lo que se atribuye a la barrera que éstos ejercieron a los gases $\left(\mathrm{CO}_{2}\right.$ y $\left.\mathrm{O}_{2}\right)$. Sin embargo, no se observó un efecto de los recubrimientos en la pérdida de peso de las ciruelas. Un aumento en el contenido en HPMC y una disminución del contenido en CA aumentó los niveles de etanol y acetaldehído, aumentó la firmeza de la pulpa y redujo el 'bleeding' de las ciruelas recubiertas. La cohesión de la matriz de HPMC y la integridad física del recubrimiento pudo afectar la barrera a los gases $\mathrm{CO}_{2}$ y $\mathrm{O}_{2}$ del recubrimiento, dado que se observó una relación entre las 
propiedades mecánicas de las películas aisladas y los niveles de etanol y acetaldehído y la firmeza de la pulpa de las ciruelas recubiertas. Así se observó, que los recubrimientos con $G$ proporcionaban mayores niveles de etanol y acetaldehído que los recubrimientos de M. Además, la reducción del contenido de ambos plastificantes aumentó los niveles de etanol y acetaldehído y la firmeza de la pulpa de las ciruelas.

Se observó una correlación entre las propiedades mecánicas de las películas aisladas y el aspecto y brillo de las ciruelas recubiertas. Las formulaciones de $G$ proporcionaron películas flexibles y mejoraron el aspecto de las ciruelas recubiertas. Sin embargo, las formulaciones de M proporcionaron películas frágiles y quebradizas y empeoraron el aspecto y brillo de las ciruelas recubiertas.

\section{IV.4. EFECTO DEL CONTENIDO EN CERA DE ABEJA Y DEL CONTENIDO EN SÓLIDOS DE LA FORMULACIÓN EN LAS CARACTERÍSTICAS DE LAS PELÍCULAS Y EN LA CALIDAD POSTCOSECHA DE MANDARINAS 'CLEMENULES' RECUBIERTAS}

IV.4.1. Análisis de las emulsiones y de las películas preformadas en placa

\section{IV.4.1.1. Aspecto de las emulsiones y de las películas}

El contenido en CA de las formulaciones influyó en el aspecto de las emulsiones y de las películas. Todas las emulsiones mostraron un aspecto opaco de color blanco y una ligera separación de fases a las $24 \mathrm{~h}$ de su elaboración, que tras la agitación volvía a dar una emulsión homogénea.

Las películas con 40 y con $60 \%$ de CA mostraron un aspecto mate en la cara expuesta al aire durante el secado y un aspecto brillante en la cara expuesta a la placa lo que pone de manifiesto el cremado del lípido durante el secado de las mismas. El incremento en el contenido de lípido acentuó las diferencias de aspecto entre la cara expuesta al aire y la expuesta a la placa durante el secado. 
A pesar de que la relación CA:AE se mantuvo constante en todas las formulaciones $(1: 0,2)$, se observó que un incremento en el contenido de CA modificaba el aspecto de las películas. Las películas con $40 \%$ de CA fueron las que mostraron un aspecto más homogéneo, aunque presentaron algunos agregados de CA. Al aumentar el contenido de CA aumentó el número de agregados de CA. Las películas con $80 \%$ de CA mostraron un aspecto heterogéneo, con una separación importante de la CA en la superficie de las mismas. Otros autores han observado el efecto del contenido en lípido en la isotropía de las películas. Así por ejemplo, Han et al. (2006) observaron que al reducir el contenido en CA en películas a base de almidón, mejoraba la distribución del lípido. Nuestros resultados indican una saturación del sistema a partir de un $40 \%$ de lípido bien por un defecto de emulsificante (AE) o por un exceso de lípido (CA).

La integridad física de las películas también varió con el contenido en lípido, perdiendo integridad a medida que aumentaba en contenido en lípido. Las formulaciones con $80 \%$ de CA no llegaron a formar una red cohesionada siendo extremadamente frágiles y quebradizas que se rompían al intentarlas separar de la placa. La pérdida de integridad física con la adición de lípido se puede atribuir a las discontinuidades que el lípido produce en la matriz estructural de HPMC, siendo éstas puntos de fractura que reducen la resistencia de la película a la tracción mecánica (Shellhammer y Krochta, 1997; Pérez-Gago y Krocha, 2001; Petersson y Stading 2005). Además, los lípidos y entre ellos la CA presentan baja cohesividad e integridad estructural lo que los hace muy quebradizos (Gontard et al., 1995). En las películas con 80\% de CA, las propiedades mecánicas estuvieron claramente influenciadas por las propiedades de la CA dado el bajo contenido de HPMC de las mismas.

\section{IV.4.1.2. Permeabilidad al vapor de agua de las películas}

Las formulaciones con $80 \%$ de CA proporcionaron películas quebradizas de las que no se pudo determinar la PVA. Por tanto, se estudió la PVA de las películas con un contenido en CA de 40 y 60\%. En estas películas se observó una reducción de la PVA al aumentar el contenido en CA. No se observaron diferencias significativas al variar la orientación de la película en ninguna de las formulaciones estudiadas (Tabla IV.9), lo indica que el cremado del lípido fue lo suficientemente importante como para formar 'películas bicapa', o la presencia de 
microfracturas en las mismas.

Tabla IV.9. Efecto del contenido en CA y del CS de la formulación en la PVA de las películas'

\begin{tabular}{ccc}
\hline Formulación & \multicolumn{2}{c}{ PVA $\left(\mathrm{g} \mathrm{mm} / \mathrm{KPa} \mathrm{h} \mathrm{m}^{2}\right)$} \\
\cline { 2 - 3 } & $\mathrm{up}^{\mathrm{zz}}$ & down \\
\hline $40 \% \mathrm{CA}^{\mathrm{zz}}{ }^{{ }^{2}} \% \mathrm{CS}$ & $4,55 \mathrm{~b}$ & $4,32 \mathrm{~b}$ \\
$60 \% \mathrm{CA}-{ }^{{ }{ }_{0}} \% \mathrm{CS}$ & $3,32 \mathrm{a}$ & $2,94 \mathrm{a}$ \\
$80 \% \mathrm{CA}-{ }^{{ }^{0}} \% \mathrm{CS}$ & --- & --- \\
\hline
\end{tabular}

$\mathrm{Z}$ El CS de las formulaciones se mantuvo constante al 10\%.

ZZ Orientación de la película durante la determinación de la PVA en función de la posición de secado en placa.

Por columnas, valores de PVA seguidos de la misma letra no difieren significativamente y viceversa $(\mathrm{p}<0,05)$.

No se observaron diferencias significativas al variar la orientación de la película en ninguna de las formulaciones estudiadas $(p<0,05)$.

\section{IV.4.2. Análisis de calidad de las mandarinas 'Clemenules' recubiertas}

\section{IV.4.2.1. Pérdida de peso}

La Figura IV.23 muestra la pérdida de peso de las mandarinas recubiertas y control. El efecto de los recubrimientos en la pérdida de peso varió a lo largo del almacenamiento. Tras un almacenamiento en refrigeración de 2 y 3 semanas, todos los recubrimientos fueron efectivos reduciendo la pérdida de peso de las mandarinas a excepción del recubrimiento $40 \% \mathrm{CA}-8 \% \mathrm{CS}$. Al prolongar el almacenamiento en refrigeración hasta 4 semanas, los recubrimientos con $40 \%$ y con $60 \%$ de CA perdieron efectividad y sólo los recubrimientos con $80 \%$ CA redujeron la pérdida de peso de las mandarinas. Cabe señalar que en ciruelas 'Angeleno' a las que se aplicó recubrimiento de igual composición no se observó esta pérdida de efectividad al prolongar el tiempo de almacenamiento, siendo efectivos tras 6 semanas de almacenamiento en refrigeración seguido de 3 semanas a $20^{\circ} \mathrm{C}$ (Tabla IV.2).

Las formulaciones con $80 \%$ de CA formaron películas frágiles (Apartado IV.4.1.1) y recubrimientos de textura pulverulentas con baja adhesividad que se desprendían fácilmente con la manipulación de los frutos (Apartado IV.4.2.7). Sin embargo, la fragilidad de estos 
recubrimientos no pareció afectar las propiedades barrera al vapor de agua de los mismos, ya que éstos fueron los más efectivos reduciendo la pérdida de peso de las mandarinas. Este resultado pudo ser debido a distintas causas: (1) que durante el almacenamiento no se manipularon los frutos, lo que pudo evitar el desprendimiento de los recubrimientos, y (2) que a pesar de existir una pérdida de recubrimiento, esta no tuviera lugar a nivel de los estomas y discontinuidades de la piel del fruto, en los cuales la cutícula presenta microfracturas que facilitan la salida de vapor de agua del fruto (Gleen y Pooviah, 1989). Por tanto, el recubrimiento habría permanecido obturando estas vías de salida de vapor de agua que suponen una importante pérdida de peso.

Además, la HR durante el almacenamiento pudo influir en las propiedades barrera de los recubrimientos, incrementando la PVA en mayor o menor grado en función del carácter hidrofílico de los mismos. En este sentido, los recubrimientos formulados con $40 \%$ y con $60 \%$ de CA, de mayor contenido en HPMC que los recubrimientos con 80\%CA (Tabla III.6), pudieron experimentar un mayor incremento de la PVA durante el almacenamiento. Los resultados indican que la hidrofobicidad del recubrimiento fue el factor determinante de la barrera al vapor de agua del mismo. Otros autores han encontrado correlación entre la hidrofobicidad del recubrimiento y la pérdida de peso del fruto recubierto (Mannhein y Soffer, 1996).

El efecto del contenido en CA de los recubrimientos dependió del CS de la formulación. Para un CS del $4 \%$ un incremento en el contenido en CA sólo fue efectivo reduciendo la pérdida de peso al cabo de 4 semanas de almacenamiento refrigerado. Sin embargo, al 8\% de CS el incremento en el contenido en CA del recubrimiento redujo la pérdida de peso de las mandarinas en todos los periodos de almacenamiento ensayados. En cuanto al efecto del CS de la formulación en la pérdida de peso de las mandarinas recubiertas cabe decir que, en general, a igual contenido en CA del recubrimiento un aumento en el CS no modificó la pérdida de peso del fruto recubierto.

El aumento en el CS de las formulaciones aumenta la cantidad de de recubrimiento adherido al fruto y da lugar a recubrimientos de mayor espesor (Cisneros-Zevallos y Krochta, 2003). Para materiales isotrópicos o de características uniformes a lo largo de los mismos, las propiedades 
barrera varían con el espesor de éstos ya que el espesor determina la distancia a recorrer por el permeato y, por tanto la resistencia del material a la difusión (Ben-Yehoshua, 1967; Meheriuk y Lau, 1988; Hagenmaier y Shaw, 1992; Hagenmaier y Baker, 1994; Park et al, 1994). En la presente experiencia no se observó un efecto del CS en la barrera a la humedad del recubrimiento cuando se mantenía constante el contenido en CA, lo que pudo ser debido a las características anisotrópicas de nuestros recubrimientos. Los recubrimientos utilizados son emulsiones en las que el lípido (CA y AE), que ejerce la barrera al vapor de agua, se distribuye de manera más o menos homogénea en la matriz continua de HPMC. Dada la naturaleza hidrofilica de la matriz de HPMC, el agua puede difundir a través de ésta, sorteando las partículas de lípido dispersas. Si el incremento en el CS de la formulación simplemente se traduce en un mayor grosor del mismo sin alterar la estructura del mismo o distribución del lípido, la barrera al vapor de agua no se ve afectada, puesto que la difusión de la misma sigue la ruta descrita. Sin embargo, un aumento en el contenido en CA incrementa la barrera al vapor de agua de los recubrimientos dado que obstaculiza la difusión de agua a través de los mismos.

Otros autores han obtenido resultados similares a los observados en esta experiencia. Así, Pérez-Gago et al. (2003b) y Rojas et al. (2002) vieron cómo variaciones en el CS de recubrimientos a base de HPMC y CA no modificaban la pérdida de peso de mandarinas 'Fortune'. 


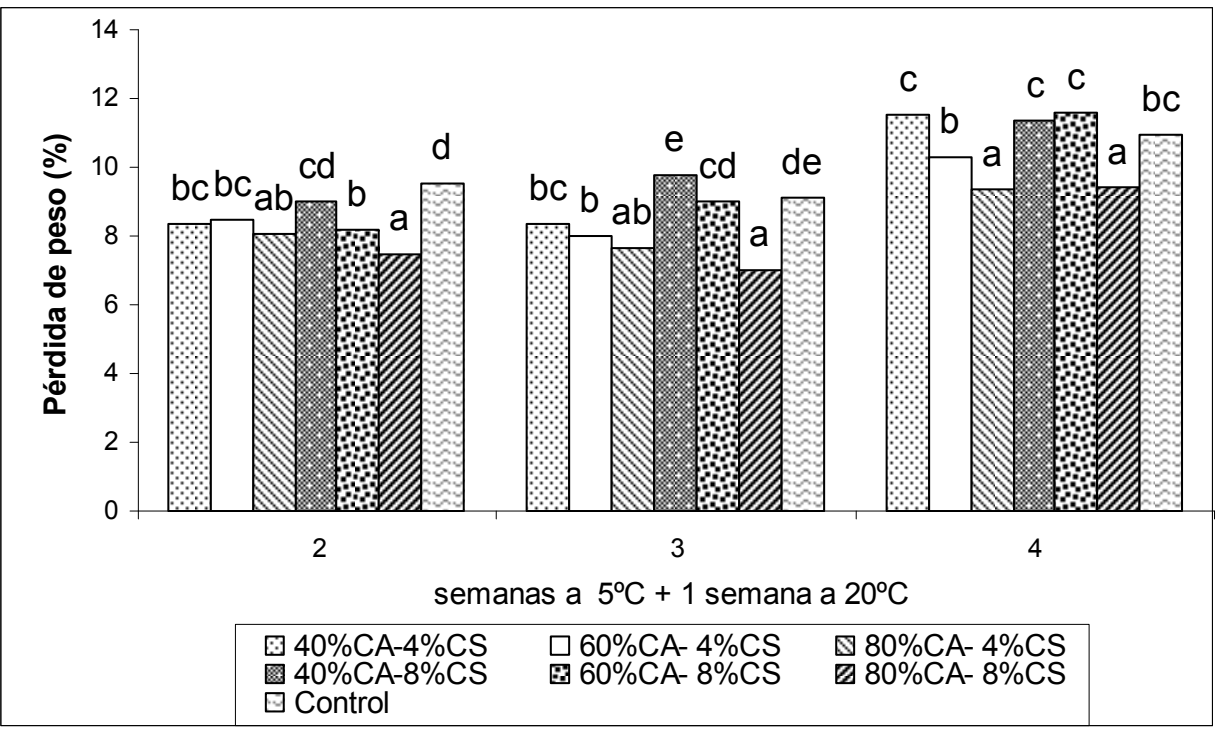

En cada periodo de almacenamiento, valores seguidos de la misma letra no difieren significativamente $(\mathrm{p}<5 \%)$.

Figura IV.23. Pérdida de peso (\%) de mandarinas 'Clemenules' recubiertas y control: efecto del contenido en CA y del CS del recubrimiento.

\section{IV.4.2.2. Sólidos solubles totales, acidez e índice de madurez}

Al prolongar el almacenamiento se observó una reducción de la acidez y un aumento del IM, manteniéndose los valores de sólidos solubles (no se muestran datos). No se observó un efecto significativo del tratamiento en éstos parámetros de calidad de las mandarinas.

\section{IV.4.2.3. Contenido de $\mathrm{CO}_{2}$ y $\mathrm{O}_{2}$ interno}

La piel de las frutas regula el intercambio de los gases $\mathrm{CO}_{2}$ y $\mathrm{O}_{2}$ restringiendo la entrada de $\mathrm{O}_{2}$ del entorno al interior del fruto y la salida de $\mathrm{CO}_{2}$ del interior del mismo. Los recubrimientos aplicados en la superficie de los frutos aportan una barrera adicional a los gases $\mathrm{CO}_{2}$ y $\mathrm{O}_{2}$ que afecta el transporte de éstos, modificándolo en mayor o menor medida dependiendo de las características de los mismos (composición, grosor, habilidad sellando las rutas de paso de los gases, etc.). 
La Figura IV.24 muestra el contenido en $\mathrm{CO}_{2}$ y $\mathrm{O}_{2}$ interno de las mandarinas recubiertas y control. Los frutos recubiertos con las formulaciones al 80\% de CA mostraron una atmósfera interna similar a la de los frutos control. Sin embargo, los frutos recubiertos con las formulaciones al 60 y al $40 \%$ de CA mostraron niveles de $\mathrm{CO}_{2}$ interno hasta un $50 \%$ superiores a la de los frutos control y a los recubiertos con las formulaciones al $80 \%$ de $\mathrm{CA}$, acompañado este aumento de $\mathrm{CO}_{2}$ de una disminución en el nivel de $\mathrm{O}_{2}$ interno. No se observaron diferencias significativas en los niveles de $\mathrm{CO}_{2}$ y $\mathrm{O}_{2}$ internos entre los frutos recubiertos con las formulaciones al $40 \%$ de $\mathrm{CA}$ y al $60 \%$ de CA. Estos resultados muestran que los recubrimientos con $80 \%$ de CA no restringieron la entrada de $\mathrm{O}_{2}$ al interior del fruto ni la salida de $\mathrm{CO}_{2}$ del interior del mismo, y por tanto o ejercieron un efecto barrera a éstos gases. Sin embargo, el resto de recubrimientos si que restringieron el flujo de ambos gases, lo que pone de manifiesto el efecto de la composición del recubrimiento en la barrera los gases $\mathrm{CO}_{2}$ y $\mathrm{O}_{2}$ del mismo.

Han et al. (2006) propusieron un modelo de transporte de $\mathrm{O}_{2}$ en películas emulsionadas y según éste modelo, el $\mathrm{O}_{2}$ se transporta a través de canales de difusión formados por las partículas de lípido. Estos autores observaron que la permeabilidad al $\mathrm{O}_{2}$ aumentaba a partir de un contenido de CA por la formación de un gran número de canales de difusión de $\mathrm{O}_{2}$. En los recubrimientos estudiados, también se observó un incremento de la permeabilidad al $\mathrm{O}_{2}$ al aumentar el contenido en CA en las formulaciones, lo que pudo estar relacionado con un incremento en el número de canales de difusión del $\mathrm{O}_{2}$. Además, en películas emulsionadas, la matriz de hidrocoloide ejerce la principal barrera a los gases $\mathrm{CO}_{2}$ y $\mathrm{O}_{2}$ y en nuestra experiencia, ésta se vio afectada por el contenido en CA de las formulaciones. Al aumentar el contenido en $\mathrm{CA}$ de la formulación se redujo el contenido de HPMC (Tabla III.6), que es el componente que forma la matriz hidrofílica responsable de la barrera a los gases del recubrimiento.

El CS de las formulaciones afectó la atmósfera interna de los frutos a los que se aplicó las formulaciones con 40 y $60 \%$ de CA, sin afectar la atmósfera interna de los frutos recubiertos con las formulaciones al $80 \%$ de CA. El incremento en el CS de los recubrimientos al 40 y al $60 \%$ de $\mathrm{CA}$ incrementó los niveles de $\mathrm{CO}_{2}$ interno de las mandarinas y redujo los niveles de $\mathrm{O}_{2}$ interno. Estos resultados indican que el factor determinante 
de la permeabilidad a los gases $\mathrm{CO}_{2}$ y $\mathrm{O}_{2}$ en los recubrimientos al $80 \%$ de CA es la proporción relativa de HPMC y CA de la formulación. Sin embargo, por debajo del $80 \%$ de CA, otros factores de composición como el CS tienen un efecto en la barrera a los gases del recubrimiento.

El aumento en el CS de la formulación pudo aumentar el grosor del recubrimiento (Cisneros-Zevallos y Krochta, 2003) y, por tanto, la distancia que los gases $\mathrm{CO}_{2}$ y $\mathrm{O}_{2}$ tienen que recorrer para su difusión, lo que aumenta la resistencia de los recubrimientos a la difusión de ambos gases. Otros autores han observado con anterioridad el efecto del CS en la barrera a los gases $\mathrm{CO}_{2}$ y $\mathrm{O}_{2}$ de los recubrimientos. Así por ejemplo, Cisneros-Zevallos y Krochta (2003) observaron una reducción en la permeabilidad al $\mathrm{O}_{2}$ y $\mathrm{CO}_{2}$ al aumentar el CS de recubrimientos a base de HPMC en manzanas cv. 'Fuji'. 

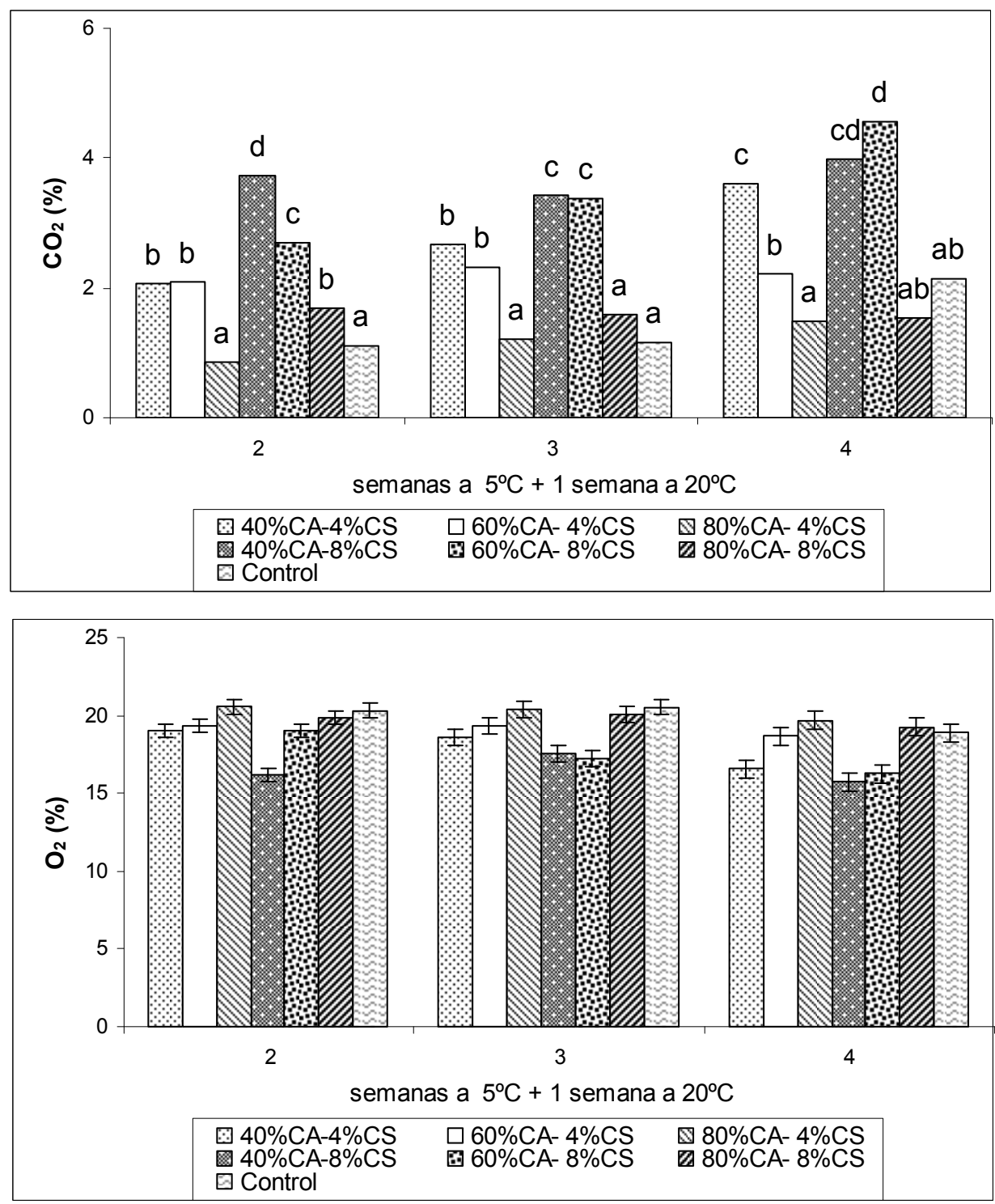

En cada periodo de almacenamiento, valores seguidos de la misma letra no difieren significativamente $(p<5 \%)$.

Las barras de error muestran valores de LSD (5\%).

Figura IV.24. $\mathrm{CO}_{2}$ y $\mathrm{O}_{2}$ interno de mandarinas 'Clemenules' recubiertas y control: efecto del contenido en CA y del CS del recubrimiento. 


\section{IV.4.2.4. Etanol y acetaldehído en zumo}

Los niveles de etanol y acetaldehído en zumo se correlacionaron con los niveles de $\mathrm{CO}_{2}$ interno de las mandarinas. Esta correlación entre los niveles de $\mathrm{CO}_{2}$ interno del fruto y el contenido en etanol y acetaldehído del mimo ha sido observado en trabajos previos entre los que se encuentran los de Ke y Kader (1990) y Davis et al. (1973). Así, los frutos recubiertos con las formulaciones al $80 \%$ de CA mostraron niveles de etanol y acetaldehído similares a la de los frutos control, y el resto de tratamientos mostraron niveles superiores de ambos componentes. Además, el incremento en el contenido en CA del recubrimiento de $40 \%$ a $60 \%$ redujo significativamente los niveles de etanol y acetaldehído en zumo y el incremento del CS aumentó los niveles de ambos componentes (Figura IV.25). 

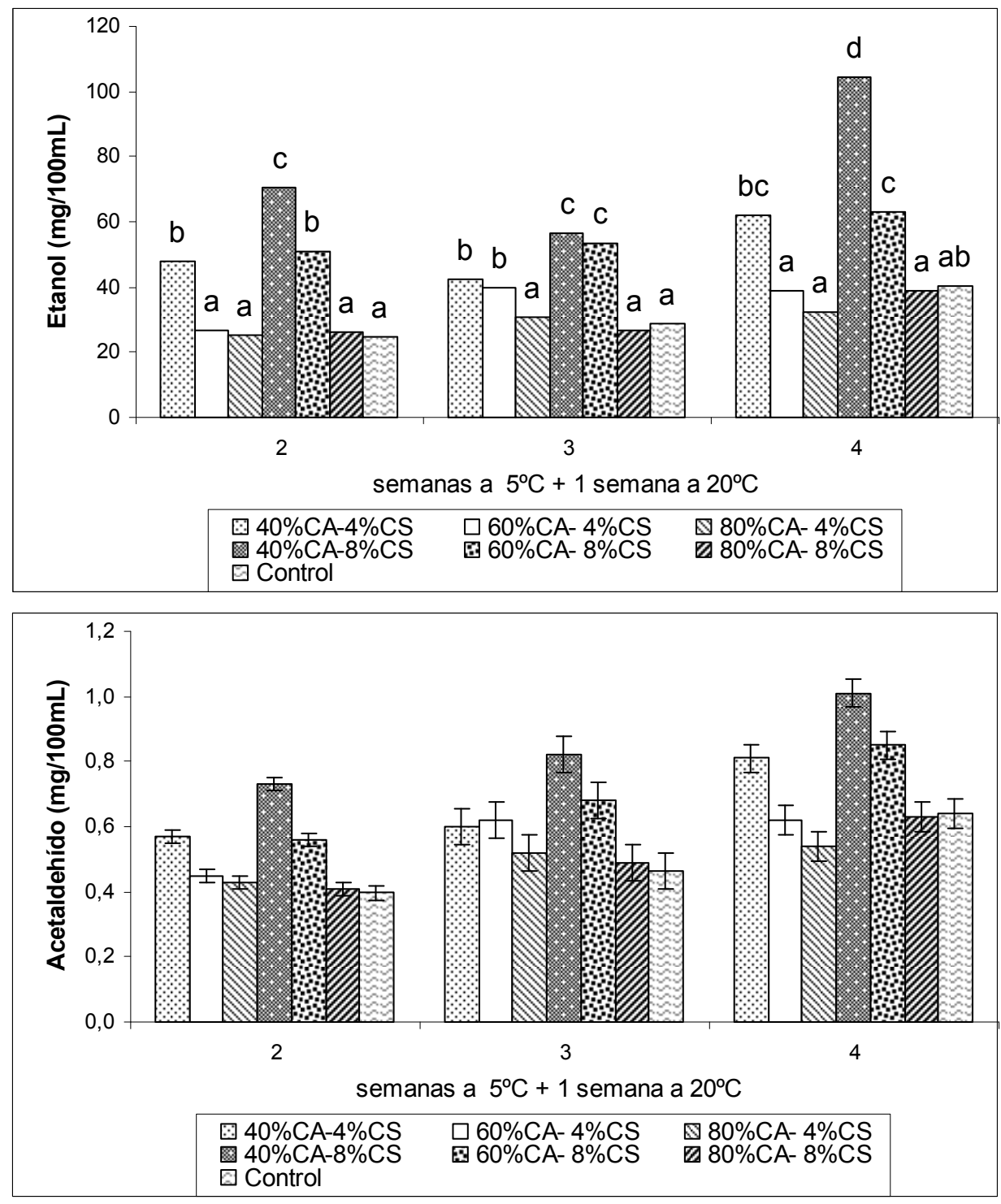

En cada periodo de almacenamiento, valores seguidos de la misma letra no difieren significativamente $(p<5 \%)$.

Las barras de error muestran valores de LSD (5\%).

Figura IV.25. Etanol y acetaldehído $(\mathrm{mg} / 100 \mathrm{~mL})$ en zumo de mandarinas 'Clemenules' recubiertas y control: efecto del contenido en CA y del CS del recubrimiento. 


\section{IV.4.2.5. Firmeza}

La Figura IV.26 representa la deformación producida en las mandarinas tras aplicar una fuerza de compresión. Por tanto, un incremento de los valores de deformación de las mandarinas, indican una pérdida de firmeza o turgencia de las mismas y viceversa. Los resultados indican que los recubrimientos fueron efectivos manteniendo la firmeza de las mandarinas. Aunque se observaron diferencias significativas de deformación en los frutos recubiertos con las distintas formulaciones, no se observó una tendencia en función de la composición del recubrimiento para los distintos periodos de almacenamiento ensayados. Por tanto, a partir de los resultados obtenidos es difícil definir el efecto del contenido en CA del recubrimiento y el efecto del CS en la firmeza de las mandarinas.

Algunos estudios realizados en cítricos muestran una relación entre la firmeza del fruto y la pérdida de peso del mismo, siendo la deshidratación la responsable de la pérdida de turgencia del fruto y, por tanto, de la pérdida de firmeza (Ben-Yehoshua, 1985; Cuquerella et al., 1988; Pozzan et al., 1993). En la presente experiencia los frutos recubiertos fueron los que mayor firmeza y menor pérdida de peso presentaron, lo que pone de manifiesto un posible efecto de la deshidratación en la pérdida de firmeza de las mandarinas. 


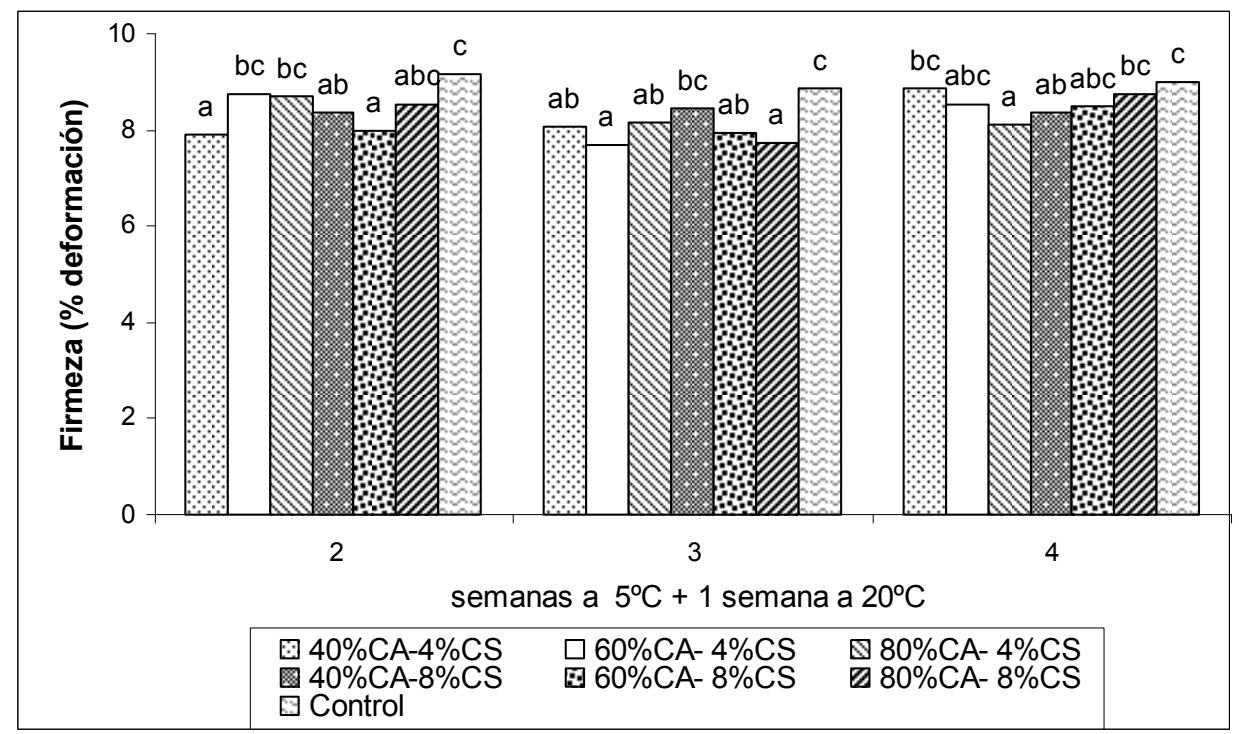

En cada periodo de almacenamiento, valores seguidos de la misma letra no difieren significativamente $(\mathrm{p}<5 \%)$.

Figura IV.26. Firmeza (\% deformación) de mandarinas 'Clemenules' recubiertas y control: efecto del contenido en CA y del CS del recubrimiento.

\section{IV.4.2.6. Desórdenes fisiológicos}

Los desórdenes fisiológicos observados fueron picado o 'pitting', que se manifiesta en la piel con depresiones redondeadas que se oscurecen a medida que avanza el deterioro, y necrosis peripeduncular o 'stem end rind breakdown' ('SERB'), que se manifiesta en torno al pedúnculo con depresiones que adquieren una coloración marrón. Se evaluó la incidencia de ambos desórdenes, expresándose el resultado como ID.

No se observaron daños significativos en las mandarinas almacenadas durante 2 semanas en frigoconservación. Sin embargo, al prolongar el almacenamiento en frigoconservación aumentaron los daños tanto por 'pitting' como por 'SERB', siendo este aumento más acusado en los frutos control que mostraron un daño entre ligero y medio tras un almacenamiento en frigoconservación de 3 semanas, y un daño medio al cabo de 4 semanas. Los frutos se mantuvieron sin daños al cabo de 3 semanas en frigoconservación y mostraron un daño ligero al cabo de 4 
semanas, lo que indica que los recubrimientos tuvieron un efecto beneficioso protegiendo al fruto de ambos desórdenes. No se observó un efecto de la composición del recubrimiento en la incidencia de éstos desórdenes (no se muestran datos).

La necrosis peripeduncular o 'SERB' se produce por una deshidratación de los tejidos anejos al pedúnculo (Martínez-Jávega y del Río, 1998). Por tanto, es previsible que una reducción de la deshidratación del fruto tras la aplicación de recubrimientos, reduzca los daños por 'SERB'. Los daños por 'pitting' se atribuyen a las bajas temperaturas a las que puede exponer el fruto a largo de su desarrollo y/o durante su almacenamiento. Éstas afectan a la permeabilidad de las membranas celulares, produciendo un colapso de las mismas y una pérdida de compartimentación celular (Medeira et al., 1999). Esta pérdida de compartimentación celular, pone en contacto los enzimas de oxidación con sus correspondientes sustratos, y a nivel de la piel se manifiesta con el manchado típico la lesión por 'pitting'. En la presente experiencia, la barrera a los gases $\mathrm{CO}_{2}$ y $\mathrm{O}_{2}$ creada por algunos de los recubrimientos, pudo interferir en los procesos oxidativos descritos. Algunos autores atribuyen la reducción de daños por frío en frutos recubiertos a la modificación de la atmósfera interna del fruto que éstos producen (Wang, 2000).

Otros autores han observado un efecto beneficioso de los recubrimientos reduciendo la incidencia de desórdenes fisiológicos en cítricos (Cuquerella et al., 1981; Aljuburi y Huff, 1984; McDonald, 1986; Hagenmaier et al., 2002; Pérez-Gago et al., 2002; Rojas, 2002).

\section{IV.4.2.7. Índice de desprendimiento del recubrimiento}

La fragilidad observada en las películas con $80 \%$ de CA (Apartado IV.4.1.1) también se manifestó en los correspondientes recubrimientos, los cuales presentaron una textura pulverulenta y una baja adhesividad, desprendiéndose fácilmente con la manipulación de los frutos. La Figura IV.27 muestra que los recubrimientos con $80 \%$ de CA se desprendían casi en su totalidad tras la fricción (valores en torno a 4), y los recubrimientos con 60 y con $40 \%$ de CA se desprendían en una pequeña cantidad (valores en torno a 1$)$. 
En general, el incremento en el CS de las formulaciones aumentó el desprendimiento del recubrimiento lo que pudo ser debido a un incremento en el grosor del mismo (Cisneros-Zevallos y Krochta, 2003). En este caso, la capa más externa de recubrimiento pudo quedar menos adherida a la superficie del fruto presentando mayor sensibilidad a la abrasión (Rojas, 2002).

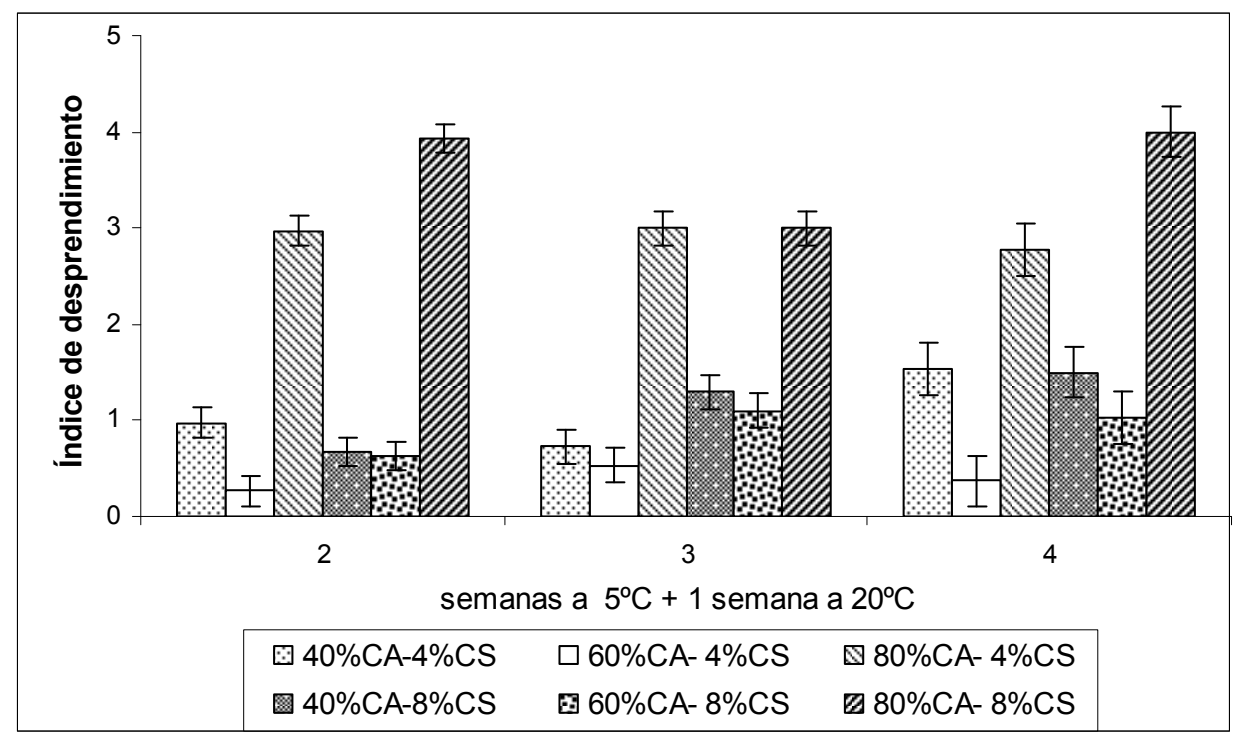

Efecto del contenido en CA y del CS del recubrimiento.

Las barras de error muestran valores de LSD (5\%).

Figura IV.27. Índice de desprendimiento de los recubrimientos aplicados a mandarinas 'Clemenules': efecto del contenido en CA y del CS del recubrimiento.

\section{IV.4.2.8. Evaluación organoléptica: 'flavor' y 'off-flavor'}

El 'flavor' del fruto disminuyó al prolongar el almacenamiento. No obstante, los frutos presentaron una calidad aceptable incluso tras 3 semanas de almacenamiento en refrigeración. No se observaron diferencias significativas de 'flavor' entre tratamientos (no se muestran datos).

El 'off-flavor' de las mandarinas aumentó al prolongar el 
almacenamiento y varió con el tratamiento aplicado, siendo mayor en los frutos recubiertos. La composición de los recubrimientos tuvo un efecto en 'off-flavor' de los frutos. Al aumentar el contenido en CA de los recubrimientos disminuyó el 'off-flavor' y al aumentar el CS aumentó el 'off-flavor' (Figura IV.28). Así por ejemplo, los frutos recubiertos con las formulaciones $40 \% \mathrm{CA}-8 \% \mathrm{CS}$ mostraron niveles medianamente perceptibles (valores en torno a 2) al cabo de 2 y 3 semanas de frigoconservación y alcanzaron niveles bastante perceptibles (valores en torno a 3) al cabo de 4 semanas de frigoconservación, mientras que el resto de tratamientos mostraron valores de off-favor ligeros (valores en torno a 1) en los distintos periodos de almacenamiento ensayados. Estos resultados indican que los recubrimientos empleados permiten prolongar el almacenamiento a $5{ }^{\circ} \mathrm{C}$ de las mandarinas 'Clemenules' hasta 4 semanas, manteniendo una buena calidad organoléptica de las mismas, e incluso 4 semanas si se aplican recubrimientos con un contenido en CA superior a $40 \% \mathrm{y} / \mathrm{o}$ con un CS inferior al $8 \%$.

Los resultados observados se correlacionan con los niveles de etanol y acetaldehído en zumo de las mandarinas. Así por ejemplo, los frutos recubiertos con las formulaciones al $80 \%$ de CA que mostraron niveles de etanol hasta un $40 \%$ inferiores a los del resto de frutos recubiertos, mostraron un 'off-flavor' hasta un 50\% inferior. El CS de los recubrimientos, cuyo aumento incrementó los niveles de etanol hasta en un $60 \%$, aumentó el 'off-flavor' hasta en un $60 \%$. La relación existente entre los niveles de etanol y acetaldehído de los frutos y el desarrollo de 'off-flavor' ha sido observado en trabajos previos (Kader, 1986; Ke y Kader , 1990). Además, la susceptibilidad de los cítricos, y en concreto de las mandarinas, al desarrollo de 'off-flavor', ha sido observada con anterioridad (Davis et al., 1973; Ke y Kader, 1990), especialmente tras la aplicación de recubrimientos de baja permeabilidad a los gases (Cohen et al., 1990; Baldwin et al., 1995; Hagenmaier y Shaw, 2002). 


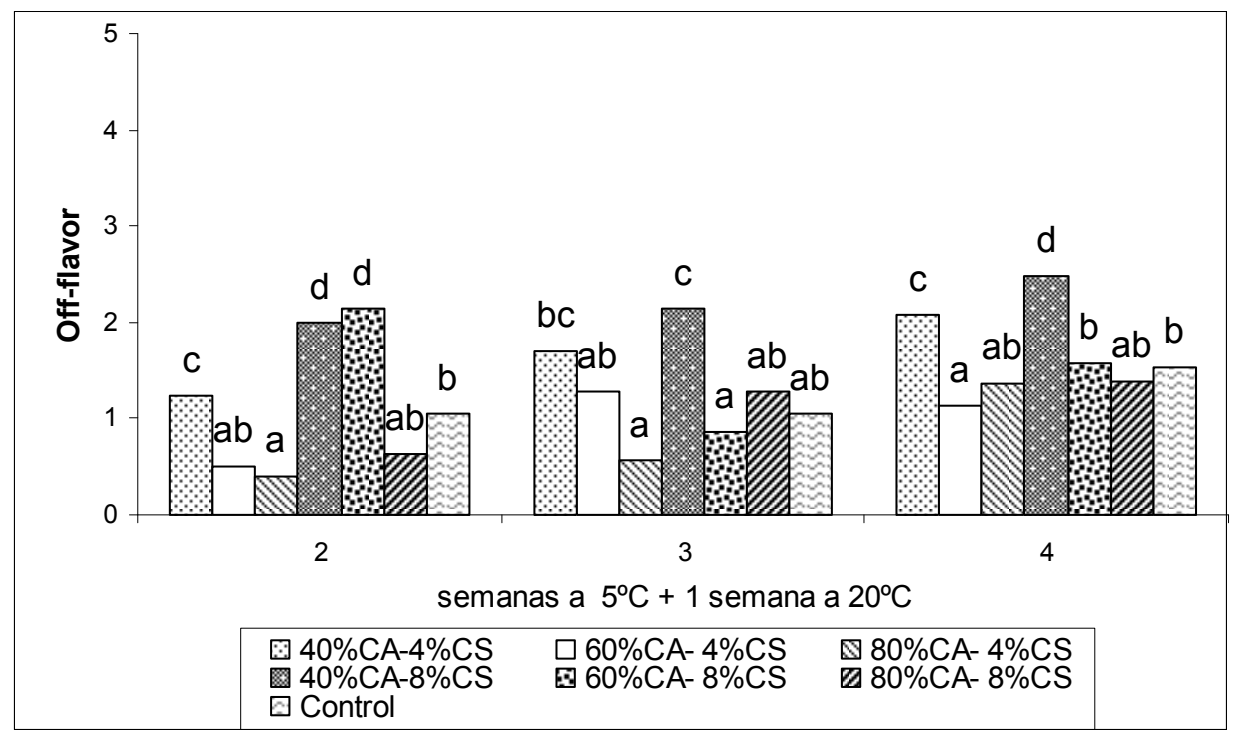

En cada periodo de almacenamiento, valores seguidos de la misma letra no difieren significativamente $(\mathrm{p}<5 \%)$.

Figura IV.28. 'Off-flavor' de mandarinas 'Clemenules' recubiertas y control: efecto del contenido en CA y del CS del recubrimiento.

\section{IV.4.2.9. Aspecto externo y brillo del fruto}

Los tratamientos 40\%CA-4\%CS y $60 \%$ CA-4\%CS mostraron un aspecto externo y un brillo similar a los frutos control, pero el resto de tratamientos mostraron peor aspecto (menores puntuaciones de aspecto externo) y menor brillo (menores puntuaciones de brillo) (Figura IV.29). La composición de los recubrimientos afectó ambos parámetros. Al aumentar el contenido en CA y/o el CS empeoró el aspecto del fruto y disminuyó el brillo. Las formulaciones con $80 \%$ de CA formaron recubrimientos pulverulentos de color blanquecino que daban un aspecto mate al fruto y fueron las peor valoradas. Al aumentar el CS de las formulaciones, empeoró el aspecto externo de los frutos. Los recubrimientos con 40 y con $60 \%$ de CA, que al $4 \%$ de CS mostraban un buen aspecto, cuando se formularon al $8 \%$ de CS, presentaron manchas blancas y pulverulentas y un aspecto mate, obteniendo menores puntuaciones de aspecto externo y menor brillo (Figura IV.30). 

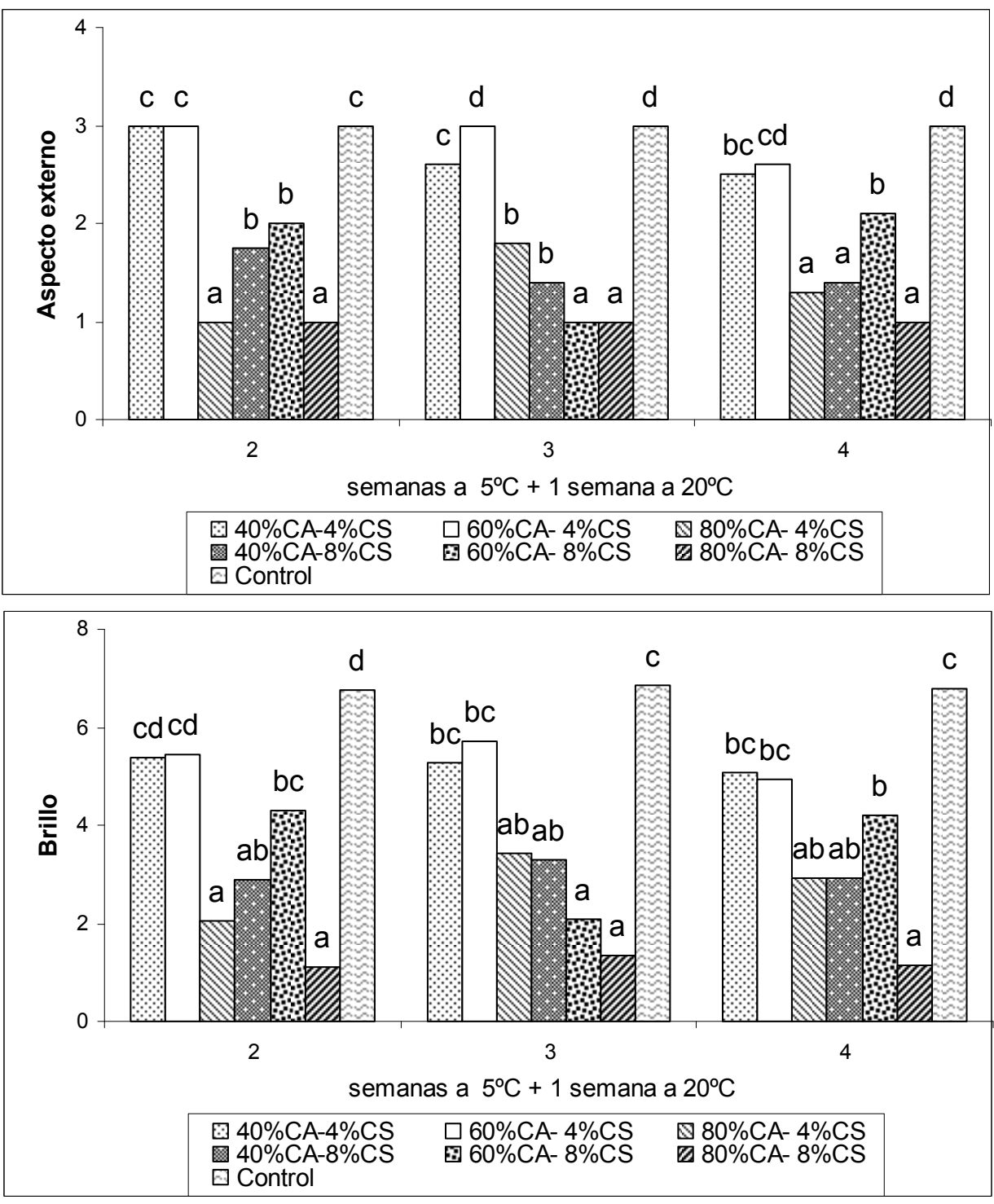

En cada periodo de almacenamiento, valores seguidos de la misma letra no difieren significativamente $(\mathrm{p}<5 \%)$.

Figura IV.29. Aspecto externo y brillo de mandarinas 'Clemenules' recubiertas y control: efecto del contenido en CA y del CS del recubrimiento. 


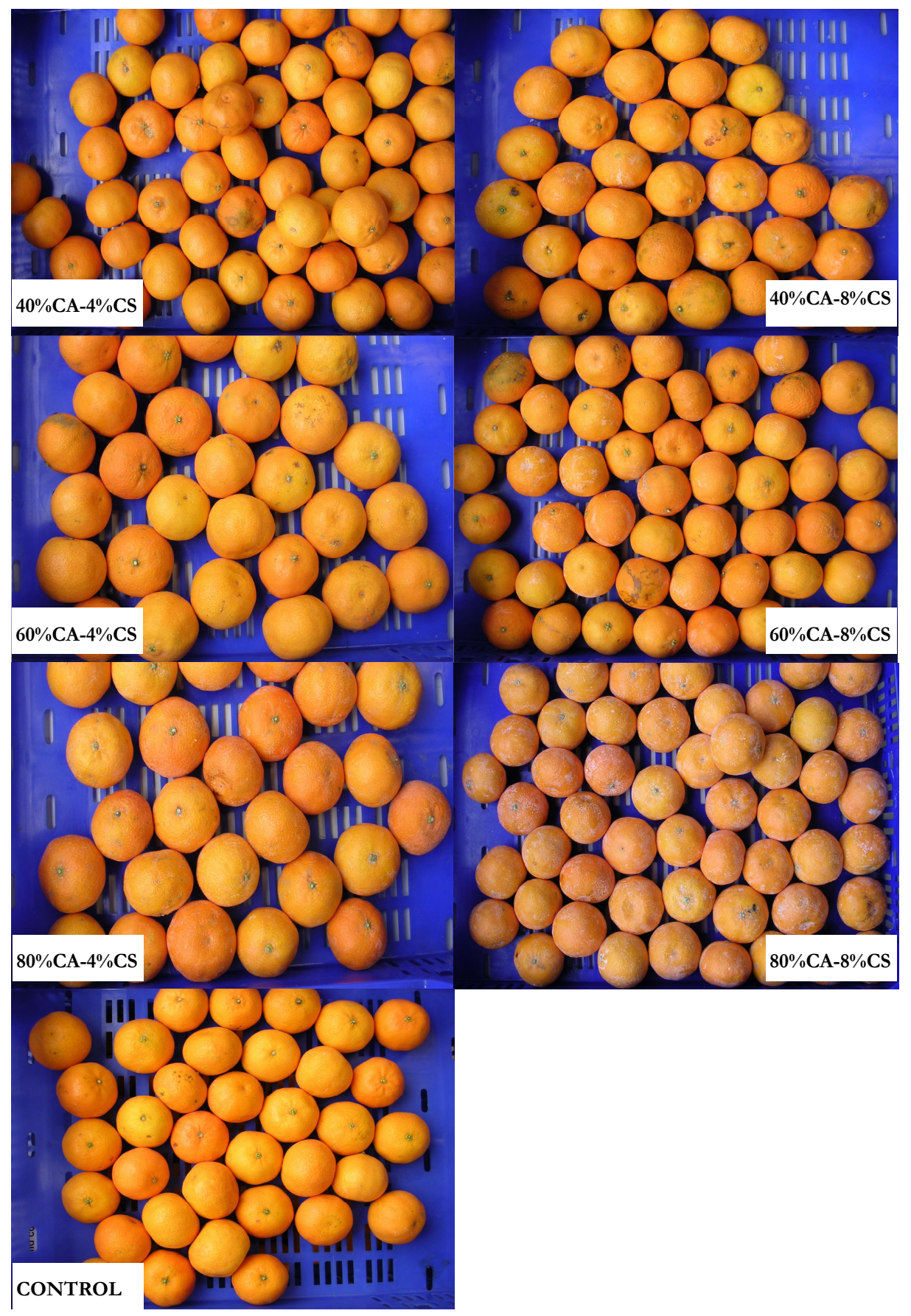

Figura IV.30. Aspecto de mandarinas 'Clemenules' recubiertas y control tras un almacenamiento de 2 semanas a $5^{\circ} \mathrm{C}+1$ semana a $20^{\circ} \mathrm{C}$. 


\section{IV.4.3. Síntesis de resultados}

El objetivo de la presente experiencia fue estudiar el efecto del contenido de CA y el CS de recubrimientos compuestos a base de HPMC y CA en la calidad postcosecha de mandarinas cv. 'Clemenules'. Para ello se estudió el efecto de estos factores en las propiedades de películas aisladas y se evaluaron distintos parámetros de calidad de las mandarinas recubiertas, comparándolas con frutas control. A continuación se hace un resumen de los resultados más relevantes.

Los recubrimientos estudiados redujeron la pérdida de peso, la pérdida de firmeza y la incidencia de daños fisiológicos externos de las mandarinas, pero no mejoraron significativamente el aspecto externo y brillo de las mandarinas, y en algunos casos aumentaron los niveles de etanol y acetaldehído y los malos sabores.

Un aumento en el contenido en CA de 40 a $80 \%$, con la consiguiente reducción en el contenido de HPMC, redujo la integridad física del recubrimiento pero no afectó la capacidad del recubrimiento para reducir la pérdida de peso de las mandarinas 'Clemenules'. Además, el aumento en el contenido de $\mathrm{CA}$, redujo los niveles de $\mathrm{CO}_{2}$ interno y aumentó los niveles de $\mathrm{O}_{2}$ interno, y redujo los niveles de etanol y acetaldehído en zumo y los malos sabores. Sin embargo, una reducción en el contenido en CA mejoró el aspecto externo de las mandarinas 'Clemenules' recubiertas y aumentó su brillo.

El CS de las formulaciones afectó la calidad de las mandarinas 'Clemenules' recubiertas. Un aumento en el CS aumentó la barrera a los gases $\mathrm{CO}_{2}$ y $\mathrm{O}_{2}$, aumentado los niveles de etanol y acetaldehído y los malos sabores en mandarinas 'Clemenules' recubiertas. Además, redujo el grado de adhesión del recubrimiento y su resistencia a la manipulación, y redujo el brillo del recubrimiento y empeoró el aspecto externo de las mandarinas recubiertas. Sin embargo, el CS no afectó la pérdida de peso de las mandarinas 'Clemenules' recubiertas, ni tampoco a la firmeza, ni a los desórdenes fisiológicos externos de las mandarinas.

Como conclusión general cabe decir que un aumento en el contenido de CA y una reducción del contenido de HPMC reduce la pérdida de peso y los niveles de etanol y acetaldehído, mejorando el sabor 
de las mandarinas. Sin embargo, un exceso de CA y/o un defecto de HPMC del recubrimiento, empeora la adhesión a la piel del fruto, el aspecto y brillo del mismo, lo que obliga a establecer un compromiso entre los distintos atributos de calidad involucrados, determinar el tiempo de almacenamiento óptimo y/o optimizar la composición de los recubrimientos para su aplicación a mandarinas 'Clemenules'. En cuanto al CS sería interesante estudiar el CS mínimo para obtener recubrimientos funcionales aplicables a mandarinas 'Clemenules'.

\section{IV.5. EFECTO DEL TIPO Y CONTENIDO DE ÁCIDO GRASO DE LA FORMULACIÓN EN LAS CARACTERÍSTICAS DE LAS PELÍCULAS Y EN LA CALIDAD POSTCOSECHA DE MANDARINAS 'ORTANIQUE’ RECUBIERTAS}

\section{IV.5.1. Análisis de las emulsiones y de las películas preformadas en placa}

\section{IV.5.1.1. Aspecto de las emulsiones y de las películas}

Las formulaciones estudiadas en esta experiencia fueron las mismas que en la experiencia 'Efecto del tipo y contenido de $A G$ de la formulación en las características de las películas y en la calidad postcosecha de ciruelas 'Angeleno' recubiertas'. La evaluación del aspecto de las emulsiones y de las películas preformadas en placa se describe en el Apartado IV.2.1.1.

\section{IV.5.1.2. Propiedades mecánicas de las películas}

Las formulaciones estudiadas en esta experiencia fueron las mismas que en la experiencia 'Efecto del tipo y contenido de $A G$ de la formulación en las características de las peliculas y en la calidad postcosecha de ciruelas 'Angeleno' recubiertas'. Las propiedades mecánicas de estas películas se muestran en el Apartado IV.2.1.2.

\section{IV.5.1.3. Permeabilidad al vapor de agua de las películas}

Las formulaciones estudiadas en esta experiencia fueron las mismas que en la experiencia 'Efecto del tipo y contenido de $A G$ de la formulación en las características de las películas y en la calidad postcosecha de ciruelas 'Angeleno' 
recubiertas'. Los resultados de PVA correspondientes se muestran en el Apartado IV.2.1.3.

\section{IV.5.2. Análisis de calidad de las mandarinas 'Ortanique' recubiertas}

\section{IV.5.2.1. Pérdida de peso}

La Figura IV.31 muestra la pérdida de peso de las mandarinas 'Ortanique' recubiertas y control expresada en porcentaje de peso relativo al peso inicial del fruto. Las pérdidas de peso aumentaron al prolongar el tiempo de almacenamiento, llegando a ser de un 11\% al cabo de 6 semanas de almacenamiento en frigoconservación más 1 semana a $20{ }^{\circ} \mathrm{C}$. Los recubrimientos fueron efectivos reduciendo la pérdida de peso de las mandarinas a partir de 3 semanas de almacenamiento refrigerado y se alcanzaron reducciones de peso de hasta un $5 \%$ en algunos tratamientos. En anteriores experiencias realizadas con ciruelas 'Angeleno' a las que se aplicó recubrimientos de igual composición a los estudiados en esta experiencia, no se observó una efectividad de los mismos reduciendo la pérdida de peso de los frutos, lo que confirma la importancia de las características del fruto en la funcionalidad de los recubrimientos.

El tipo de AG del recubrimiento afecto la pérdida de peso de las mandarinas recubiertas. Los recubrimientos conteniendo AO fueron más efectivos reduciendo la pérdida de peso que los que contenían AP, y éstos a su vez más efectivos que los de AE.

La mayor efectividad de los recubrimientos con AO reduciendo la pérdida de peso de las mandarinas pudo ser debida a una mejora en la barrera al vapor de agua de estos recubrimientos, conforme a los datos de PVA de las películas aisladas (Tabla IV.7). La formación de una capa oleaginosa y continua de $\mathrm{AO}$ en la superficie de los recubrimientos pudo sellar las discontinuidades del mismo y ejercer un barrera al vapor de agua en las zonas del recubrimiento desprovistas de CA, evitando la pérdida de agua del fruto. Además, la adición de $\mathrm{AO}$ a las formulaciones pudo aumentar la flexibilidad de los recubrimientos, de acuerdo con los resultados observados en películas aisladas (Figura IV.9), facilitando la adaptación del mismo a los cambios de volumen de fruto durante el almacenamiento y mejorando su integridad física, lo que se traduce en una 
mejora de las propiedades barrera del recubrimiento.

El efecto del contenido de AG en la pérdida de peso de los frutos recubiertos varió a lo largo del almacenamiento y con el tipo de AG. Hasta 2 semanas de almacenamiento a $20{ }^{\circ} \mathrm{C}$ una reducción del contenido de $\mathrm{AE}$ o de $\mathrm{AP}$, redujo la pérdida de peso de las mandarinas y al prolongar el almacenamiento, el contenido de AG del recubrimiento dejó de afectar a la pérdida de peso de las mandarinas, independientemente del tipo empleado. El contenido de AO del recubrimiento no afectó la pérdida de peso de las mandarinas, lo que indica que un aumento en el contenido de AO del $8 \%$ al $20 \%$ (b.s.) no mejora la barrera al vapor de agua del recubrimiento.

Atendiendo a la composición de los recubrimientos estudiados, observamos que una reducción del contenido de AG de las formulaciones va acompañada de un incremento en el contenido de HPMC, manteniéndose constante el contenido de CA (Tabla III.2). Por tanto, de acuerdo con los resultados obtenidos se puede decir que la sustitución de AP y/o AE por HPMC mejora la barrera al vapor de agua del recubrimiento, a pesar del carácter hidrofílico del HPMC e hidrofóbico de los AG, lo que pudo ser debido a una mejora en la distribución de las partículas de CA en la matriz de HPMC al aumentar el contenido de HPMC, dado su carácter emulsificante (Callegarin et al., 1997). 


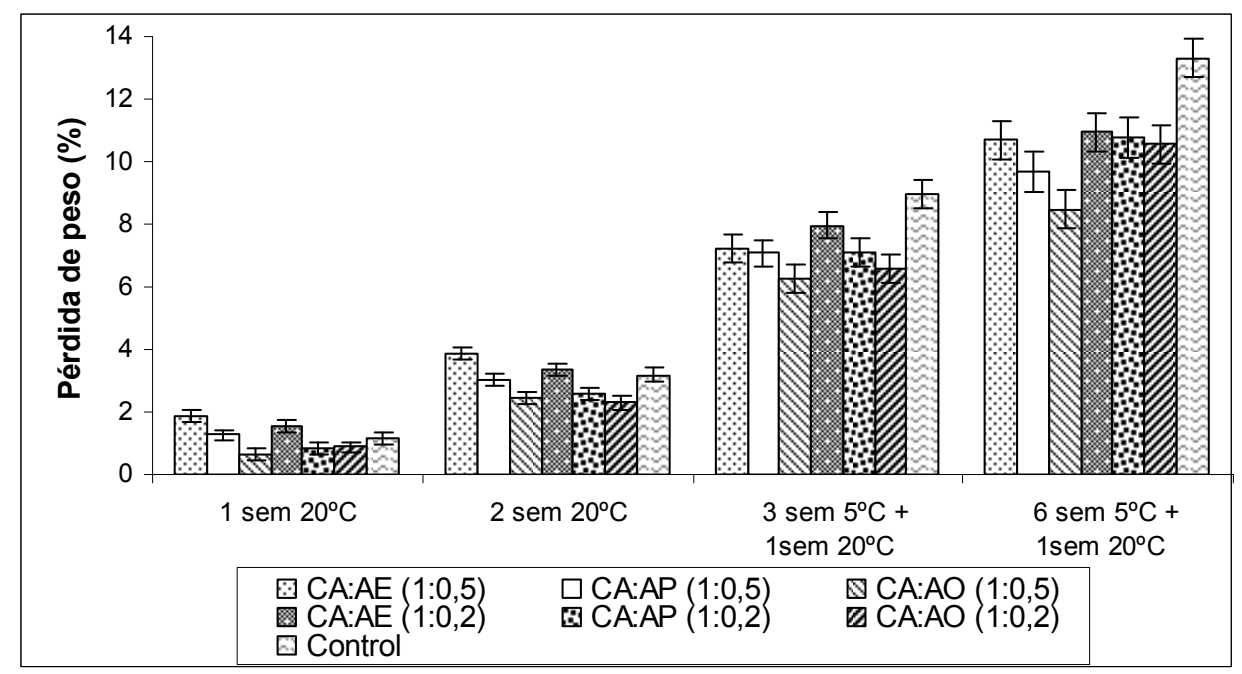

Las barras de error muestran valores de LSD (5\%).

Figura IV.31. Pérdida de peso (\%) de mandarinas 'Ortanique' recubiertas y control: efecto del tipo y contenido de AG del recubrimiento.

\section{IV.5.2.2. Sólidos solubles totales, acidez e índice de madurez}

No se observó un efecto significativo del tiempo de almacenamiento ni del tratamiento aplicado en la acidez, los sólidos solubles y el IM de las mandarinas (no se muestran datos).

\section{IV.5.2.3. Contenido de $\mathrm{CO}_{2}$ y $\mathrm{O}_{2}$ interno}

La Figura IV.32 muestra el contenido de $\mathrm{O}_{2}$ y $\mathrm{CO}_{2}$ interno de las mandarinas recubiertas y control. En ella se observa que los niveles de $\mathrm{O}_{2}$ interno disminuyeron al prolongar el tiempo de almacenamiento, aumentando los niveles de $\mathrm{CO}_{2}$ interno. Se observa, además, un descenso del contenido en $\mathrm{O}_{2}$ y un aumento del $\mathrm{CO}_{2}$ de los frutos recubiertos respecto a los frutos control lo que indica que los recubrimientos ejercieron una barrera a los gases $\mathrm{O}_{2}$ y $\mathrm{CO}_{2}$. La composición de los mismos afectó las propiedades barrera a ambos gases.

El tipo de AG afectó las propiedades barrera a los gases $\mathrm{O}_{2}$ y $\mathrm{CO}_{2}$ del recubrimiento y este efecto dependió del contenido del mismo y del 
tiempo de almacenamiento. Para una proporción CA:AG $(1: 0,5)$ los recubrimientos con $\mathrm{AO}$ dieron menores niveles de $\mathrm{O}_{2}$ interno y mayores niveles de $\mathrm{CO}_{2}$ interno que los recubrimiento con AP. Los recubrimientos con AP dieron a su vez menores niveles de $\mathrm{O}_{2}$ y mayores niveles de $\mathrm{CO}_{2}$ que los recubrimientos con $\mathrm{AE}$. Estos resultados indican que los recubrimientos con $\mathrm{AO}$ ejercieron una mayor barrera a ambos gases que los recubrimientos con AP y estos a su vez mejor que los de AE. Sin embargo, para una proporción CA:AG de (1:0,2) sólo se observó un efecto del tipo de AG cuando los frutos se almacenaron 1 semana a $20^{\circ} \mathrm{C}$, siendo indiferente para el resto de ensayos realizados. Estos resultados indican que el tipo de $\mathrm{AG}$ afecta la barrera a los gases $\mathrm{CO}_{2}$ y $\mathrm{O}_{2}$ a partir de un cierto contenido del mismo en la formulación y que por debajo de éste hay otros factores que determinan las propiedades barrera a los gases del recubrimiento.

La mayor barrera a los gases $\mathrm{CO}_{2}$ y $\mathrm{O}_{2}$ de los recubrimientos con $\mathrm{AO}$ en los casos descritos, pudo ser debida a una mejor integridad física del recubrimiento y de su capacidad sellando las vías de intercambio a los gases, lo que pudo ser debido a una mayor flexibilidad de éstos (Figura IV.9). La adición de AO pudo, por tanto, mejorar la continuidad del recubrimiento en la superficie del fruto y su capacidad para adaptarse a los cambios de volumen del fruto durante el almacenamiento y a los cambios de temperatura a lo largo del almacenamiento, reduciendo el intercambio a los gases $\mathrm{CO}_{2}$ y $\mathrm{O}_{2}$.

En general, al reducir contenido de AE y AP del recubrimiento disminuyó el $\mathrm{O}_{2}$ interno y aumentó el $\mathrm{CO}_{2}$. Sin embargo, el contenido en AO no afectó las propiedades barrera a los gases $\mathrm{O}_{2}$ y $\mathrm{CO}_{2}$ del recubrimiento.

Según Guilbert (1986) en recubrimientos compuestos los hidrocoloides, como la HPMC, aportan al recubrimiento la barrera a los gases $\mathrm{O}_{2}$ y $\mathrm{CO}_{2}$, y los lípidos la barrera al vapor de agua. Por tanto, la barrera a los gases $\mathrm{O}_{2}$ y $\mathrm{CO}_{2}$ está más afectada por el contenido de hidrocoloide de la formulación que por el contenido de lípido. Atendiendo a la composición de los recubrimientos estudiados (Tabla III.3) observamos que una reducción del contenido de $A G$ de las formulaciones va acompañada de un incremento en el contenido de HPMC. Por tanto el incremento de la barrera a los gases observado al 
reducir el contenido de AE o de AP pudo ser debido a un aumento del contenido de HPMC. Sin embargo, en los recubrimientos de AO, ni el contenido de HPMC, ni el de AO afectaron la barrera a los gases $\mathrm{O}_{2}$ y $\mathrm{CO}_{2}$. Este resultado pone de manifiesto que la adición de $\mathrm{AO}$ a los recubrimientos tiene un efecto importante en la barrera a los gases, hasta el punto de disipar los efectos del contenido en HPMC, y que, como se ha comentado en el presente epígrafe, puede estar relacionado con las propiedades mecánicas de estos recubrimientos. 

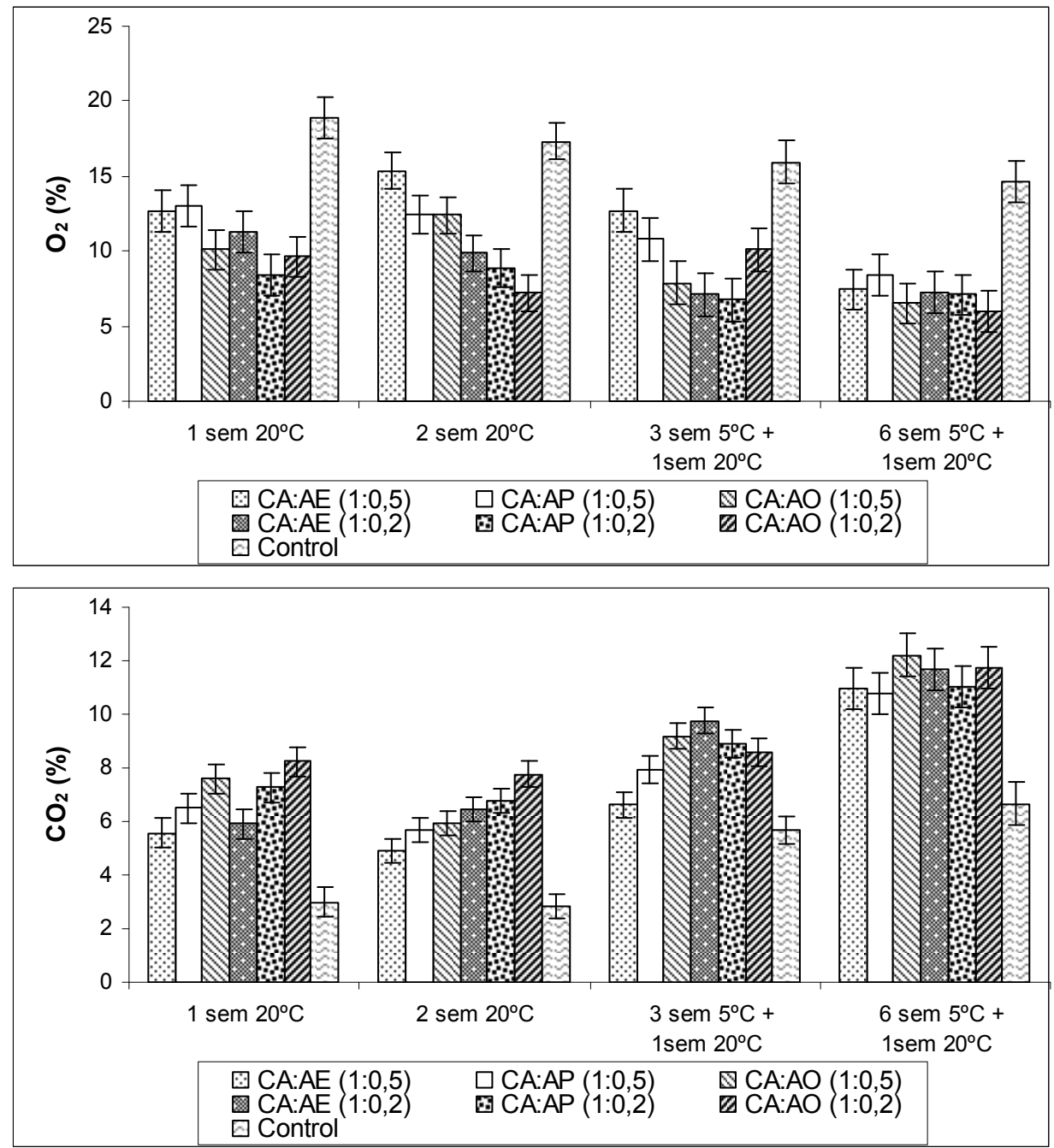

Las barras de error muestran valores de LSD (5\%).

Figura IV.32. $\mathrm{O}_{2}$ y $\mathrm{CO}_{2}$ interno de mandarinas 'Ortanique' recubiertas y control: efecto del tipo y contenido de AG del recubrimiento. 


\section{IV.5.2.4. Etanol y acetaldehído en zumo}

La modificación de la atmósfera interna de las mandarinas estuvo acompañada de un incremento en el contenido de etanol y acetaldehído de las mismas, de manera que una reducción de los niveles de $\mathrm{O}_{2}$ interno y/o un aumento de los niveles de $\mathrm{CO}_{2}$ supuso un aumento de los niveles de etanol y acetaldehído en zumo.

La aplicación de recubrimientos y la prolongación del tiempo de almacenamiento aumentaron los niveles de etanol y acetaldehído de las mandarinas, alcanzándose niveles de etanol en torno a $500 \mathrm{mg} / 100 \mathrm{~mL}$ (Figura IV.33). Estos niveles de etanol resultan relativamente altos si se comparan con los obtenidos en otras variedades de mandarina almacenadas en condiciones similares. Sin embargo, son comparables a los obtenidos por Salvador et al. (2000) en mandarinas 'Ortanique' en similares condiciones de almacenamiento. Los resultados obtenidos indican la importancia del cultivar en la síntesis de etanol de las mandarinas.

La composición del recubrimiento afectó al contenido de etanol y acetaldehído de forma análoga a cómo afectó la atmósfera interna del fruto. Así, el tipo de AG afectó a los niveles de ambos componentes sólo en los recubrimientos con proporción CA:AG (1:0,5), siendo los recubrimientos con $\mathrm{AO}$ los que mayores niveles de etanol y acetaldehído proporcionaron y los de AE los de menores niveles. Sólo el contenido de AE y AP del recubrimiento afectó los niveles de etanol y acetaldehído de las mandarinas, siendo menores al reducir el contenido de los mismos y/o aumentar el contenido de HPMC de la formulación. 

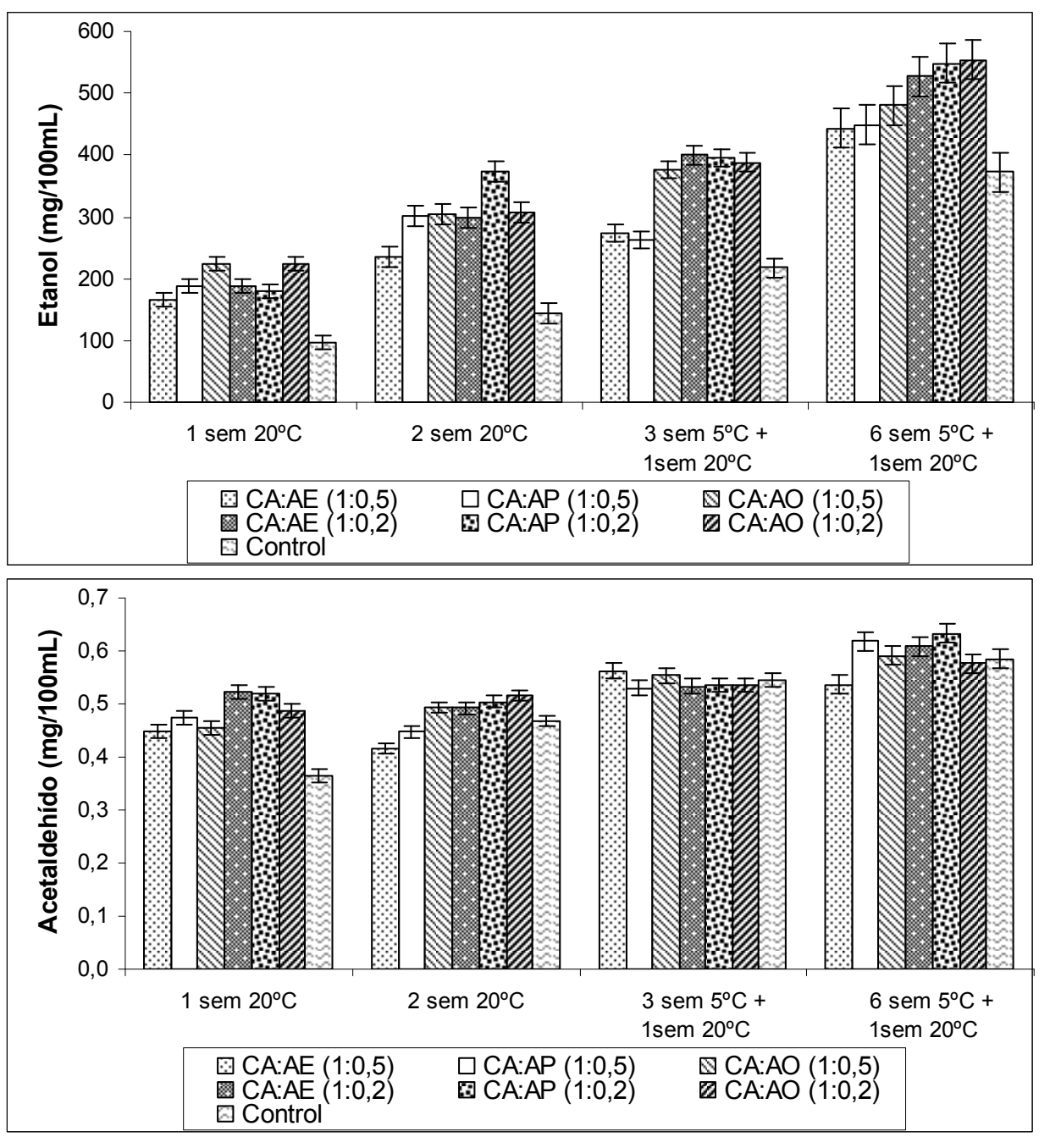

Las barras de error muestran valores de LSD (5\%).

Figura IV.33. Etanol y acetaldehído (mg/100mL) en zumo de mandarinas 'Ortanique' recubiertas y control: efecto del tipo y contenido de AG del recubrimiento. 


\section{IV.5.2.5. Firmeza}

La firmeza de las mandarinas disminuyó al prolongar el tiempo de almacenamiento, observándose un incremento de la deformación de las mimas. La aplicación de los recubrimientos CA:AO (1:0,5) redujo la pérdida de firmeza de las mandarinas respecto a los frutos control a partir de 3 semanas en frigoconservación (Figura IV.34). Esta retención de firmeza pudo ser debida a una menor deshidratación de las mandarinas (Figura IV.31), lo que mantuvo la turgencia de las mismas y redujo su deformación (Ben-Yehoshua, 1985; Cuquerella et al., 1988 Pozzan et al., 1993).

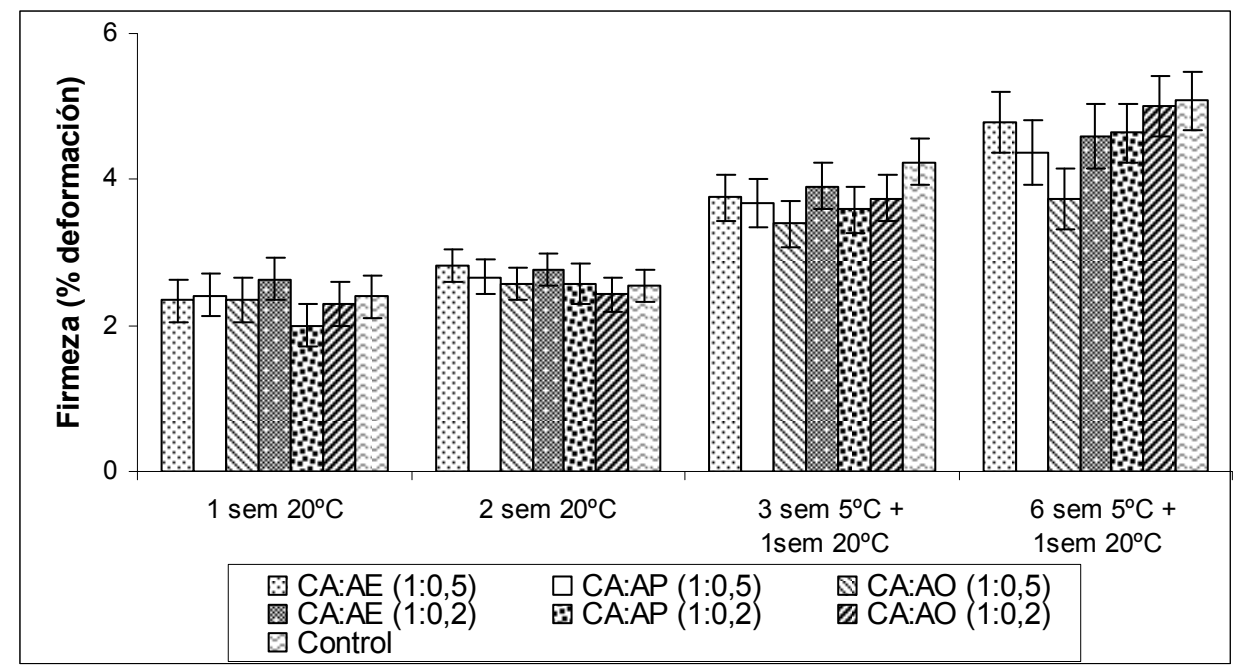

Las barras de error muestran valores de LSD (5\%).

Figura IV.34. Firmeza (\% deformación) de mandarinas 'Ortanique' recubiertas y control: efecto del tipo y contenido de AG del recubrimiento.

\section{IV.5.2.6. Desórdenes fisiológicos}

La incidencia de desórdenes fisiológicos fue mínima incluso tras 6 semanas de frigoconservación. Sólo algunos frutos presentaron daños ligeros por 'SERB' o 'pitting', pero en ningún caso fueron representativos del tratamiento en cuestión. Estos resultados indican la baja sensibilidad de las mandarinas 'Ortanique' al desarrollo de desórdenes fisiológicos, el 
buen estado fisiológico de las mismas antes del almacenamiento y las buenas prácticas postcosecha utilizadas. No se observaron diferencias significativas entre los distintos tratamientos (no se muestran datos).

Salvador et al. (2000) observaron que las mandarinas 'Ortanique' almacenadas a $5{ }^{\circ} \mathrm{C}$ hasta 13 semanas no desarrollaban daños por frío y que la aparición de los mismos se daba a partir de 13 semanas a temperaturas de refrigeración en torno a $1^{\circ} \mathrm{C}$. También observaron que la aplicación de recubrimientos a base de cera de polietileno reducía la incidencia de los daños en frutos almacenados a $1{ }^{\circ} \mathrm{C}$. Por tanto, las condiciones de almacenamiento empleadas en nuestro estudio preservaron a las mandarinas de los daños por frío, evitando el desarrollo de los mismos.

\section{IV.5.2.7. Índice de color}

La degradación de las clorofilas de la piel de los cítricos durante la maduración y senescencia, supone una pérdida de la coloración verde y un desenmascaramiento de los carotenoides, que son pigmentos de color amarillo y naranja, con el consiguiente cambio de color. Conforme avanza la maduración y senescencia, se pierden las tonalidades amarillas, predominando las naranjas, que permanecen inalteradas durante la senescencia. El índice de color (IC) es un indicador de éste viraje de color que experimentan los cítricos y su medida resulta interesante en frutos sometidos a tratamientos de desverdización, puesto que permite evaluar la eficiencia de los mismos.

Para detectar un posible efecto de la aplicación de recubrimientos en el color de la piel de las mandarinas, se midió el IC. Sin embargo, no se observaron diferencias en el IC entre tratamientos (no se muestran datos).

\section{IV.5.2.8. Índice de desprendimiento del recubrimiento}

La Figura IV.35 muestra el índice de desprendimiento de los recubrimientos aplicados. En ella se observa que el desprendimiento de los mismos fue poco importante, siendo ligero en el peor de los casos, lo que indica una buena resistencia de los recubrimientos a la abrasión y una buena adhesión de los mismos a la superficie de las mandarinas. 
En general el desprendimiento de los recubrimientos disminuyó al reducir el contenido de AG de los mismos y fue menor en los formulados con AP y AO. La mejora de la adhesión de estos recubrimientos pudo estar relacionada con la mayor flexibilidad de los mismos tal y como se observó en las propiedades mecánicas de las películas aisladas (Figura IV.9).

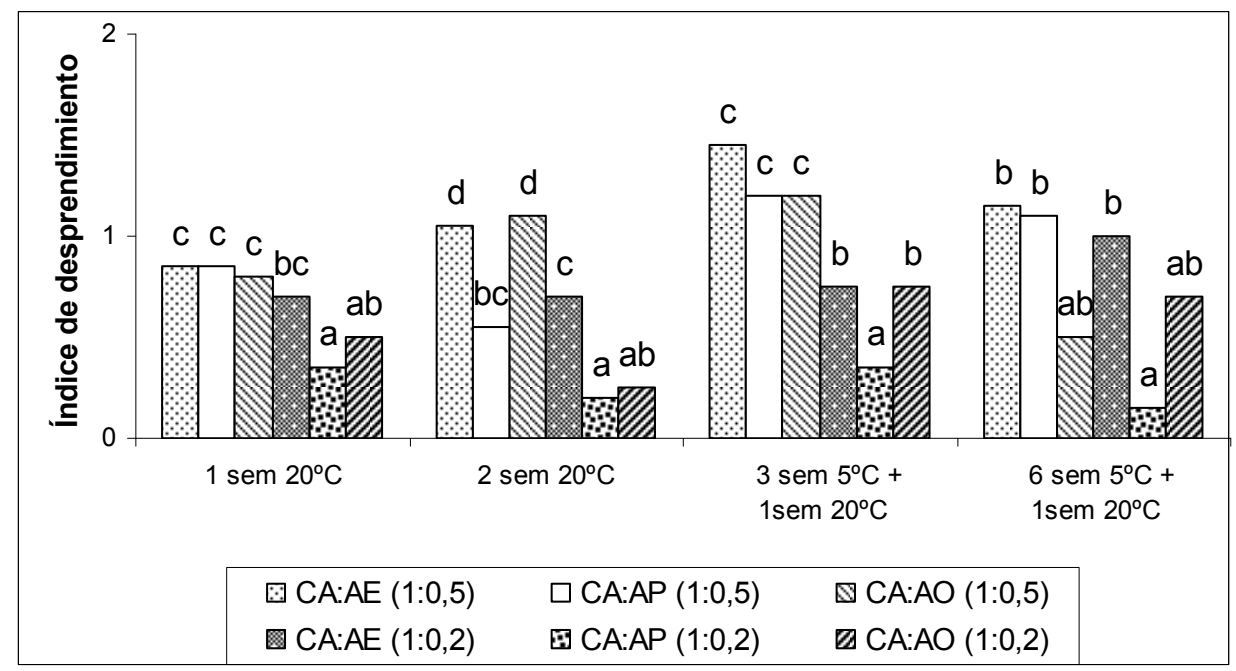

Las barras de error muestran valores de LSD (5\%).

Figura IV.35. Índice de desprendimiento de los recubrimientos aplicados a mandarinas 'Ortanique': efecto del tipo y contenido de AG del recubrimiento.

\section{IV.5.2.9. Evaluación organoléptica: 'flavor' y 'off-flavor'}

El 'flavor' del las mandarinas disminuyó al prolongar el tiempo de almacenamiento, pero se mantuvo dentro de una calidad aceptable, incluso tras 6 semanas de frigoconservación. El tipo de AG afectó el 'flavor' del fruto en el caso de recubrimientos con proporción CA:AG $(1: 0,5)$, siendo menor en los recubrimientos de AO. El contenido de AO no afectó el 'flavor' de las mandarinas y el contenido de AE y AP sólo afectó el 'flavor' en mandarinas almacenadas 1 y 2 semanas a $20^{\circ} \mathrm{C}$, disminuyéndolo al disminuir el contenido de los mismos (Figura IV.36).

El 'off-flavor' de las mandarinas aumentó al prolongar el 
almacenamiento de 1 a 2 semanas a $20{ }^{\circ} \mathrm{C}$, alcanzando niveles medianamente perceptibles (valores en torno a 2). Para la mayoría de tratamientos, un aumento del periodo de frigoconservación no aumentó el 'off-flavor' de las mismas y sólo en algún tratamiento se observó un incremento del 'off-flavor' hasta niveles bastante perceptibles (valores en torno a 3). No se observó un claro efecto de la composición de los recubrimientos en el 'off-flavor' de las mandarinas (Figura IV.36).

En general, se observó una correspondencia entre los niveles de etanol y acetaldehído de las mandarinas y el 'flavor' de las mismas, con una tendencia similar en cuanto a la composición de los recubrimientos. Sin embargo, resulta interesante ver que a pesar de los altos niveles de etanol alcanzados (en torno a $500 \mathrm{mg} / 100 \mathrm{~mL}$ ), la calidad de las mandarinas sea aceptable y que los niveles de 'off-flavor' sean relativamente bajos, puesto que el contenido en etanol se ha relacionado con los malos sabores de los cítricos (Davis et al., 1973; Ke y Kader, 1990). En la presente experiencia el umbral de detección de 'off-flavor' (valores en torno a 1) se correspondió con niveles de etanol en torno a $200 \mathrm{mg} / 100 \mathrm{~mL}$ y el máximo 'off-flavor' detectado (valores en torno a 3) se correspondió con niveles de etanol en torno a $500 \mathrm{mg} / 100 \mathrm{~mL}$. En anteriores experiencias realizadas con mandarinas 'Clemenules' el umbral de detección de 'off-flavor' se dio a concentraciones de etanol en torno a $50 \mathrm{mg} / 100 \mathrm{~mL}$ y concentraciones en torno a $100 \mathrm{mg} / 100 \mathrm{~mL}$ dieron un 'off-flavor' bastante perceptible con valores en torno a 3. Estos resultados ponen de manifiesto que en la calidad organoléptica de los cítricos intervienen, además de los niveles de etanol en zumo, otros factores propios del cultivar. Salvador et al. (2000) obtuvieron resultados similares en mandarinas 'Ortanique', observando que al cabo de 8 semanas de almacenamiento en refrigeración más una semana a $20^{\circ} \mathrm{C}$ se alcanzaban niveles de etanol en zumo en torno a 400 $\mathrm{mg} / 100 \mathrm{~mL}$, no detectándose malos sabores y siendo la calidad o 'flavor' satisfactoria. 

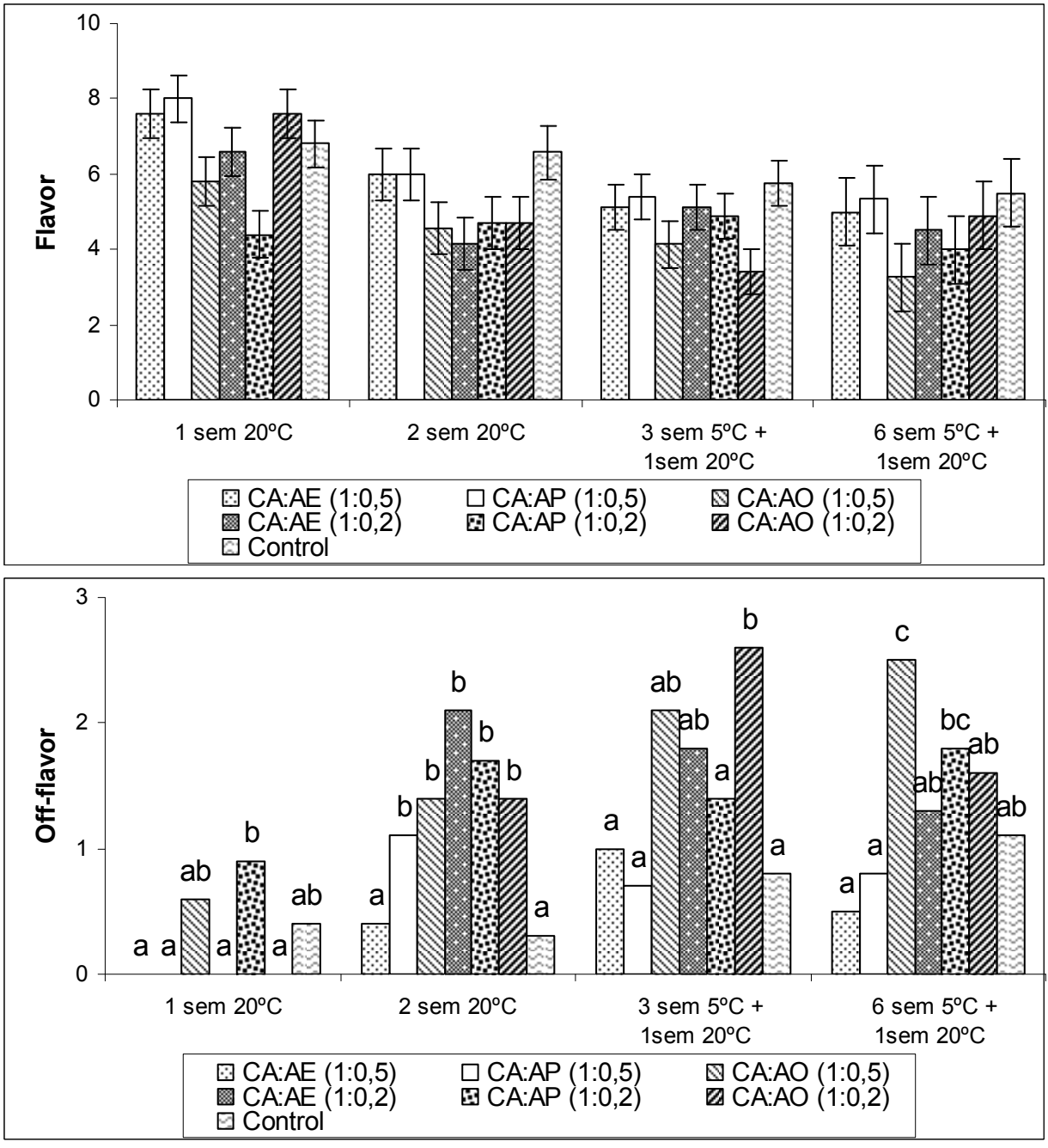

Las barras de error muestran valores de LSD (5\%).

En cada periodo de almacenamiento, valores seguidos de la misma letra no difieren significativamente $(\mathrm{p}<5 \%)$.

Figura IV.36. 'Flavor' y 'Off-flavor' de mandarinas 'Ortanique' recubiertas y control: efecto del tipo y contenido de AG del recubrimiento. 


\section{IV.5.2.10. Aspecto externo y brillo del fruto}

No se observaron diferencias de aspecto y brillo a lo largo del almacenamiento entre los distintos tratamientos (no se muestran datos).

\section{IV.5.3. Síntesis de resultados}

El objetivo de la presente experiencia fue estudiar el efecto del tipo y contenido de AG de recubrimientos compuestos a base de HPMC y CA en la calidad postcosecha de mandarinas cv. 'Ortanique'. Para ello se estudió el efecto de estos factores en las propiedades de películas aisladas y se evaluaron distintos parámetros de calidad de las mandarinas recubiertas, comparándolas con frutas control. A continuación se hace un resumen de los resultados más relevantes.

Los recubrimientos estudiados redujeron la pérdida de peso y de firmeza de las mandarinas 'Ortanique', y a pesar de incrementar los niveles de etanol y acetaldehído de las mandarinas, no redujeron de manera significativa la calidad organoléptica de las mismas.

El tipo de AG afectó la funcionalidad de los recubrimientos. De los AG estudiados (AE, AP y AO), el AO resultó el más efectivo reduciendo la pérdida de peso, lo que se tradujo en una mayor firmeza de las mandarinas. Además, el tipo de AG afectó la barrera a los gases $\left(\mathrm{CO}_{2} \mathrm{y}\right.$ $\mathrm{O}_{2}$ ) de los recubrimientos a partir de un cierto contenido del mismo (proporción CA:AG 1:0,5). El AO incrementó la barrera a los gases $\left(\mathrm{CO}_{2}\right.$ y $\mathrm{O}_{2}$ ) del recubrimiento respecto al resto de $A G$, observándose un aumento en los niveles de etanol y acetaldehído. Se observó asimismo una reducción del 'flavor' de las mandarinas, pero se mantuvo un nivel de calidad organoléptica aceptable incluso tras 6 semanas de frigoconservación seguido de una semana a $20^{\circ} \mathrm{C}$.

La mayor efectividad de los recubrimientos con AO reduciendo la pérdida de peso de las mandarinas y aumentando la barrera a los gases $\left(\mathrm{CO}_{2}\right.$ y $\left.\mathrm{O}_{2}\right)$ del recubrimiento pudo ser debido a la formación de una capa oleaginosa que sellara las discontinuidades del recubrimiento, y a una mejora en la flexibilidad del recubrimiento que redujera su fracturabilidad y facilitara la adaptación del mismo a los cambios de volumen de fruto 
durante el almacenamiento, mejorando su integridad física y su capacidad para formar una capa continua en la superficie del fruto.

Entre los resultados obtenidos cabe señalar algunos datos interesantes relativos a las características de este cultivar de mandarina. En primer lugar su baja sensibilidad al desarrollo de daños fisiológicos externos de las mandarinas y, en segundo lugar, la producción elevada de etanol, en comparación con mandarinas 'Clemenules' y naranjas 'Valencia' sin el desarrollo de malos sabores.

\section{IV.6. EFECTO DEL TIPO Y CONTENIDO DE PLASTIFICANTE DE LA FORMULACIÓN EN LAS CARACTERÍSTICAS DE LAS PELÍCULAS Y EN LA CALIDAD POSTCOSECHA DE NARANJAS 'VALENCIA' RECUBIERTAS}

IV.6.1. Análisis de las emulsiones y de las películas preformadas en placa

\section{IV.6.1.1. Aspecto de las emulsiones y de las películas}

Todas las emulsiones mostraron el aspecto lechoso que se ha descrito en las anteriores experiencias y fueron estables a las $24 \mathrm{~h}$ de su elaboración. El aspecto, la textura y fracturabilidad de las películas varió con el tipo y contenido de plastificante. Las películas con una relación HPMC:plastificante 1:100 fueron homogéneas, blancas, translúcidas y de aspecto mate en la cara expuesta al aire durante el secado y brillante en la cara expuesta a la placa. A este ratio de HPMC:plastificante las películas de $\mathrm{G}$ fueron las más flexibles, las de $\mathrm{S}$ las más quebradizas y las de $\mathrm{P}$ mostraron una fracturabilidad intermedia. Al aumentar el contenido de plastificante de las formulaciones (ratio HPMC:plastificante 1:300), el efecto del tipo de plastificante se hizo más patente. De esta manera, al aumentar el contenido en $G$ aumentó la flexibilidad de las películas y se mantuvo el aspecto y color respecto a las de menor contenido en G. Al incrementar el contenido de $\mathrm{P}$ se obtuvieron películas poco flexibles pero resistentes a la tracción y se mantuvo el aspecto homogéneo, la translucencia y el color blanquecino de las mismas. Al aumentar el contenido en S se obtuvieron películas extremadamente frágiles, de color 
blanco, de mayor opacidad que el resto de películas y con una textura pulverulenta en la superficie de las mismas, que pudo ser debida a la cristalización de la $\mathrm{S}$. El volumen molecular de la S, mayor a del resto de plastificantes, y el estado sólido de la misma (Tabla III.7) pudo dificultar la capacidad de ésta para integrarse en la molécula de HPMC, favoreciendo su cristalización (Sothornvit y Krocha, 2000).

\section{IV.6.1.2. Permeabilidad al vapor de agua de las películas}

El tipo y contenido de plastificante afectó la PVA de las películas. Las películas de P mostraron la menor PVA. No se observaron diferencias de PVA entre las películas de $S$ y $G$ formuladas con un bajo contenido en plastificante. Sin embargo, al aumentar el contenido en plastificante de la formulación, las películas de G mostraron mayor PVA que las de S. En general, un incremento en el contenido de $G$ aumentó la PVA de las películas, mientras que un incremento en el contenido de $\mathrm{S}$ o $\mathrm{P}$ no afectó la PVA de las películas. La orientación de las películas durante la medida sólo afectó a las películas $100 \mathrm{~S}$ y 100P, que mostraron menor PVA en posición ‘down' (Tabla IV.10).

Los plastificantes interfieren en las fuerzas que estabilizan las moléculas de hidrocoloide, debilitando la cohesión de la matriz que éstos forman. Esto supone un aumento de la flexibilidad y permeabilidad de las películas resultantes (Banker, 1966; McHugh y Krochta, 1994d). Por tanto, las propiedades barrera de las películas de hidrocoloide son un indicador del grado de cohesión del hidrocoloide. La naturaleza química, tamaño, forma, polaridad, longitud de cadena y numero de grupos funcionales de interacción con el hidrocoloide son características de los plastificantes que determinan su capacidad para debilitar la cohesión del hidrocoloide (Ninnemann, 1968; Lieberman y Gilbert 1973; Donhowe y Fennema 1993a; Cuq et al., 1997; Gueguen et al., 1998; Sothornvit y Krochta, 2001).

En la presente experiencia, el $G$ aumentó significativamente la PVA de las películas respecto al resto de plastificantes estudiados, lo que indica una mayor capacidad de éste debilitando la cohesión de la matriz de HPMC. El mayor número de grupos hidroxilos en la molécula de G (Tabla III.7) puede explicar la mayor habilidad plastificante del mismo frente al $\mathrm{P}$, ya que éstos grupos son los que interfieren en la estabilidad de 
la molécula de HPMC. El gran volumen molecular de la $\mathrm{S}$ debido a su peso molecular y presencia de anillos (Tabla III.7), pudo dificultar su interacción con la matriz de HPMC, reduciendo su habilidad plastificante respecto al G (Sothornvit y Krochta, 2000).

Tabla IV.10. Efecto del tipo y contenido de plastificante de la formulación en la PVA de las películas

\begin{tabular}{ccc}
\hline Formulación & \multicolumn{2}{c}{ PVA $\left(\mathrm{g} \mathrm{mm} / \mathrm{KPa} \mathrm{h} \mathrm{m}^{2}\right)$} \\
\cline { 2 - 3 } & \multicolumn{1}{c}{$\mathrm{d}^{\mathrm{z}}$} & \multicolumn{1}{c}{$3,41 \mathrm{~b} \mathrm{NS}$} \\
\hline $100 \mathrm{G}$ & $3,95 \mathrm{c} \mathrm{NS}$ & $3,42 \mathrm{~b} \mathrm{~A}$ \\
$100 \mathrm{~S}$ & $3,92 \mathrm{c} \mathrm{B}$ & $1,84 \mathrm{a} \mathrm{A}$ \\
$100 \mathrm{P}$ & $2,61 \mathrm{~b} \mathrm{~B}$ & $6,05 \mathrm{c} \mathrm{NS}$ \\
$300 \mathrm{G}$ & $6,43 \mathrm{~d} \mathrm{NS}$ & $4,13 \mathrm{~b} \mathrm{NS}$ \\
$300 \mathrm{~S}$ & $4,39 \mathrm{c} \mathrm{NS}$ & $2,39 \mathrm{a} \mathrm{NS}$ \\
$300 \mathrm{P}$ & $2,01 \mathrm{a} \mathrm{NS}$ &
\end{tabular}

Z Orientación de la película durante la determinación de la PVA en función de la posición de secado en placa.

Por columnas, valores de PVA seguidos de la misma letra minúscula no difieren significativamente $(\mathrm{p}<0,05)$.

Por filas, valores de PVA seguidos de la misma letra mayúscula no difieren significativamente $(\mathrm{p}<0,05)$

\section{IV.6.2. Análisis de calidad de las naranjas 'Valencia' recubiertas}

\section{IV.6.2.1. Pérdida de peso}

La Figura IV.37 muestra la pérdida de peso de las naranjas 'Valencia' recubiertas y control tras los distintos periodos de almacenamiento ensayados. En ella se observa una progresiva pérdida de peso de los frutos que alcanza hasta un $4 \%$ del peso inicial al cabo de 8 semanas a $5{ }^{\circ} \mathrm{C}$ más 1 semana a $20^{\circ} \mathrm{C}$.

De los resultados obtenidos cabe destacar que los recubrimientos no redujeron la pérdida de peso de las naranjas, lo que se corresponde con resultados obtenidos en mandarinas 'Clemenules' recubiertas con recubrimientos de igual contenido en CA ( $40 \%$ b.s.) tras 4 semanas de frigoconservación (Figura IV.23). Sin embargo, en mandarinas 'Ortanique' en los que se aplicó recubrimientos de similar composición a los de la presente experiencia, si se observó una reducción de la pérdida de peso (Figura IV.31). 
El tipo de plastificante afectó la pérdida de peso de las naranjas y éste efecto dependió del contenido del mismo. Para una proporción HPMC:plastificante de 1:100 los recubrimientos de $\mathrm{P}$ fueron los más efectivos reduciendo la pérdida de peso de las naranjas, y los de $G$ los menos efectivos. Sin embargo, para una proporción HPMC:plastificante de 1:300, los recubrimientos con $G$ fueron los más efectivos reduciendo la pérdida de peso.

Las propiedades de las películas aisladas (Apartado IV.6.1.1 y Apartado IV.6.1.2) pueden explicar éstos resultados. Las formulaciones con proporción HPMC:plastificante de 1:100 dieron lugar a películas se similar integridad física, independientemente del plastificante utilizado, pero con distinta PVA en función del plastificante utilizado, siendo las películas de $\mathrm{P}$ las de menor PVA. Por tanto, las propiedades barrera al vapor de agua de los mismos pudieron determinar su habilidad para reducir la transpiración del fruto y la pérdida de peso. Sin embargo, el tipo de plastificante tuvo un efecto notable en la integridad física de las películas formuladas al 1:300 de HPMC:plastificante, siendo las películas de $G$ las más flexibles y las de $S$ las más quebradizas. Por tanto, la integridad física de los recubrimientos de $\mathrm{S}$ y $\mathrm{P}$ pudo empeorar respecto a la de los recubrimientos de $G$, siendo por tanto éstos últimos los más efectivos reduciendo la transpiración de las naranjas y la pérdida de peso. 


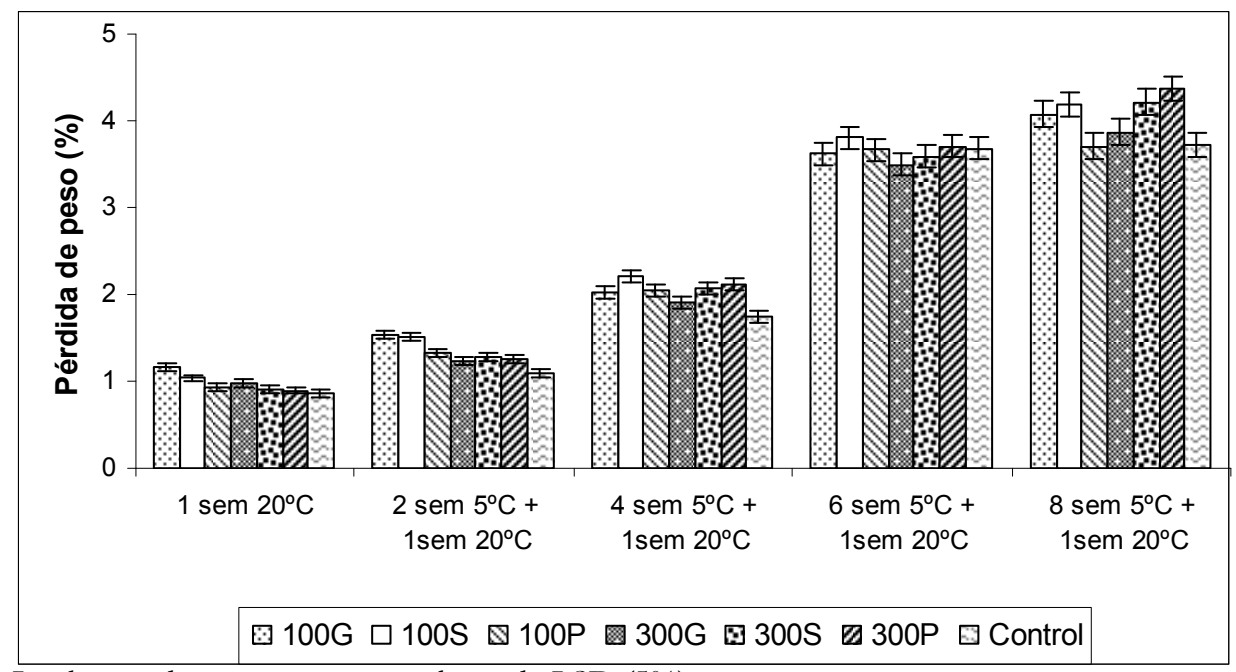

Las barras de error muestran valores de LSD (5\%).

Figura IV.37. Pérdida de peso (\%) de naranjas 'Valencia' recubiertas y control: efecto del tipo y contenido de plastificante del recubrimiento.

\section{IV.6.2.2. Sólidos solubles totales, acidez e índice de madurez}

Al prolongar el almacenamiento se observó una reducción de la acidez y un aumento del contenido en sólidos solubles y del IM (no se muestran datos). No se observó un efecto significativo del tratamiento aplicado en éstos parámetros de calidad de las naranjas.

\section{IV.6.2.3. Contenido de $\mathrm{CO}_{2} \mathrm{y} \mathrm{O}_{2}$ interno}

La Figura IV.38 muestra el contenido de $\mathrm{CO}_{2}$ y $\mathrm{O}_{2}$ interno de las naranjas 'Valencia' recubiertas y control tras los distintos periodos de almacenamiento ensayados. En general, los frutos recubiertos mostraron mayores niveles de $\mathrm{CO}_{2}$ interno y menores niveles de $\mathrm{O}_{2}$ interno que los frutos control, lo que indica el efecto barrera a ambos gases de los recubrimientos aplicados. El tipo de plastificante del recubrimiento afectó los niveles de $\mathrm{CO}_{2}$ y $\mathrm{O}_{2}$ interno de las naranjas y éste efecto dependió de la proporción de HPMC:plastificante de la formulación. Para una proporción HPMC:plastificante de 1:100, los recubrimientos de $\mathrm{P}$ proporcionaron los mayores niveles de $\mathrm{CO}_{2}$ interno y los menores niveles 
de $\mathrm{O}_{2}$ interno y los de $\mathrm{G}$ los menores niveles de $\mathrm{CO}_{2}$ y los mayores niveles de $\mathrm{O}_{2}$. Sin embargo, para una proporción HPMC:plastificante de 1:300, los recubrimientos con $\mathrm{G}$ dieron los mayores niveles de $\mathrm{CO}_{2}$ interno y los menores niveles de $\mathrm{O}_{2}$.

Las propiedades de las películas aisladas (Apartado IV.6.1) pueden explicar los resultados obtenidos. Las formulaciones con proporción HPMC:plastificante de 1:100 dieron películas con una integridad física similar, independientemente del plastificante incorporado. Sin embargo, las formulaciones al 1:300 de HPMC:plastificante mostraron diferente integridad física en función del plastificante incorporado, siendo las películas de $\mathrm{G}$ las más flexibles y las de $\mathrm{S}$ la más quebradizas. Por tanto, los recubrimientos al 1:100 pudieron presentar una integridad física similar, siendo las propiedades barrera a los gases $\mathrm{CO}_{2}$ y $\mathrm{O}_{2}$ de los mismos las que determinaran su comportamiento en el fruto recubierto. Sin embargo, a una proporción HPMC:plastificante de 1:300 la integridad física de los recubrimientos de $\mathrm{S}$ y $\mathrm{P}$ pudo empeorar respecto a la de los recubrimientos de $G$, siendo por tanto éstos últimos los más efectivos restringiendo el paso a los gases $\mathrm{CO}_{2} \mathrm{y} \mathrm{O}_{2}$. La integridad de los recubrimientos $300 \mathrm{~S}$ pudo verse seriamente comprometida dada la fragilidad observada en las correspondientes películas, lo que se corresponde con una reducción de los niveles de $\mathrm{CO}_{2}$ interno en los frutos a los que se aplicó éstos recubrimientos respecto al resto de frutos recubiertos. 

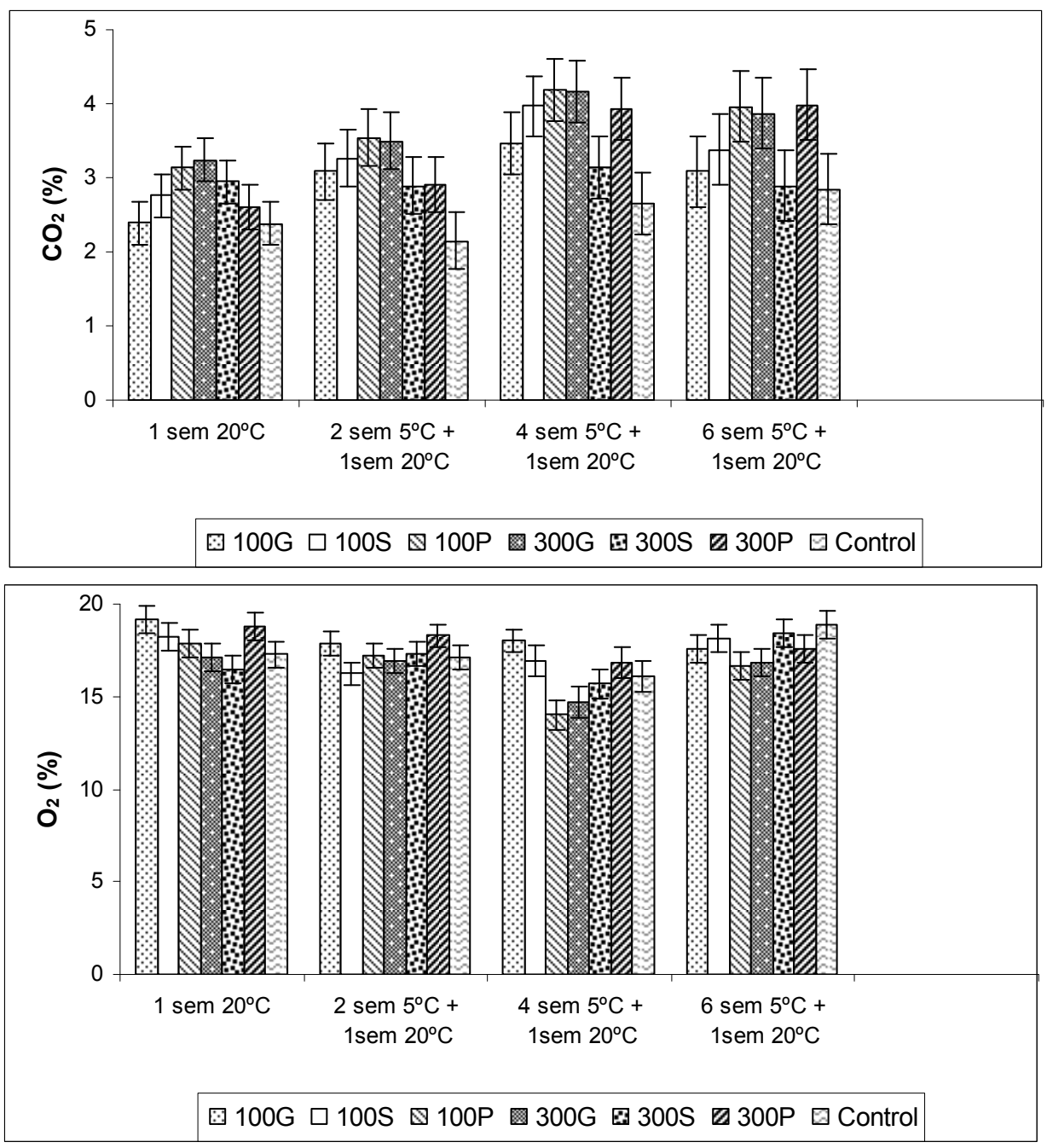

Las barras de error muestran valores de LSD (5\%). Datos de $\mathrm{CO}_{2}$ y $\mathrm{O}_{2}$ interno correspondientes al periodo de almacenamiento de 8 semanas a $5{ }^{\circ} \mathrm{C}+1$ semana a $20^{\circ} \mathrm{C}$ no disponibles.

Figura IV.38. $\mathrm{CO}_{2}$ y $\mathrm{O}_{2}$ interno de naranjas 'Valencia' recubiertas y control: efecto del tipo y contenido de plastificante del recubrimiento. 


\section{IV.6.2.4. Etanol y acetaldehído en zumo}

Los niveles de etanol y acetaldehído en zumo de las naranjas aumentaron al prolongar tiempo de almacenamiento, alcanzando concentraciones de $100 \mathrm{mg} / 100 \mathrm{~mL}$ y $1 \mathrm{mg} / 100 \mathrm{~mL}$ de etanol y acetaldehído respectivamente al cabo de 8 semanas de frigoconservación. En general, los niveles de ambos compuestos fueron mayores en los frutos recubiertos, pero no se observó una tendencia del comportamiento de los recubrimientos en función del tipo y contenido de plastificante de la formulación (Figura IV. 33). 

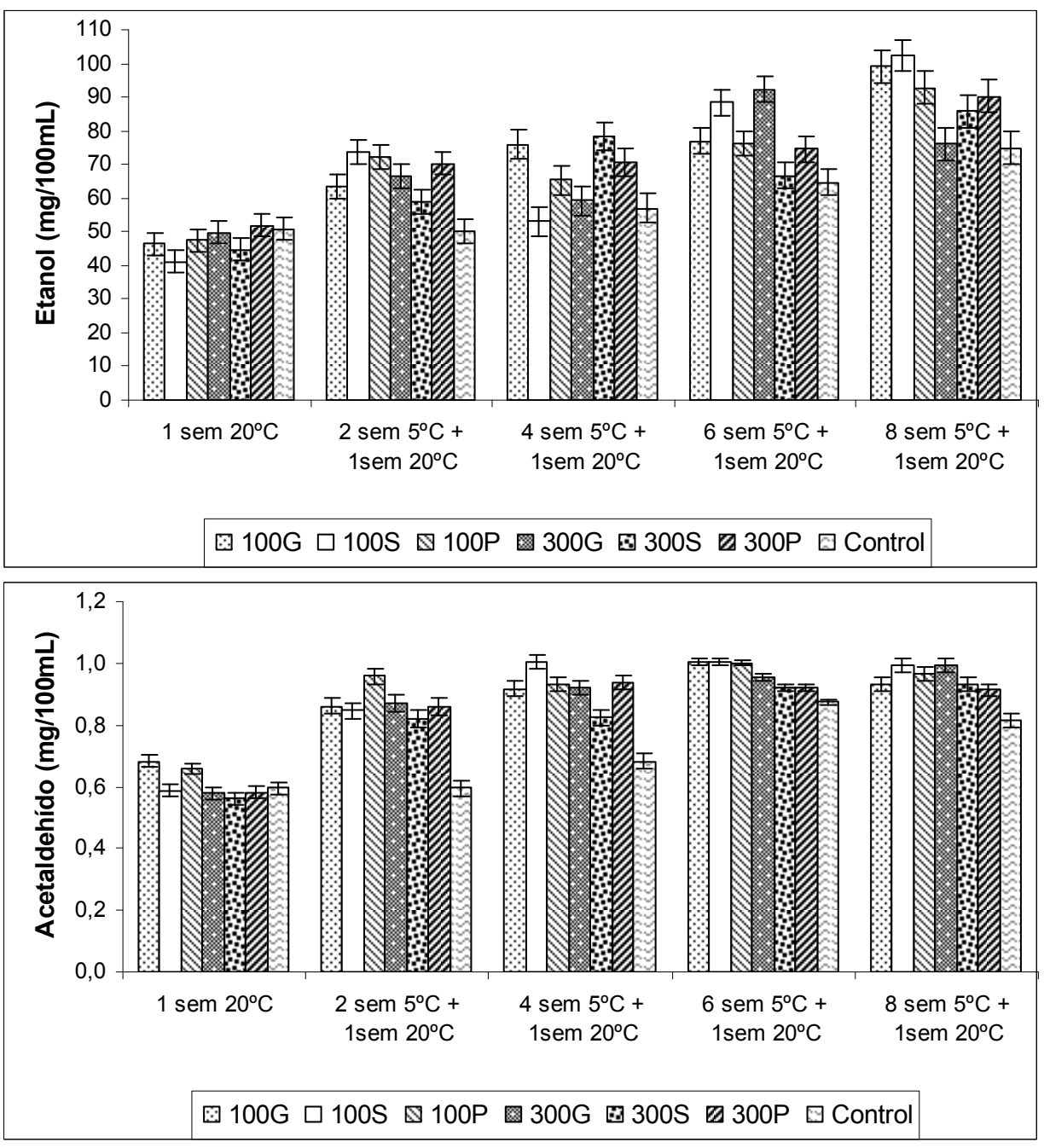

Las barras de error muestran valores de LSD (5\%).

Figura IV.39. Etanol y acetaldehído (mg/100mL) en zumo de naranjas 'Valencia' recubiertas y control: efecto del tipo y contenido de plastificante del recubrimiento. 


\section{IV.6.2.5. Firmeza}

La deformación de los frutos aumentó al prolongar el tiempo de almacenamiento, pero no se observaron diferencias entre los distintos tratamientos aplicados (no se muestran datos).

\section{IV.6.2.6. Desórdenes fisiológicos}

La incidencia de desórdenes fisiológicos fue mínima incluso tras 8 semanas de frigoconservación, y sólo algunos frutos presentaron un ligero daño por 'SERB' que no fue representativo del conjunto de los mismos. Estos resultados indican la poca sensibilidad de las naranjas 'Valencia' al desarrollo de desórdenes fisiológicos, el buen estado fisiológico de las mismas antes del almacenamiento y las buenas prácticas postcosecha utilizadas. No se observaron diferencias significativas entre los distintos tratamientos (no se muestran datos).

\section{IV.6.2.7. Índice de color}

En la presente experiencia, el color externo de los frutos evolucionó desde tonos naranjas con matices amarillentos al comienzo del almacenamiento (valores de IC en torno a 11) a tonos naranja intenso al cabo de 8 semanas de frigoconservación (valores de IC en torno a 12), lo que se corresponde con un aumento en índice de color de los mismos. No se observó un efecto del tratamiento aplicado en éste parámetro de calidad de los frutos (no se muestran datos).

\section{IV.6.2.8. Índice de desprendimiento del recubrimiento}

Dow (2002) ha observado que la adición de plastificantes a películas de HPMC reduce la resistencia de las mismas a la deformación y aumenta su adhesividad cuando se aplican a modo de recubrimientos.

En la presente experiencia se observó un efecto de la composición en la flexibilidad y/o fragilidad de las películas (Apartado IV.6.1.1). Sin embargo, estas diferencias de flexibilidad y fragilidad de las películas aisladas, no se tradujeron en diferencias de resistencia del recubrimiento a la abrasión (no se muestran datos). 


\section{IV.6.2.9. Evaluación organoléptica: 'flavor' y 'off-flavor'}

Al prolongar el tiempo de almacenamiento las naranjas perdieron acidez y aromas propios de fruta fresca y ganaron dulzor. Los valores de 'flavor' al comienzo del almacenamiento correspondieron a una calidad excelente y disminuyeron hasta una calidad aceptable al cabo de 8 semanas en frigoconservación. No se detectaron diferencias significativas entre tratamientos (no se muestran datos).

Las naranjas no desarrollaron un 'off-flavor' importante, ni tras un almacenamiento de 8 semanas en frigoconservación (Figura IV.40). El 'off-flavor' del fruto al inicio del almacenamiento estuvo en torno a cero (ausencia de 'off-flavor') y no incrementó sustancialmente al prolongar el almacenamiento, presentando valores en torno a 2 ('off-flavor' medianamente perceptible) al cabo de 8 semanas de frigoconservación. En general, los frutos control mostraron menor 'off-flavor' que los recubiertos. Sin embargo, aunque se observaron diferencias significativas de 'off-flavor' entre los frutos recubiertos, no se observó una tendencia en función de la composición del recubrimiento para los distintos periodos de almacenamiento ensayados. Por tanto, a partir de los resultados obtenidos es difícil definir el efecto del tipo y contenido de plastificante del recubrimiento en el 'off-flavor' de las naranjas.

Algunos trabajos muestran que, en general, concentraciones de etanol en torno a $200 \mathrm{mg} / 100 \mathrm{~mL}$ dan lugar a malos sabores en cítricos (Ahmad y Khan, 1978) y en concreto en naranjas 'Valencia' los malos sabores se dan a partir de concentraciones de etanol en torno a $80 \mathrm{mg} / 100 \mathrm{~mL}$ (Ke y Kader, 1990). El contenido en etanol, es un indicador de malos sabores en cítricos. Sin embargo, la percepción de los malos sabores no puede atribuirse, exclusivamente, al contenido de éste compuesto en el fruto, puesto que existen otros factores involucrados en el desarrollo y detección de los malos sabores y que son propios del tipo de fruto y de la variedad estudiada, como la presencia de otros compuestos aromáticos y la interacción de todos ellos con el resto de componentes del fruto. Así por ejemplo, en la presente experiencia el umbral de detección de 'off-flavor' ('off-flavor' ligeramente perceptible) se correspondió con niveles de etanol en torno a $70 \mathrm{mg} / 100 \mathrm{~mL}$ y el máximo 'off-flavor' detectado fue medianamente perceptible (puntuaciones en torno a 2 ) y se correspondió con niveles de etanol en torno a $100 \mathrm{mg} / 100 \mathrm{~mL}$. Mientras 
que en experiencias realizadas con mandarinas 'Clemenules' el umbral de detección del 'off-flavor' se dio a concentraciones de etanol en torno a $50 \mathrm{mg} / 100 \mathrm{~mL}$, y concentraciones de etanol de $100 \mathrm{mg} / 100 \mathrm{~mL}$ dieron un 'off-flavor' bastante perceptible con puntaciones de 'off-flavor' en torno a 3.

Los resultados indican que las naranjas 'Valencia' recubiertas con los recubrimientos ensayados se pueden almacenar hasta 8 semanas a $5{ }^{\circ} \mathrm{C}$ sin una pérdida importante de calidad organoléptica.

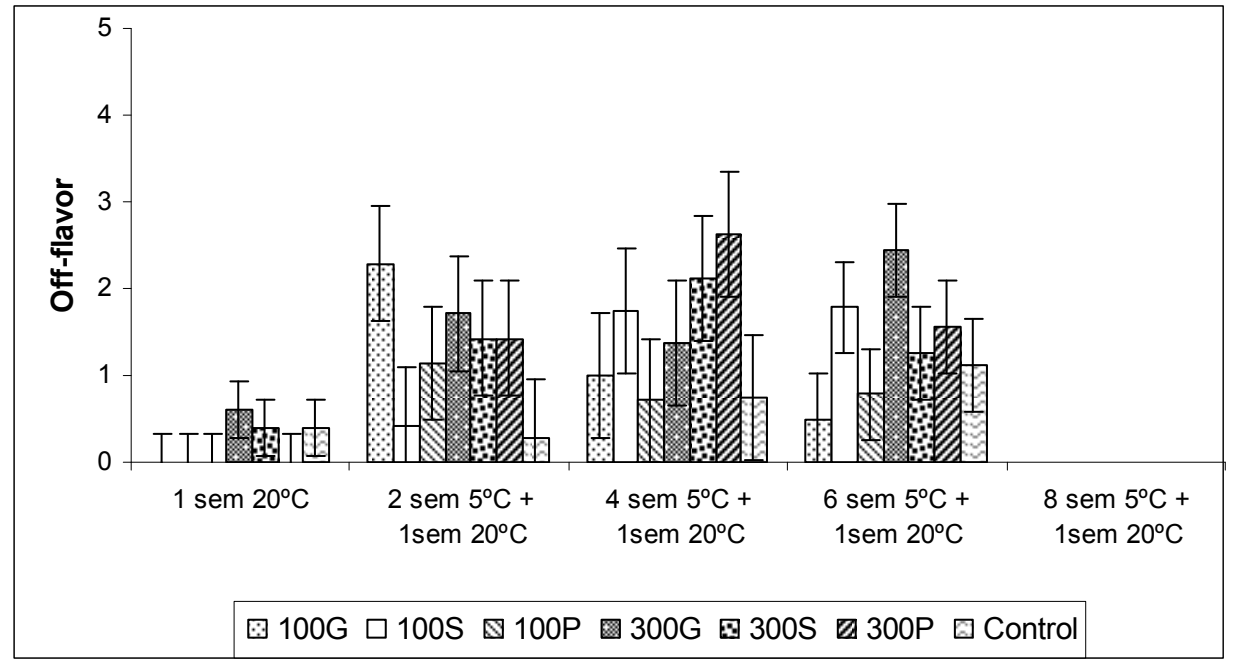

Las barras de error muestran valores de LSD (5\%).

Datos de 'Off-flavor' correspondientes al periodo de almacenamiento de 8 semanas a 5 ${ }^{\circ} \mathrm{C}+1$ semana a $20{ }^{\circ} \mathrm{C}$ no disponibles.

Figura IV.40. 'Off-flavor' de naranjas 'Valencia' recubiertas y control: efecto del tipo y contenido de plastificante del recubrimiento.

\section{IV.6.2.10. Aspecto externo y brillo del fruto}

Las naranjas control presentaron un aspecto turgente y uniforme a lo largo del almacenamiento, mientras que, en algunos casos, los frutos recubiertos presentaron un aspecto turgente pero con manchas blancas en la piel. El grado de manchado de los frutos recubiertos disminuyó a lo largo del almacenamiento, siendo muy evidente para los dos primeros periodos de almacenamiento ensayados, y casi imperceptible en los 
siguientes. Cabe apuntar que en mandarinas 'Clemenules' a las que se aplicaron recubrimientos de similar composición a los estudiados en esta experiencia no se observó este manchado de la piel. El diferente comportamiento de los recubrimientos según el tipo de fruto al que se aplicó pudo ser debido a las características morfológicas de la piel de cada fruto. En el caso de mandarinas 'Clemenules' en las que la piel es tersa el recubrimiento se pudo distribuir a lo largo de la piel de una forma homogénea. Sin embargo, en el caso de naranjas 'Valencia' en las que la piel es porosa, se pudo producir una mala distribución del recubrimiento con una acumulación del mismo en las depresiones de la misma, con la consiguiente aparición de manchas blancas.

Los resultados indican una evolución de los recubrimientos a lo largo del almacenamiento, que afecta al aspecto de los mismos y que pudo estar acusada por una pérdida parcial de éstos o por cambios en las propiedades de sus componentes. En este sentido cabe apuntar que las distintas conformaciones estructurales de los lípidos, incluida la CA, varían con las condiciones de temperatura y humedad ambientales, pudiendo variar desde estructuras cristalinas y compactas a estructuras de menor organización y mayor fluidez, modificando sus propiedades. Así por ejemplo, Fox (1958) observó que un aumento en la temperatura de 23 a 35 ${ }^{\circ} \mathrm{C}$, y del periodo de almacenamiento inducía la recristalización y reestructuración de las ceras mejorando el empaquetamiento de las mismas y la orientación y, por tanto, la barrera al vapor de agua. Kester y Fennema (1989c) obtuvieron resultados similares en películas de papel con una lámina de estearil alcohol. Kamper y Fennema (1985) observaron que en películas bicapa de HPMC y ácidos palmítico y esteárico, un descenso en la temperatura de 5 a $-19{ }^{\circ} \mathrm{C}$ aumentaba la rigidez y microfractura y la PVA de las mismas. También observaron el mismo efecto al reducir la temperatura de 25 a $5{ }^{\circ} \mathrm{C}$.

En la presente experiencia la CA pudo experimentar cambios conformacionales a lo largo del almacenamiento, afectando el aspecto externo de los recubrimientos. Asimismo, la hidratación de la HPMC durante el almacenamiento pudo producir cambios en el recubrimiento que afectaran a su aspecto.

La composición de los recubrimientos también afectó el aspecto de los mismos. Un incremento en el contenido de plastificante redujo la 
intensidad de manchado. Entre los plastificantes utilizados, la $\mathrm{S}$ fué el que proporcionó menor manchado y el $\mathrm{P}$ el de mayor manchado.

La evaluación sensorial de las naranjas varió a lo largo del almacenamiento. Hasta 2 semanas en refrigeración los frutos control fueron los mejor valorados y los de mayor brillo, sin observarse diferencias significativas entre los frutos recubiertos. A partir de 2 semanas de frigoconservación no se observaron diferencias de aspecto externo y brillo entre tratamientos, incluido el control (no se muestran datos).

\section{IV.6.3. Síntesis de resultados}

El objetivo de la presente experiencia fue estudiar el efecto del tipo y contenido de plastificante de recubrimientos compuestos a base de HPMC y CA en la calidad postcosecha de naranjas cv. 'Valencia'. Para ello se estudió el efecto de estos factores en las propiedades de películas aisladas y se evaluaron distintos parámetros de calidad de las ciruelas recubiertas, comparándolas con frutas control. A continuación se hace un resumen de los resultados más relevantes.

El tipo y contenido de plastificante afectó las propiedades de las películas aisladas. El efecto del tipo de plastificante en las propiedades mecánicas de las películas fue muy acusado en las formulaciones con proporción HPMC:plastificante de 1:300. A esta proporción el G dio lugar a películas flexibles, el $P$ películas de menor flexibilidad que el $G$ y la $\mathrm{S}$ dio películas muy quebradizas. El tipo de plastificante afectó la PVA de las películas independientemente de su contenido. Las películas de $\mathrm{P}$ dieron la menor PVA y las de $\mathrm{S}$ y $\mathrm{G}$ dieron una PVA similar. Un aumento en el contenido de $G$ aumentó la PVA de las películas, pero un aumento en el contenido de $\mathrm{P}$ o $\mathrm{S}$ no afectó la PVA de las películas. Las características de las moléculas de plastificante, como son el numero de grupos hidroxilo, el peso molecular, estado físico y linealidad, pudieron afectar el comportamiento de los mismos.

En general, los recubrimientos no mejoraron la calidad postcosecha de las naranjas 'Valencia'. El tipo y contenido de plastificante afectó las propiedades barrera al vapor de agua y a los gases del recubrimiento, modificando la pérdida de peso y la atmósfera interna de las naranjas recubiertas. Sin embargo, cabe apuntar que las diferencias en 
la composición de la atmósfera interna de las naranjas no se tradujeron en diferencias en el contenido de etanol y acetaldehído, ni en el sabor de las mismas.

El efecto del tipo de plastificante en las propiedades barrera de los recubrimientos varió con la proporción relativa HPMC:plastificante y se relacionó con las propiedades de las películas aisladas. Para una proporción HPMC:plastificante de 1:300, los recubrimientos de G fueron los más efectivos reduciendo la pérdida de peso y ejerciendo una barrera a los gases $\left(\mathrm{CO}_{2}\right.$ y $\left.\mathrm{O}_{2}\right)$.

Las naranjas control presentaron un aspecto externo uniforme a lo largo del almacenamiento, mientras que los frutos recubiertos presentaron manchas blancas en la piel y menor brillo que las naranjas control. El grado de manchado de los frutos recubiertos disminuyó a lo largo del almacenamiento, siendo casi imperceptible al cabo de 6 semanas de frigoconservación. La composición de los recubrimientos afectó el aspecto de los mismos. Un incremento en el contenido de plastificante redujo la intensidad de manchado. El tipo de plastificante también afectó el manchado de los frutos, siendo los recubrimientos de $\mathrm{S}$ los que menor manchado proporcionaron y los de $\mathrm{P}$ los de mayor manchado.

Entre los resultados obtenidos cabe señalar algunos datos interesantes relativos a las características de este cultivar de naranja. En primer lugar su baja sensibilidad al desarrollo de daños fisiológicos externos y, en segundo lugar, la baja susceptibilidad al desarrollo de malos sabores. 
V. CONCLUSIONES 
1. Las propiedades barrera de las películas aisladas y de los recubrimientos comestibles aplicados a las frutas no siempre se corresponden, siendo las propiedades mecánicas las que determinan, en la mayoría de los casos, esta diferencia.

2. Los recubrimientos estudiados mejoraron la calidad postcosecha de las ciruelas 'Angeleno', reduciendo la deshidratación, el ablandamiento y los desórdenes fisiológicos. En mandarinas 'Clemenules' y 'Ortanique' los recubrimientos redujeron la deshidratación, la pérdida de firmeza y los desórdenes fisiológicos, pero no mejoraron sustancialmente la calidad de las naranjas 'Valencia'.

3. Las características intrínsecas de los frutos estudiados (ciruelas 'Angeleno', naranjas 'Valencia' y mandarinas 'Clemenules' y 'Ortanique') determinan la funcionalidad de los recubrimientos comestibles a base de hidroxipropilmetilcelulosa y cera de abeja.

4. La proporción relativa de cera de abeja e hidroxipropilmetilcelulosa es el factor de composición con mayor repercusión en la calidad postcosecha de ciruelas 'Angeleno' y mandarinas 'Clemenules' recubiertas.

5. Las mejoras observadas en los distintos atributos de calidad de las ciruelas 'Angeleno', mandarinas 'Clemenules' y 'Ortanique' y naranjas 'Valencia' recubiertas no son unidireccionales, puesto que variaciones en la composición de los mismos pueden mejorar algunos parámetros de calidad empeorando otros. Esto obliga a establecer un compromiso de calidad entre los factores involucrados y/u optimizar los recubrimientos a base de hidroxipropilmetilcelulosa y cera de abeja para su aplicación a éstas frutas.

6. En ciruelas 'Angeleno' un aumento en el contenido de cera de abeja y una reducción del contenido de hidroxipropilmetilcelulosa reduce la pérdida de peso y de turgencia, mejorando el aspecto externo de las mismas. Mientras que una reducción en el contenido de cera de abeja y un aumento del contenido en hidroxipropilmetilcelulosa aumenta el brillo de la piel y reduce el ablandamiento y los daños fisiológicos de la pulpa, 
que son los factores de deterioro que limitan del periodo de vida útil de las ciruelas 'Angeleno'.

7. En mandarinas 'Clemenules', un aumento en el contenido de cera de abeja y una reducción del contenido de hidroxipropilmetilcelulosa reduce la pérdida de peso y los niveles de etanol y acetaldehído, mejorando el sabor del fruto. Sin embargo, un exceso de cera de abeja y/o un defecto de hidroxipropilmeticelulosa del recubrimiento, empeora el aspecto y brillo del mismo.

8. En ciruelas 'Angeleno' el tipo de ácido graso afecta su aspecto externo y brillo, sin afectar al resto de parámetros de calidad de las mismas. De los ácidos grasos estudiados el ácido oleico proporciona el mejor aspecto y brillo del recubrimiento. Las proporciones de ácido graso estudiadas no afectan la calidad de las ciruelas 'Angeleno' recubiertas.

9. En mandarinas 'Ortanique' el tipo de ácido graso del recubrimiento afecta la pérdida de peso, la firmeza, la barrera a los gases $\mathrm{CO}_{2}$ y $\mathrm{O}_{2}$, los niveles de etanol y acetaldehído y el 'flavor'. De los ácidos grasos estudiados, el ácido oleico ejerce la mayor barrera al vapor de agua y a los gases $\left(\mathrm{CO}_{2}\right.$ y $\left.\mathrm{O}_{2}\right)$, disminuyendo la pérdida de peso, aumentando los niveles de etanol y acetaldehído, y reduciendo el 'flavor' de las mandarinas. Por tanto, si se aplican recubrimientos de este tipo a mandarinas 'Ortanique' hay que tener presente el tiempo de almacenamiento de las mismas.

10. La incorporación de glicerol a los recubrimientos mejora el aspecto y el brillo, y reduce el ablandamiento de la pulpa y la pérdida de peso de las ciruelas 'Angeleno' recubiertas. Un incremento en el contenido de plastificante reduce la pérdida de peso de las ciruelas, pero no el ablandamiento de las mismas.

11. Las mejoras observadas en la funcionalidad de los recubrimientos aplicados a ciruelas 'Angeleno' al modificar el tipo y contenido de plastificante se correlacionan con un aumento en la flexibilidad de las películas aisladas. 
12. En naranjas 'Valencia' el tipo y contenido de plastificante afecta al aspecto externo de las naranjas recubiertas y a las propiedades barrera al vapor de agua y a los gases del recubrimiento, afectando a la pérdida de peso y a la atmósfera interna de las naranjas recubiertas. El efecto del tipo de plastificante en las propiedades barrera de los recubrimientos varía con la proporción relativa HPMC:plastificante y se relaciona con las propiedades de las películas aisladas.

13. Un aumento en el contenido en sólidos aumenta la barrera a los gases $\mathrm{CO}_{2}$ y $\mathrm{O}_{2}$, aumentado los niveles de etanol y acetaldehído y los malos sabores en mandarinas 'Clemenules' recubiertas. Además, reduce el grado de adhesión y brillo y empeora el aspecto del recubrimiento. En futuras experiencias sería interesante estudiar el contenido en sólidos mínimo para obtener recubrimientos funcionales aplicables a mandarinas 'Clemenules'.

14. La información obtenida en la presente tesis doctoral permite trazar, en líneas generales, el comportamiento de los recubrimientos comestibles a base de hicroxipropilmetilcelulosa y cera de abeja en la calidad postcosecha de ciruelas 'Angeleno', mandarinas 'Clemenules' y 'Ortanique' y naranjas 'Valencia'. Pero se requiere hacer más investigación para optimizar la composición de estos recubrimientos para su aplicación en estas frutas.

15. En futuras investigaciones se puede contemplar la capacidad de estos recubrimientos para actuar como agentes portadores de sustancias antimicrobianas y nutricionales. 
VI. BIBLIOGRAFÍA 
Abbot, J.A.; Conway, W.S. 1989. Postharvest calcium chloride infiltration effects textural attributes of apples. J. Am. Soc. Hort. Sci., 114:932936.

AENOR (Asociación Española de Normalización y Certificación). 1987. Análisis sensorial. Tomo I. Alimentación. Recopilación de Normas UNE. Ed. AENOR, Madrid, pp. 253.

Ahmad, M.; Khan, I. 1987. Effect of waxing and cellophane lining on chemical quality indices of citrus fruit. Plant Food Hum. Nutr., 37:4757.

Aljurubi, H.J.; Huff, A. 1984. Reduction in chilling injury to stored grapefruit (Citrus paradise Macf.) by vegetable oils. Scientia Hort., 24:53-58.

Allen, L.; Nelson, A.I.; Steinberg, M.P.; McGill, J.N. 1963. Edible CornCarbohydrate food coatings I. Development and physical testing of starch-algin coating. Food Technol., 17:1437-1442.

Alleyne, V.; Hagenmaier, R.D. 2000. Candelilla-shellac: an alternative formulation for coating apples. HortSci., 35(4):691-693.

Artés, F. 2000. Tratamientos alternativos para preservar mejor la calidad de los cítricos refrigerados. Levante Agrícola, 352:229-238.

Artés, F. 2006. El envasado en atmósfera modificada mejora la calidad de consumo de los productos hortofrutícolas intactos y mínimamente procesados en fresco. Rev. Iber. Tecnología Postcosecha, 7(1):41-47.

Artz, W.E. 1990. Emulsifiers. En Food Additives. Eds. A.L. Branen; D.M. Davidson; S. Salminen, Marcel Dekker, New York, U.S.A., pp. 347-393.

Ashley, R.J. 1985. Permeability and plastic packaging. En Polymer permeability. Ed. J. Comyn, Elsevier Applied Science Publishers, New York, U.S.A., pp. 269-307.

ASTM D882-97. Standard Test Method for Tensile Properties of Thin Plastic Sheeting. Ed. Am. Soc. for testing and Materials.

Austin, L.; Burns, J. 1994. Application of coatings. En Protein-based films and coatings. Eds. J.M. Krochta; E.A. Baldwin; M.O. Nisperos-Carriedo, Technomic Publishing Co., Inc. Lancaster, U.S.A., pp 189-200. 
Avena-Bustillos, R.J.; Krochta, J.M. 1993. Water vapor permeability of caseinate-based edible films as affected by $\mathrm{pH}$, calcium crosslinking and lipid content. J. Food Sci., 58(4):904-907.

Ayrancy, E.; Buyuktas, B.S.; Cetin, E.E. 1997. The effect of molecular weight of constituents on mechanical properties of cellulose-based edible films. Lebesnsm. Wiss. u. Technol., 30(1):101-104.

Ayrancy, E.; Tunc, S. 2004. The effect of edible coatings on water and vitamin C loss of apricots (Armeniaca vulgaris Lam.) and green peppers (Capsicum annuum L.). Food Chem., 87:339-342.

Bai, J.; Baldwin, E.A.; Hagenmaier, R.D. 2002. Alternatives to shellac coatings provide comparable gloss, internal gas modification, and quality for 'Delicious' apple fruit. HortSci., 37(3):559-563.

Bai, J.; Hagenmaier, R.D; Baldwin, E.A. 2003a. Coating selection for 'Delicious' and other apples. Postharv. Biol. Technol., 28:381-390.

Bai, J.; Alleyne, V.; Hagenmaier, R.D.; Mattheis, J.P.; Baldwin, E.A. 2003b. Formulation of zein coatings for apples (Malus domestica Borkh). Postharv. Biol. Technol., 28:259-268.

Baldwin, E.A. 1994. Edible coatings for fresh fruits and vegetables: past, present and future. Eds. J.M. Krochta; E.A. Baldwin; M.O. NisperosCarriedo, Technomic Publishing Co., Inc. Lancaster, U.S.A., pp. 24-64.

Baldwin, E.A.; Nisperos-Carriedo, M.O.; Shaw, P.E.; Burns, J.K. 1995. Effect of coatings and prolonged storage conditions on fresh orange flavour volatiles, degrees brix, and ascorbic acid levels. J. Agric. Food Chem., 43:1321-1331.

Baldwin, E.A.; Nisperos, M.O.; Hagenmaier, R.D.; Baker, R.A. 1997. Use of lipids in coatings for food products. Food Technol., 51(6):6-63.

Baldwin, E. A. 1999. Surface treatments and edible coatings in food preservation. En Handbook of food preservation. Ed. M. Shafiur-Rahman, Marcel Dekker, Inc. New York, U.S.A., pp. 577-609.

Baldwin, E. A.; Burns, J.K.; Kazokas, W.; Brecht, J.K.; Hagenmaier, R.D.; Bender, R.J.; Pesis, E. 1999. Effect of two edible coatings with different permeability characteristics on mango (Magnifera indica L.) ripening during storage. Postharv. Biol. Technol., 17:215-226. 
Banker, G.S. 1966. Film coating theory and practice. J. Pharm. Sci., 55(1): 81-89.

Banks, N.H. 1983. Evaluation of methods for determining internal gases in banana fruit. J. Exper. Bot., 34:871-879.

Banks, N.H. 1984. Some effects of TAL Pro-Long coating on ripening bananas. J. Exper. Bot., 35:127-137.

Banks, N.H. 1985. Internal atmosphere modification in Pro-Long coated apples. Acta Hort., 157:105-112.

Banks, N. H.; Dadzie., B.K.; Cleland, D.J. 1993. Reducing gas exchange of fruits with surface coatings. Postharv. Biol. Technol., 3: 269-284.

Barreiro, M.G.; Cebola-Lidon, F.; Pinto, M. 2001. Physicochemical characterisation of the postharvest senescence of winter melon 'Tendral'. Fruits, 56:51-58.

Basiouny, F.; Baldwin, E.A. 1997. The use of liquid coating compounds as postharvest application to plum fruits. Proc. Fla. State Hort. Soc., 110:219-222.

Bauchot, A.D.; John, P.; Soria, Y.; Recasens, I. 1995. Sucrose ester-based coatings formulated with food compatible antioxidants in the prevention of superficial scald in stored apples. J. Am. Soc. Hort. Sci., 120:491-496.

Beaudry, R.M. 1999. Effect of $\mathrm{O}_{2}$ and $\mathrm{CO}_{2}$ partial pressure on selected phenomena affecting fruit and vegetable quality. Postharv. Biol. Technol., 15:293-303.

Ben-Abda, J.; Martínez-Jávega, J.M. 1999. Efecto de recubrimientos céreos sobre la calidad de mandarina cv. 'Fortune' en la comercialización directa y frigoconservación. Revista Iberoamericana de Tecnología Postcosecha, 1(2):142-149.

Ben-Abda, J.; Martínez-Jávega, J.M.; Monterde, A. 1999. Evaluación de un recubrimiento comestible como alternativa al uso de ceras convencionales en mandarinas. Actas de Horticultura de la SECH, 27(4):255-260.

Ben, J.; Gaweda, M. 1992. The effect of increasing concentration of carbon dioxide in controlled atmosphere storage of plums $\mathrm{cv}$. Wegierka Zwyka. Acta Physiol. Plant, 14: 143-158. 
Ben-Yehoshua, S. 1967. Some physiological effects on various skin coatings on orange fruit. Israel J. Agr. Res., 17:17-27.

Ben-Yehoshua, S. 1985. Individual seal-packaging of fruits and vegetables in plastic film - a new postharvest technique. HortSci., 20(1):32-37.

Bennett, H. 1975. Industrial waxes. En Natural and synthetic waxes, compounded waxes and technology, vol. 1-2. Ed. Chemical Publishing Co., Inc. New York, U.S.A.

Bertran, L.C.; Tanada-Palmu, P.S.; Siani, A.C.; Grosso, C.R. 2005. Effect of fatty acids and 'Brazilian elmini' on composite films based on gelatin. Food hydrocolloid, 19:73-82.

Biquet, B. 1987. Moisture transfer in foods and edible moisture barriers. Evaluation of a chocolate coating as an edible moisture barrier in an intermediate moisture food model system. Master of Science, Ed. University of Minnesota, Minnesota, U.S.A.

Biquet, B.; Labuza, T.P. 1988. Evaluation of the moisture permeability characteristics of chocolate films as an edible moisture barrier. J. Food Sci., 53(4):989-998.

Bravin, B.; Peressini, D.; Sensidoni, A. 2004. Influence of emulsifier type and content on functional properties of polysaccharide lipid-based edible films. J. Agr. Food Chem., 52:6448-6455.

Bruemmer, J.H. 1989. Terminal oxidase activity during ripening of Halmin orange. Phytochem., 28:2901-2902.

Buera, P.; Karel, M. 1993. Application of the WLF equation to describe the combined effects of moisture and temperature on non-enzymatic browning rates in food systems. J. Food Process. Pres., 17:31-45.

Callegarin, F.; Quezada-Gallo, J.A.; Debeaufort, F.; Voilley, A. 1997. Lipids and biopackaging. J. Am. Oil Chem. Soc., 74(10):1183-1192.

Cheftel, J.C.; Cheftel, H. 1976. Frutas y legumbres. En Introducción a la bioquímica y tecnología de alimentos. Vol.1. Ed. Acribia, Zaragoza, pp. 135290.

Chen, X.; Grant, L.A. 1995. Nature Seal ${ }^{\mathrm{TM}}$ delays yellowing of lemons. Proc. Fla. State Hort. Soc., 108:285-288. 
Cisneros-Zevallos, L.; Krochta, J.M. 2002. Internal modified atmospheres of coated fresh fruits and vegetables: understanding relative humidity effects. J. Food Sci., 67(8):2792-2797.

Cisneros-Zevallos, L.; J.M. Krochta. 2003. Dependence of coating thickness on viscosity of coating solution applied to fruits and vegetables by dipping method. J. Food Sci., 68 (2):503-510.

Claypool, L.L.; Allen, F.W. 1951. The influence of temperature and oxygen level on the respiration and ripening of Wickson plums. Hilgardia, 21(6):129-160.

Claypool, L.L.; King, J.R. 1941. Fruit waxing in relation to character of cover. Proc. Am. Soc. Hort. Sci., 38:261-265.

Cohen, E.; Shalom, Y; Rosenberg, I. 1990. Postharvest ethanol buildup and off-flavor in 'Murcot' tangerine fruits. J. Am. Hort. Soc., 115:775778.

Conway, W.S.; Sams, C.E.; Abbot, J.A.; Bruton, B.D. 1991. Postharvest calcium treatment on apple fruit provide broad spectrum protection against postharvest pathogens. Plant Dis., 75:620-622.

Couey, H.M. 1960. Effect of temperature and modified atmosphere on storage life, ripening behaviour and dessert quality of 'El Dorado' plums. Proc. Am. Soc. Hort. Sci., 75: 207-215.

Couey, H.M. 1965. Modified atmosphere storage of 'Nubiana' plums. Proc. Am. Soc. Sci., 86: 166-168.

Crisosto, C.H.; Gordon, F.; Zhiguo, J. 1999. Susceptibility to chilling injury of peach, nectarine and plum cultivars grown in California. HortSci., 34: 1116-1118.

Crisosto, C.H.; Kader, A.A. 2004. Plum and fresh prune postharvest quality maintenance guidelines. En The commercial storage of fruits, vegetables and florist and nursery stocks. Eds. K.C. Gross; C.Y. Wang; M Saltveit, $\quad$ Agricultural Handbook $66 \quad$ (2). http://usna.usda.gov/hb66/112plum.pdf

Cuq, B.; Gontard, N.; Cuq, J.L.; Guilbert, S. 1997. Selected functional properties of fish myofibrillar protein-based films as affected by hydrophilic plasticizers. J. Agr. Food Chem., 45(3):622-626. 
Cuquerella, J.; Martínez-Jávega, J.M.; Jiménez-Cuesta, M. 1981. Some physiological effects of different wax treatments on Spanish citrus fruit during cold storage. Proc. Int. Soc. Citriculture, 2: 734-737.

Cuquerella, J.; Saucedo, C.; Martinez-Jávega, J.M.; Mateos, M. 1988. Influencia de la temperatura y envolturas plásticas en la conservación de mandarinas 'Fortune'. Actas de Horticultura de la SECH, 2:410417.

Dharkar, S.D.; Savagaon,K.A.; Srirangarajan, A.N.; Sreenivasan, A. 1966. Irradiation of mangoes I. Radiation-induced delay in ripening of ‘Alphonso' Mangoes. J. Food Sci., 31(6):863-869.

Dharkar, S.D.; Sreenivasan, A. 1971. Effect of gamma irradiation on the postharvest physiology of five banana varieties grown in India. J. Food Sci., 36(2):243-247.

Davis, P.L.; Roe, B.; Bruemmer, J.H. 1973. Biochemical changes in citrus fruits during controlled-atmosphere storage. J. Food Sci., 38:225-229.

Day, B. 1993. Fruit and vegetables. En Principles and applications of modified atmosphere packaging of foods. Ed. R. Parry, Blackie Academic \& Professional, London, UK, pp. 115-133.

Debeafourt, F.; Voilley, A. 1995. Effect of surfactants and drying rate on barrier properties of emulsified edible films. Int. J. Food Sci. Technol., 30:183-190.

Debeaufort, F.; Voilley, A.; Meares, P. 1994. Water vapor permeability and diffusivity through methylcellulose edible films. J. Memb. Sci., 91:125-133.

Delporte, B. 1995. Films comestibles composites. Role de la nature et de l'état physique des lipides sur les propriétés foncionelles des films. Memorie de fin d'étude. Katholieke Universiteit Leuven, Leuven, Bélgica, pp. 62-69.

Directiva 95/2/CE. 1995. Directiva 95/2/CE del Parlamento Europeo y del Consejo de 20 de Febrero de 1995 relativa a aditivos alimentarios distintos de los colorantes y edulcorantes. Diario Oficial de la Unión Europea, 18.03.1995

Directiva 06/52/CE. 2006. Directiva 06/52/CE del Parlamento Europeo y del Consejo de 5 de Julio de 2006 por la que se modifica la Directiva 95/2/CE relativa a aditivos alimentarios distintos de los colorantes y 
edulcorantes y la Directiva 94/35/CE relativa a los edulcorantes utilizados en los productos alimenticios. Diario Oficial de ls Unión Europea, 26.07.2006.

Dong, L.; Laurie, S.; Zhou, H.W. 2002. Effect of 1-methylcyclopropene on ripening of 'Canino' apricots and 'Royal Zee' plums. Postharv. Biol. Technol., 24:135-145.

Donhowe, I.G. 1993. Water vapor and oxygen permeability of wax films. J. Am. Oil Chem. Soc., 70(9):867-873.

Donhowe, I.G; Fennema, O. 1993a. The effects of plasticizers on cristallinity, permeability and mechanical properties of methylcellulose films. J. Food Process. Pres., 17(4): 247-257.

Donhowe, I.G; Fennema, O. 1993b. The effects of solution composition and drying temperature on crystallinity, permeability and mechanical properties of methylcellulose films. J. Food Process. Pres., 17(4): 231246.

Doolittle, A.K. 1965. Mechanism of plastization. En Plasticizer Technology, vol. 1. Ed. P.F. Bruins, Reinhold Publishing, New York, U.S.A., pp. 120.

Dow Chemical Co., 2002. Evaluation of films containing metocel in tablet coating. En Methocel cellulose ethers in aqueous systems for tablet coating. Technical information, pp. 14-19. http://dow.com.

El-Samahy, S.K.; Youssef, B.M.; Askar, A.A.; Swailam, H.M. 2000. Microbiological and chemical properties of irradiated mango. J. Food Safety, 20(3):139-156.

Erbil, H.Y.; Mnftngil, N. 1986. Lengthening the postharvest life of peaches by coating with hydrophobic emulsions. J. Food. Process. Pres., 10:269-279.

Fennema, O.; Donhowe, I.; Kester, J.J. 1994. Lypid type and location of the relative humidity gradient influence on the barrier properties of lipids to water vapor. J. Food Eng., 22:225-239.

Fidler, J.C.; North, C.J. 1971. The effect of periods of anaerobiosis on the storage of apples. J. Hort. Sci., 46:213-221.

Fishman, M.L.; Gross, K.C.; Gillespie, D.T.; Sondey, S.M. 1989. Macromelecular components of tomato fruit pectin. Arch. Biochem. Biophys., 274:179-191. 
Fox, R.C. 1958. The relationship of wax crystal structure to the water transmission rate of wax films. J. Tech. Assoc. Pulp Paper Ind., 41(6):283-289.

García, M.A.; Martino, M.N.; Zaritzky, N.E. 1998. Plasticized starchbased coatings to improve strawberry (Fragaria $x$ ananassa) quality and stability. J. Agr. Food Chem., 46:3758-3767.

García, M.A.; Martino, M.N.; Zaritzky, N.E. 1999. Edible starch films and coatings characterization: SEM, water vapor and gas permeabilities. J. Scaning Microscop., 21(5):348-355.

Garro Galiana, R. 1998. Lípidos I: Ácidos grasos, grasas neutras, lípidos complejos. En Guía para el curso de bioquímica. Ed. Servicio de Publicaciones de la Universidad Politécnica de Valencia, Valencia, 98.396:226-244.

Ghaouth, A.E.; Arul, J.; Ponnampalam, R.; Boulet, M. 1991. Chitosan coatings effect on storability and quality of fresh strawberries. J. Food Sci., 56:1618-1620.

Gennadios, A.; Weller, C.L. 1990. Edible films and coatings from wheat and corn proteins. Food Technol., 44(10):63-69.

Gladon, R.J.; Reitmeier, C.A.; Gleason, M.L.; Nonnecke, G.R.; Agnew, N.H.; Olsen, D.G. Irradiation of horticultural crops at Iowa State University. HortSci., 32(4):582-585.

Gontard, N.; Duchez, C.; Cuq., J.L.; Gilbert, S. 1994. Edible composite films of wheat gluten and lipids: water vapor permeability and other physical properties. Int. J. Food. Sci. Technol., 29:39-50.

Gontard, N.; Marchesseau, S.; Cuq, J.L.; Guilbert, S. 1995. Water vapour permeability of edible bilayer films of wheat gluten lipids. Int. J. Food Sci. Technol., 30(1):49-56.

Gueguen, J.; Viroben, G.; Noireaux, P.; Subirade, M. 1998. Influence of plasticizers and treatments on the properties of films from pea proteins. Industrial Crops and Products, 7:149-157.

Guilbert, S. 1986. Technology and application of edible protective films. En Food packeaging and preservation: Theory and Pratice. Ed. M. Mathlouthi, Elsevier Applied Science Publishers, New York, U.S.A., pp. 371-394. 
Gunstone, F.D.; Padley, F.B. 1997. Fatty acids and lipids structure. En Lipid technologies and applications. Eds. F.D. Gunstone, F.B. Padley, Marcel Dekker, Inc. New York, U.S.A., pp. 1-17.

Guo, J.H. 1993. Effects of plasticizers on water permeation and mechanical properties of cellulose acetate: antiplastization in slightly plasticized polymer. Drug Devel. Ind. Pharm., 19(13):1541-1555.

Hagenmaier, R. D.; Shaw, P.E. 1992. Gas permeability of fruit coating waxes. J. Am. Soc. Hort. Sci., 117(1): 105-109.

Hagenmaier, R.D.; Baker, R.A. 1993a. Reduction in gas exchange of citrus fruit by wax coatings. J. Agr. Food Chem., 41:283-287.

Hagenmaier, R.D.; Baker, R.A. 1993b. Cleaning method affects shirinkage rate of citrus fruit. HortSci., 28(8):824-825.

Hagenmaier, R.D.; Baker, R.A. 1994. Internal gases, ethanol content and gloss of citrus fruit coated with polyethylene wax, canauba wax, shellac or resin at different application levels. Proc. Fla. State Hort. Soc., 107:261-265.

Hagenmaier, R.D.; Baker, R.A. 1995. Layered coatings to control weight loss and preserve gloss of citrus fruit. HortSci., 30:296-298.

Hagenmaier, R.D.; Baker, R.A. 1997. Edible Coatings from MorpholineFree Wax Microemulsions. J. Agr. Food Chem., 45: 349-352.

Hagenmaier R.D.; Shaw, P.E. 2002. Changes in volatile components of stored tangerines and other speciality citrus fruits with different coatings. J. Food Sci., 67:1742-1745.

Hagenmaier, R.D.; Goodner, K.; Russell, R.; Dou, H. 2002. Storage of 'marsh' grapefruit and 'Valencia' oranges with different coatings. Proc. Fla. State Hort. Soc., 115: 303-308.

Hall, D.J. 1981. Innovations in citrus waxing. An overview. Proc. Fla. State. Hort. Soc., 94:258-263.

Hallman, G.J. 1999. Ionizing radiation quarantine treatments against tephridit fruit flies. Postharv. Biol. Technol., 16:93-106.

Han, C.; Zhao, Y.; Lconrad, S.W.; Traber, M.G. 2004. Edible coatings to improve storability and enhance nutritional value of fresh and frozen strawberries (Fragaria $x$ ananassa) and raspberries (Rubus ideaus). Postharv. Biol. Technol., 33:67-78. 
Han, J.H.; Seo, G.H.; Park, I.M.; Kim, G.N.; Lee, D.S. 2006. Physical and mechanical properties of pea starch edible films containing beeswax emulsions. J. Food Sci., 71(6):290-296.

Hardenburg, R.E. 1967. Wax and related coatings for horticultural products. Ed. U.S.D.A., Agric. Res. Serv. Publ., AR, 51-15.

Henriod, R.E. 2006. Postharvest characteristics of navel oranges following high humidity and low temperature storage and transport. Postharv. Biol. Technol., 42:57-64.

Hernández, E.; Baker, R.A. 1991. Candelilla wax emulsion, preparation and stability. J. Food Sci., 56:1382-1383, 1387.

Hernández-Muñoz, P.; Almenar, E.; Ocio, M.J.; Gavara, R. 2006. Effect of calcium dips and chitosan coatings on postharvest life of strawberries (Fragaria $x$ ananassa). Postharv. Biol. Technol., 39:247-253.

Hershko, V.; Nussinovitch, A. 1998. Relationship between hydrocolloid coating and mushroom structure. J. Agr. Food Chem., 46(8):29882997.

Holcroft, D.M.; Kader, A.A. 1999. Controlled atmosphere induced changes in $\mathrm{pH}$ and organic acid metabolism may affect color of stored strawberry fruit. Postharv. Biol. Technol., 17:19-32.

Hutchinson, F.M.; Krochta, J.M. 2002. Moisture barrier properties of whey protein-beeswax bilayer composite films. En Moisture Barrier properties of whey protein isolate-lipid composite films and coatings. Mater thesis dissertation. University of California, Davis, U.S.A., pp.19-48.

Immergut, E.H.; Mark, H.F. 1965. Principles of plasticization. En Plasticization and Plasticizer Processes. Ed. R.F. Gould, Am. Chemical Soc., Washington, U.S.A., pp. 1-26.

Jeong, J.; Huber, D.J.; Sargent, S.A. 2002. Influence of 1methylcyclopropene (1-MCP) on ripening and cell-wall matrix polysaccharides of avocado (Persea americana) fruit. Postharv. Biol. Technol., 25:241-256.

Jimenez-Cuesta, M.; Cuquerella, J.; Martínez-Jávega, J.M. 1981. Determination of a color index for citrus degreening. Proc. Int. Soc. Citriculture, 2:750-753. 
Johnston, J.W.; Banks, N.H. 1998. Selection of a surface coating and optimisation of its concentration for use on 'Hass' avocado (Persea Americana Mill.) fruit. N.Z.J. Crop. Hort. Sci., 26:143-141.

Jongjareonrak, A.; Benjakul, S.; Visessanguan, W.; Tanaka, M. 2006. Fatty acids and their sucrose esters affect the properties of fish gelatin-based film. Eur. Food Res. Technol., 222:650-657.

Kader, A.A. 1986. Biochemical and physiological basis for effects of controlled and modified atmospheres for fruits and vegetables. Food Technol., 40(5):99-104.

Kader, A.A.; Zagory, D.; Kerbel, E.L. 1989. Modified atmosphere packaging of fruits and vegetables. Crit. Rev. Food. Sci. Nutr., 28:1-30.

Kader, A.A. 1992. Modified atmospheres during transport and storage. En Postharvest Technology of Horticultural Crops. Ed. A.A. Kader, Division of Agriculture Natural Resources, University of California, 3311:85-92.

Kamper, S.L.; Fennema, O. 1984a. Water vapor permeability of an edible, fatty acid, bilayer film. J. Food Sci., 49:1482-1485.

Kamper, S.L.; Fennema, O. 1984b. Water vapor permeability of edible bilayer films. J. Food Sci., 49:1478-1481.

Kamper, S.L.; Fennema, O. 1985. Use an edible film to maintain water and vapor gradients in foods. J. Food Sci., 50:382-384.

Kaplan, H.J. 1986. Washing, waxing and color adding. En Fresh Citrus Fruits. Eds. W.F. Wardowski, S. Nagy, W. Grierson, AVI Pub. Co., New York, U.S.A., pp. 379-395.

Karel, M.; Proctor, B.E.; Wiseman, G. 1959. Factors affecting water vapor transfer through food packaging films. Food Technol., 13:6974.

Kays, S.J. 1991. Postharvest physiology of perishable plant products. Ed. Van Nostrand, Reinhold Co., In. New York, U.S.A., pp. 532.

Ke, D.; Kader, A.A. 1990. Tolerance of 'Valencia' oranges to controlled atmospheres as determined by physiological responses and quality attributes. J. Am. Soc. Hort. Sci., 115:779-783.

Ke, D.; Rodríguez-Sinobas, L.; Kader, A.A. 1991. Physiology and prediction of fruit tolerance to low-oxygen atmosphere. J. Am. Soc. Hort. Sci., 116:253-260. 
Kester, J. J.; Fennema, O.R. 1986. Edible films and coatings: a review. Food Technol., 40(12):47-59.

Kester, J.J.; Fennema, O.R. 1989a. Resistance of lipid films to water vapor transmission. J. Am. Oil Chem. Soc., 66:1139-1146.

Kester, J. J.; Fennema, O.R. 1989b. The influence of polymorphic form on oxygen and water vapour transmission through lipid films. J. Am. Oil Chem. Soc., 66:1147-1153.

Kester, J.J.; Fennema, O. 1989c. Tempering the influence on oxygen and water vapour transmission through a stearyl alcohol film. J. Am. Oil Chem. Soc., 66:1154-1157.

Kester, J. J.; Fennema, O.R. 1989d. An edible film of lipid and cellulose ethers: performance in a model frozen-food system. J. Food Sci., 54:1390-1392, 1406.

Koelsch, C.M.; Labuza, T.P. 1992. Functional, physical and morphological properties of methyl cellulose and fatty acid-based edible barriers. Lebensm. Wiss. u. Technol., 25:404-411.

Krochta, J.M. 1990. Emulsion film on food products to control mass transfer. En Food Emulsion and Foams: Theory and Practice. Eds. E.L. Gaden; E. Doi, Plenum Press., New York, U.S.A., pp. 65-78.

Kramer, G.F.; Wang, C.Y.; Conway, W.S. 1991. Inhibition of softening by polyamine application in 'Golden Delicious' and 'McIntosh' apples. J. Amer. Soc. Hort. Sci., 116:813-817.

Krochta, J.M.; De Mulder-Johnston, C. 1997. Edible and biodegradable polymer films: changes and opportunities. Food Technol., 51:61-72.

Kumins, C.A. 1965. Transport through polymer films. J. Polym. Sci., Part C, 10:1-9.

Labuza T.P.; Contreras-Medellin, R. 1981. Prediction of moisture protection requeriments for foods. Cereal Food World, 26:335-343.

Landmann, W.; Lovegren, N.V.; Feuge, R.O. 1960. Permeability of some fat products to moisture. J. Am. Oil Chem. Soc., 37:1-4.

Laurie, S.; Klein, J.D. 1991. Acquisition of low temperature tolerance in tomatoes by exposure to high temperature stress. J. Am. Soc. Hort. Sci., 116:1007-1012. 
Laurie, S.; Zeidman, M; Zuthi, Y.; Ben-Arie, R. 1992. Controlled atmosphere storage to decrease physiological disorders in peaches and nectarines. Hassadeh, 72(9): 1118-1122.

Laurie, S.; Klein, J.D.; Watkins, C.; Ross, G.; Boss, P.; Ferguson, I.F. 1993. Prestorage heat treatment of tomatoes prevents chilling injury and reversivility inhibits ripening. Acta Horticulturae, 343:283-285.

Leung, H.K. 1986. Water activity and other colligative properties of foods. En Physical and Chemical Properties of Food. Ed. M.R. Okos, Amer. Soc. of Agricultural Engineers, Michigan, U.S.A., pp. 138-185.

Li, H.; Yu, T. 2001. Effect of chitosan on incidence of brown rot, quality and physiological attributes of postharvest peach fruit. J. Sci. Food Agr., 81(2):269-274.

Lieberman, E.R.; Gilbert, S.G. 1973. Gas permeation of collagen films as affected by cross-linkage, moisture and plasticizer content. J. Polym. Sci., 41:33-43.

Little, C.R. Peggie, I.D. 1987. Storage injury of pome fruit cause by stress levels of oxygen, carbon dioxide, temperature, and ethylene. HortSci., 22:783-790.

Lu, J.Y.; Stevens,C.; Khan, V. A.; Kabwe, M.; Wilson, C.L. 1991. The effect of ultraviolet irradiation on shelf-life and ripening of peaches and apples. J. Food Quality, 14(4):299-305.

Mahmoud, R.; Savello, P.A. 1992. Mechanical properties of an water vapour transferability through whey protein films. J. Dairy Sci., 75:942-946.

Mahmoud, R.; Savello, P.A. 1993. Solubility and hydrolyzability of films produced by transglutaminase catalytic cross-linking of whey proteins. J. Dairy Sci., 76:29-35.

Mannhein, C.H. y Soffer, T. 1996. Permeability of different wax coatings and their effect on citrus fruit quality. J. Agric. Food Chem., 44:919923.

Martín-Polo, M.; Voilley, A.; Blond, G.; Colas, B.; Mesnier, M.; Floquet, N. 1992a. Hydrophobic films and their efficiency against moisture transfer. 2. Influence of the physical state. J Agr. Food Chem., 40:413-418. 
Martín-Polo, M.; Mauguin, C.; Voilley, A. 1992b. Hydrophobic films and their efficiency against moisture transfer. 1. Influence of film preparation technique. J. Agr. Food Chem., 40:407-412.

Martínez-Jávega, J.M. y del Río, M.A. 1998. Desórdenes fisiológicos en postcosecha. En Manejo postcosecha de frutas y verduras en Iberoamérica. Ed. R. Báez, Cyted-Rytep, Hermosillo, Méjico, pp. 57-62.

Martínez-Jávega, J.M. y Cuquerella, J. 2000. Manejo postcosecha de frutos cítricos de producción integrada. Actas del $2^{\circ}$ Congreso Iberoamericano de Tecnología Postcosecha y Agroexportaciones. Eds. C. Saucedo; F. Villamizar; R. Báez, Bogotá, Colombia, pp. 15-19.

Martínez-Navarrete, N.; Andrés, A.; Chiralt, A.; Fito, P. 1998. Transiciones de fase en alimentos. En Termodinámica y cinética de sistemas alimento entorno. Ed. Servicio de Publicaciones de la Universidad Politécnica de Valencia, Valencia, pp. 220-276.

Martínez-Solano, J.R.; Sánchez-Bel, P.; Valedenegro-Espinoza, M.; Martínez-Madrid, C.; Sánchez, A.; Romojaro, F. 2001. Efectos de la ionización con electrones acelerados sobre las frutas y hortalizas destinadas al consumo en fresco. Publ. Centro Tecnológico Nacional de la Conserva y la Alimentación, 11:28-38.

Mason, J.L.; Jasmin, J.J.; Granger, R.L. 1975. Softening of 'McIntosh' apples by a postharvest dip in calcium chloride solution plus thickener. HortSci., 10:524-525.

Maxie, E.C.; Robinson, B.J.; Catlin, P.B. 1958. Effect of various oxygen concentrations on the respiration of Wickson plum fruit and fruit tissues. Proc. Am. Soc. Hort. Sci., 71:145-156.

Maxie, E.C.; Sommer, N.F.; Muller, C.J.; Rae, H.L. 1966. Effect of Gamma Radiation on the ripening of 'Bartlett' pears. Plant Physiology, 41:437-442.

McDonald, R.E. 1986. Effects of vegetable oils, $\mathrm{CO}_{2}$, and film wrapping on chilling injury and decay of lemons. HortSci., 21:476-477.

McHugh, T.H.; Avena-Bustillos, R.; Krochta, J.M. 1993. Hydrophilic edible films: modified procedure for water vapor permeability and explanation of thickness effects. J. Food Sci., 58(4): 899-903.

McHugh, T.H; Krochta, J.M. 1994a. Permeability properties of edible films. En Edible Coatings and films to improve Food Quality. Eds. J.M. 
Krochta; E.A. Baldwin; M.O. Nisperos-Carriedo, Technomic Publishing Co., Inc. Lancaster, U.S.A., pp. 139-187.

McHugh, T. H.; Krochta, J.M. 1994b. Water vapor permeability properties of edible whey protein-lipid emulsion films. J. Am. Oil Chem. Soc., 71(3):307-311.

McHugh, T. H.; Krochta, J.M. 1994c. Dispersed phase particle size effects on water vapor permeability of whey protein-beeswax edible emulsion films. J. Food Process. Pres., 18:173-188.

McHugh, T. H.; Krochta, J.M. 1994d. Sorbitol-vs glycerol-plasticized whey protein edible films: integrated oxygen permeability and tensile property evaluation. J. Agr. Food Chem., 42(4): 841-845.

McHugh, T.H. 2000. Protein-lipid interactions in edible films and coatings. Nahrung, 44(3): 148-151.

Medeira, M.C.; Maia, M.I.; Vitor, R.F. 1999. The first stages of preharvest 'peel pittings' development in 'Encore' mandarin. An histological and ultrastructural study. Ann Bot. London, 83(6):667673.

Meheriuk, M.; Lau, O. 1988. Effect of two polymeric coatings on fruit quality of Bartlett and d'Anjou pears. J. Am. Soc. Hort. Sci., 113:222226.

Mellenthin, W.M.; Chen, P.M.; Borgic, D.M. 1982. In-line application of porous wax coating materials to reduce friction discoloration of 'Bartlett' and 'd'Anjou' pears. HortSci., 17:215-217.

Miller, K.S.; Krochta, J.M. 1997. Oxygen and aroma barrier properties of edible films: A review. Trends Food Sci. Technol., 8:228-237.

Meir, S.; Philosoph-Hadas, S.; Laurie, S.; Droby, S.; Akerman, M.; Zauberman, G.; Shapiro, B.; Cohen, E.; Fuchs, Y. 1996. Reduction of chilling injury in stored avocado, grapefruit, and bell papper by methyl jasmonate. Can. J. Bot., 74:870-874.

Miller, W.R.; McDonald, R.E.; Smittle, B.J. 1995. Quality of 'Sharpblue' blueberries after electron beam irradiation. HortSci., 30(2):306-308.

Miller, W.R.; McDonald, R.E.; Chaparro, J. 2000. Tolerance of selected orange and mandarin hybrid fruit to low-dose irradiation for quarantine purposes. HortSci., 35(7):1288-1291. 
Mitchell, J.R. 1979. Reology of polysaccharide solutions and gels. En Polisaccharides in food. Eds. J.M.V. Blanshard; J.R. Mitchell, Butterworths, London, UK., p. 51.

Mitchell,F.G.; Guillou, R.; Parsons, R.A. 1972. Commercial cooling of fruits and vegetables. University of California, Agricultural Experiment Station Extension Service, Publ. 43.

Mitchell, G.; Kader, A.A. 1992. Postharvest treatment for insect control. En: Postharvest Technology of Horticultural Crops. Ed. A.A. Kader, Univ. of California, 3311:161-165.

Mitchell, F.G.; Crisosto, C.H. 1995. The use of cooling and cold storage to stabilize and preserve fresh stone fruits. Pennsylvania Fruit News, 75:40-52.

Monterde, A.; Salvador, A.; Cuquerella, J.; Martínez-Jávega, J.M. 2002. Aplicación de sustancias naturales en la postcosecha de cítricos- Rev. Levante Agrícola, 361:263-266.

Monterde, A.; Salvador, A.; Ben-Abda, J.; Martínez-Jávega, J.M. 2003. Efecto de la aplicación de recubrimientos de origen natural en la calidad de mandarinas y naranjas. En Maduración y Post-Recolección de frutos y hortalizas. Eds. C. Merodio; I. Escribano, pp. 203-208.

Morillon, V.; Debeaufort, F.; Blond, G.; Capelle, M.; Voilley, A. 2002. Factors affecting the moisture permeability of lipid-based edible films: a Review. Crit. Rev. Food Sci. Nutr., 42:67-89.

Mrozek, R.F.; Burkhardt, T.H. 1973. Factors causing prune side craking. Transactions Am. Soc. Agr. Engineers. 16:686-692,695.

Ninnemann, K.W. 1968. Measurement of physical properties of flexible films. En The Science and Technology of polymer Films. Ed. O.J. Sweeting, Interscience, London, UK., 546-649.

Nisperos-Carriedo, M.O.; Shaw, P.E. 1990. Comparison of volatile flavour components in fresh and processed orange juices. J. Agr. Chem., 38:1048-1052.

Nisperos-Carriedo, M. O. 1994. Edible coatings and films based on polysaccharides. En Protein-based films and coatings. Eds. J.M. Krochta; E.A. Baldwin,; M.O. Nisperos-Carriedo. Technomic Publishing Co., Inc. Lancaster, U.S.A., pp. 305-335. 
Nichols, W.C. and Patterson, M.E. 1987. Ethanol accumulation and poststorage quality of 'Delicious' apples during short term, low-O2, CA storage. HortSci. 22:89-92.

Noguchi, H. 1981. Hydratation around hydrophobic groups. En Water activity: influences on food quality. Ed. L.B. Rockland; G.F. Stewart, Academic Press, Inc. New York U.S.A., pp. 281-293.

O’Beirne, D. 1991. Irradiation of fruits and vegetables: applications and issues. Horticulture in New Zeeland, 2:13-16.

Orliac, O.; Rouilly, A.; Silvestre, F.; Rigal, L. 2002. Effects of additives on the mechanical properties, hydrophobicity and water uptake of thermo-moulded films produced from sunflower protein isolate. Polymer, 43: 5417-5425.

Park, H.J.; Weller, C.L.; Vergano, P.J.; Testin, R.F. 1993. Permeability and mechanical properties of cellulose-based edible films. J. Food. Sci., 58(6):1361-1364,1370.

Park, H.; Chinnan, M.; Shewfelt, R. 1994. Edible coating effects on storage life and quality of tomatoes. J. Food Sci., 59:568-570.

Pascat, B. 1985. Study of some factors affecting permeability. En Polymer permeability. Ed. J. Comyn, Elsevier Applied Science Publishers, New York, U.S.A., pp. 7-24.

Patterson, M.E.; Nichols, W.C. 1988. Metabolic response of 'Delicious' apples to carbon dioxide in anoxic and low-oxygen environments. HortSci., 23:866-868.

Paull, R.E. 1999. Effect of temperature and relative humidity on fresh commodity quality. Postharv. Biol. Technol., 15:263-277.

Pérez-Gago, M. B.; Krochta, J.M. 2001. Lipid particle size effect on water vapor permeability and mechanical properties of whey protein/beeswax emulsion films. J. Agr. Food Chem., 49: 996-1002.

Pérez-Gago, M. B.; Rojas, C.; Del Río, M.A. 2002. Effect of lipid type and amount of edible hydroxypropyl methylcellulose-lipid composite coatings used to protect postharvest quality of mandarins cv. Fortune. J. Food Sci., 67(8):2903-2909.

Pérez-Gago, M. B., Rojas, C.; and Del Río, M.A. 2003a. Effect of hydroxypropyl methylcellulose-lipid edible composite coatings on plum 
(cv. Autumn Giant) quality during storage. Journal of Food Science 68(3): 879-883.

Pérez-Gago, M.B.; Rojas, C.; Del Río, M.A. 2003b. Effect of Hydroxypropyl methylcellulose-beeswax edible composite coatings on postharvest quality of 'Fortune' mandarins. Acta Horticulturae, 599:583-587.

Petracek, P.D., Dou, H. and Malik, I. 1997. A postharvest pitting of temple oranges stimulated by high temperature storage and wax application. Proc. Fla. State. Hort. Soc. 110:211-214.

Petracek, P.D.; Dou, H.; Pao, S. 1998. The influence of applied waxes on postharvest physiological behaviour and pitting of grapefruit. Postharv. Biol. Technol., 14:99-106.

Petracek, P.D.; Hagenmaier, R.D.; Dou, H. 1999. Waxing effects on citrus fruit physiology. En Advances in postharvest diseases and disorders control of citrus fruit. Ed. M. Schirra, Research Signpost, India. pp.71-92.

Petersson, M.; Stading, M. 2005. Water vapour permeability and mechanical properties of mixed starch-monogliceride films an effect on film forming conditions. Food hydrocolloids, 19:123-132.

Phan The, D.; Debeaufort, F.; Péroval, C.; Despré, D.; Courthaudon, J.L.; Voilley, A. 2002. Arabinoxylan-lipid-based edible films and coatings. 3. Influence of drying temperature on film structure and functional properties. J. Agr. Food Chem., 50:2423-2428.

Ponappa, T.; Scheerens, J.C.; Miller, A.R. 1993. Vacuum infiltration of polyamines increases firmness of strawberry slices under various storage conditions. J. Food Sci., 58:361-364.

Porat, R.; Weiss, B.; Cohen, L.; Daus, A.; Biton, A. 2005. Effects of polyethylene wax content and composition on taste, quality, and emission of off-flavor volatiles in 'Mor' mandarins. Postharv. Biol. Technol., 38:262-268.

Porritt, S.W. 1974. Commercial storage of fruits and vegetables. Ed. Canada Department of Agriculture, Ottowa, Canada., Publ. 1532.

Pozzan, M.A.; Cuquerella, J.; Navarro, P. 1993. Efecto de diferentes recubrimientos en la comercialización directa de naranjas 'Navelina'. Actas de Horticultura de la SECH., 9:614-619. 
Prince, L.M. 1977. Schuman's microemulsion. En Microemulsions, theory and practice. Ed. Prince, L.M., Academic Press, New York, U.S.A., pp.1-20.

Price, W.E.; Sabarez, H.T.; Storey, R.; Back, P.J. 2000. Role of the waxy skin layer in the moisture loss during dehydratation of prunes. J. Agr. Food Chem., 48:4193-4198.

Quezada-Gallo. J.A.; Debeaufort, F.; Callegarin, F.; Voilley, A. 2000. Lipid hydrophobicity, physical state and distribution effects on the properties of emulsion-based films. J. Membrane Sci., 180:37-46.

Retamales, J.; Cooper, T.; Streif, J.; Kama, J.C. 1992. Preventing cold storage disorders in nectarines. J. HortSci., 67:619-626.

Richardson, D.G. 1985. CA recommendations for pears (including Asian pears). En Controlled atmospheres for the storage and transport of perishable agricultural commodities. Ed. S.M. Blankenship, Michigan State Univ., East Laning, U.S.A., 28:422-444.

Rojas, C.; Pérez-Gago, M.B.; del Rio, M.A. 2002. Solid content effect of edible coatings on postharvest quality of mandarins. Proceedings of the 6th Int. Symposium on Fruit, Nut and vegetable production Engineering, Postdam, Germany, pp 303-307.

Rojas, C. 2002. Desarrollo de nuevos recubrimientos comestibles y aplicación en cerezas, albaricoques y mandarinas. Tesis Doctoral. Ed. Universidad Politécnica de Valencia, Valencia.

Rojas, C.; Pérez-Gago, M.B.; Del Río, M.A. 2003. Recubrimientos comestibles en cerezas cv. 'Burlat' y 'Ambrunesa'. Agricola Vergel, 346-356.

Roos, Y.; Karel, M. 1991. Applying state diagrams to food processing and development. Food Technol., 21:72-74.

Salvador, A.; Cuquerella, J.; Navarro, P. 2000. Susceptibility of 'Ortanique' citrus fruit harvested in Valencia to chilling injury during cold storage. En Improving postharvest technologies of fruits, vegetables and ornamentals. Proc. Refrigeration Sci. Tech., 2:498-505.

Salvador, A.; Cuquerella, J.; Martinez-Jávega, J.M. 2003. 1-MCP treatment prolongs postharvest life of 'Santa Rosa' plums. J. Food Sci., 68:15041510 . 
Saltveit, M.E. 1982. Procedures for extracting and analysing internal gas samples from plant-tissues by gas chromatography. HortSci., 17(6): 878-881.

Sapru, V.; Labuza, T.P. 1994. Disperse phase concentration effect on water vapor permeability in composite methylcellulose-steraric acid edible films. J. Food Process. Preserv., 18:359-368.

Schiffmann-Nadel, M.; Lattar, F.S.; Waks, J. 1971. The response of grapefruit to different storage temperatures. J. Am. Soc. Hort. Sci., 96:87-90.

Schirra, M.; Mulas, M. 1995. Fortune mandarin quality following restorage water dips and intermittent warming during cold storage. HortSci., 30(3):560-561.

Schirra, M.; D'Hallewin, G. 1997. Storage performance of 'Fortune' mandarins following hot water dips. Postharv. Biol. Technol., 10:229238.

Schirra, M.; Mulas, M.; Fadda, A.; Cauli, E. 2004. Cold quarantine responses of blood oranges to postharvest hot water and hot air treatments. Postharv. Biol. Technol., 31:191-200.

Schultz, T.H.; Miers, J.C.; Owens, H.S.; Maclay, W.D. 1949. Permeability of pectinate films to water vapor. J. Phys. Colloid Chem., 53:13201330 .

Sears, J.K.; Dary, J.R. 1982. Mechanism of Plasticizer Action. En The technology of plasticizers. Eds. J.K. Sears; J.R. Darby, John Wiley \& Sons, New York, U.S.A., pp 35-77.

Seow, C.C.; Cheah, P.B.; Chang, Y.P. 1999. Antiplastization by water in reduced-moisture systems. J. Food Sci., 64(4):576-581.

Sharma, S.C. 1981. Gums and hydrocolloids in oil-water emulsions. Food Tecnol., 35(1):59-67.

Shellhammer, T. H.; Krochta, J.M. 1997. Whey protein emulsion film performance as affected by lipid type and amount. J. Food Sci., 62(2):390-394.

Sherwin, C.P.; Smith, D.E.; Fulcher, R.G. 1998. Effect of fatty acid type on dispersed particle size distribution in emulsion edible films. J. Agr. Food Chem., 46:4534-4538. 
Sive, A.; Resnizki, D. 1979. Extension of storage life of 'Red Rosa' plums with controlled atmosphere storage. Bul. Intl. Inst. Refrig., 59:1148.

Smilanick, J.L.; Fouse, D.C. 1989. Quality of nectarines stored in insecticidal low $\mathrm{O}_{2}$ atmospheres at 5 and $15{ }^{\circ} \mathrm{C}$. J. Am. Soc. Hort. Sci., 114:431-436.

Smith, S.M.; Stow, J.R. 1984. The potential of a sucrose ester coating material for improving the storage and shelf life qualities of Cox's Orange Pippin Apples. Ann. Appl. Biol., 104:383-391.

Smith, S.; Geeson, J.; Stow, J. 1987. Production of modified atmospheres in delicious fruits by the use of films and coatings. HortSci., 24: 45147.

Snowdon, A. 1990. Stone fruits. En $A$ colour atlas of post-harvest. Diseases and disorders of fruits and vegetables. Vol. 1: General Introduction \& Fruits. Ed. Wolfe Scientific Ltd., London, UK., pp. 218-237.

Sothornvit, R.; Krochta, J.M. 2000. Plasticizer effect on oxygen permeability of $\beta$-lactoglobulin films. J. Agr. Food Chem.,48:62986302 .

Sothornvit, R.; Krochta, J.M. 2001. Plasticizer effect on mechanical properties of B-lactoglobulin films. J. Food Eng., 50:149-155.

Sothornvit, R.; Reid, D.S.; Krochta, J.M. 2002. Plasticizer effect on the glass transition temperature of beta-lactoglobulin $(\beta-\mathrm{Lg})$ films. Trans. Am. Soc. Agr. Eng., 45(5), 1479-1484.

Sothornvit, R.; Krochta, J.M. 2005. Plasticizers in edible films and coatings. En Innovations in Food Packaging. Ed. J.H. Han, Elsevier Publishers, New York, U.S.A., pp.403-433.

Storey, R.; Price, W.E. 1999. Microstructure of the skin of d'Agen plums. Scientia Horticulturae, 81: 279-286.

Talens, P.; Krochta., J.M. 2005. Plasticizing effects of beeswax and carnauba wax on tensile and water vapor permeability properties of whey protein films. J. Food Sci., 70(3):239-243.

Tanada-Palmu, P.S; Grosso, C.R. 2004. Effect of edible wheat glutenbased films and coatings on refrigerated strawberry (Fragaria annanassa) quality. Postharv. Biol. Technol., 36:199-208. 
Togrul, H.; Arslan, N. 2003a. Carboxymethyl cellulose from sugar beet pulp cellulose as hydrophilic polymer in coating mandarin. J. Food Eng., 62:271-279.

Togrul, H.; Arslan, N. 2003b. Extending shelf-life of peach and pear by using CMC from sugar beet pulp cellulose as hydrophilic polymer emulsions. Food Hydrocolloids, 18:215-226.

UNE 87 023. 1995. Ensayo de clasificación por ordenación. En Análisis Sensorial. Tomo 1. Alimentación. Ed. AENOR, Madrid, pp.151-166.

Valverde, J.M.; Valero, D.; Martínez-Romero, F.G; Castillo, S.; Serrano, M. 2005. Novel edible coating based on Aloe vera gel to maintain table grape quality and safety. J. Agr. Food Chem., 53:7807-7813.

Vargas, M.; Albors, A.; Chiralt, A.; González-Martínez, C. 2006. Quality of cold-stored strawberries as affected by chitosan-oleic acid edible coatings. Postharv. Biol. Technol., 41:164-171.

Villalobos, R. 2003. Propiedades de recubrimientos comestibles formulacdos con hidroxipropilmetilcelulosa y tensoactivos. Tesis doctoral. Ed. Universidad Politécnica de Valencia, Valencia.

Wang, C.Y. 2000. Postharvest techniques for reduce low-temperature injury in chilling-sensitive comodities. En Improving Postharvest technologies of fruits, vegetables and ornamentals. Eds. F. Artés; M.I. Gil; M.A. Conesa., Int Inst. Refrig., Murcia, pp.467-472.

Waters, G.G.; Brekke, J.E. 1961. Stabilized raisins for dry cereal products. J. Food Technol., 5:236-238.

Whitaker, B.D. 1993. A reassessment of heat stress as a means of reducing chilling injury in tomato fruit. En Physiological Basis of Postharvest Techologies. Acta Horticulturae, 343:281-282.

Wills, R.H.; Lee, T.H.; Graham, D; McGlasson, W.B.; Hall, E.G. 1981. Physiology and biochemistry. En Postharvest, an Introduction to the physiology and Handling of Fruits and Vegetables. Ed. AVI Publishing Co., Inc. Westport, U.S.A., pp.18-41.

Wills, R.H.; Lee, T.H., McGlasson; W.B., Hall, E.G.; Graham, D. 1984. Fisiología y manipulación de frutas y hortalizas en post-recolección. Ed. Acribia, S.A., Zaragoza, p.195. 
Wills, R.; McGlasson, B.; Graham, D; Joyce, D. 1998. Postharvest: An introduction to the physiology and handling of fruit, vegetable and ornamentals. Ed. Cab International, New York, U.S.A., p.262.

Wilson, A.S. 1995. Plasticisers: Principles and Practice. Ed. The Institute of Materials, London. UK.

Wong, DWS.; Gastineau, F.A.; Grogorski, K.S.; Tillin, S.J.; Pavlath, A.E. 1992. Microstructure and surface energy. J. Agr. Food Chem., 40:540544.

Yang, L.; Paulson, A.T. 2000. Effects of lipids on mechanical and moisture barrier properties of edible gellan films. Food Res. Int., 33:571-578.

Yu, L.; Gleason, M.L.; Nonnecke, G.R.; Olson, D.G.; Gladon, R.J. 1995. Quality of electron beam irradiated strawberries. J. Food Sci., 60(5):1084-1087.

Yu, L.; Reitmeier, C.A.; Love, M.H. 1996. Strawberry texture and pectin content as affected by electron bean irradiation. J. Food Sci., 61(4):844-846.

Zabik, M.E.; Dawson, L.E. 1963. The aceptablility of cooked poultry protected by an edible acetylated monoglyceride coating during fresh and frozen storage. Food Technol., 17:87-91.

Zaritzky, N.E., García, M.A. and Martino, N.M. 2000. Quality attributes of starch coated refrigerated strawberries (Fragaria x Annanassa). En Improving postharvest technologies of fruits, vegetables and ornamentals. Eds. F. Artés, M.I. Gil, M.A. Conesa. Int. Inst. Refrig., pp.581-587.

Zhang, D.; Quantick, P. 1998. Antifungal effects of chitosan coating on fresh strawberries and raspberries during storage. J. Hort. Sci. Biotechnol., 73:763-767.

Zhang, Y.; Han, J.H. 2006. Plastization of pea starch films with monosaccharides and polyols. J. Food Sci., 71(6):253-261. 
